$\frac{1}{8}$

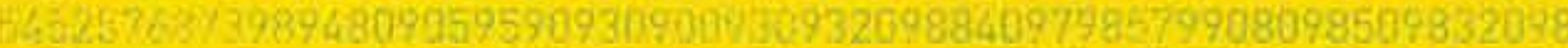

\title{
FINANCING EDUCATION IN SUB-SAHARAN AFRICA
} Meeting the Challenges of Expansion, Equity and Quality
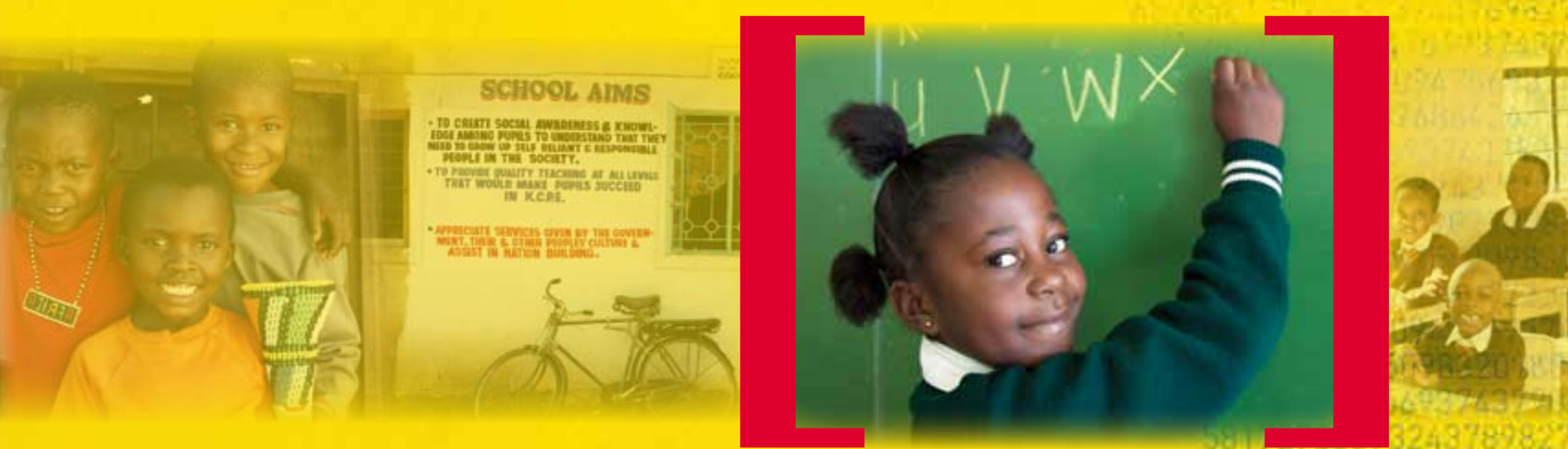

0
0
0
되
$z$
0
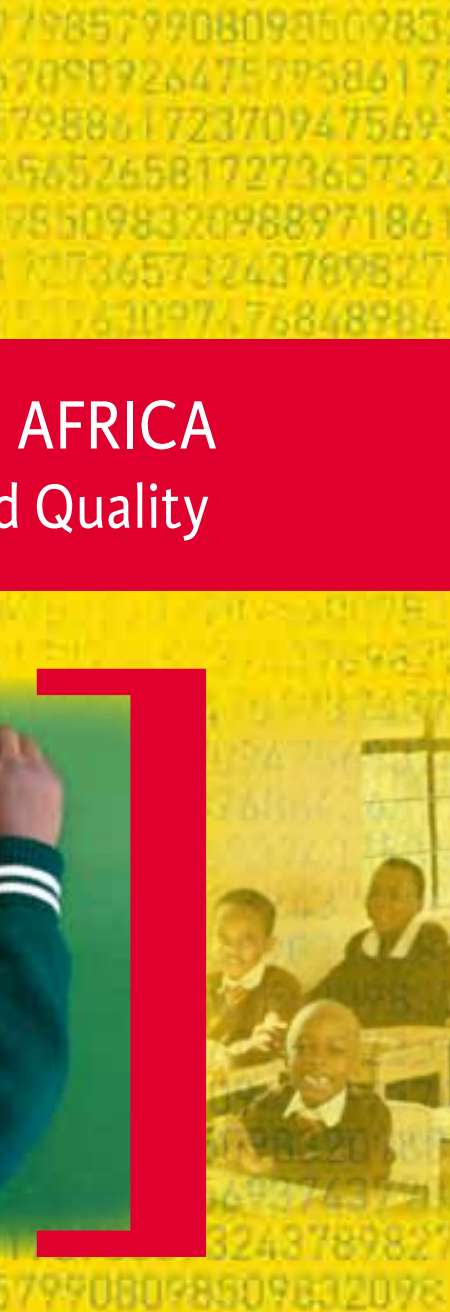
6.779999264757988 1727365732437 27636221 


\section{FINANCING EDUCATION IN SUB-SAHARAN AFRICA Meeting the Challenges of Expansion, Equity and Quality}

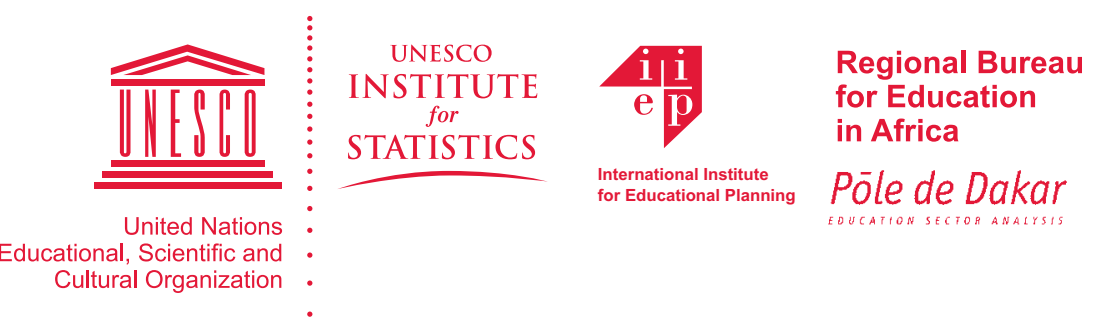




\section{UNESCO}

The constitution of the United Nations Educational, Scientific and Cultural Organization (UNESCO) was adopted by 20 countries at the London Conference in November 1945 and entered into effect on 4 November 1946. The Organization currently has 193 Member States and 7 Associate Members.

The main objective of UNESCO is to contribute to peace and security in the world by promoting collaboration among nations through education, science, culture and communication in order to foster universal respect for justice, the rule of law, and human rights and fundamental freedoms that are affirmed for the peoples of the world, without distinction of race, sex, language or religion, by the Charter of the United Nations.

To fulfill its mandate, UNESCO performs five principal functions: 1) prospective studies on education, science, culture and communication for tomorrow's world; 2) the advancement, transfer and sharing of knowledge through research, training and teaching activities; 3) standard-setting actions for the preparation and adoption of internal instruments and statutory recommendations; 4) expertise through technical co-operation to Member States for their development policies and projects; and 5) the exchange of specialised information.

\section{UNESCO INSTITUTE FOR STATISTICS}

The UNESCO Institute for Statistics (UIS) is the statistical office of UNESCO and is the UN depository for global statistics in the fields of education, science and technology, culture and communication.

The UIS was established in 1999. It was created to improve UNESCO's statistical programme and to develop and deliver the timely, accurate and policyrelevant statistics needed in today's increasingly complex and rapidly changing social, political and economic environments.

\section{INTERNATIONAL INSTITUTE FOR EDUCATIONAL PLANNING}

The International Institute for Educational Planning (IIEP) is an international centre for advanced training and research in the field of educational planning. It was established by UNESCO in 1963 with the aim of contributing to the development of education worldwide by expanding both knowledge and the supply of competent professionals in educational planning.

\section{UNESCO-BREDA}

The UNESCO Office in Dakar and Regional Bureau for Education in Africa (UNESCO-BREDA) is the largest UNESCO Office in Africa. Created in 1970 initially to deal with educational planning in sub-Saharan Africa, the Office has progressively extended its activities to include science, human and social sciences, culture, communication and information.

The Pôle de Dakar for education sector analysis is a platform of expertise and training reporting to UNESCO-BREDA. Created in 2001, the Pôle de Dakar supports countries, as well as technical and financial partners, in the areas of education system analysis, development of strategies and monitoring of education sector policies.

Published in 2011 by:

UNESCO Institute for Statistics

P.O. Box 6128, Succursale Centre-Ville

Montreal, Quebec H3C 3J7

Canada

Tel: (1 514) 343-6880

Fax: (1 514) 343-5740

Email: publications@uis.unesco.org

http://www.uis.unesco.org

(C) UNESCO-UIS 2011

Ref: UIS/AP/11-01

ISBN: 978-92-9189-079-2

Design: Bang Marketing - bang-marketing.com

Photo credits: Frontcover / Cliff Parnell (iStockphoto), David Harris (iStockphoto), Stuart Fox (Getty Images), Ranplett (iStockphoto) Backcover / Andrew Rich (iStockphoto), Lightkey (iStockphoto), Poco_bw (iStockphoto), MissHibiscus (iStockphoto)

Printing: Transcontinental Métrolitho

The authors are responsible for the choice and presentation of the facts contained in this book and for the opinions expressed therein which are not necessarily those of UNESCO and do not commit the Organization. The designations employed and the presentation of material in this publication do not imply the expression of any opinion whatsoever on the part of UNESCO concerning the legal status of any country, territory, city or area, or of its authorities, or concerning the delimitation of its frontiers or boundaries. 


\section{FOREWORD}

The World Education Forum, held in Dakar, Senegal in 2000, has proven to be a momentous occasion. The international community formally pledged that "no country shall be thwarted from meeting the [Education for All (EFA)] goals due to lack of resources" (Education for All Forum, 2000). Since then, national governments, international organizations and various stakeholders have been seeking to address the gap in resources which are required to reach these goals.

This report presents a new series of data highlighting the tremendous financial commitment of African governments and the international community to achieve EFA. Over the past ten years, real expenditure on education has risen by $6 \%$ annually across sub-Saharan Africa (SSA), according to the report. It is often assumed that the resources were used to widen enrolment. Yet, recent data show that many countries also made significant investments to improve their educational services. In Burundi and Mozambique, for example, expenditure levels rose by an average of $12 \%$ each year. Out of 26 countries with available data, only one country - the Central African Republic - reduced spending on education.

As a result of these investments, remarkable progress has been made in educational development in sub-Saharan Africa. The number of children in primary schooling has increased by 48\% - from 87 million to 129 million - between 2000 and 2008. Enrolment in preprimary, secondary and tertiary education has also grown by more than $60 \%$ during the same period.

Despite these significant improvements, many SSA countries are still a long way from achieving universal primary education (UPE) of adequate quality by 2015 . The most recent data show that, in one-third of SSA countries, approximately $50 \%$ of all children do not complete primary education. Thirty-two million children of primary school age are still out of school in the region.

While achieving UPE will remain the priority for most SSA countries, the report stresses that a more complex challenge in the region will be to design and implement appropriate policies for financing post-primary education. As increasing numbers of primary school graduates demand access to secondary education, governments will need to expand further education by balancing resource requirements and availability, social demands and economic needs for a more highly skilled labor force.

Given the uncertainties in the current economic climate, most African governments will have to make strategic decisions on how to provide their growing student populations with higher levels of education. This report examines these policy trade-offs by presenting the most comprehensive and timely data available on the financing of education in 45 SSA countries. Many of the indicators have never been published before and reflect a range of policy issues, such as changes in teacher salaries and private funding of education.

This report is largely the result of efforts by the UNESCO Institute for Statistics (UIS) to improve the production and use of education finance data. In seeking to promote and foster good statistical practices, the UIS works closely with key partners, such the ADEA Working Group on Education Statistics, the African Union and AFRISTAT. In addition, the UIS recently launched a new regional modular questionnaire to fill major gaps in statistical information as identified by African policymakers.

Building national statistical capacities is a key role of the UIS. The Institute has deployed a number of statistical staff in the region in order to tailor support to the specific needs of individual countries. In collaboration with the UNESCO Regional Bureau for Education in Africa (BREDA), UNESCO's International Institute for Education Planning (IIEP) and the African regional office of the World Bank, the UIS is working to improve the production of education finance data in 10 SSA countries. The project aims to build the capacities of national statistical teams in order to develop and implement sustainable mechanisms to regularly produce and use education finance indicators. This work and the resulting report have received support from the Fast Track Initiative Education Program Development Fund, the World Bank and a range of donors contributing to core activities of the UIS. 
As a result of these efforts, the coverage of finance data has significantly improved. For example, the UIS now publishes data on total government expenditure on education for $67 \%$ of SSA countries, compared to just $13 \%$ in 2005 . With better coverage of data, the international community can more accurately track progress in educational development and education financing.

Overall, the report aims to provide governments and other stakeholders in SSA countries with a solid statistical foundation on education financing, while analysing related trends and policy trade-offs. It is hoped that this report marks an important step towards improved collection and use of education finance statistics for national planning, budgeting and monitoring.

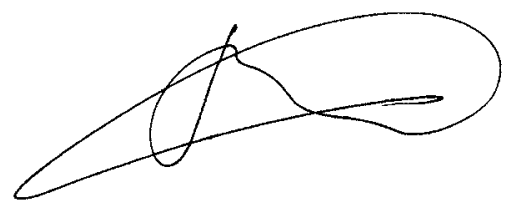

Hendrik van der Pol

Director

UNESCO Institute for Statistics 


\section{ACKNOWLEDGEMENTS}

Data used in this report were provided by sub-Saharan African countries through the annual UNESCO Institute for Statistics (UIS) data collections. We would like to express our gratitude to the statisticians who carefully responded to the UIS questionnaires and participated in education statistics diagnostic studies. Additional information and statistics were supplied by the Pôle de Dakar (UNESCO-BREDA) and UNESCO's International Institute for Educational Planning (IIEP). Information was also gathered from other international organizations, such as the United Nations Statistics and Population Divisions, the World Bank and the Organisation for Economic Co-operation and Development (OECD).

This publication was prepared by a team led by Shinsaku Nomura, under the general guidance of Albert Motivans, Head of Education Indicators and Data Analysis at the UIS. Authors of the report are: Michael Bruneforth (Chapter 2), Shinsaku Nomura (Chapters 1, 2,5 and 6) and Saïd O. Voffal (Chapter 3) from the UIS; Borel Foko and Guillaume Husson (Chapter 3) from the Pôle de Dakar (UNESCO-BREDA); Serge Peano (Chapter 4) from the IIEP; and Laurence Wolff (Chapters 5 and 6) as a consultant. Yusuf Sayed (University of Sussex) played an advisory role. Jean Claude Ndabananiye assisted in the presentation of data.

We would like to express our gratitude to the experts who provided invaluable feedback on the draft, including: Jean-Claude Balmès (Agence Française de Développement), Mathieu Brossard (World Bank), Lene Buchert (University of Oslo), Laurent Cortese (Education for All Fast Track Initiative Secretariat) and Birger Fredriksen (World Bank).

We would also like to acknowledge the contributions of UIS colleagues to the overall quality of the report: Olivier Labé, Claudine Marchand, Simon Normandeau, Pascale Ratovondrahona, Nhung Truong, Tomoko Umeno (intern) and Wendy Xiaodan Weng. The efforts and support of staff in UIS field offices in sub-Saharan Africa, the Data Processing, Standards and I.T. Services (DPSS) section, and the Education Indicators and Data Analysis (EIDA) unit are also noted with gratitude.

This report was edited by Alison Clayson and Amy Otchet. Katja Frostell managed the overall publication production process. 


\section{ABBREVIATIONS}

\begin{tabular}{|c|c|}
\hline AEC & African Economic Community \\
\hline AfDB & African Development Bank \\
\hline AHELO & Assessment of Higher Education Learning Outcomes \\
\hline $\mathrm{AU}$ & African Union \\
\hline BREDA & UNESCO Office in Dakar and Regional Bureau for Education in Africa \\
\hline CEPD & Primary school leaving certificate (Certificat d'études du premier degré) \\
\hline ECOWAS & Economic Community of West African States \\
\hline EFA & Education for All \\
\hline EFA FTI & Education for All Fast-Track Initiative \\
\hline HDI & Human development index \\
\hline IIEP & UNESCO International Institute for Educational Planning \\
\hline IMF & International Monetary Fund \\
\hline ISCED & International Standard Classification of Education \\
\hline MDGs & Millennium Development Goals \\
\hline NEPAD & New Partnership for Africa's Development \\
\hline NGO & Non-governmental organization \\
\hline ODA & Official development assistance \\
\hline OECD & Organisation for Economic Co-operation and Development \\
\hline PASEC & CONFEMEN's Programme on the Analysis of Education Systems \\
\hline PPP & Purchasing power parity \\
\hline PRSP & Poverty Reduction Strategy Paper \\
\hline PTA & Parent-teacher association \\
\hline SACMEQ & Southern and Eastern African Consortium for Measuring Educational Quality \\
\hline SFAl & School Fee Abolition Initiative \\
\hline SSA & Sub-Saharan Africa \\
\hline TIMSS & Trends in International Mathematics and Science Study \\
\hline TVET & Technical and vocational education and training \\
\hline UNDP & United Nations Development Programme \\
\hline UNECA & United Nations Economic Commission for Africa \\
\hline UNESCO & United Nations Educational, Scientific and Cultural Organization \\
\hline UNICEF & United Nations Children's Fund \\
\hline UIS & UNESCO Institute for Statistics \\
\hline UPE & Universal primary education \\
\hline
\end{tabular}




\section{TABLE OF CONTENTS}

Foreword 3

Acknowledgements 5

Abbreviations 6

Introduction 11

Purpose of the report 11

Why data on finance and costs are fundamental 11

Content of the report 12

Chapter 1. Contexts for financing education in sub-Saharan Africa

1.1 Historical and geographical context 14

1.2 Demographic and social context 14

1.3 Macroeconomic context 17

1.4 Public financing 19

1.5 International aid and governance 20

1.6 Context of educational development 22

1.6.1 Today's education systems in sub-Saharan Africa 22

1.6.2 Expansion of education systems 22

1.7 Conclusion 26

Chapter 2. Public financing of education 28

2.1 Introduction 28

2.2 Government commitments to educational development 29

2.2.1 Public education financing 29

2.2.2 Donor financing 32

2.2.3 Expenditure by level of education 34

2.2.4 Nature of spending by level of education 36

2.2.5 Analysis of education expenditure per student 37

2.3 Equity of resource allocation 42

2.4 Conclusion 44

Chapter 3. Financing teachers 45

3.1 Introduction 45

3.2 Spending on teaching personnel 46

3.3 Remuneration of teachers: Inter- and intra-country diversity 46

3.3.1 Variations in average teacher remuneration across countries 48

3.3.2 Differences in teacher salaries by contract type and qualification 50

3.4 Trends and sustainability of teacher salaries 52

3.4.1 Decrease in average primary teacher salaries 52

3.4.2 Factors for the decrease in primary teacher salaries 53 
3.4.3 Sustainability of salary policies

3.5 Teacher management

3.6 Trade-offs in education policymaking

3.7 Conclusion

Chapter 4. Private financing of education

4.1 Introduction

4.2 Private commitments to educational development

4.3 Household expenditure on education

4.4 Abolishing tuition fees for primary schools

4.5 Private schools

4.6 Public-private partnerships

4.7 Conclusion

Chapter 5. Financing the quality of education

5.1 Introduction

5.2 The definition of education quality

5.3 Measuring education quality in sub-Saharan Africa

5.4 Data on enabling inputs

5.5 Allocation of resources for improved learning

5.6 Conclusion

Chapter 6. Education financing in sub-Saharan Africa: Real gains but many challenges

6.1 Introduction

6.2 Summary of key findings

6.3 Policy implications for financing education in sub-Saharan Africa

6.3.1 Recognising persistent external constraints, growing educational demands and emerging opportunities

6.3.2 Addressing trade-offs by setting priorities

6.4 Evidence-based planning using education and finance data

\section{References}

Glossary

Definition of Indicators

\section{List of boxes}

Box 1. World governance indicator 
Box 4. Official development assistance for education per 5 to 24-year-old population in sub-Saharan African countries and world regions, 2008

Box 5. Comparison of the base salary of qualified and non-qualified teachers at the beginning and end of their careers in Uganda

Box 6. Influence of parents' education levels

Box 7. Examples of the types of private schools in Cameroon

\section{List of tables}

Table 1. Selected economic indicators, sub-Saharan Africa, 1970-2009 18

Table 2. $\quad$ Trends in enrolment in sub-Saharan Africa by education level, 1970-2008 23

Table 3. Average teacher remuneration as a ratio of GDP per capita and distribution of teachers by category in public 51 primary education, 2008 or most recent year

Table 4. Trends in average teacher salaries as a ratio of GDP per capita in public primary schools in Africa, 1975-2009

Table 5. Comparison of the statutory salary for qualified and non-qualified public school teachers at the beginning and

Table 6. Household and government expenditure on education as a percentage of GDP and household expenditure as a proportion of all expenditure on education, most recent year

Table 7. Conceptual framework for classifying household education expenditure

Table 8. Proportion of household expenditure devoted to education by income quintile, most recent year

Table 9. Distribution of household expenditure on education by income level, most recent year

Table 10. Average household expenditure on education (in LCU) per child in Ghana, 2007

Table 11. Aggregated expenditure on education by households (in thousands LCU) in Ghana, 2007

Table 12. Public expenditure on textbooks and learning materials in primary and secondary education as a share of total current expenditure, 2009 or most recent year

Table 13. Cost effectiveness analysis of the impact on learning achievement based on primary school leaving certificate (CEPD) examination in Togo, 2003

Table 14. Key cost-effective and high-impact interventions

\section{List of figures}

Figure 1. Projected population pyramid of sub-Saharan Africa by sex, 2010 and 2030

Figure 2. Child dependency ratio by region, 1990 and 2008

Figure 3. Adult and youth literacy rates in sub-Saharan Africa by sex, 1985 to 2007 or most recent year

Figure 4. GDP and GDP per capita growth in sub-Saharan Africa in constant 2005 PPP\$, 1980-2009

Figure 5. Domestic revenue as a percentage of GDP by national income level, 2004-2008

Figure 6. Trends in official development assistance flows to sub-Saharan Africa, 1990-2008

Figure 7. Gross intake ratio to the last grade by duration of primary education in sub-Saharan Africa, 2009 or most recent year

Figure 8. Survival rate by grade of primary education in selected countries, 2008

Figure 9. Number of students in secondary education in sub-Saharan Africa, 1970-2008

Figure 10. Total public expenditure on education as a percentage of total public expenditure and GDP per capita (PPP\$), 2009 or most recent year

Figure 11. Public education expenditure as a percentage of total public expenditure in relation to total public expenditure as a percentage of GDP

Figure 12. Regional GDP devoted to the education sector, 2008

Figure 13. Average annual growth rate of real public education expenditure between 1999 and 2009 or most recent year

Figure 14. Total public expenditure on education as a percentage of GDP, 1999-2000 and 2009 or most recent year

Figure 15. Per capita official development assistance for education in purchasing power parity by country and region, 2008

Figure 16. Official development assistance for education as a ratio of total public education expenditure by national income level, 2008

Figure 17. Public education expenditure by level as a percentage of total education expenditure, 2009 or most recent year

Figure 19. Distribution of primary education expenditure by nature in public institutions, 2009 or most recent year 
Figure 22. Primary education expenditure per pupil as a percentage of GDP per capita, 2009 or most recent year

Figure 23. Change in number of students and real expenditure per pupil in primary education between 1999-2002 and 2009 or most recent year

Figure 24. Ratio between current expenditure per secondary student and per primary pupil for SSA and non-SSA countries, 41 2009 or most recent year

Figure 25. Ratio between current expenditure per tertiary student and per primary pupil for SSA and non-SSA countries, 2009 or most recent year

Figure 26. Lorenz curve of structural distribution of public expenditure on education, 2008

Figure 27. Number of primary and secondary education teachers in sub-Saharan Africa, 1970-2008

Figure 28. Teacher salaries as a percentage of current expenditure by education level, 2008 or most recent year

Figure 29. Teacher salaries as a percentage of public current expenditure on primary education, 2008 or most recent year

Figure 30. Average salary of public primary education teachers as a ratio of GDP per capita, 2009 or most recent year

Figure 31. Relationship between average salary of primary education teachers as a ratio of GDP per capita and the primary pupil-teacher ratio, 2009 or most recent year

Figure 32. Relationship between average salary of public primary education teachers as a ratio of GDP per capita and the percentage of expenditure on items other than teacher salaries in recurrent primary education expenditure, 2008 or most recent year

Figure 33. Salaries of public primary education teachers in PPP\$, 2009 or most recent year

Figure 34. Sources of education financing in Madagascar and Benin for all levels of education

Figure 35. Proportion of household contributions to education expenditure by level, 2001-2006

Figure 36. Source and flows of funding for a primary school in Ghana

Figure 37. Source and flows of funding for a primary school in Benin

Figure 38. Expenditure per primary student by father's education level, Burkina Faso, 2009

Figure 39. Share of enrolment in private primary schools in sub-Saharan Africa, 1999 and 2009 or most recent year

Figure 40. Share of enrolment in private secondary schools in sub-Saharan Africa, 1999 and 2009 or most recent year

Figure 41. Dimensions of public-private partnerships in education

Figure 42. Survival rate to Grade 5 and the last grade of primary education, 2009 or most recent year

Figure 43. SACMEQ scores in reading and mathematics, 2005

Figure 44. Percentage of children who are able to read at least at the basic level, 2005

Figure 45. Percentage of students who answer correctly on more than $40 \%$ of common French language test items, 2004-2009

Figure 46. Estimated literacy rate among 22 to 44 -year-olds with six years of education

Figure 47. Estimated percentage of students who survive to the end of primary education and who are able to read in SACMEQ countries

Figure 48. Coefficient of efficiency for primary completion and for completion with reading skills

Figure 49. Pupil-teacher ratio in primary education, 2009 or most recent year

Figure 50. Comparison of the percentage of trained primary teachers, 2009 or most recent year

Figure 51. Gross enrolment ratio for pre-primary education, 2009 or most recent year

Figure 52. Public expenditure on primary education per pupil in PPP\$, 2009 or most recent year 


\section{INTRODUCTION}

\section{PURPOSE OF THE REPORT}

Over the past few years, there has been an explosion in school enrolment in sub-Saharan Africa (SSA). With increasing national and international commitments and support to education since the Millennium Development Goals (MDGs) Summit and World Education Forum (WEF) in 2000, primary education enrolment increased worldwide from 86.7 million in 2000 to 128.6 million in 2008, and gross enrolment rates (GERs) are now over $100 \%{ }^{1}$. Over the same period, enrolment in secondary education increased globally from 22 million to 36.3 million, and enrolment in higher education from 1.8 million to 4.5 million. While the quantitative expansion is impressive, the education system in the SSA region must cope with numerous obstacles. Because of repetition and dropout, many countries are still far from achieving the universal primary education (UPE) goal by 2015 . Equally important, the quality of education in the region is recognized as being far behind the rest of the world. With increased social pressure for expansion of post-primary education, governments face a challenge - how to expand educational opportunities, improve quality and increase equity with limited and inadequate financial resources.

This report aims to address these issues by examining local policies and developing a region-specific knowledge base for SSA that sheds light on the key strengths and challenges of the education systems. This is especially important for the SSA region because of the general paucity of information. Countries continuously face difficult policy questions but do not have good answers due to the absence of evidence and tools for forecasting the policy consequences. The process of effectively financing education expansion and quality improvement is rendered more complex by the lack of solid statistics on the costs and financing of education. To make the most efficient and effective use of limited resources, it is increasingly important for countries to have comprehensive and comparable data on education finance, not only for strategic planning and decisionmaking but also for monitoring progress.

The report has been prepared with this objective in mind to enable countries in SSA to have a solid analytical base on the costs and financing of education and to use this information more effectively for decisionmaking. It provides region-specific facts from an education finance perspective by consolidating the available information in a policy-relevant manner. In addition to documentation on the traditional and basic indicators, thematic analyses of the constituents of education expenditure are included. Information is also provided on public and private expenditure on education, along with analyses of teacher salaries and the costs associated with quality education. Moreover, this report highlights achievements to date in educational development from an education finance perspective and addresses present issues and the challenges that lie ahead. Finally, it offers governments and other stakeholders in SSA countries an in-depth review of critical issues related to the financing of education and places data on education finance in a cross-country and regional perspective.

\section{WHY DATA ON FINANCE AND COSTS ARE FUNDAMENTAL}

Data on education finance and expenditure are essential for effectively addressing critical education policy questions. These data help decisionmakers to determine the financial feasibility of achieving both quantitative and qualitative education goals and to decide on how to achieve equity in the provision of educational opportunities. They are also used to determine which particular mixes of financial policies and programmes can have the greatest impact on reaching objectives such as improved access, completion and learning, as well as to recognize the trade-offs and implications that can arise from the implementation of any particular set of education financing decisions.

\section{Financial feasibility, trade-offs and sustainability}

SSA countries have all agreed on the need for all children to complete quality primary education. Such objectives are often set in national development goals. However, achieving this target can be very ambitious for the poorest countries. In addition, providing a complete primary education does not suffice, since there are social and economic needs and pressures to expand and improve secondary, technical and vocational, and higher education. To meet growing educational demands from various stakeholders, decisions will inevitably involve trade-offs. The most obvious ones are: how much to spend on quantitative growth compared to quality improvement; how much to spend on different levels of education; and the extent to which the private sector and households should be encouraged to increase their financial support to education. In addition, it is important that these policy concerns include the issue of sustainability.

\footnotetext{
The GER includes under- and over-age children who may start school late or repeat grades.
} 


\section{Educational equity}

Equity concerns are highlighted during the discussion on policy trade-offs, because the main objective of public provision of education is to ensure equitable educational opportunities to all citizens in a country. Data on education financing are needed for decisionmaking on issues related to equity - identifying the extent to which some population groups receive more public financial resources than others and then designing policies to redress all or some of these inequities. Inequity in the provision of financial resources can be calculated in terms of per student expenditure by region, by urban-rural breakdowns, and by different socio-economic backgrounds and levels of educational attainment of students. Due to limited publically available resources, policy decisions about encouraging private and household expenditure for education must take into account equity issues at each level of education.

\section{Quality, cost efficiency and cost effectiveness}

Besides meeting purely quantitative goals of rising enrolment, policymakers increasingly need to consider improving the quality of education. Provision of quality education to an expanding student population requires efficiency of resource use, and an assessment of cost efficiency requires solid financial data. With a growing awareness of low student achievement at the end of the primary cycle, many SSA countries are focusing on learning achievement and outcomes. Recently, many studies have shown a wide variety of potential quality improvement interventions with cost implications. Costs have a very strong impact on this issue. Many interventions can be costly but have little impact on learning, while other interventions can be less costly, yet have a significant impact.

\section{CONTENT OF THE REPORT}

The report seeks to highlight achievements to date in educational development in the SSA region through a focus on the costs and financing of education, as well as to present issues and challenges that lie ahead. While much of the discussion is centered on primary education, the costs and financing of secondary and tertiary education are also examined.

Chapter 1 provides contextual information about the region, including historical background, characteristics of the population, economic environment, public financing, international aid and an education sector overview. It stresses the importance of understanding the key external constraints, the growing demand for education and emerging opportunities for the sustainable financing of educational development in SSA.
Chapter 2 analyses the breakdown of education expenditure in light of international comparisons and evolution over time. It addresses major questions on funding and allocation of education resources in relation to trade-offs, such as access versus quality, level of education and types of expenditure (recurrent, capital, teacher salaries and learning materials). It reviews the growth of public education expenditure during the 2000s and examines how the growth trend affected the enrolment expansion in SSA countries. It also examines expenditure per student and discusses inequity of resource allocation.

Chapter 3 examines the costs and financing of teachers in the region by linking the issue to overall sustainability of the financing of education. Teacher costs are by far the most important factor in education budgets. The chapter focuses on the level of remuneration that attracts quality teachers and maintains their motivation; remuneration policy by different categories of teachers; historical development and sustainability of remuneration systems; teacher management; and trade-offs between salaries and other current expenditure.

Chapter 4 reviews private spending on education. The chapter starts by discussing expenditure by households, which are the largest private financiers of education in many countries. It also discusses the impact of school fee abolition and the recent trend of rising private school enrolment among the urban middle class. The chapter concludes with a review of new roles for private actors and opportunities for public-private partnerships in the provision of educational services.

Chapter 5 focuses on issues related to quality in the context of financing and costs of education. Because of persistent resource constraints, SSA countries face a dilemma of how to allocate resources to improve the quality of education while at the same time expanding access to education. The chapter begins with an overview of definitions of quality, followed by a review of evidence on learning achievement, as well as on the provision of essential inputs into basic education. It concludes with a discussion of ways to identify the key policy interventions needed to improve quality.

The final chapter synthesizes the issues associated with the costs and financing of education and discusses the challenges ahead. It highlights the importance of setting priorities by recognising external constraints, continuously growing demand for education and emerging opportunities. It also emphasises the importance of evidence-based planning supported by regular use of education and finance data. 


\section{MAP OF SUB-SAHARAN AFRICA}

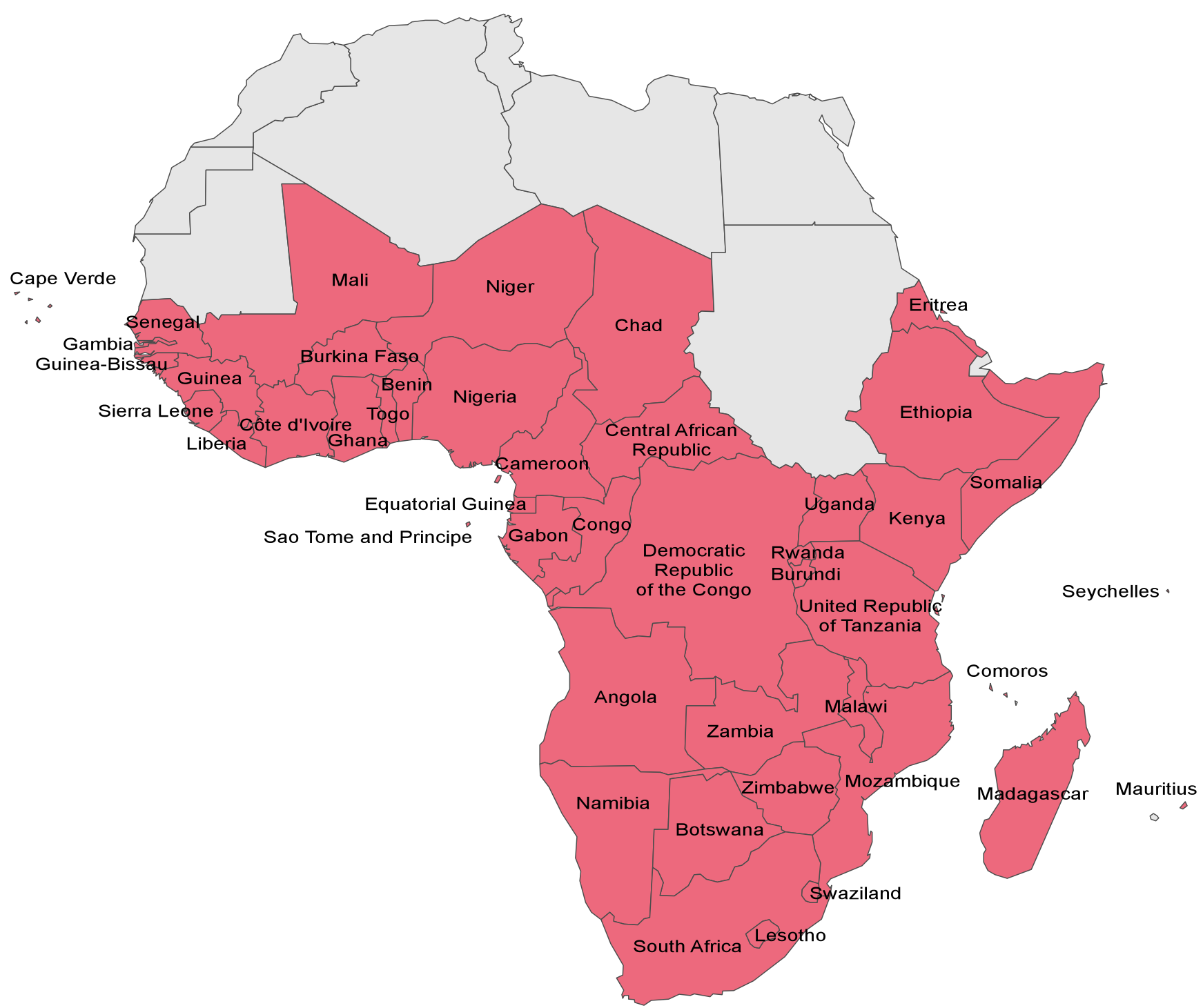




\title{
Chapter 1
}

\section{CONTEXTS FOR FINANCING EDUCATION IN SUB-SAHARAN AFRICA}

\author{
Shinsaku Nomura (UNESCO Institute for Statistics)
}

This chapter provides key contextual information about SSA, including historical background, characteristics of the population, economic environment, public financing, international aid and an overview of the education sector. It stresses the importance of understanding the key external constraints, the growing demand for education and emerging opportunities for the sustainable financing of educational development in SSA. As a result of fast population growth and increasing demand at all levels of education, financial constraints in the education sector are likely to persist. However, while SSA countries face particular challenges in meeting the EFA goals and sustainable educational development due to external environments, increased national and international commitments, international and regional initiatives, and the active roles of civil society organizations and the private sector have propelled educational development throughout the region during the past decade.

\subsection{HISTORICAL AND GEOGRAPHICAL CONTEXT}

The SSA region is quite diverse in its historical, cultural, political and environmental contexts. Covering 21.2 million square kilometers, the sub-continent has a diverse geography and climate. The northern part of the region is characterized by a vast desert with little vegetation; a cross-continental plateau stretches from eastern to southern Africa; and tropical forests can be found in central Africa. An arid and hot desert climate is usual in the Sahara zone; a wet and hot tropical climate is common in West and Central Africa; and a dry and cool highland climate is found in the eastern plateau.

The geographical diversity, combined with different histories of cultural, social, economic and political developments, create a unique mosaic of nations and societies across the continent. Out of a total of 45 countries $^{2}$, the largest is the Democratic Republic of the Congo, covering 2.2 million square kilometers, and the smallest country is Sao Tome and Principe, with 1,000 square kilometers (World Bank, 2004). The population sizes range from 158 million in Nigeria to 85,000 in Seychelles in 2010. Many SSA nations became independent from former colonial rule in the 1960s, while the youngest nation in SSA, South Sudan, became independent in 2011.

The countries of the region have gone through distinct historical developments. The year 1960 is called the "African year" since as many as 17 countries gained independence from colonial regimes. Throughout the 1960s, another 15 countries in the region became independent. Expectations were high in the 1960s for economic development of the resource-rich continent of Africa, with strong economic links to European countries. However, recurrent balance of payment failures and economic regression led a number of African governments to adopt structural adjustment policies in the 1980s, which were intended to open up markets, encouraged deregulation and private initiative, and reduced state economic intervention. While the pace of economic development has picked up in SSA countries since the mid-1990s, the region is still considered to be the poorest in the world.

Socio-economic diversity, different historical and political developments, and insufficient economic growth have all affected educational development in SSA. Various attempts have been made to achieve UPE since independence (e.g. Kenya), but due to various economic, social and environmental contexts, many SSA countries are still struggling with the development of their education systems today.

\subsection{DEMOGRAPHIC AND SOCIAL CONTEXT}

In 2010, approximately 815 million people lived in SSA, representing $11.8 \%$ of the world's population of 6.9 billion. ${ }^{3}$ The population of the region is young (43\% were under the age of 15 in 2010) and it is growing fast, with an estimated growth rate of 2.4\% between 2005 and 2010 . While this rate has declined from $2.8 \%$ two decades ago, it is still the fastest regional population growth rate in the world. By 2030, the population of SSA is estimated to increase to 1.3 billion (see Figure 1), representing about $15.7 \%$ of the world's population.

\footnotetext{
2 The list of sub-Saharan African countries according to the UNESCO Institute for Statistics (UIS) classification is attached in Appendix I. Seen also the map of Sub-Saharan Africa. 3 UN Population Division medium-variant projections.
} 
This very young and fast-growing population means that there is a large and rising demand for education. The 5 to 14-yearold age cohort in SSA is expected to grow by $34 \%$ over the next 20 years, from 226 million in 2010 to 303 million in $2030^{4}$ (UN Population Division, 2010). This demographic pressure has important implications for education financing: the needs of 77 million more children will have to be met, in addition to reaching the existing goal of achieving 100\% enrolment rates. Education systems throughout SSA will thus have to be expanded so that there will be an adequate number of schools, enough qualified teachers, appropriate learning materials and equipped classrooms.

A population structure with large groups of children and youth also places a heavy burden on the working age cohorts.

Figure 2 shows an international comparison of child dependency ratios. ${ }^{5}$ While this ratio has declined in SSA since 1990, the decline was slower than in almost all other world regions. Today the ratio in SSA remains the world's highest with
79.4 dependent children (below age 15) per 100 persons of working age (15 to 64 years) in 2008. This ratio is more than three times higher than the value for Central and Eastern Europe and substantially higher than the Arab States, which has the second highest regional value with 54.5 dependent children per 100 working persons. The extremely high child dependency ratio means that children in SSA cannot benefit in the same way as children in other regions. For example, even if a country in SSA and a country in North America and Western Europe allocate the same $20 \%$ of government expenditure to the education sector, the share of the pie that each child receives is much smaller in the SSA region because of the large size of the child population.

Another important characteristic of the African population is its ethnic, linguistic and cultural diversity. While English, French and Portuguese are commonly used in many African countries, over 2,000 living African languages are identified in the region (UNESCO, 2010a). This linguistic diversity can also

\section{Figure 1}

\section{PROJECTED POPULATION PYRAMID OF SUB-SAHARAN AFRICA BY SEX, 2010 AND 2030}

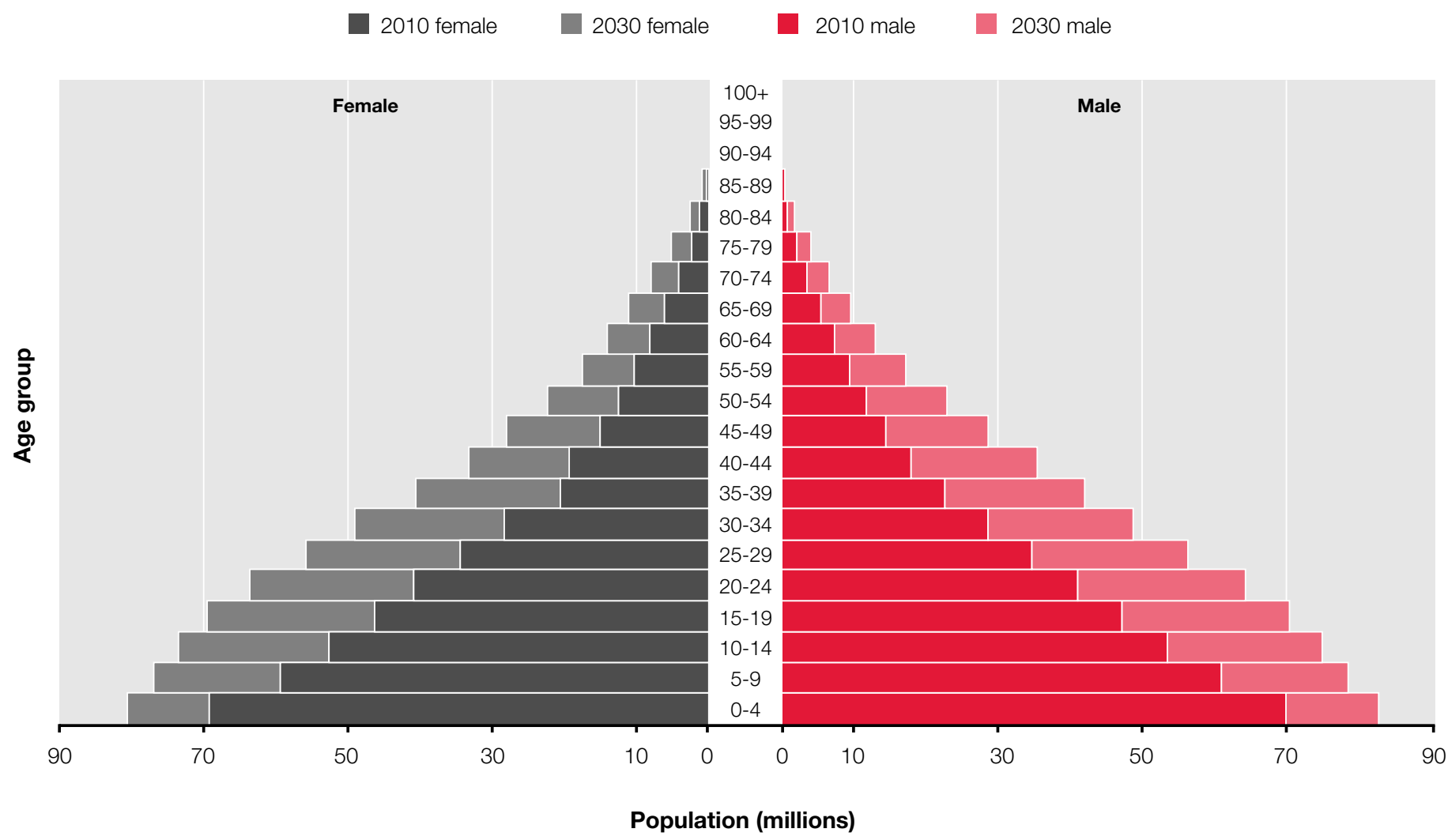

Source: UN Population Division, World Population Prospects: The 2008 Revision online database (March 2010) and Statistical Table A1.

4 This age group is used as a proximate cohort for primary and lower secondary education.

5 The child dependency ratio is the ratio of the population aged 0-14 years to the population aged 15-64 years. It is presented as the number of dependants per 100 persons of working age (15 to 64 years). The total dependency ratio is calculated by including the population aged 65 years and over in the dependants group. 


\section{CHILD DEPENDENCY RATIO BY REGION, 1990 AND 2008}

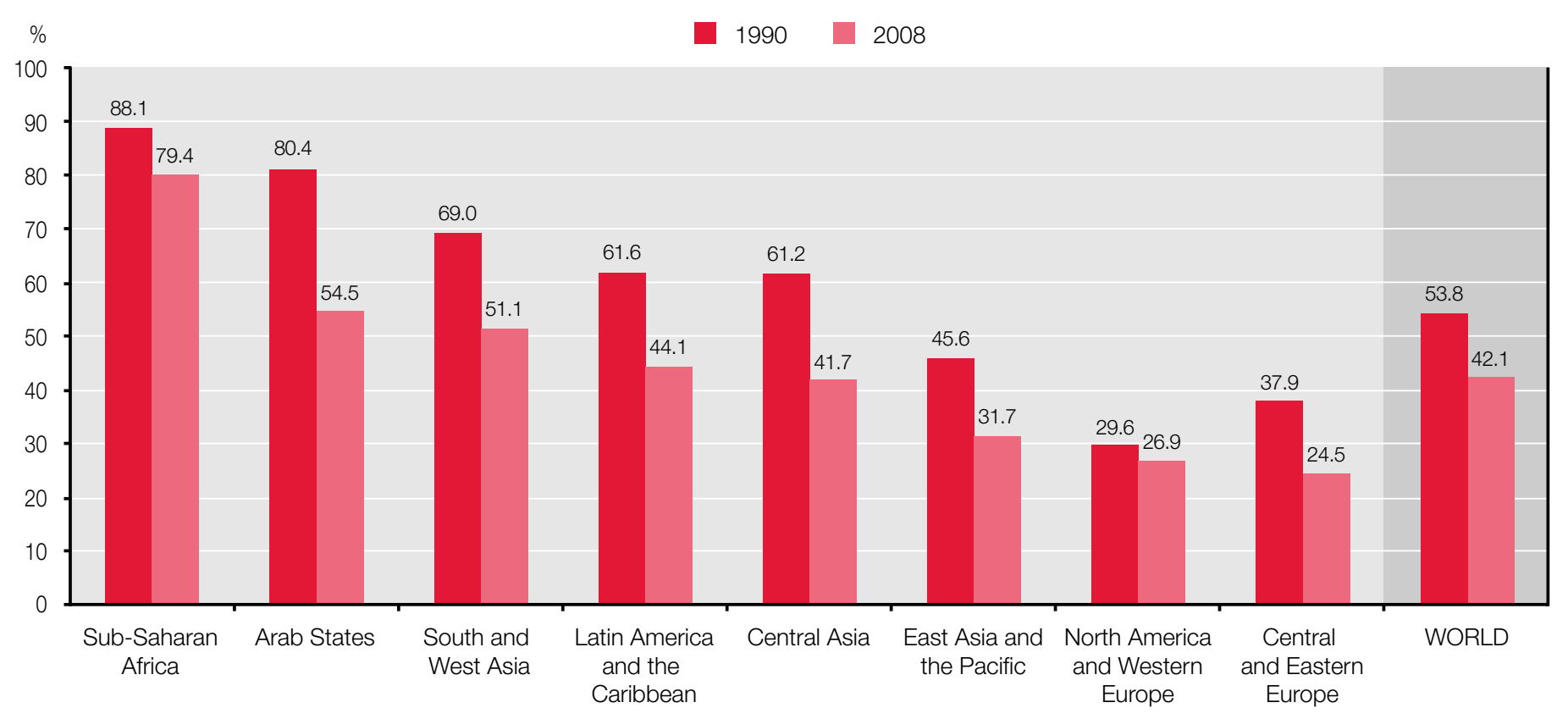

Sources: UNESCO Institute for Statistics calculations based on UN Population Division, World Population Prospects:

The 2008 Revision online database (March 2010) and Statistical Table A1.

be found within societies. Many people are commonly multilingual and use more than four or five languages in their daily lives. Great linguistic diversity represents a challenge for education systems as children from different linguistic backgrounds sometimes find it difficult to learn in a language that is different from their mother tongue. While having a common language of instruction is sometimes an important asset for nation building, balancing this with educational access for minority groups and preserving the richness of culture and history in local languages are important as well.

According to the United Nations Development Programme's (UNDP) human development index $(\mathrm{HDI})^{6}$, the region accounted for 22 out of 24 countries with low rankings in human development in 2009 (UNDP, 2009). While some SSA countries had a gross domestic product (GDP) per capita of higher than $\$ 10,000$ in purchasing power parity (PPP) in 2008 (Botswana, Equatorial Guinea, Gabon, Mauritius, Seychelles, South Africa), overall GDP per capita for the region was PPP\$2,073 (World Bank, 2010). ${ }^{7}$ According to the UNDP Human Development Report for 2009, more than $70 \%$ of the SSA population is living on less than US\$1.25 per day in Burundi, Guinea, Malawi, Mozambique, Rwanda and the United Republic of Tanzania.
One of the key causes for low human development in some countries is intermittently occurring conflicts, even though the incidence of these has decreased. In general, post-conflict countries have a low revenue base, high expenditure needs and weak institutional capacity, which complicate development of the education and social sectors (AfDB, 2008).

Despite continuous improvement, the literacy rate - which is one of the components of the $\mathrm{HDI}$ - remains relatively low in SSA. The adult literacy rate in SSA increased from 53\% to 62\% over the last two decades (see Figure 3). The rate of increase was greater among women than men, which has helped to reduce the gender gap. However, 167 million adults (104 million women and 63 million men) are still considered to be illiterate in SSA today.

Prevalence of disease and poor health conditions are other factors of low human development. HIV/AIDS, tuberculosis, malaria and various tropical diseases are commonly found in SSA. It is the region with the highest mortality rate for children under 5 years old at 144.3 per 1,000 for 2008 (World Bank, 2010) ${ }^{8}$ A major threat for the SSA population is the prevalence of HIV/AIDS. In 2008, the number of people living

\footnotetext{
6 In 2009, the HDI was a composite index of life expectancy at birth, adult literacy rate, gross enrolment ratio and GDP per capita, calculated by the UNDP.

Purchasing power parity (PPP) is a currency conversion rate that adjusts for differences in price levels among countries. This means that a given sum of money, when converted into US dollars at PPP rates, will buy the same basket of goods and services in all countries (UIS, 2007).

8 Mortality rates for children under 5 years in other developing regions are: 28.5 per 1000 for East Asia and Pacific; 23.1 for Latin America and the Caribbean; 34.4 for North Africa and the Middle East; and 76.2 for South Asia.
} 


\section{Figure 3}

\section{ADULT AND YOUTH LITERACY RATES IN SUB-SAHARAN AFRICA BY SEX, 1985 TO 2007 OR MOST RECENT YEAR}

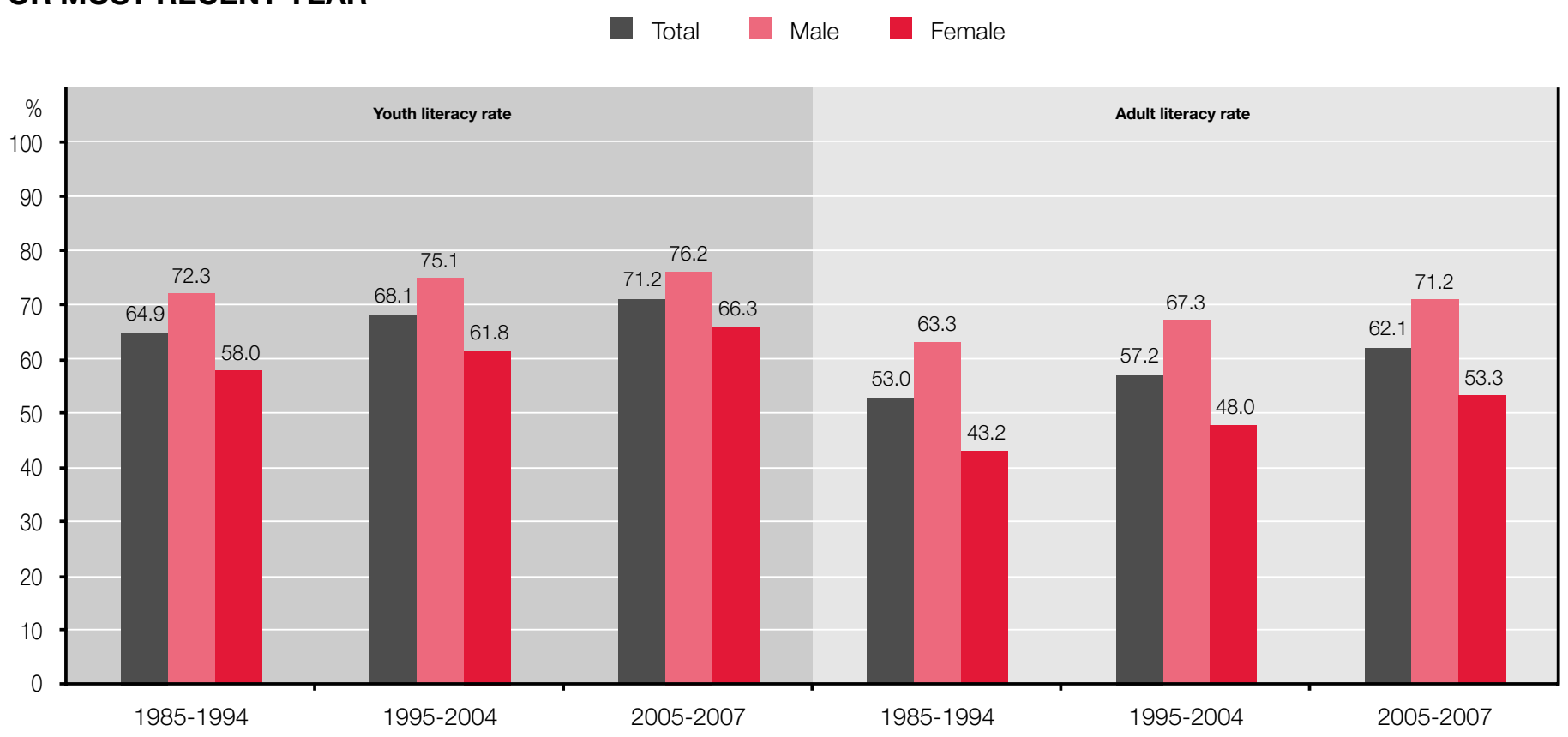

Source: UNESCO Institute for Statistics estimates using Statistical Table A1.

with HIV was approximately 22.4 million in SSA (compared to 33.4 million worldwide). Annually, around 1.9 million people are newly infected, and 1.4 million AIDS-related deaths are reported in SSA countries (UNAIDS, 2009). While the number of reported cases for new infections has declined during the past decade, ${ }^{9}$ HIV/AIDS is still a persistent issue for social and economic development across the region.

The prevalence of HIV/AIDS also has important implications for the cost of education on both the supply and demand sides. It is estimated that currently 122,000 teachers in SSA are living with HIV (World Bank, 2009). In Mozambique and Zambia, $9.5 \%$ and $14.3 \%$ of primary school teachers respectively are considered to be infected with HIV/AIDS. ${ }^{10} \mathrm{~A}$ loss of teachers and increased teacher absenteeism due to sickness are commonly observed phenomena. In Mozambique, AIDSrelated costs in 2005 were estimated at US\$3.3 million due to teacher absenteeism and US\$0.3 million due to increased teacher-training costs (UNESCO, 2005). HIV/AIDS also creates a problem on the demand side. In SSA, an estimated 12 million children have been orphaned by AIDS by 2005 , and this number is expected to rise to 15.7 million by 2010 (UNICEF, 2006). Orphans are less likely to attend school due to the difficulty of financing their schooling costs and the lack of family and home support. As a consequence, the prevalence of HIV/AIDS has created a serious threat to educational development.

\subsection{MACROECONOMIC CONTEXT}

During the four years preceding the financial crisis in 2008, the SSA region experienced stable economic growth of around $6 \%$ per annum, which was up from a $4 \%$ growth rate between 1995 and 2005 (see Figure 4). After a long period of difficult economic growth during the 1980s and 1990s, this relatively stable growth in the 2000s was supported by increasing global demand for commodities and manufactured goods. Consequently, GDP per capita (in 2005 constant PPP\$) in SSA increased from PPP\$1,543 in 2000 to PPP\$1,912 in 2008 (see Table 1).

However, as a result of the global financial crisis since mid2008 , the region's growth rate decelerated to an estimated 1.2\% in 2009 (World Bank, 2010). This, coupled with an estimated population growth rate of $2.4 \%$, resulted in a negative GDP per capita growth of $1.3 \%$ for SSA.

Furthermore, with globalization, the contribution of trade to GDP in SSA increased from 51.8\% in 1990 to $75.0 \%$ in 2008. This high reliance on trade makes the region particularly

\footnotetext{
9 There are cases where HIV/AIDS prevalence has been successfully contained, for example in Uganda.

10 These percentages were calculated by using World Bank (2009) data together with UIS data on teachers. According to World Bank (2009) estimations, some 6,700 primary school teachers are infected with HIV/AIDS in Mozambique and 6,300 in Zambia. According to 2007 UIS data, Mozambique has a total of 70,400 primary school teachers and Zambia has 44,000.
} 
$\square$ GDP per capita, PPP\$ (left axis) $\multimap$ Real GDP growth rate (right axis) $\quad \longrightarrow$ Real GDP per capita growth rate (right axis)

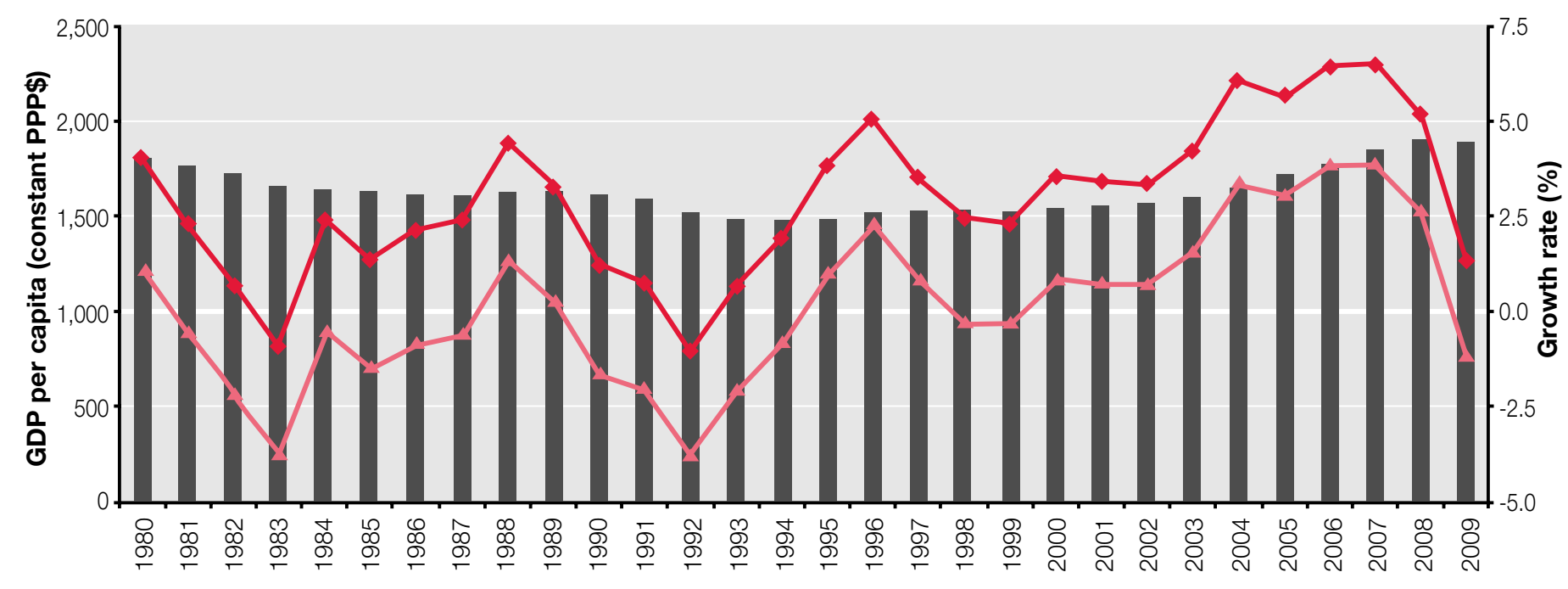

Source: World Bank, WDI online database (September 2010).

\section{Table 1}

\section{SELECTED ECONOMIC INDICATORS, SUB-SAHARAN AFRICA, 1970-2009}

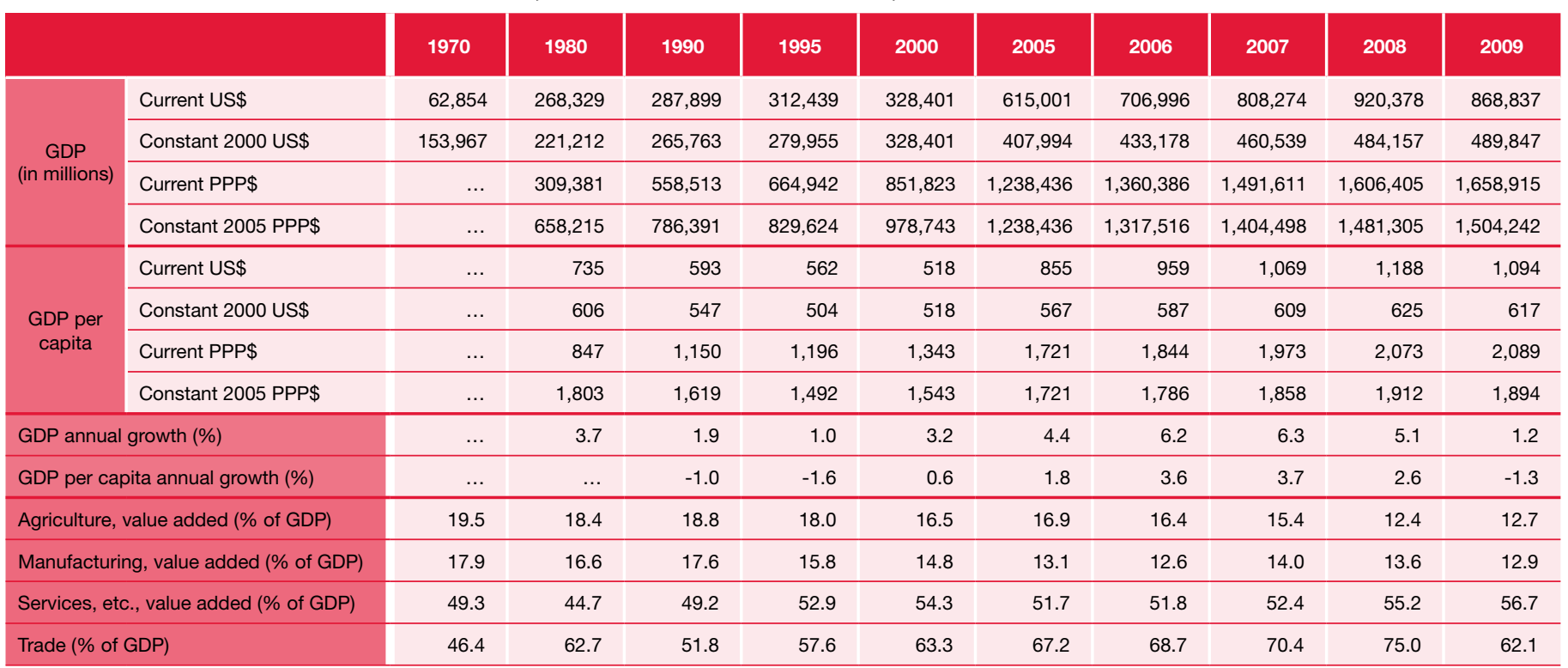

Notes: GDP and GDP per capita annual growth rates are calculated by the UIS based on raw data. Growth rates for 1980 refer to average annual growth rates between 1970 and $1980 ; 1990$ for the period between 1980 and 1990; 1995 for the period between 1990 and 1995; 2000 for the period between 1995 and 2000; and 2005 for the period between 2000 and 2005.

Source: World Bank WDI database. 
vulnerable to external shocks. Due to a drop in trade volume in the region by 46\% between 2008 and 2009 (AGOA, 2010), many SSA countries suffered from economic slowdown.

Although African countries are pursuing intra-regional integration through the framework for a continent-wide African Economic Community (AEC) that was set up in $1991^{11}$, a large part of regional trade still depends on trade with non-SSA countries. In addition, many African countries are suffering from a declining flow of remittances and foreign direct investment, which had been rapidly increasing during the decade before the financial crisis in 2008.

The labour force in the SSA region is still primarily agricultural, although the contribution of this sector to GDP shrank from $18.8 \%$ in 1990 to $12.7 \%$ in 2009 (World Bank, 2010). In $2001,58 \%$ of male and $73 \%$ of female workers in SSA were active in the agriculture sector (World Bank, 2004). ${ }^{12}$ Rapid urbanization has been observed in the region, and the number of workers in the informal sector is growing. While no accurate figures are available, it is estimated that in the late 1990s the informal sector employed $89 \%$ of the labour force in Ghana, $60 \%$ in the United Republic of Tanzania, and $40 \%$ of the urban labour force in Kenya (Xaba, Horn and Motala, 2002). UN-HABITAT expects that more than $50 \%$ of the population in SSA will be living in urban areas by 2030 (UN-HABITAT, 2010).

While unemployment varies from one SSA country to another, it is a serious issue for much of the region. Some of the highest unemployment rates in SSA are found in South Africa, Namibia and Botswana, where rates were 27\%, 25\% and 20\% respectively in the mid-2000s (World Bank, 2010). In South Africa, youth unemployment (population aged 15 to 24 years) was almost twice as high as adult unemployment, reaching $47 \%$ in 2007 (World Bank, 2010). Some anecdotal evidence indicates that the unemployment problem has been exacerbated further in many SSA countries due to the global financial crisis, which has led to the closure of factories and the withdrawal of foreign direct investment.

\subsection{PUBLIC FINANCING}

In most countries of the world, education is largely financed by the government. A commonly agreed rationale for public intervention in education is that it fosters important external benefits for societies. For example, a number of studies have pointed out the positive social impact of education, thus reinforcing arguments in favour of government interventions in this sector. ${ }^{13}$ However, public provision of educational services is always constrained by the availability of public resources. Many SSA countries have relatively weak public resource collection capacity, and hence, resource allocation for education is also affected.

For many SSA countries, it is very difficult to raise public revenue because of macroeconomic and growth instability, high debt ratios, weak tax administration and large informal sectors. Resource-rich SSA countries exhibit relatively strong revenue collection performance, yet domestically generated revenue for many countries is less than $20 \%$ of GDP. Figure $\mathbf{5}$ presents domestically generated revenue as a percentage of GDP for three groups of countries according to GDP per capita PPP. The first group includes countries with a GDP per capita below PPP $\$ 1,000$ in 2008; the second group represents those with a GDP per capita of PPP $\$ 1,000-3,000$; and the third group covers countries with a GDP per capita of PPP\$3,000 and above. To highlight the economic dimension of national development, this grouping will be used for the comparison of countries in SSA throughout this report (see Appendix I).

In general, the share of domestically generated revenue in GDP tends to be greater in high-income countries. On the other hand, low-income countries - and in particular lowincome SSA countries - face difficult trade-offs between increasing public spending for social welfare, increasing taxes, and maintaining debt sustainability. Furthermore, their weak revenue collection capacity limits the amount of resources available for public services and their provision.

Along with taxation, monetary financing and internal borrowing, foreign borrowing has historically been one of the most important ways through which governments raise the resources needed to implement their development policies. However, foreign borrowing has been a double-edged sword as the loans obtained from donors and other creditors need to be repaid at some point (World Bank, 2008). This was the case for many SSA countries in the 1990s, which suffered from large foreign debt burdens that they had accumulated from earlier years. In 1996, the International Monetary Fund (IMF) and the World Bank launched an initiative called Heavily Indebted Poor Countries, with the aim of ensuring that no poor country would face a debt burden that it could not manage. By the end of 2009, 29 SSA countries had been approved for the debt reduction packages under this initiative (IMF, 2010).

\footnotetext{
11 Within this framework, eight regional economic communities have been formed to establish free trade areas and customs unions, as well as to ensure the free movement of people both within and among the regions (UNECA and $\mathrm{AU}, 2008$ ).

12 This figure excludes Nigeria and South Africa.

13 A comprehensive discussion of the costs and benefits of education is documented in Woodhall (2004). An international comparison of social rates of return to education is presented, for example, by Psacharopoulos and Patrinos (2002). Wolfe and Zuvekas (1997) present discussions on non-monetary benefits of education.
} 


\section{Figure 5}

\section{DOMESTIC REVENUE AS A PERCENTAGE OF GDP BY NATIONAL INCOME LEVEL, 2004-2008}

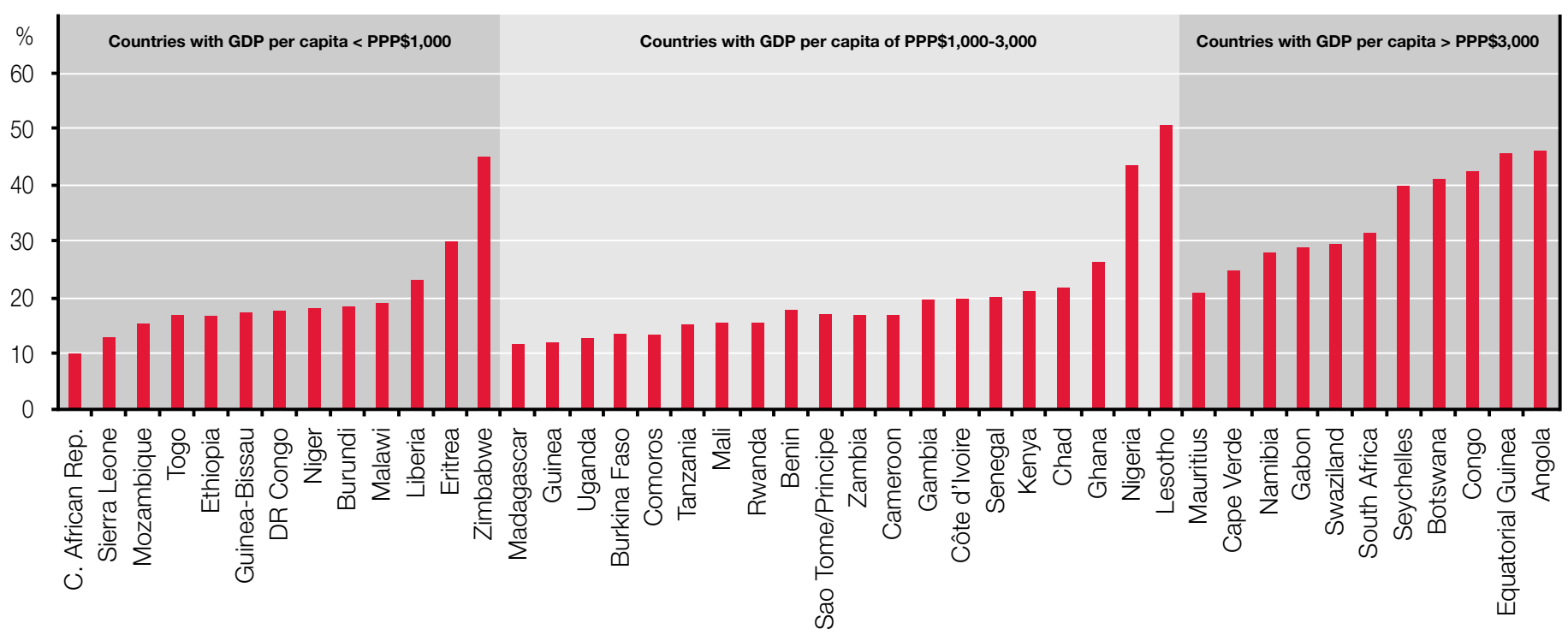

Notes: Reference year is 2004 to 2008 depending on data availability. GDP per capita data are for 2008 except for Zimbabwe (2005). Sources: Domestic revenue as a percentage of GDP: Pôle de Dakar (UNESCO-BREDA). GDP per capita: World Bank.

\subsection{INTERNATIONAL AID AND GOVERNANCE}

While the largest part of government expenditure in most countries is covered by public sources, international aid plays a non-negligible role in some SSA countries. The flow of net official development assistance (ODA) began to decreaseduring the late 1990s (see Figure 6) as a result of complex factors, including general tightening of government budgets in donor countries, the end of the Cold War, and growing doubt in public opinion over the effectiveness of aid (World Bank, 2000). This reduction in ODA increased apprehension worldwide that development progress would suffer. In 2000, time-bound and quantified Millennium Development Goals (MDGs) were set by the international community to rejuvenate global commitment to development and poverty reduction. Consequently, the amount of net ODA to SSA increased threefold, from US\$11.5 billion in 2000 to US\$32.8 billion in 2008 , representing $26 \%$ of total aid to developing countries in the world. Ethiopia received the largest amount of net ODA in 2008 (US\$3.2 billion), followed by the United Republic of Tanzania and Mozambique, with US\$2.3 billion and US\$1.9 billion respectively. Cape Verde and Sao Tome and Principe received the highest per capita ODA in 2008, with US\$454 and US $\$ 401$ respectively. ${ }^{14}$
During the 2000s, there was not only an increase in ODA but also improvement in the governance of international aid. Formerly, aid-recipient countries were criticized by the international community for lack of accountability, mismanagement and corruption, while donors were criticized for their self-interested and project-oriented development agenda. In 2005, over 100 donors and developing countries agreed to undertake landmark reforms in the way they do business together (OECD, 2006). These reforms, known as the Paris Declaration on Aid Effectiveness, aim to increase efforts to harmonise aid delivery by all donors, align aid with recipient countries' development objectives and, in particular, ensure result-oriented management of aid. Building on the commitments of the Paris Declaration, the Accra Agenda for Action was drawn up in 2008, initiating an action plan to accelerate progress through promoting country ownership of development programmes, ODA predictability and the use of untied aid. Civil society organizations and regional initiatives also played an increasing role in Africa during this period.

Furthermore, the African Union (AU) ${ }^{15}$ launched the New Partnership for Africa's Development (NEPAD) in 2001 to tackle a multitude of development issues. In the area of educational development, the $\mathrm{AU}$ initiated the Decade of Education for Africa. ${ }^{16}$

\footnotetext{
14 The estimate is made by the UIS. Data for ODA are from OECD-DAC, and population data are from the UIS database.

15 The AU was formed in 2001, based on the former Organization of African Unity (OAU).

${ }_{16}$ The first decade covered 1997-2006, and the second decade covers 2006-2015.
} 


\section{TRENDS IN OFFICIAL DEVELOPMENT ASSISTANCE FLOWS TO SUB-SAHARAN AFRICA, 1990-2008}

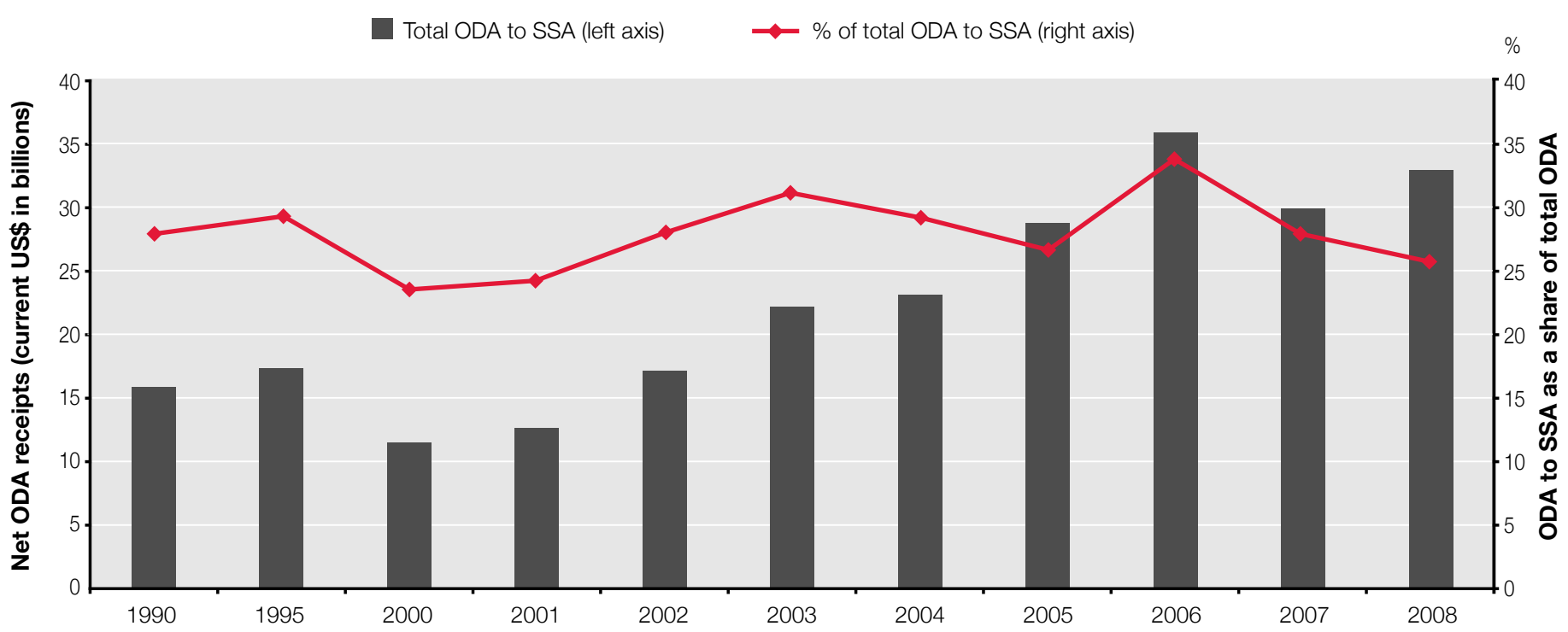

Source: OECD-DAC online database, 2010.

The external flow of aid to the education sector in the region increased from current US\$1.1 billion in 2002 to US\$2.6 billion in 2008 as a result of a series of international development agendas. In 2000, the international community announced through the Dakar Framework for Action that "no countries seriously committed to education for all will be thwarted in their achievement of this goal by a lack of resources" (UNESCO, 2000). However, there is a risk of over-reliance on external aid in some SSA countries. Among the countries with available data, Liberia, Mali, Rwanda and Zambia seem to have financed more than $50 \%$ of their education budgets from external sources in 2008. ${ }^{17,18}$ This high reliance on foreign aid increases vulnerability to external conditions. The recent global financial crisis has already begun to affect foreign donors, resulting in aid budget cuts (AfDB and OECD 2009) and increasing risk for aid-dependent countries.

In order to use and coordinate external funds more effectively and to improve monitoring of budgetary processes, many SSA countries are struggling to enhance public finance management. To increase the predictability of available funds and resource allocation to different sectors, especially to the social sector, medium-term expenditure frameworks have been introduced in many countries. These frameworks are prepared as part of the overall national strategic plans - such as national visions, poverty reduction strategy papers and five-year plans - with the aim of allocating resources efficiently across sectors and across time. The development of such budgetary instruments has increased the credibility of resource use, and funds from donors have also been effectively mainstreamed.

While public financing mechanisms have improved, there are still some constraints related to administrative capacity and governance (see Box 1 for more information). It has been argued that simply allocating public resources for the right goods and services may not lead to desired outcomes if good governance is lacking (Rajkumar and Swaroop, 2008). In the education sector, the consequences of weak governance are evident, for example, in the leakage of non-salary cash flows and instructional materials, misallocation of resources, weak teacher management (including the problems of high teacher absenteeism and low motivation), and so on (UNESCO, 2008). Although a number of SSA countries - including Botswana, Mauritius and Rwanda - have made remarkable progress in adopting international standards of good governance, the risk of potential loss of scarce resources due to weak management and governance is a concern in other countries.

Governments of many SSA countries and development partners have increased resources for educational development over the past decade. However, a number of attempts have been made to estimate the cost of achieving EFA targets by 2015 and have revealed financing gaps (e.g. UNESCO, 2010b). They have also indicated that the resources dedicated to educational

\footnotetext{
17 The estimate is made by the UIS. Data on ODA are from OECD-DAC, and the total education expenditure figure is taken from the UIS database.

18 More detailed analysis is found in Chapter 2.
} 


\section{WORLD GOVERNANCE INDICATOR}

Governance is defined as the traditions and institutions by which authority in a country is exercised. This includes the process by which governments are selected, monitored and replaced; the capacity of the government to effectively formulate and implement sound policies; and the respect of citizens and the state for the institutions that govern economic and social interactions among them (Kaufman and Kraay, 2008).

To monitor a country's quality of governance, the world governance indicator has been developed by the World Bank. This indicator is used to assess political and economic institutions in six areas: i) government effectiveness; ii) voice and accountability; iii) political stability and absence of violence; iv) regulatory quality; v) rule of law; and vi) control of corruption. It makes it possible to establish a percentile rank for all countries in the world, ranging from 0 (weak governance) to 100 (good governance).

The average percentile rank for the SSA region was 30.1 in 2008, which was the lowest among all regions along with South Asia, with a ranking of 30.8. Some SSA countries are located at a high percentile, however. For example, Botswana and Mauritius are situated above the $70^{\text {th }}$ percentile rank.

development in SSA are insufficient. While concerns over the financing gaps are becoming more acute as the 2015 deadline approaches, it may be difficult for many stakeholders to increase resources for education (see more detailed discussion in Chapter 2).

Nonetheless, a number of new initiatives and innovative schemes for sustainable development have been launched. The increased role played by civil society organizations in good governance and accountability, as well as their role in implementing development agendas by partnering with international organizations, have been largely acknowledged by the Accra Agenda for Action. In addition, the private sector has become an emerging financier of development through innovative financing schemes and public-private partnerships. ${ }^{19}$

\subsection{CONTEXT OF EDUCATIONAL DEVELOPMENT}

\subsubsection{Today's education systems in sub-Saharan Africa}

Education systems vary greatly among SSA countries. Following the 1997 International Standard Classification of Education (ISCED 1997) ${ }^{20}$, the primary education level (ISCED 1) may last for five years (as is the case in 2 SSA countries), six years (33 countries) or seven years (10 countries). There are also some regional tendencies in the structure of education systems. For example, a seven-year primary education programme is more likely to be found in southern African countries. Secondary education, which can be divided into lower (ISCED 2) and upper (ISCED 3) levels, may also take five to seven years to complete, depending on the country.

It should be noted that some SSA countries - for example, Kenya, Somalia and Malawi - have an eight- or nine-year basic education system. The lower grades of their basic education system are considered as the primary level (ISCED 1) and the upper grades are considered to be at the lower secondary level (ISCED 2) according to the ISCED classification. Completing both primary and secondary education can take 11 to 13 years in SSA. ${ }^{21}$ With such varied education systems, the reference grade for primary education completion is not the same for all SSA countries. This also has an implication for the analysis of education expenditure as primary education may cover different grades in different countries. A comparison of core education structures in SSA is presented in Appendix II.

\subsubsection{Expansion of education systems}

The education systems of SSA countries have expanded substantially over the past four decades. Enrolment in primary education increased 5.5 times, from 23 million in 1970 to 129 million in 2008. Secondary school enrolment grew 8.5 times, from 4 million to 36 million. Enrolment at the tertiary level also grew considerably during the same period, although it was smaller than at the primary or secondary level: tertiary enrolment increased 22.3 times, from 0.2 million to 4.5 million, and pre-primary enrolment increased 2.6 times, from 4.3 million to 10.9 million between 1990-2008 (see Table 2).

The GERs of each education level also grew during the same period. Primary GER increased from 52.5\% to 101.6\%; secondary GER increased from $11.3 \%$ to $34.1 \%$; and tertiary GER increased from $0.8 \%$ to $6.1 \%$. However, GER growth was not linear. Although the absolute number of students in SSA increased from 55 million to 59 million between 1985 and 1990, the GER declined from $79.3 \%$ to $72.8 \%$ at the primary level of education. Secondary GER also declined, from 23.3\% to $22.5 \%$, over the same period. This means that the rate of enrolment growth was slower than the rate of population growth

\footnotetext{
19 Please see Chapter 4 for a detailed discussion on private financing.

20 The UIS is currently revising ISCED. The updated ISCED is expected to be released in 2011 and implemented starting in 2013

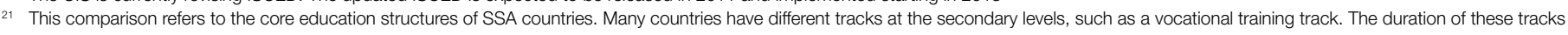
is often different from that of the main academic track.
} 
in the SSA region during this period, which was marked by economic stagnation. From 1980 to 2000, the primary GER increased by less than 5 percentage points, but then grew by almost 20 percentage points between 2000 and 2008.

Rapid enrolment growth was observed particularly during the 2000s as a result of increased international efforts through the MDGs and Education for All (EFA) (see Table 2). The number of students in primary schools increased from 87 million to 129 million between 2000 and 2008, and primary education GER increased from $82.2 \%$ to $101.6 \%$. This rapid enrolment growth was also supported by political commitment. One of the most dramatic policy changes in educational development was the abolition of school fees, introduced in the 1990s (e.g. Cameroon, Ethiopia, Ghana, Malawi, Uganda among others) and in the 2000s (e.g. Benin, Burundi, Lesotho, Liberia, Mozambique, Rwanda, Sierra Leone, the United Republic of Tanzania, Zambia - among others). While budgetary constraints often appear as a barrier to providing free primary education, SSA countries increased their commitment to educational development by allocating more resources to the education sector during the 2000s.

While education systems have been expanding rapidly in SSA, reaching educational development goals still remains a daunting task for many countries. Measured by the rate of completion of primary education, the EFA goals require not only enrolling but retaining students in the education system until the end of the primary cycle. However, measuring the primary completion rate is no easy task, because enrolment data that countries collect through administrative sources do not necessarily include the number of students who have completed primary education. Instead, two indicators are widely used to measure progress towards UPE: the gross intake ratio to the last grade of primary school and the adjusted net enrolment rate. ${ }^{22}$

Figure 7 presents a comparison of gross intake ratios in SSA countries for the last grade of primary education, which is considered a proxy for the primary completion rate. The countries are clustered by the duration of their primary education cycle. According to the most recent data, about one-third of the countries exceed $80 \%$. However, 5 out of 38 countries (one-eighth) have less than $50 \%$ of the proxy primary completion rate. The rate ranges from $33.5 \%$ in Chad to $105.1 \%$ in Seychelles. ${ }^{23}$ The average primary completion rate for the region was around $65 \%$ in 2008 , indicating that there is still a long way to go before achieving universal primary completion.

Both access to the first grade of primary education and retention are significant obstacles to achieving EFA in the region. Out of the 39 countries with data for the years between 2006 and 2009,2424 countries had a gross intake ratio for the first grade of primary education that exceeded 100\%, 13 countries had a ratio ranging between $80 \%$ and $100 \%$, and 2 countries had a ratio below $80 \%$. While the regional average of the gross intake ratio was $115.7 \%$ in 2008 , some SSA countries are still struggling to provide children with access to primary schools, especially in conflict-affected, fragile states.

The problem of access can also be considered from a different angle. In 2007, there were 32 million children out of school in the SSA region, and more than $60 \%$ of those in the primary

\section{Table 2}

\section{TRENDS IN ENROLMENT IN SUB-SAHARAN AFRICA BY EDUCATION LEVEL, 1970-2008}

\begin{tabular}{|c|c|c|c|c|c|c|c|c|c|}
\hline \multicolumn{10}{|c|}{ Number of students by level (in thousands) } \\
\hline Primary & 23,473 & 31,048 & 46,337 & 55,498 & 59,562 & 70,451 & 86,757 & 112,156 & 128,548 \\
\hline Secondary & 4,260 & 5,734 & 8,883 & 13,588 & 14,888 & 18,400 & 22,015 & 30,986 & 36,349 \\
\hline Pre-primary & $\ldots$ & $\ldots$ & $\ldots$ & $\ldots$ & 10.5 & 10.6 & 12.1 & 14.8 & 16.7 \\
\hline Primary & 52.5 & 60.6 & 77.6 & 79.3 & 72.8 & 75.8 & 82.2 & 95.4 & 101.6 \\
\hline Secondary & 11.3 & 13.2 & 17.8 & 23.3 & 22.5 & 23.9 & 25.0 & 31.0 & 34.1 \\
\hline Tertiary & 0.8 & 1.1 & 1.7 & 2.4 & 3.0 & 3.6 & 4.2 & 5.5 & 6.1 \\
\hline
\end{tabular}

Note: To calculate regional sums, missing data are imputed by the UIS.

Source: UNESCO Institute for Statistics database.

\footnotetext{
22 The EFA Global Monitoring Report 2010 discusses the pros and cons of these commonly used measures for primary completion and mentions the importance of reviewing cohort completion rates.

${ }_{23}$ This rate indicates the ratio of non-repeaters enrolled in the last grade of primary education compared to the population of the corresponding age. Therefore, when there are over-aged or under-aged pupils enrolled in the last grade of primary education, the ratio can exceed $100 \%$.

24 Six countries do not have data on gross intake ratios for the period 2006-2009.
} 


\section{Figure 7}

\section{GROSS INTAKE RATIO TO THE LAST GRADE BY DURATION OF PRIMARY EDUCATION IN SUB-SAHARAN AFRICA, 2009 OR MOST RECENT YEAR}

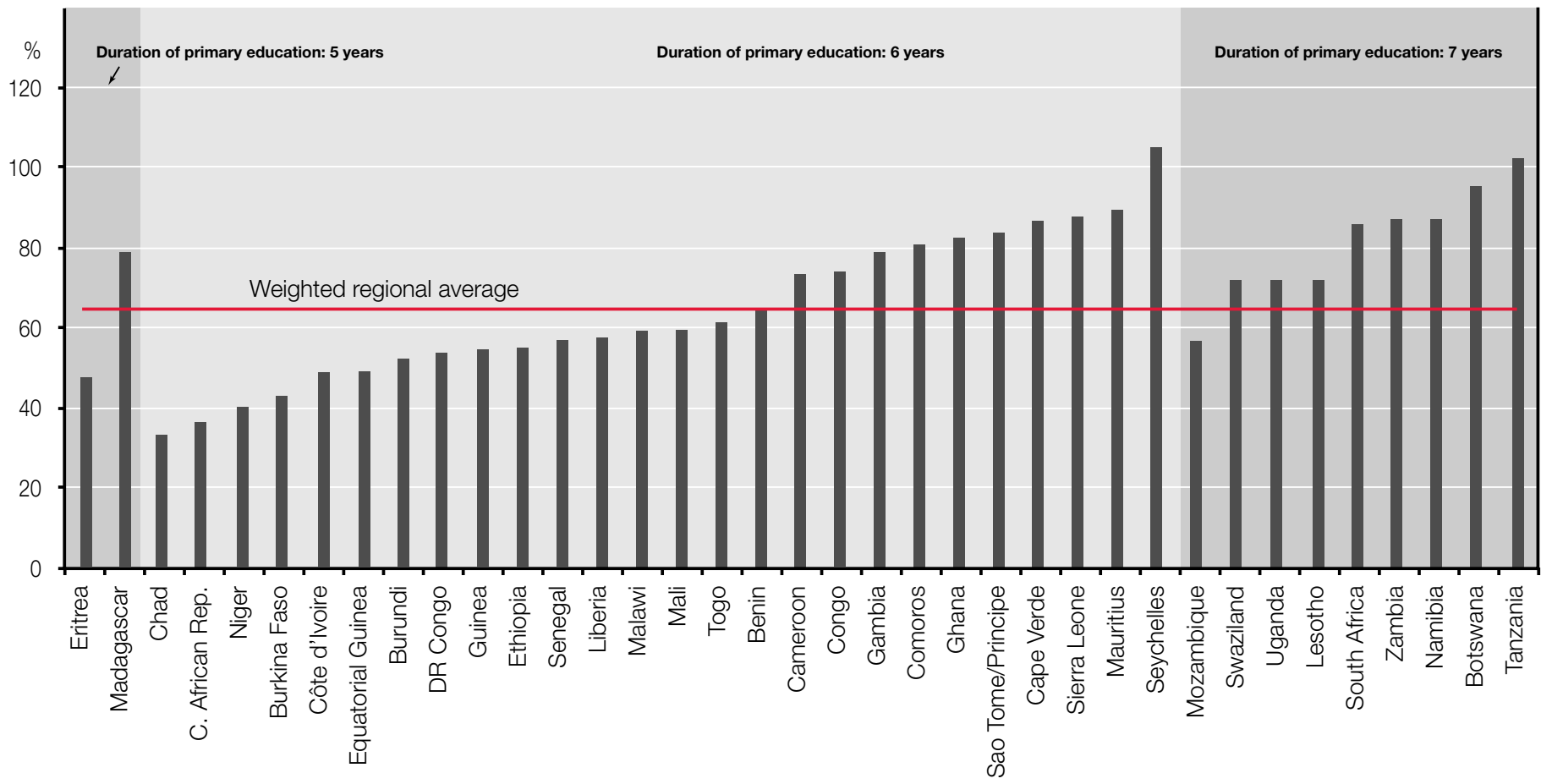

Source: UNESCO Institute for Statistics, Statistical Table A3.

school-age group are expected to never enrol in school (see Box 2 for more information). This proportion of out-of-school children is the largest among all regions in the world, since in other regions children tend to eventually enter school at an older age. From analyses of household surveys, children from rural and poor households are much more likely to remain out of school than children from urban and rich households (UNESCO, 2010b). Consequently, much effort is still required in SSA to enrol children who are likely to never attend school, in particular disadvantaged children (such as street children and orphans) and the children of marginalized groups (including nomadic and pastoralist groups).

In addition to providing access to education, keeping children in school is a challenge in many SSA countries. Many report low retention and high repetition and dropout rates. Figure 8 shows the survival rates of children at the primary education level in selected SSA countries. Of the children who enter the first grade of primary education, the percentage who reach Grade 6 varies substantially across countries. In Mali, 80\% of pupils who enter Grade 1 reach Grade 6, while only 40\% reach Grade 6 in Ethiopia. Dropout occurs quite often at early grades. For example in Ethiopia and Mozambique, more than 25\% of children who enter Grade 1 drop out before Grade 3. As these case studies show, the retention of children in school is a major problem for achieving UPE in many SSA countries.

Over the past four decades, notable growth in enrolment has also been observed for secondary and tertiary education in SSA. As a result of increasing numbers of primary school completers, there is a growing demand for post-primary education. Rising enrolment in secondary education is a function of the increasing number of children in each age cohort, the proportion who complete primary education and are admitted into secondary education, and their progress through the secondary school system (Verspoor with the SEIA Team, 2008). As a result of the current EFA policy in almost every SSA country, demand for secondary education is steadily increasing in the region and so is pressure on the secondary education system to meet this demand.

As shown in Figure 9, secondary education enrolment has grown steadily. In 1970, there were approximately 4.2 million students at the secondary education level in the region. This number had more than doubled by 1980 , reaching 8.9 million, and then increased to 14.9 million in 1990, 22.0 million in 2000, 


\section{TYPOLOGY OF OUT-OF-SCHOOL CHILDREN}

The UIS has developed a typology which helps policymakers to select appropriate policy options for different groups of outof-school children. Out-of-school children of primary school age fall into two main groups with respect to their exposure to education. The first group consists of children who have yet to start school, and the second group comprises children who have dropped out before reaching the theoretical completion age for primary school.

The first group can be broken down further in terms of the probability of future school participation. The first sub-group includes out-of-school children who are likely to start school at some point in the future, while the second sub-group includes those who will never begin schooling. Household surveys, such as the Demographic Health Surveys (DHS) and Multiple Cluster Indicator Surveys (MICS), are used in an ongoing effort to identify the different groups of out-of-school children.

Source: UNESCO Institute for Statistics, 2005.

and 36.3 million in 2008. Data for lower and upper secondary education enrolment became available during the most recent decade only. According to these data, enrolment growth was fairly equal between the lower and upper secondary levels. Lower secondary enrolment grew by $77 \%$ between 2000 and 2007, while upper secondary enrolment grew by $71 \%$. The actual increase in the number of students was 10 million in lower secondary education and 5.5 million in upper secondary education.

While the size of enrolment at the tertiary level is still relatively small, it had the fastest growth rate among all levels of education over the past four decades in SSA. Enrolment at the tertiary level increased 22.3 times between
1970 and 2008, from 0.2 million to 4.5 million students. This fast growth can be partly explained by the small enrolment size at the baseline year of 1970. As a result of this rapid increase, the share of tertiary students in the total student population in the region grew from $0.7 \%$ in 1970 to $2.5 \%$ in 2008. The increase in the relative size of tertiary enrolment implies that SSA governments have been compelled to secure sufficient resources to this level of education, unless financing has come from non-public sources.

Although increasing pre-primary school enrolment is one of the EFA goals, enrolment at this level still remains relatively small in SSA. Between 1990 and 2008, the GER of pre-primary education increased from $10.5 \%$ to $16.7 \%$ in the region.

\section{Figure 8}

\section{SURVIVAL RATE BY GRADE OF PRIMARY EDUCATION IN SELECTED COUNTRIES, 2008}

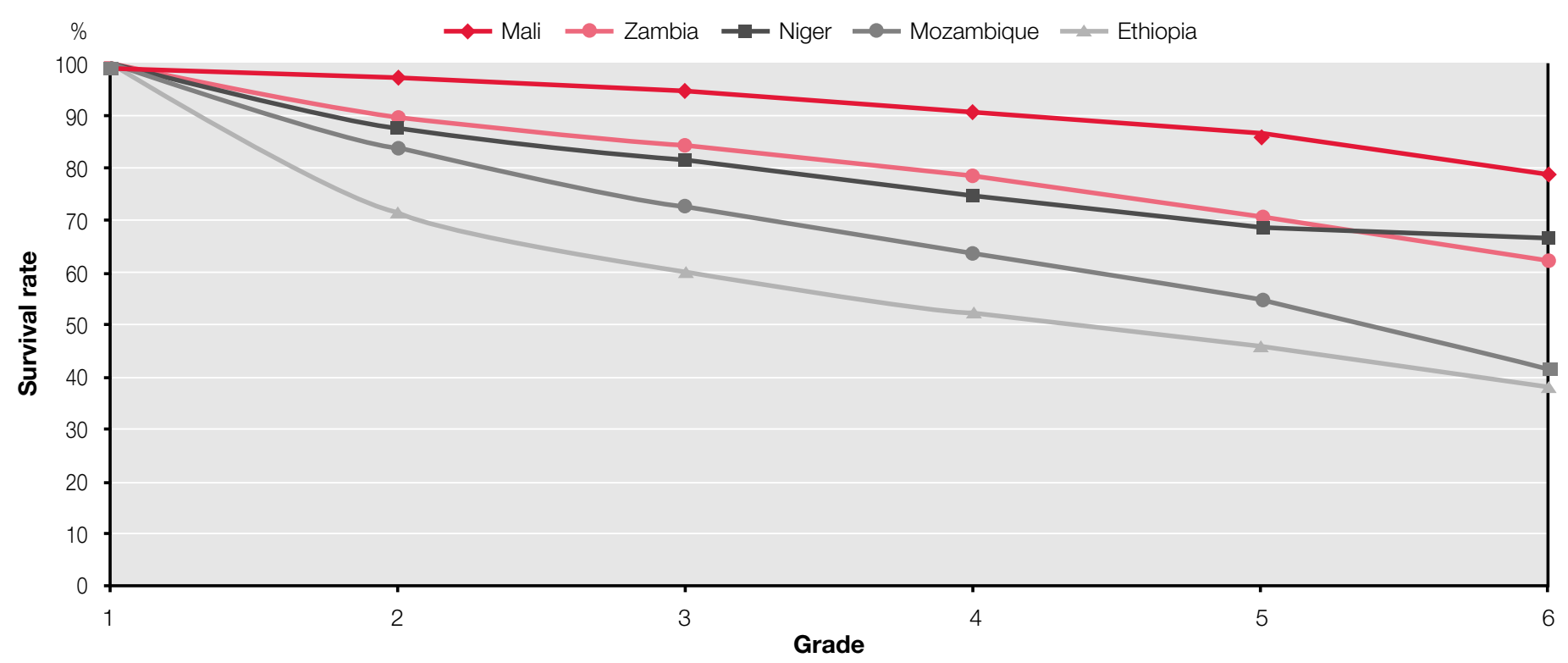

Source: UNESCO Institute for Statistics database. 
Coverage at this level, however, is still much smaller than that of primary and secondary education. One possible explanation is that SSA governments focused more on primary education since achieving UPE is a priority for many countries, and more resources were allocated to primary education than to preprimary education.

\subsection{CONCLUSION}

Supported by increased national and international commitments, SSA countries experienced rapid growth in enrolment at all education levels during the past decade. However, the SSA region faces particular challenges in meeting EFA goals and ensuring sustainable educational development because of a variety of external factors, including economic growth, resource mobilisation and governance. As a result of demographic pressure and steady increases in enrolment at primary and post-primary education levels, the demand for education will continue to grow in SSA. In a context of persistent external constraints and a surging demand for education, these countries will continue to face financial limitations in providing an education of adequate quantity and quality for their populations.

The annual population growth rate of the SSA region, estimated at 2.4\% between 2005 and 2010, is the fastest among all regions in the world. Its population is estimated to increase from 863 million in 2010 to 1.3 billion by 2030 . The 5 to 14 -year-old age cohort in the region is expected to grow by 34\% over the next 20 years, from 226 million in 2010 to 303 million in 2030. Such an increase in the number of children in this age group means that the needs of 77 million more students will have to be met, in addition to reaching the existing goal of achieving $100 \%$ enrolment rates.

Growth in the demand for education is amplified by providing primary school access for children who are currently out of school and access to post-primary education for the increasing number of primary school graduates. The need for better quality education also requires the allocation of more resources to the education sector (see Chapter 5).

The demand for education in SSA will continue to grow steadily, and financial constraints are likely to persist. While the region has enjoyed relatively robust economic growth over the last decade, its increased participation in the global economy has rendered the economy of SSA more vulnerable to external shocks. The region's largely informal and agricultural labour market provides a weak tax base, which affects resource availability in the education sector. Domestically generated revenue as a percentage of GDP is less than $20 \%$ in more than one-half of SSA countries. Moreover, in 2008, the region had the world's largest ratio of dependent children (below the age of 15) - 79.4 per 100 persons of working age (aged 15 to 64 years) - which means that the burden on the working population is much higher in SSA than in any other region in the world. In terms of public service delivery, the potential loss of already scarce resources due to weak management and governance is a real issue in some SSA countries.

While these challenges are recognised, the rapid progress in educational and general development since the EFA World Education Forum and MDG Summit in 2000 has demonstrated

\section{Figure 9}

\section{NUMBER OF STUDENTS IN SECONDARY EDUCATION IN SUB-SAHARAN AFRICA, 1970-2008}

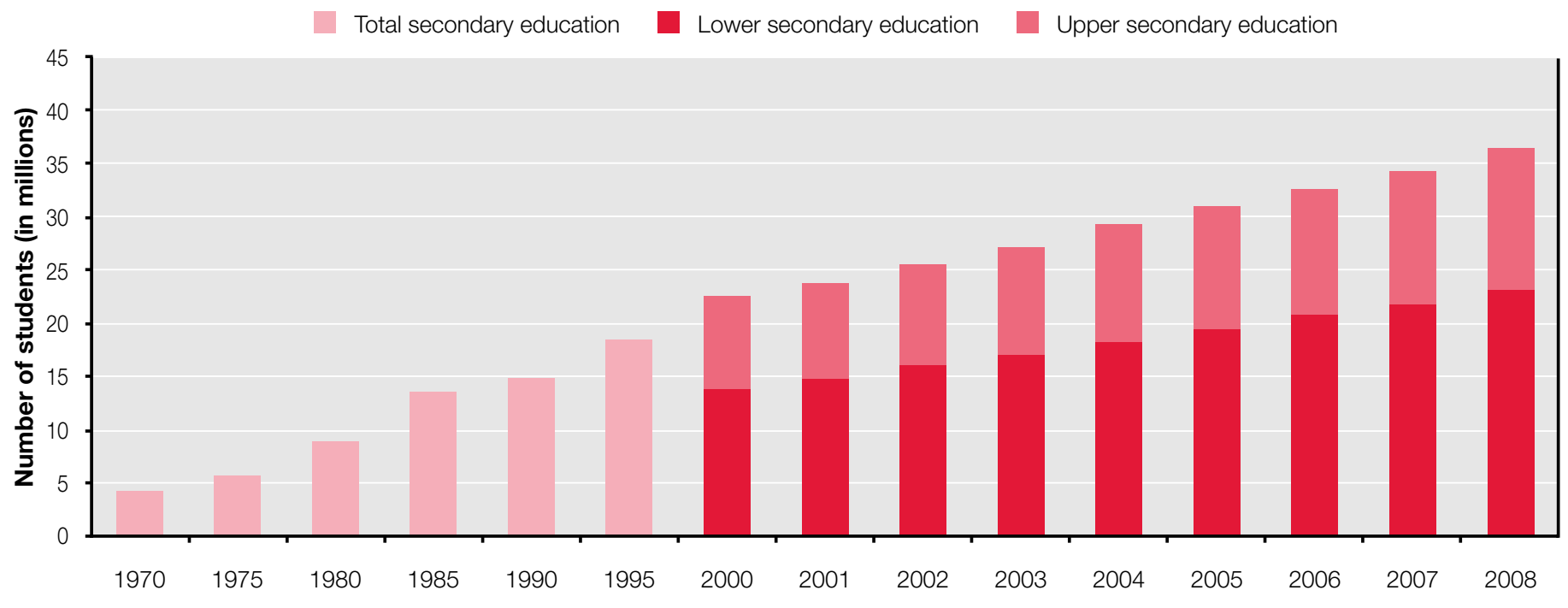

Source: UNESCO Institute for Statistics database. 
that political commitment and will, as well as partnerships between governments, development agencies and civil society, are the key to unlocking potential and overcoming obstacles. As a result of these initiatives, governments of SSA countries and development partners have increased their efforts to support educational development. International and regional initiatives have been launched throughout the SSA region, and there are new active players from civil society organizations and the private sector. It is, therefore, important to have a good understanding of the key external constraints and emerging opportunities for moving forward sustainable educational development in SSA. 


\title{
Chapter 2
}

\section{PUBLIC FINANCING OF EDUCATION}

\author{
Shinsaku Nomura and Michael Bruneforth (UNESCO Institute for Statistics)
}

This chapter addresses principal questions associated with education financing, including funding and allocation, through historical and cross-national perspectives. Government commitment to educational development through financing varies across countries and time, but in general, SSA countries have increased and maintained relatively significant amounts of public resources in the education sector since the launch of the Education for All movement in 2000. Donors are also playing a major role in the provision of resources for educational development. While more resources are likely to be needed for achieving EFA goals, the governments of SSA may have to reconsider effective reallocation of resources within the education sector because of persistent overall constraints. Specific themes, such as financing teachers and the quality of education, will be discussed in subsequent chapters.

\subsection{INTRODUCTION}

In many countries in the region, education is provided largely by the public sector, especially at the lower levels. Education is often a major part of government expenditure. In the current economic context, governments must make difficult decisions about mobilising and allocating resources, especially in light of rising demands from other public service sectors, such as infrastructure or health care. There is also competition for resources within the education system - for example, funding primary schools versus universities.

This chapter addresses two sets of questions concerning education financing. The first set is about funding: How much is available for educational development? Who is providing the resources? Furthermore, policymakers must consider

\section{IMPROVING EDUCATION FINANCE DATA IN SUB-SAHARAN AFRICA}

Since the late 1990s, a number of countries in SSA have prepared an education sector review report, referred to as a "country status report" (CSR), introduced by the World Bank and Pôle de Dakar (UNESCO-BREDA) with the aim of improving data quality and coverage. The CSR involves intensive data gathering by partnering with national teams. The main objective is to provide an analytical platform on which to build a strategic plan for the education sector as a whole and for basic education in particular. The CSR process also aims to develop the capacities of national teams, foster networks and establish a system to identify and use national data sources on education finance. These outcomes constitute a valuable asset for countries working to improve their planning and statistical systems.

In 2010, the UIS reviewed the consistency between the CSR and UIS data frameworks based on collaboration with national statistical teams. Despite some variation among countries, the conceptual framework and data coverage are on the whole consistent with the UIS data collection. Therefore, the Institute has decided to translate the finance data collected through CSRs into indicators that follow certain definitions and coverage for inclusion in the UIS database. After reviewing 33 CSRs from 27 countries, the UIS was able to improve data coverage and quality for $25 \%$ of its education finance indicators for SSA between 1999 and 2007.

The work on CSRs has been further reinforced by the introduction of a training project for national statisticians in partnership with the Pôle de Dakar of UNESCO-BREDA, the UNESCO International Institute for Education Planning (UNESCO-IIEP) and the World Bank. The main objective of the project, which was initially financed by the Education Program Development Fund, is to enable national statistical teams to develop and implement a sustainable mechanism to regularly produce and use education finance indicators. Five countries - Benin, Burkina Faso, Central African Republic, Mali and Togo - took part in the first phase of the project. The project is currently underway in Gambia, Ghana, Malawi, Rwanda and a fifth country to be determined.

For more information, please consult the following websites:

Pôle de Dakar - Education Sector Review: http://www.poledakar.org/spip.php?article268

World Bank - Country Status Reports: http://go.worldbank.org/T2XJ1TORWO 
issues related to allocation: How are the available resources allocated? Who will receive how much? For what purposes are the resources to be used? These questions are addressed by examining key indicators for SSA countries in both a historical and internationally comparative perspective.

\subsection{GOVERNMENT COMMITMENTS TO EDUCATIONAL DEVELOPMENT}

\subsubsection{Public education financing}

The first question to ask when analysing the financing of education is how much and what resources are available for educational development. The most common indicators for addressing this question are public education expenditure as a percentage of total government expenditure and as a percentage of gross domestic product (GDP). Since the public sector plays a major role in providing educational services, it is important to analyse public investment in education. Normally, the government allocates its public resources to the education sector according to the country's needs and the level of priority given to educational development. Figure $\mathbf{1 0}$ shows the global trend in public education expenditure as a percentage of total government expenditure in relation to GDP per capita (in PPP\$). The available data show that education expenditure represents from $7 \%$ to $28 \%$ of total government spending in most countries, while the range for countries in the SSA region is $11 \%$ to $28 \%$, with an average of $18.3 \%$. Overall, SSA countries tend to invest a relatively large proportion of the government budget in the education sector despite their relatively low GDPs per capita.

As previously explained, the share of education expenditure in total government expenditure indicates how committed a country is to educational development. But to better understand the strength of this commitment, it is important to consider the allocation of resources to education in light of a country's GDP. Figure $\mathbf{1 1}$ shows the relationship between education expenditure as a percentage of total government expenditure and government expenditure as a percentage of GDP. The product of these two ratios is the share of education expenditure in GDP. The relationship can be expressed by this formula:

$$
\frac{E d u E x p}{G D P}=\frac{G o v E x p}{G D P} \times \frac{E d u E x p}{G o v E x p} \times 100
$$

In this formula, public education expenditure as a percentage of GDP is obtained by multiplying total government expenditure

\section{Figure 10}

\section{TOTAL PUBLIC EXPENDITURE ON EDUCATION AS A PERCENTAGE OF TOTAL PUBLIC EXPENDITURE AND GDP PER CAPITA (PPP\$), 2009 OR MOST RECENT YEAR}

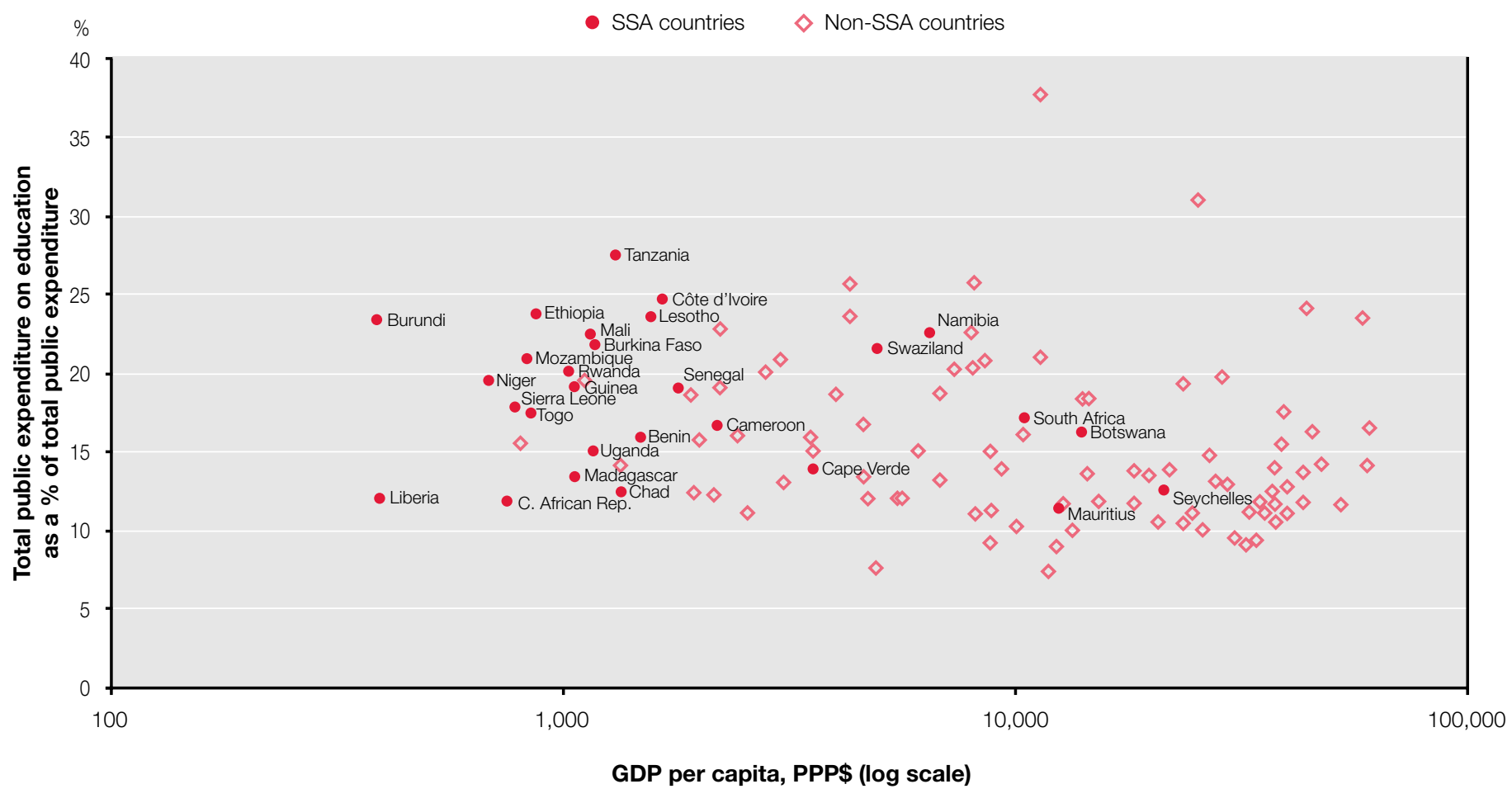

Notes: Reference year for GDP per capita is 2008. Coverage includes 28 sub-Saharan African countries and 88 countries from other regions.

Sources: Total public expenditure on education as a percentage of total public expenditure: UNESCO Institute for Statistics, Statistical Table A5. GDP per capita: World Bank. 

TOTAL PUBLIC EXPENDITURE AS A PERCENTAGE OF GDP

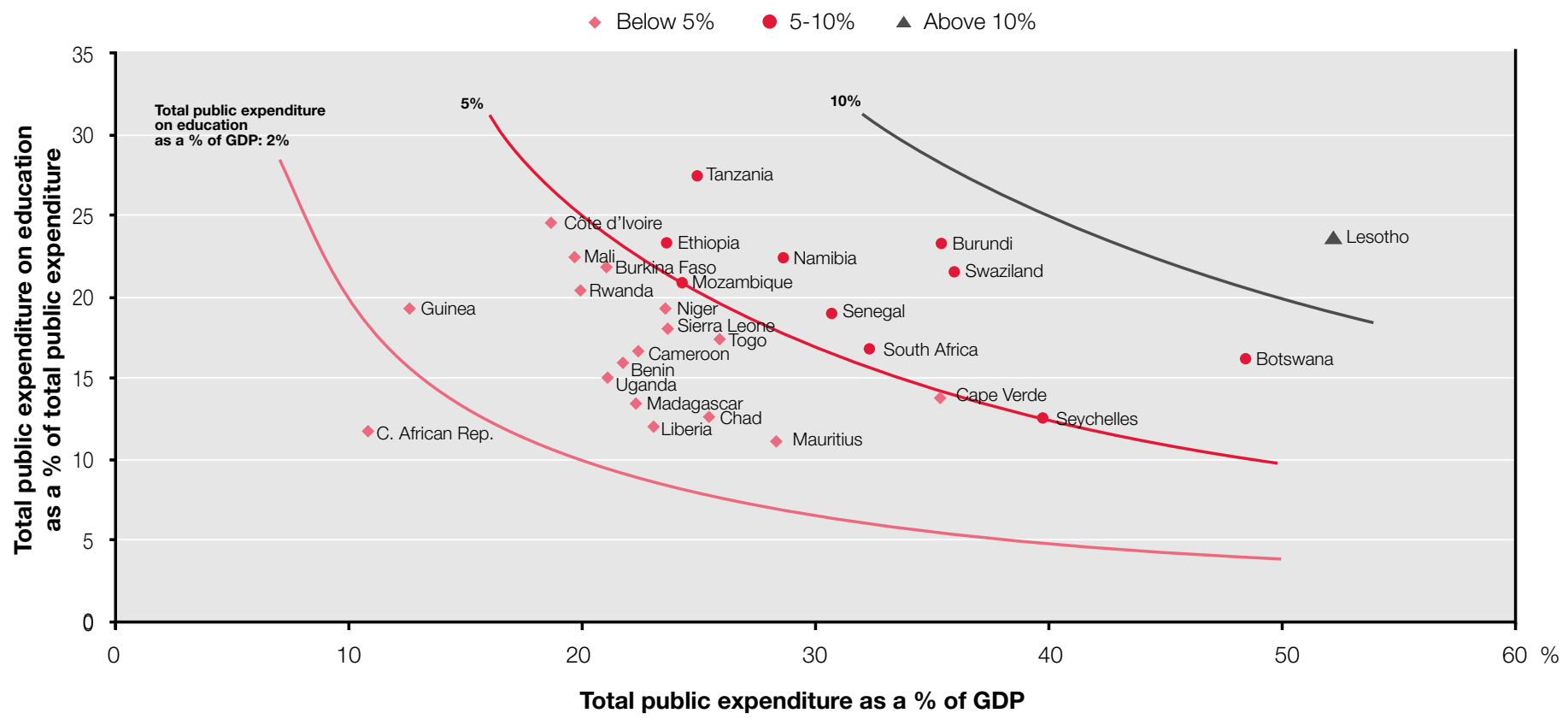

Sources: Total public expenditure on education as a percentage of total public expenditure:

\section{Figure 12}

\section{REGIONAL GDP DEVOTED TO THE EDUCATION SECTOR, 2008}

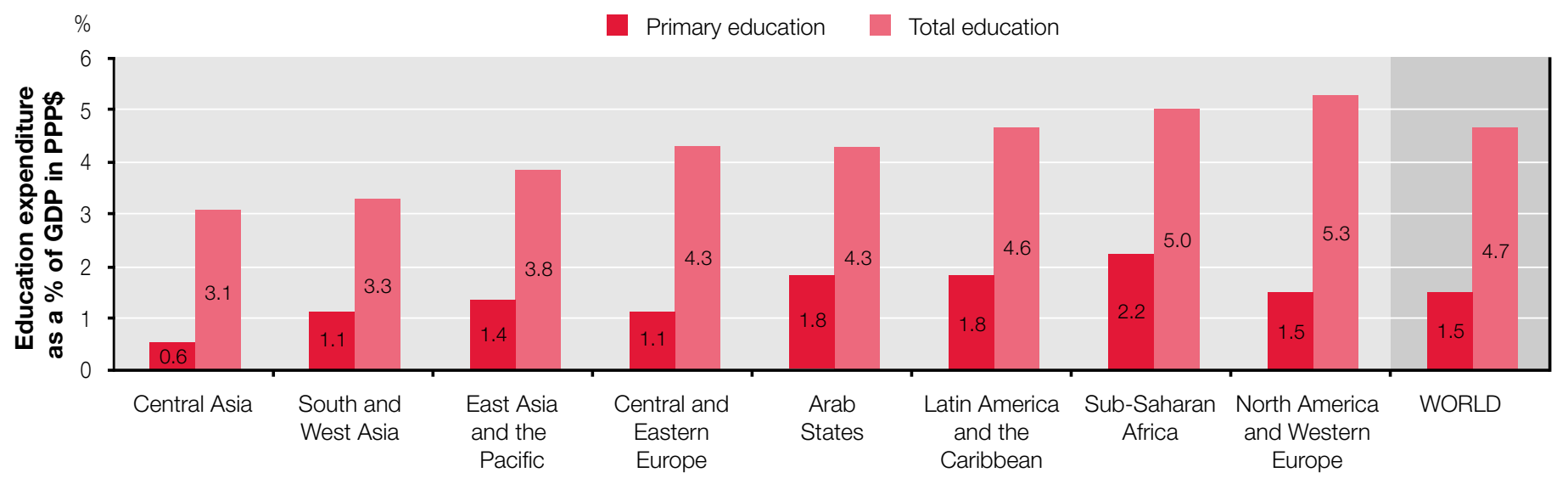

Notes: Weighted regional averages are calculated based on 130 countries with available data for 2008, which represent $83 \%$ of GDP in PPP\$ in the world.

Numbers of countries covered by region: sub-Saharan Africa (33/45), East Asia and the Pacific (17/34), South and West Asia (7/9), Latin America

and the Caribbean (20/41), Central Asia (7/9), Central and Eastern Europe (13/21) and Arab States (13/20), North America and Western Europe (20/29).

Source: UNESCO Institute for Statistics estimates. 
as a percentage of GDP with education expenditure as a percentage of total government expenditure.

Figure 11 presents total government expenditure as a percentage of GDP on the X-axis and total public education expenditure as a percentage of total government expenditure on the Y-axis. As a product of these two indicators, public education expenditure as a percentage of GDP is calculated and distinguished by different markers (above 10\%, 5\%-10\% and below 5\%). The education expenditure as a percentage of GDP becomes larger as the country moves towards the upper-right corner.

This analysis shows an interesting contrast among SSA countries with similar indicator values. For example, data show that Mozambique and Seychelles spend $5.0 \%$ of GDP on public education (both are on the $5 \%$ line). Seychelles achieves this level of educational investment by allocating 40\% of GDP to the public sector and $13 \%$ of total government expenditure to the education sector. On the other hand, Mozambique spends only $24 \%$ of GDP on the public sector but invests $21 \%$ of government expenditure in the education sector. These differences are closely linked to the government's capacity to collect revenue, as discussed in Chapter 1. At the high end, Lesotho's spending on education is supported by a large public sector (52\% of GDP) and strong commitment to education (24\% of total government expenditure). In comparing Liberia and Burkina Faso, Liberia has a larger public sector (relative to GDP) than Burkina Faso, but educational investment (relative to GDP) is larger in Burkina Faso as a result of the government's policy agenda.

Globally, public education expenditure accounts for $4.7 \%$ of the world's GDP (see Figure 12). The SSA region also devotes $5.0 \%$ of total GDP to public education expenditure, which is the second highest percentage after North America and Europe (5.3\%). However, SSA countries devote a much higher share of this allocation to primary education (2.2\% of GDP) than other regions, ranging from $0.6 \%$ in Central Asia to $1.8 \%$ in the Arab States as well as Latin America and the Caribbean. This high level of expenditure is due to a combination of demographic factors and the strong commitment of governments and international partners to the development of primary education in SSA.

\section{Increased public financing since $\mathbf{2 0 0 0}$}

As noted in Chapter 1, rapid enrolment growth across education levels has been observed since 2000. What role did the governments of SSA countries play in this achievement?

Figure 13 presents the annual growth rate of real public expenditure on education since 2000. Among 26 countries with available data, the real (adjusted for inflation) public

\section{Figure 13}

\section{AVERAGE ANNUAL GROWTH RATE OF REAL PUBLIC EDUCATION EXPENDITURE BETWEEN 1999 AND 2009 OR MOST RECENT YEAR}

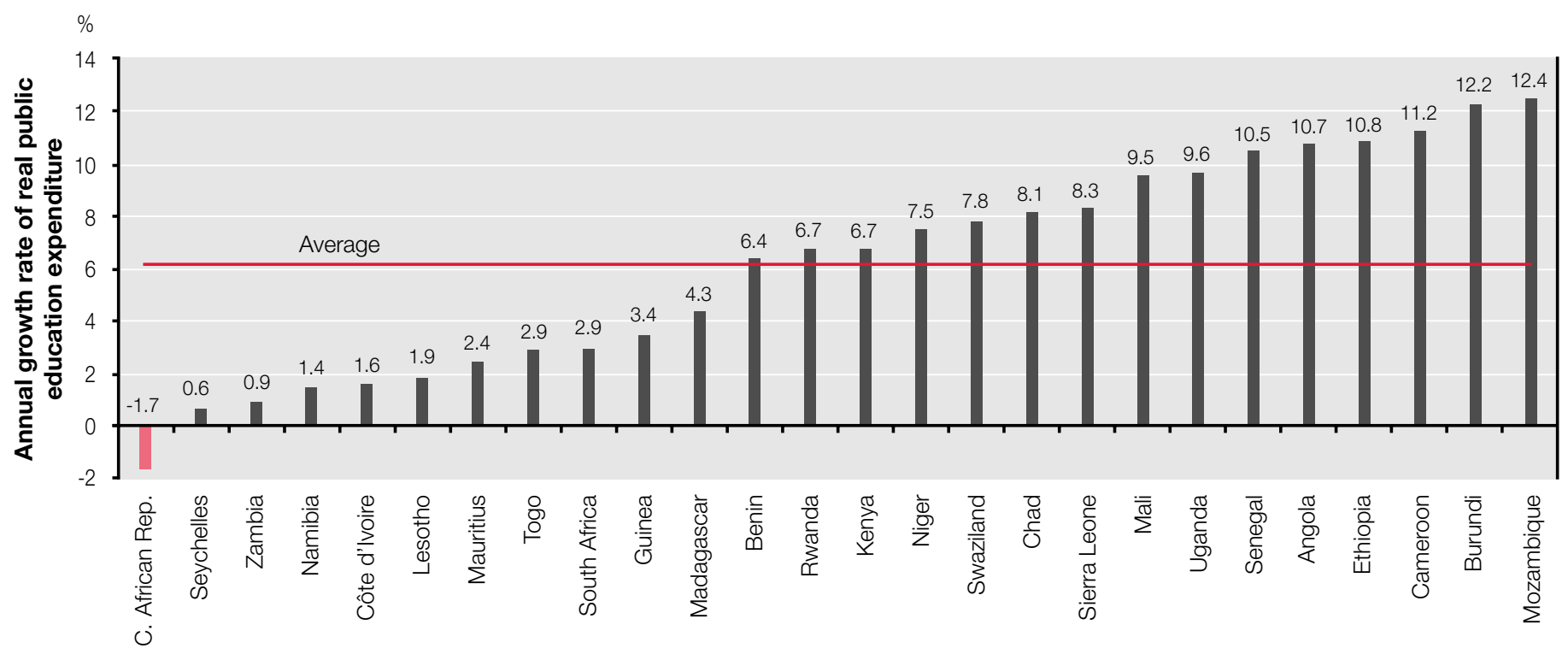

Notes: The earliest year refers to years between 1999 and 2000 depending on countries. The annual growth rate of real public education expenditure is calculated based on constant price in local currency unit. The average is a simple average of 26 countries with data available.

Sources: UNESCO Institute for Statistics calculations based on UIS database and inflation data from the World Bank. 
expenditure on education grew annually by $6.1 \%$ on average. Burundi and Mozambique experienced a growth rate of over $12 \%$ per year. Only one country, Central African Republic, experienced a decrease in real public expenditure on education during this period.

The growth of public expenditure on education is also reflected by the level of public expenditure on education as a percentage of GDP. Figure $\mathbf{1 4}$ compares public education expenditure as a percentage of GDP for selected SSA countries by income group for 1999/2000 and the latest available year (2006-2009). Among 28 SSA countries for which data are available for both periods, it was observed that 18 countries increased the share of GDP going to public education expenditure. The largest increase was observed in Burundi, where spending on public education increased from $3.2 \%$ to $8.3 \%$ of GDP. Thus the level of investment in education rose at a faster rate than the GDP growth rate. Lesotho, where real public education expenditure grew by $1.9 \%$ per year, remained the country with the highest level of public educational spending relative to GDP, with an increase of $11.4 \%$ to $12.4 \%$ over the same period.

Conversely, 10 out of 28 SSA countries with data reported decreases in the share of GDP allocated to education.

However, this does not necessarily mean that countries have reduced their financial commitments to education. In most cases, overall growth in GDP outpaced increases in education expenditure. For example, Namibia devotes a high share (6.4\%) of its GDP to education (2009). However, this share was even higher in 1999 at $7.9 \%$. This decrease was not due to a change in education policy but simply to the rise in GDP between 1999 and 2009. In fact, the real expenditure on education still increased by $1.4 \%$ per year (see Figure 13).

\subsubsection{Donor financing}

The data used so far for assessing the level of public education resources include external financing. It is important to understand who is contributing what to public resources for education. Therefore, this report compares UIS statistics on total government and public education expenditure with data on official development assistance (ODA) provided by the OECD Development Assistance Committee (OECD-DAC) (see Box $\mathbf{4}$ for more information). Nevertheless, this analysis is hampered by a lack of consistency regarding the definition of ODA. According to OECD-DAC, ODA is not necessarily registered in the public accounts of recipient governments, as it can take other forms, such as support to NGOs (OECD, 2008). The analysis of this section, thus, uses proxy information in an attempt to estimate the dependency of the education sector in SSA on external funding.

Based on the estimate in the previous analysis that $5.0 \%$ of GDP is allocated to the public education sector in SSA, the value of total public education expenditure reached US $\$ 46$

\section{Figure 14}

\section{TOTAL PUBLIC EXPENDITURE ON EDUCATION AS A PERCENTAGE OF GDP, 1999-2000 AND 2009 OR MOST RECENT YEAR}

$1999-2000$

Countries with GDP per capita of PPP\$1,000-3,000

Countries with GDP per capita > PPP $\$ 3,000$

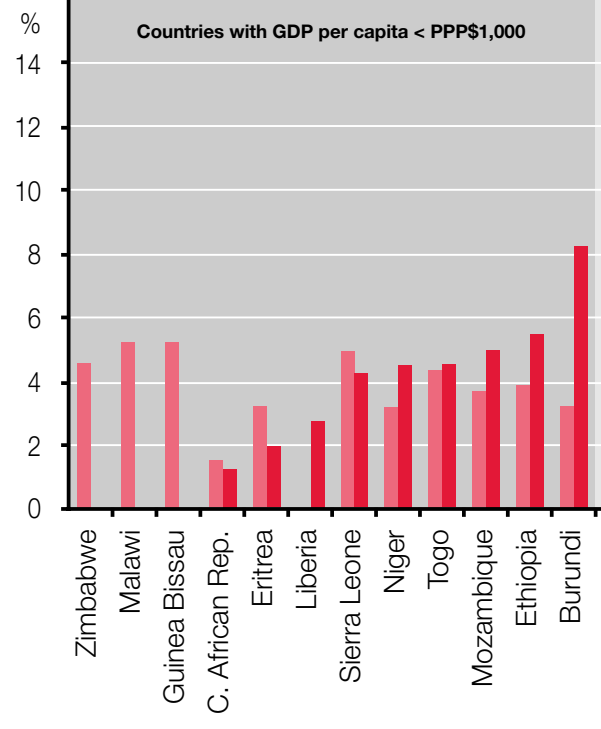

Sources: UNESCO Institute for Statistics, Statistical Table A5. GDP per capita: World Bank and Statistical Table A1. 


\section{OFFICIAL DEVELOPMENT ASSISTANCE FOR EDUCATION PER 5 TO 24-YEAR-OLD POPULATION IN SUB-SAHARAN AFRICAN COUNTRIES AND WORLD REGIONS, 2008}

An important indicator for understanding the international trend of ODA for education flows is ODA per the 5 to 24-year-old population. Figure 15 shows the amount of ODA for education per capita, expressed in PPP\$, to SSA countries and world regions.

According to the data, ODA per capita significantly varies across SSA countries, ranging from PPP\$2 in Nigeria to PPP\$167 in Cape Verde. It is important to note that low-income countries do not necessarily receive more ODA for education when estimated per capita. Among the countries with a GDP per capita below PPP\$1,000, Guinea-Bissau receives the highest amount (PPP\$34 per capita), while a number of countries in the middle- and upper-income groups receive more ODA per capita, including Cape Verde (PPP\$167), Sao Tome and Principe (PPP\$159), Comoros (PPP\$72), Mauritius (PPP\$60), Gabon (PPP\$57), etc.

According to weighted averages, the SSA region receives ODA for education amounting to PPP\$14 per capita, which is the second highest per capita ODA after the Arab States region, with PPP\$20.

\section{Figure 15}

\section{PER CAPITA OFFICIAL DEVELOPMENT ASSISTANCE FOR EDUCATION IN PURCHASING POWER PARITY BY COUNTRY AND REGION, 2008}

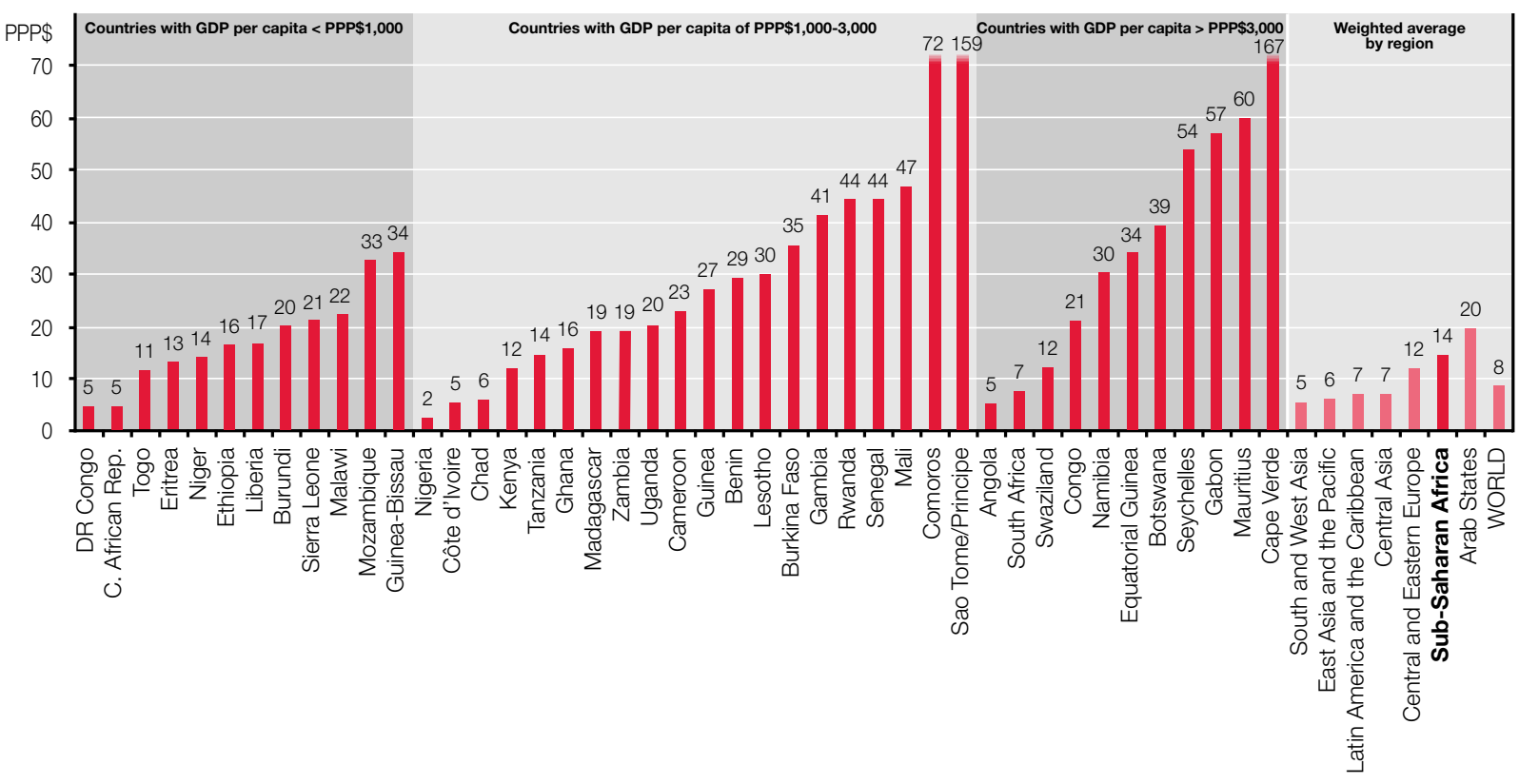

Notes: The figure is based on total ODA for education divided by the 5 to 24 -year-old population. Weighted regional averages are calculated based

on data for 132 ODA recipient countries. Numbers of countries by region: Sub-Saharan Africa (43), East Asia and the Pacific (17), South and West Asia (9), Latin America and the Caribbean (30), Central Asia (9), Central and Eastern Europe (10) and Arab States (14).

Sources: UNESCO Institute for Statistics estimates based on ODA data from the OECD-DAC online database and population data from the UIS database. GDP per capita: World Bank and Statistical Table A1.

billion in 2008. ${ }^{25}$ According to OECD-DAC, the total amount of disbursed ODA for the education sector in the region was US\$2.6 billion in 2008, indicating that donor resources account for about $5.6 \%$ of total public education resources. ${ }^{26}$

However, the proportion of ODA in public education resources varies greatly across the SSA region (see Figure 16).
For example, the amount of ODA for education that Liberia received in 2008 represented $72 \%$ of its public education expenditure, while for relatively high-income countries this figure was $5 \%$ or below, except for Cape Verde. Among some middleincome countries, like Guinea, Mali, Rwanda and Zambia, ODA accounted for approximately $50 \%$ of their public education resources in 2008.

25 Estimate from World Bank 2010 data of GDP in current US dollars. No GDP data were available for Somalia and Zimbabwe in 2008.

26 Since the definition of ODA is limited, ODA flows to non-governmental entities are included. Therefore, the proportion of ODA that governments received should be somewhat smaller than this figure. 
Figure 16

\section{OFFICIAL DEVELOPMENT ASSISTANCE FOR EDUCATION AS A RATIO OF TOTAL PUBLIC EDUCATION EXPENDITURE BY NATIONAL INCOME LEVEL, 2008}

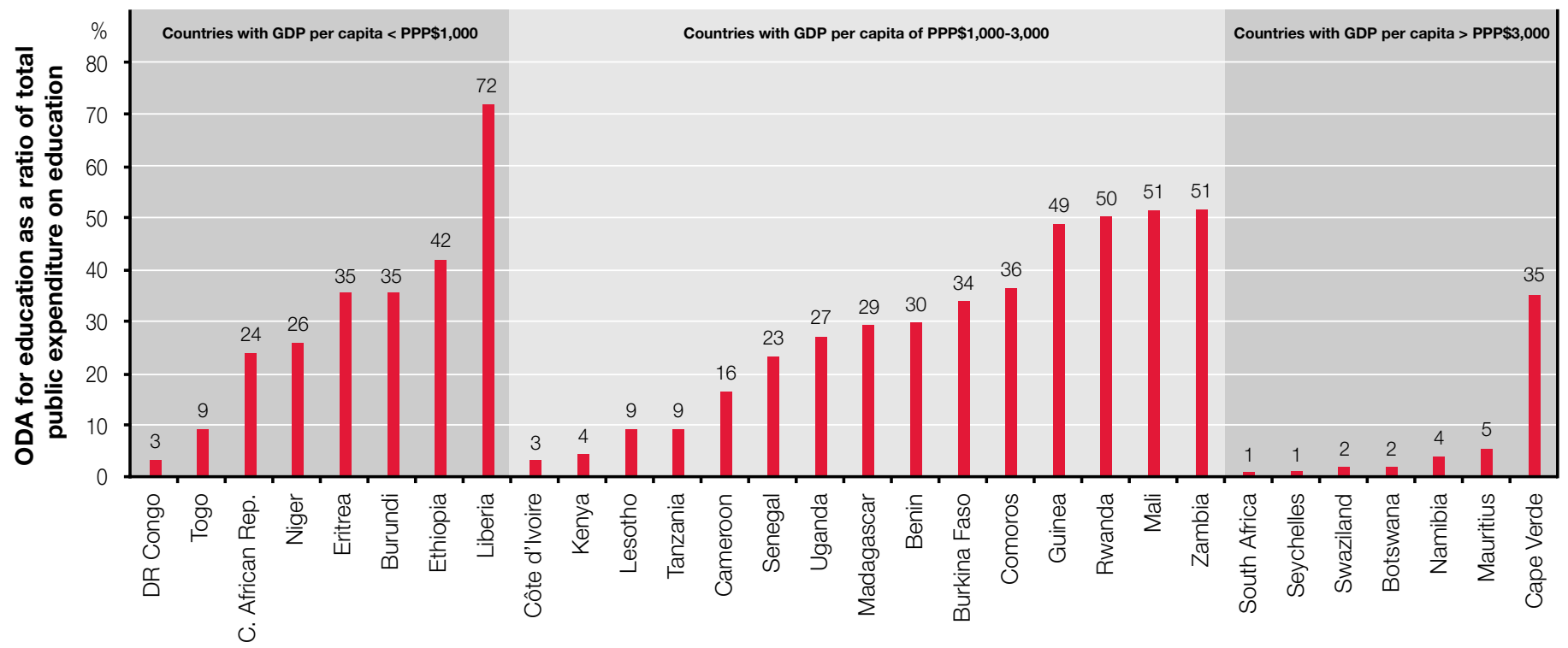

Sources: UNESCO Institute for Statistics calculations based on ODA data from the OECD-DAC and education expenditure data from the UIS database. GDP per capita: World Bank and Statistical Table A1.

It is apparent that external financing of education is already considerable, especially in some SSA countries. In this context, additional resource flows from external sources may not be realistic, because this would raise issues on both donor and recipient sides. As history has shown, donors may cut ODA during an economic recession or when public opinion doubts its effectiveness (World Bank, 2000). As a result of the economic crisis in 2008, it is possible that the amount of ODA may decline in the near future depending on the economic conditions of donor countries.

From a recipient perspective, the issue of absorptive capacity is key. OECD-DAC data show that the disbursed ODA for education in SSA in 2007 was US\$2.6 billion, while the commitment was originally US\$3.0 billion, leaving US\$400 million unspent. ${ }^{27}$ Between 2002 and 2008, the discrepancy between committed and disbursed amounts averaged around 9\% (or US\$221 million). While disbursement in 2008 slightly exceeded the committed amount, this general tendency of low disbursement indicates that there is a potential for increasing education resources, but recipient countries may not have the capacity to utilise them. This may be an important point that national policymakers should take into consideration. If donors make commitments to fill in the financing gap, recipient countries must have the capacity to use these resources effectively so that the gap can really be closed.

\subsubsection{Expenditure by level of education}

After identifying the resources available to the education sector, the next concern is allocating them by level of education. While efforts associated with EFA tend to focus on basic education, countries often have different priorities for their sub-sector development. For example, countries that are close to achieving the EFA target are shifting the focus to post-primary levels of education in order to expand opportunities for graduates of primary education.

Figure 17 shows allocation of public education expenditure by level of education. Primary education occupies the largest share in most SSA countries, but this share ranges from $68 \%$ in the United Republic of Tanzania to $18 \%$ in Botswana. ${ }^{28}$ While it is rational to assume that countries with longer primary education cycles allocate larger proportions of education expenditure to this level, there is no clear trend. Rather, it seems that the allocation of education resources reflects the development focus of the country. Among countries with seven-year primary education, Mozambique allocates $58 \%$ of education resources to primary education and Botswana allocates about 18\%.

\footnotetext{
27 The amount of ODA committed seems to have been revised from the original estimate. For example, UNESCO (2010, p. 442) shows that committed ODA for education to SSA was US $\$ 3.6$ billion, while the latest data show the committed amount of ODA was US\$3.0 billion in 2007 (OECD-DAC).

28 One of the limitations of these statistics is that some countries effectively attribute administrative costs to each level of education, while others classify these costs as "level unallocated" expenditure.
} 


\section{PUBLIC EDUCATION EXPENDITURE BY LEVEL AS A PERCENTAGE OF TOTAL EDUCATION EXPENDITURE, 2009 OR MOST RECENT YEAR}

Primary education $\square$ Secondary education $\square$ Tertiary education $\square$ Other

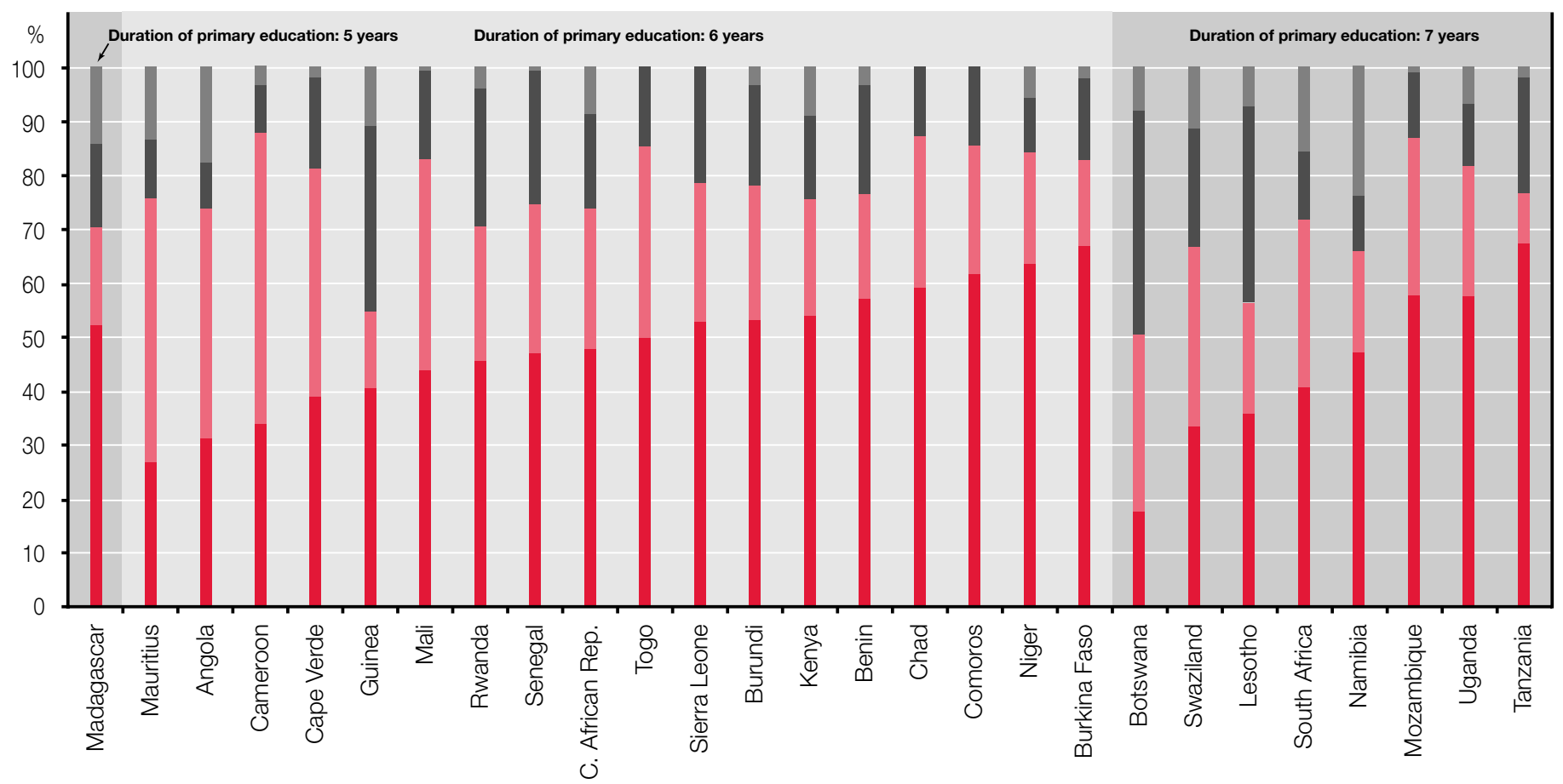

Source: UNESCO Institute for Statistics, Statistical Tables A2 and A5.

This can be explained by the fact that Botswana has already achieved UPE, while Mozambique still needs to increase the primary completion rate by 43 percentage points to reach the goal. Today, the United Republic of Tanzania allocates $68 \%$ of educational resources to primary education. This high commitment contributed to a rapid increase in the primary completion rate during the past decade.

Resource allocation by level of education evolves over time with shifting priorities of a country. An analysis of the historical trends of resource allocation by education level shows distinct development patterns across countries. For example, Burundi and Swaziland present two contrasting cases (see Figure 18). In both countries, the share of education resources allocated to the primary education level was similar in 1999 - 37\% in Burundi and 33\% in Swaziland. However, the status of enrolment was different in each country. Gross enrolment ratios in primary education were 49\% in Burundi and 94\% in Swaziland.

To achieve the EFA target, the Burundi government decided to shift resources to primary education. In 2005, it abolished school fees at the primary education level. ${ }^{29}$ Primary education expenditure - which was almost the same amount as secondary education expenditure in 1999 doubled in 2009 , composing $53 \%$ of total public education expenditure. Consequently, primary GER in Burundi increased from 49\% in 1999 to $147 \%$ in 2009. In addition, the number of out-of-school children of primary school age decreased from 723,000 in 1999 to 10,000 in 2009.

Swaziland, on the other hand, already had a relatively high GER in primary education by 1999. This seems to have enabled the government to maintain a balance in funding across education levels. Primary education accounted for $34 \%$ of government spending in both 1999 and 2008, despite minor fluctuations in the intermediary years. A similar trend was found at the secondary level of education. As these country cases show, the patterns of resource allocation by level of education reflect the different needs of countries. The example also shows that the shift in resource allocation can bring different results in educational development.

29 The government of Swaziland also decided to abolish primary school fees in 2009. 
TRENDS IN EDUCATION EXPENDITURE AND GROSS ENROLMENT RATIOS, BURUNDI AND SWAZILAND, 1999-2009

Primary education GER

Secondary education GER

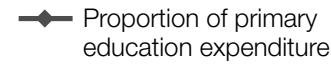

- Proportion of secondary education expenditure

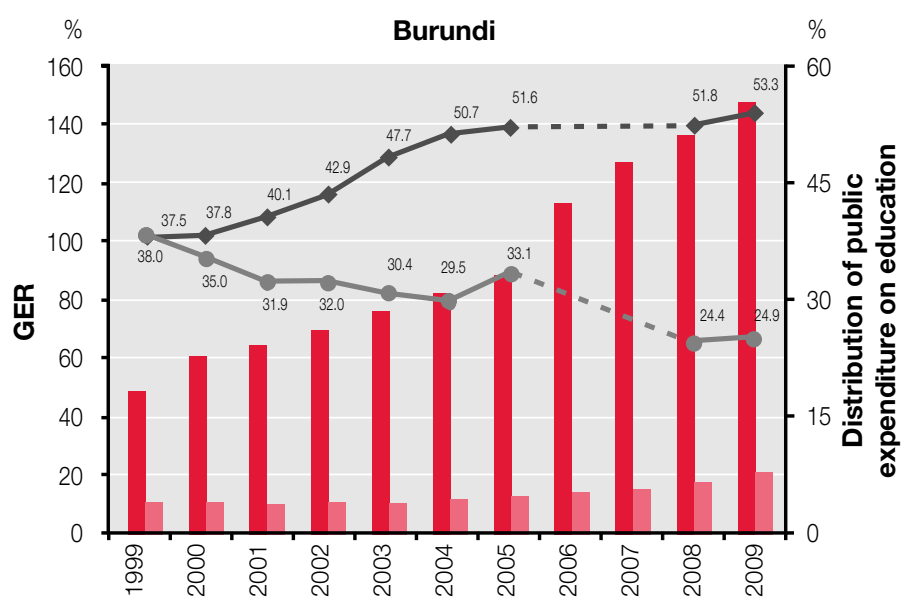

Source: UNESCO Institute for Statistics database.

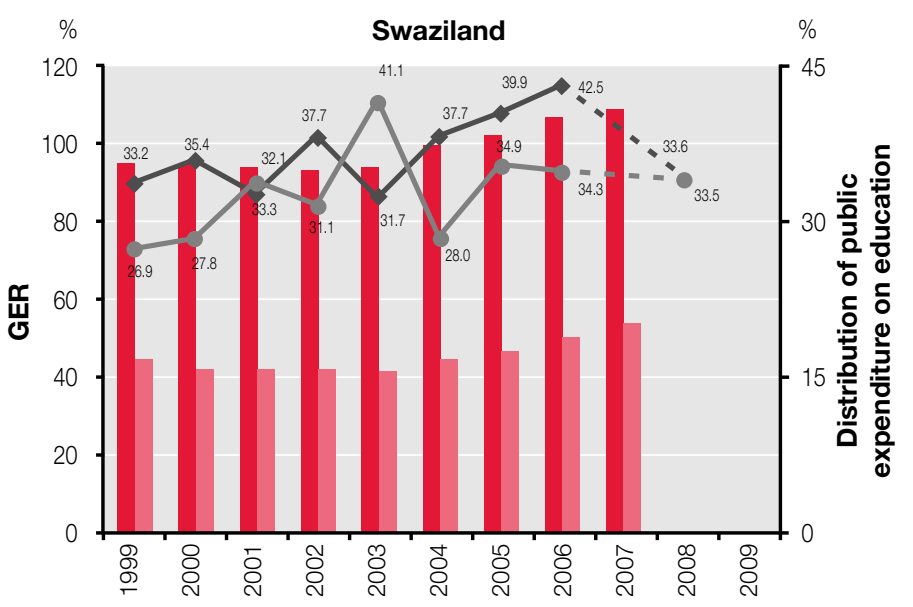

\subsubsection{Nature of spending by level of education}

While it is important to know how education expenditure is allocated across levels of education, it is crucial to examine on what the resources are being spent. Education expenditure can be divided into two large categories, current and capital expenditure. The former refers to expenditure associated with annually used and consumed items, while the latter refers to expenditure on items that can be used over a longer period of time.

Current expenditure can be divided into salaries and nonsalary current expenditure. As educational services are mostly delivered by teachers, their salaries are commonly the main current expenditure item. Non-salary current expenditure covers the rest of the operating costs, which include teaching and learning materials, textbooks, operating costs of schools, transportation costs, etc. Capital expenditure includes school construction, for example, or the purchase of heavy equipment.

In many SSA countries, current expenditure accounts for the largest share of primary education spending. Figure 19 shows a comparison of public primary education spending among SSA countries, both for current and capital expenditure. ${ }^{30}$ There is a huge difference in the share taken up by each type of expenditure, even among countries with similar levels of
GDP per capita in PPP\$. While current expenditure accounts for all primary education spending in Botswana, Chad allocates more than one-third of primary education spending to capital spending in the reference year. However, it should be noted that this proportion can vary from one year to the next due to fluctuations in the amount of capital expenditure.

In all SSA countries, salaries account for the largest share of current expenditure in primary education. Figure $\mathbf{2 0}$ shows the breakdown of current spending by salary and non-salary expenditure. As was the case with the current/capital expenditure breakdown, analysis shows that there is considerable variation among SSA countries, even for those with similar levels of GDP per capita in PPP\$. For instance, in the group of countries with GDP per capita ranging between PPP $\$ 1,000$ and PPP $\$ 3,000$, Burkina Faso spends $92 \%$ of current expenditure on salaries, while Lesotho spends only $70 \%$. Salary expenditure is discussed in greater detail in Chapter 3.

The share of non-salary spending in current expenditure is sometimes regarded as an indication of the quality of education, because it is associated with textbooks and other learning materials. The fact that salary expenditure tends to be relatively fixed and non-salary expenditure can be more variable has also encouraged the use of this comparison as a proxy measure of quality, although it needs to be interpreted with caution. For

30 The UIS also collects expenditure data from private educational institutions, but this comparison covers only public institutions. Administration costs are excluded by definition. 


\section{Figure 19}

\section{DISTRIBUTION OF PRIMARY EDUCATION EXPENDITURE BY NATURE IN PUBLIC INSTITUTIONS, 2009 OR MOST RECENT YEAR

\author{
Current expenditure \\ Capital expenditure
}

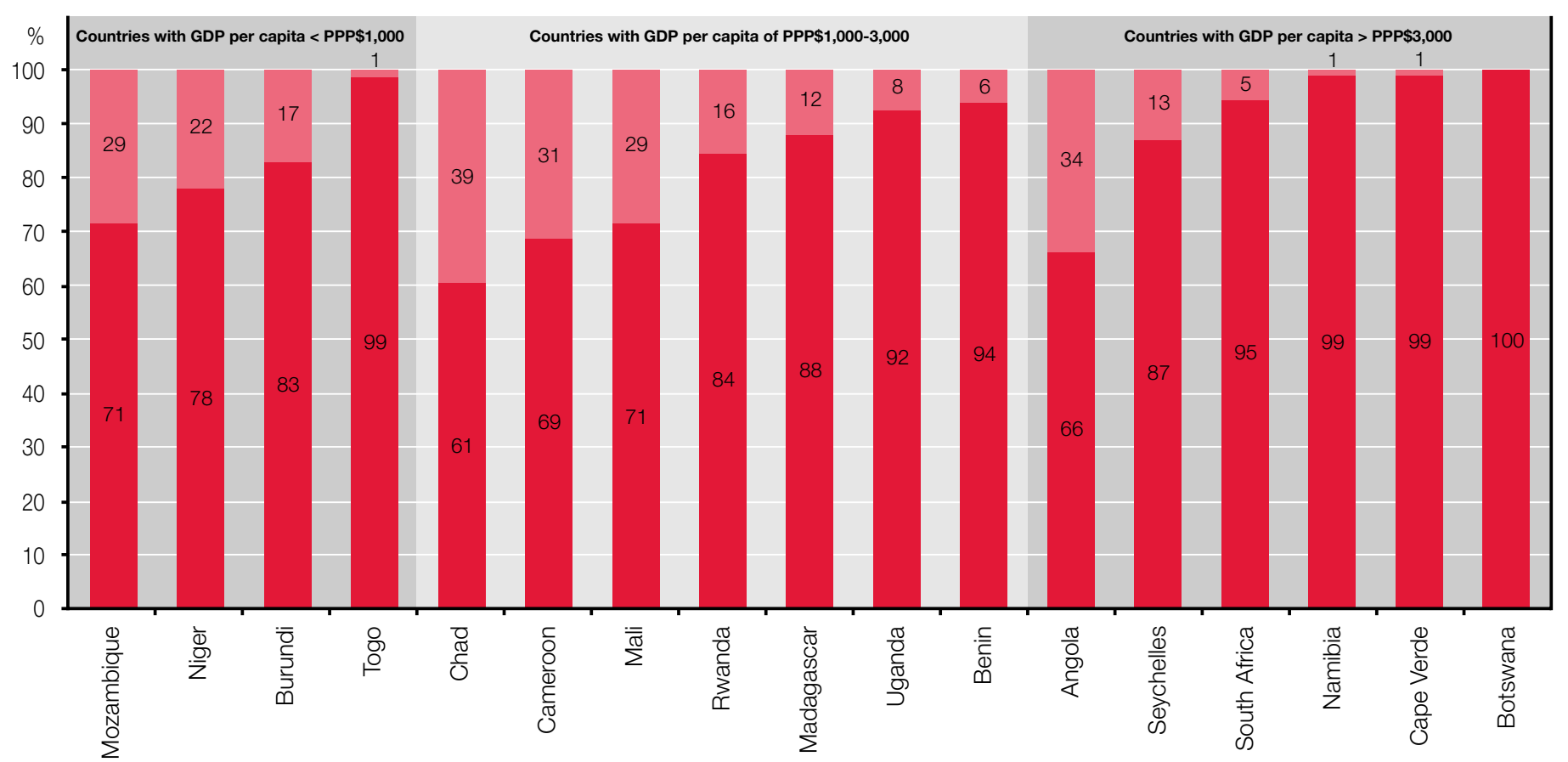

Sources: UNESCO Institute for Statistics, Statistical Table A7. GDP per capita: World Bank and Statistical Table A1.

example, an increase in teacher salaries may be very effective in improving the quality of instruction by enhancing the motivation of teachers.

The share of current spending dedicated to salary or non-salary expenditure can vary by level of education in the same country.

Figure 21 shows the spending patterns of six countries. The Central African Republic, Burundi, Mali, Mozambique and Niger follow similar patterns. They allocate a large portion of current expenditure to salaries, especially at the primary level, but this portion shrinks as the levels of education rise to secondary and tertiary. In Niger, the share of non-salary expenditure is relatively larger and it grows with the level of education.

Benin exhibits a slightly different trend. The share of salary expenditure for primary education is $74 \%$ and non-salary current expenditure accounts for $26 \%$. However, a large part of this non-salary expenditure is in the form of grants to schools, part of which are used to hire community contract teachers. This statistic, thus, needs to be reviewed with caution as it does not appear in government data on salary expenditure, even though it includes some salary components. At the tertiary level, the proportion of non-salary current expenditure reaches beyond $50 \%$ in Benin and Niger.

\subsubsection{Analysis of education expenditure per student}

\section{International comparisons and the growth in expenditure} per primary pupil

As mentioned, resource allocation by level of education depends on the priorities set by countries. It is possible to compare the efforts of countries through analysis of unit costs. By expressing expenditure per student as a percentage of GDP per capita, education expenditure can be compared to the national income level, which is a proxy measure for a country's ability to generate education financing (UIS, 2007).

The level of primary education expenditure per pupil varies greatly among SSA countries. Figure $\mathbf{2 2}$ compares SSA and non-SSA countries using two indicators: i) GDP per capita in PPP\$; and ii) primary education expenditure per student as a percentage of GDP per capita. There is a general trend of public expenditure per primary pupil increasing to around 20\% of GDP per capita as country income levels rise. Gaps in primary education expenditure per pupil across countries also seem to shrink as country income levels increase.

However, GDP per capita is not the only determinant of the level of public education expenditure per student. In fact, 


\section{Figure 20}

\section{DISTRIBUTION OF CURRENT EXPENDITURE ON PRIMARY EDUCATION IN PUBLIC INSTITUTIONS, 2009 OR MOST RECENT YEAR \\ Salary Non-salary current expenditure}

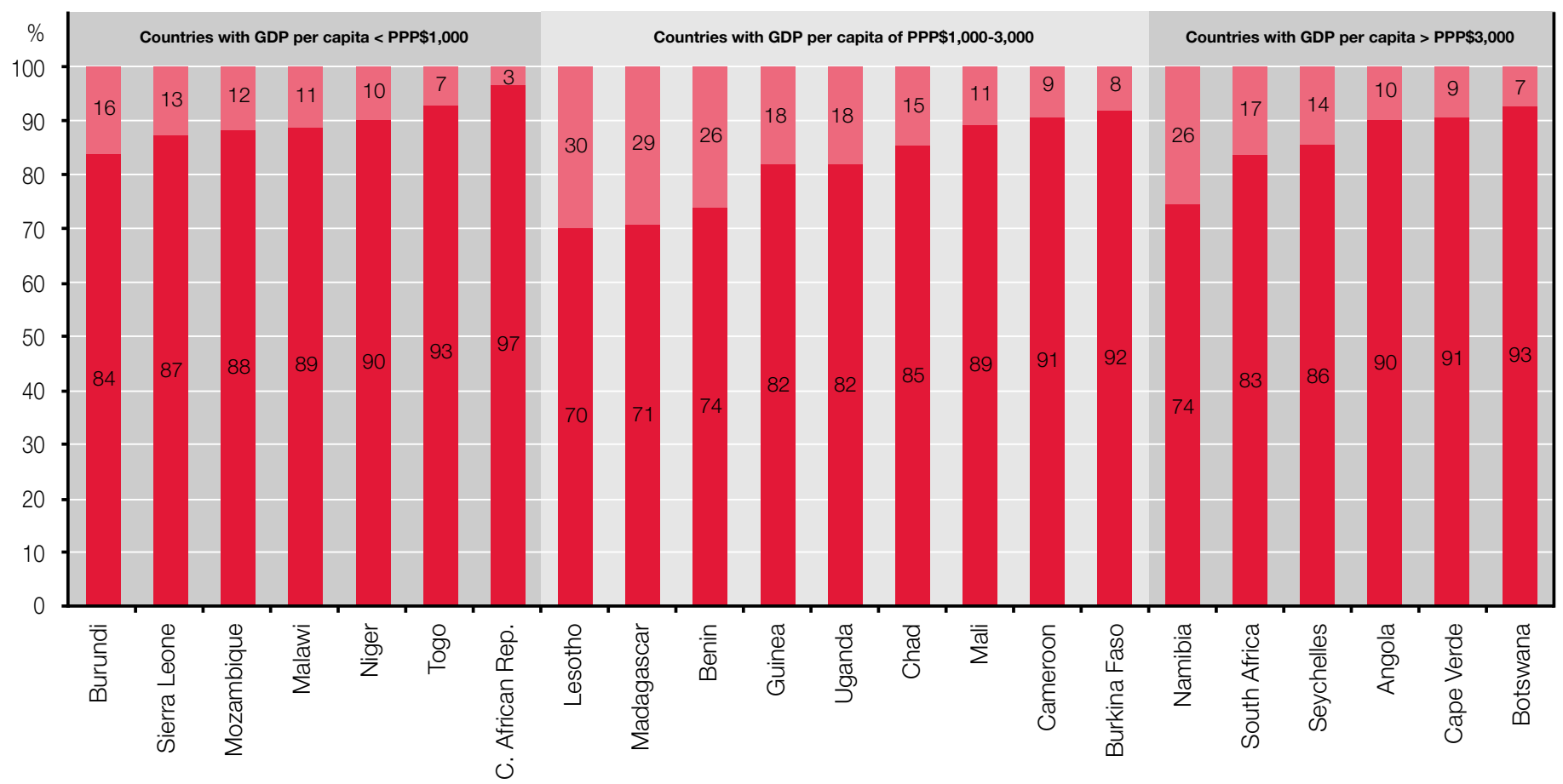

Source: UNESCO Institute for Statistics, Statistical Table A7. GDP per capita: World Bank and Statistical Table A1.

\section{Figure 21}

DISTRIBUTION OF CURRENT EXPENDITURE BY NATURE AND EDUCATION LEVEL IN PUBLIC INSTITUTIONS, 2009 OR MOST RECENT YEAR
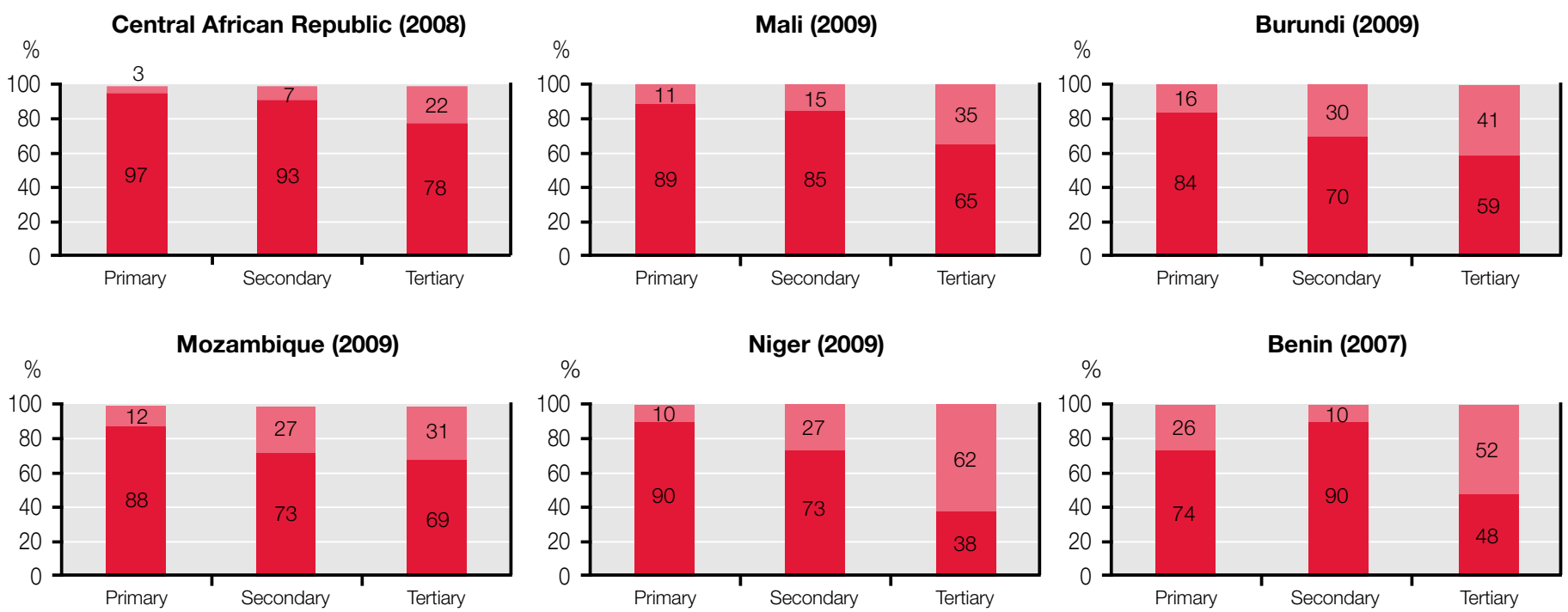

Note: Primary education data refer to 2006 for Mozambique and 2007 for Central African Republic.

Source: UNESCO Institute for Statistics, Statistical Table A7. 


\section{PRIMARY EDUCATION EXPENDITURE PER PUPIL AS A PERCENTAGE OF GDP PER CAPITA, 2009 OR MOST RECENT YEAR}

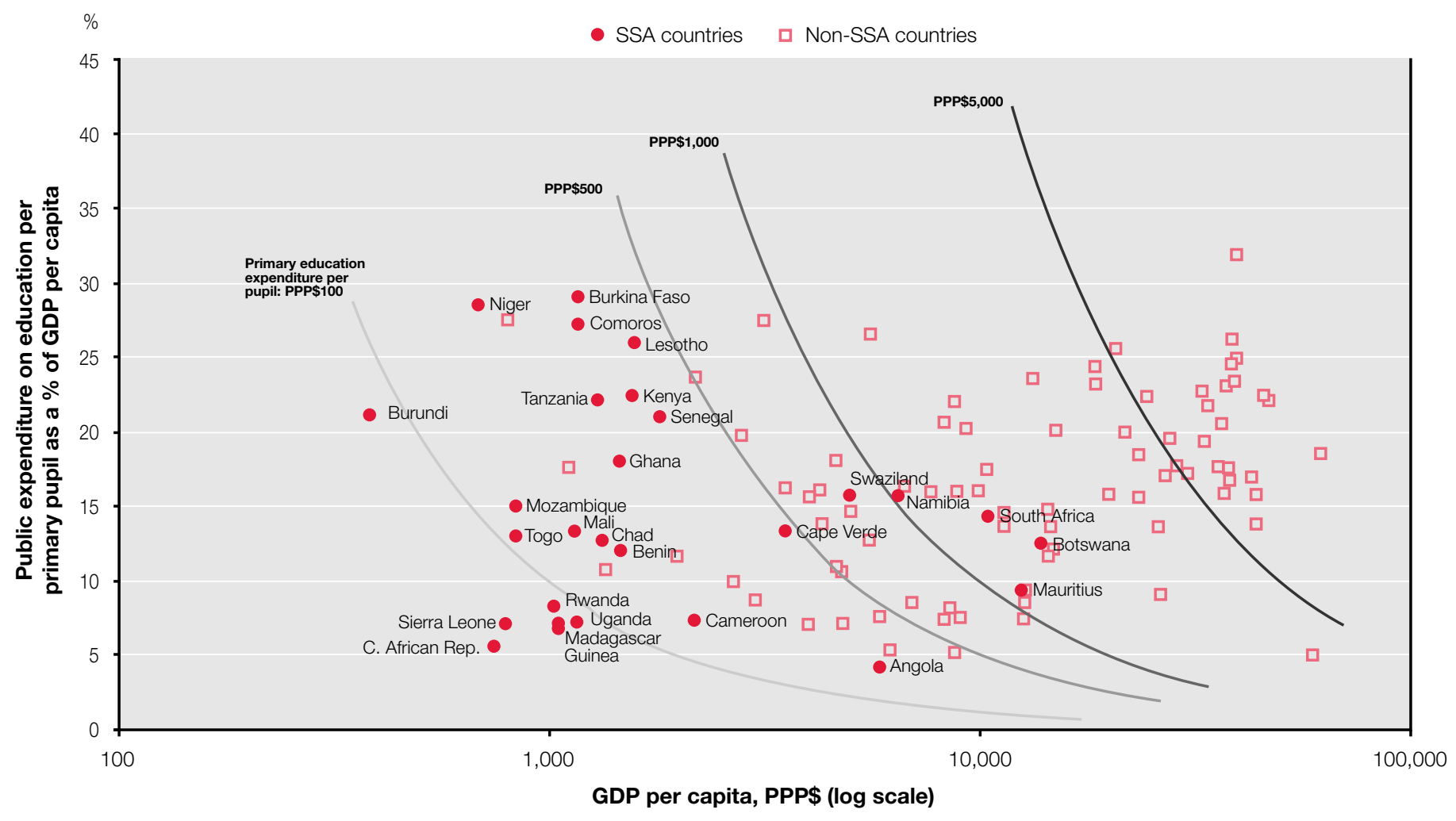

Note: Coverage includes 30 sub-Saharan African countries and 81 countries from other regions.

Sources: UNESCO Institute for Statistics, Statistical Table A6. GDP per capita: World Bank and Statistical Table A1.

among SSA countries with similar levels of national wealth, there is a large difference in public primary education spending as a ratio of GDP per capita. For example, education expenditure per primary pupil in Burkina Faso is $29 \%$ of GDP per capita, while it represents 7\% of GDP per capita in Uganda.

While for some SSA countries the level of investment per pupil as a ratio of GDP per capita is quite high, the actual amount of investment may remain relatively low because the denominator, GDP per capita, is low. In Figure 22, four indifference curves indicate investments of PPP\$100, PPP\$500, PPP\$1,000 and PPP\$5,000 per primary pupil. Three SSA countries - Botswana, Mauritius and South Africa - invest more than PPP\$1,000 per primary pupil. In contrast, even though investment per primary pupil in Burkina Faso, Niger, Comoros and Lesotho is quite high in relation to GDP per capita (PPP\$), the actual amount invested is less than PPP\$500 per pupil per year. Moreover, many countries in the region invest less than PPP $\$ 100$ per primary pupil in absolute terms. This is the case for: Burundi, Central African Republic, Guinea, Madagascar, Rwanda, Sierra Leone and Uganda.
Since 2000, SSA countries have sought to achieve EFA by paying particular attention to primary education through national policies. As already observed, both enrolment and total public expenditure on education increased in most countries since 2000. What has happened to primary education expenditure per pupil as a result of these efforts? Has the rise in public expenditure on education largely gone to accommodate the rising number of pupils?

Figure $\mathbf{2 3}$ compares primary education expenditure per pupil between 1999-2002 and 2009 or most recent year, as well as the corresponding number of pupils in primary education. Ten out of 15 countries with available data experienced both a rise in primary enrolment and growth in public expenditure per student. Thus public expenditure increased at a faster rate than enrolment. In Burundi, for example, primary school enrolment grew by more than three-fold over this period. Yet, the country still managed to increase expenditure per pupil by almost $50 \%$. This was done by increasing public resources to education by $12.2 \%$ per annum (see Figure 13) and raising the allocation to primary education by more than 50\% (see Figure 18). 
Swaziland, where real expenditure increased by $7.8 \%$ per annum (see Figure 13), doubled expenditure per pupil during the 2000s. Cape Verde, Mauritius and South Africa experienced an increase in expenditure per pupil while enrolment decreased. These countries already had high enrolment rates in 1999, so the decrease was partly the result of having less overaged children in primary education. In Lesotho and Namibia, expenditure per student decreased while enrolment grew during the same period. Since the real public education expenditure increased in both countries, this phenomenon was due to enrolment growth, which outpaced the rise in public primary education expenditure. By considering expenditure per student as a proxy of quality inputs per student, ${ }^{31}$ this trend shows that many countries did not necessarily sacrifice the quality of education during the rapid growth in enrolment occurring since 2000.

\section{Expenditure per student by level of education}

In many SSA countries, spending per student at the secondary and tertiary levels is much higher than spending per pupil at the primary level. As with primary education, the allocation of resources at higher levels of education depends on national priorities for development. To analyse the priorities in resource allocation, a comparison of expenditure per student by level is useful.

Figure 24 plots secondary GER on the X-axis and the current expenditure per secondary student as a ratio of current expenditure per primary pupil on the $\mathrm{Y}$-axis for selected SSA and non-SSA countries. A ratio of 1 means that current spending per secondary student is the same as current spending per primary pupil. A ratio of 2 means that spending per secondary student is twice as high as spending per primary pupil. The figure shows that the ratio converges between

\section{Figure 23}

\section{CHANGE IN NUMBER OF STUDENTS AND REAL EXPENDITURE PER PUPIL IN PRIMARY EDUCATION BETWEEN 1999-2002 AND 2009 OR MOST RECENT YEAR}

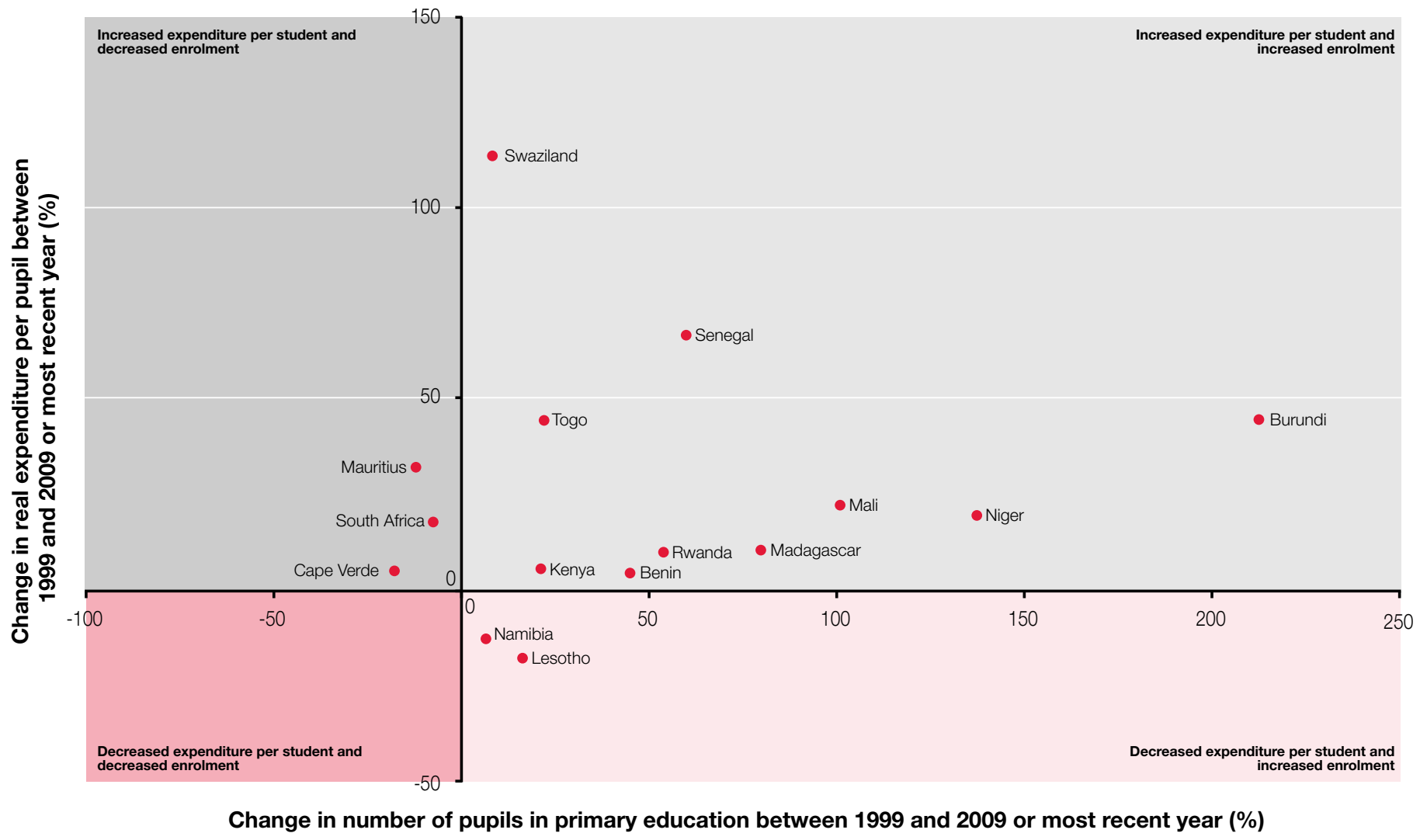

Notes: The earliest year ranges from 1999 to 2002. The change in the expenditure per pupil is calculated based on constant price in local currency. Sources: UNESCO Institute for Statistics calculation based on UIS database and inflation data from the World Bank.

31 More discussion is found in Chapter 5 . 
1 and 2 as the secondary GER increases, in particular for non-SSA countries.

However, the ratio varies widely across SSA countries. With a secondary GER of $40 \%$ or below, Angola, Mozambique, and Cameroon invest at least 5.5 times more for a secondary student than for a primary pupil. In contrast, Burkina Faso and Guinea spend slightly less for a secondary student than for a primary pupil. In their assessment of the financial sustainability of expanding post-primary education, Mingat, Ledoux and Rakotomalala (2010) observe that expenditure per student at the secondary level in SSA countries is particularly high when compared to other regions, which poses significant challenges for the development of secondary education in coming years.

Figure $\mathbf{2 5}$ exhibits a similar trend at the tertiary level. The $\mathrm{X}$-axis represents tertiary GER and the Y-axis represents current expenditure per tertiary student as a ratio of current expenditure per primary pupil. It should be noted that the scale of this figure is larger than the scale used in Figure 24.
Current expenditure per tertiary student exceeds 50 times the expenditure per primary pupil in Lesotho. While the lowest ratio is found in Mauritius (2.2), many SSA countries invest at least 10 times more for a tertiary student than for a primary pupil. An explanation for the high tertiary education costs in Botswana and Lesotho could be the large scholarships awarded to tertiary students. In the case of Lesotho, the government provides scholarships to send students abroad. However, the students who are studying abroad are not reflected in the enrolment statistics of this country, which makes current expenditure per tertiary student in Lesotho seem even higher. On the other hand, other sources of financing, namely the revenue of universities from student fees, contribute to reducing the public education expenditure per student at the tertiary level. ${ }^{32}$

These analyses of expenditure per student have two important implications for policymakers. First, many SSA countries still invest too little per student for education, especially at the lower levels of education. Due to rapidly increasing primary school enrolment during the past decade, expenditure per

\section{Figure 24}

\section{RATIO BETWEEN CURRENT EXPENDITURE PER SECONDARY STUDENT AND PER PRIMARY PUPIL FOR SSA AND NON-SSA COUNTRIES, 2009 OR MOST RECENT YEAR}

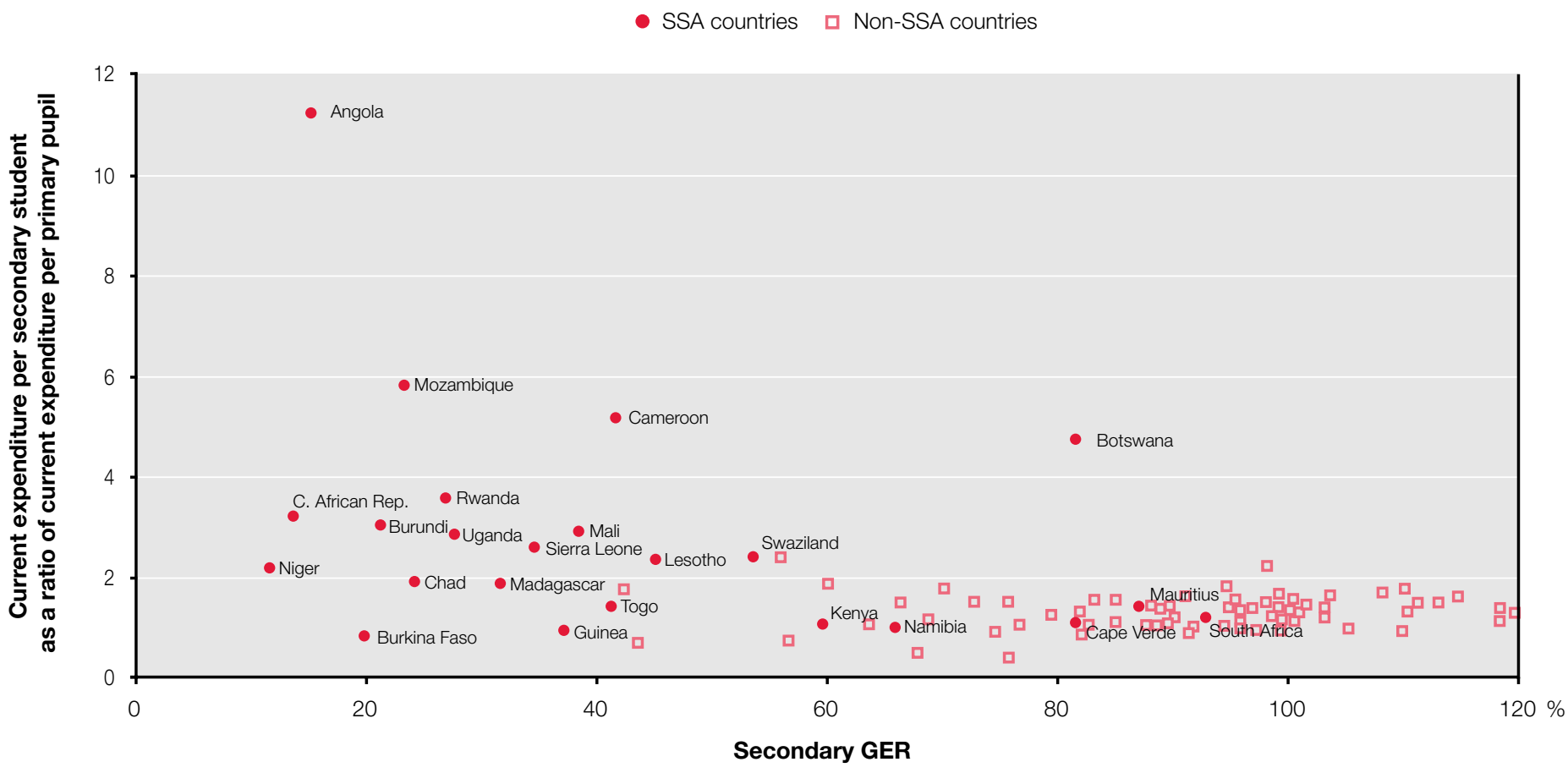

Note: Coverage includes 23 sub-Saharan African countries and 71 countries from other regions. Source: UNESCO Institute for Statistics, Statistical Table A6.

32 Public education expenditure per student is calculated by public current expenditure divided by the number of students in public schools. This figure does not include the revenue of universities from student fees, for example. 
primary pupil has decreased relative to GDP per capita in some countries in the region. As GDP per capita is low in many SSA countries, average expenditure per primary pupil is still less than PPP\$100 for much of the area. Second, expenditure is not balanced across levels of education. Expenditure per secondary and tertiary education students is generally much higher than expenditure per primary pupil in SSA. While the global trend shows that it is common to find such elevated costs at higher levels of education when the enrolment ratio is low, this will lead to an inequity of resource allocation between those who can participate in the upper levels of education and those who cannot.

\subsection{EQUITY OF RESOURCE ALLOCATION}

From a policymaker's perspective, achieving an equitable allocation of public resources among individuals in the country is an important concern. However, even if opportunities in this case for education - are equitably available to the whole population, individuals will still receive varied amounts of public benefits because their years of schooling are different. Theoretically, those who do not get access to education do not receive any public education resources. As individuals continue their schooling, they receive a larger allocation of public resources.
This analysis of equitable distribution of public education resources focuses on the appropriation of resources for individuals who stop schooling at different grades and levels. Typically, expenditure per student is higher at upper levels of education, so the benefit of spending an additional year at school is also greater at upper levels of education.

Figure 26 draws a Lorenz curve for Burkina Faso, Madagascar and Niger based on the cumulative percentage of the population expected to attain a given level of education and the cumulative percentage of public resources expected to be spent on a given cohort. The figure shows how equitably resources are likely to be allocated among the student population at primary to tertiary levels. If the curve is closer to the equity line, resource allocation is more equitable among students. On the other hand, resource allocation becomes more unequal as the curve moves further from the equity line.

These three countries exhibit distinct trends. In Niger and Burkina Faso, where intake rates for primary education are relatively low, $22 \%$ and $16 \%$ respectively of primary school-aged children never attend school. The children who never attend school do not receive any public resources, so inequality shapes

\section{Figure 25}

\section{RATIO BETWEEN CURRENT EXPENDITURE PER TERTIARY STUDENT AND PER PRIMARY PUPIL FOR SSA AND NON-SSA COUNTRIES, 2009 OR MOST RECENT YEAR}

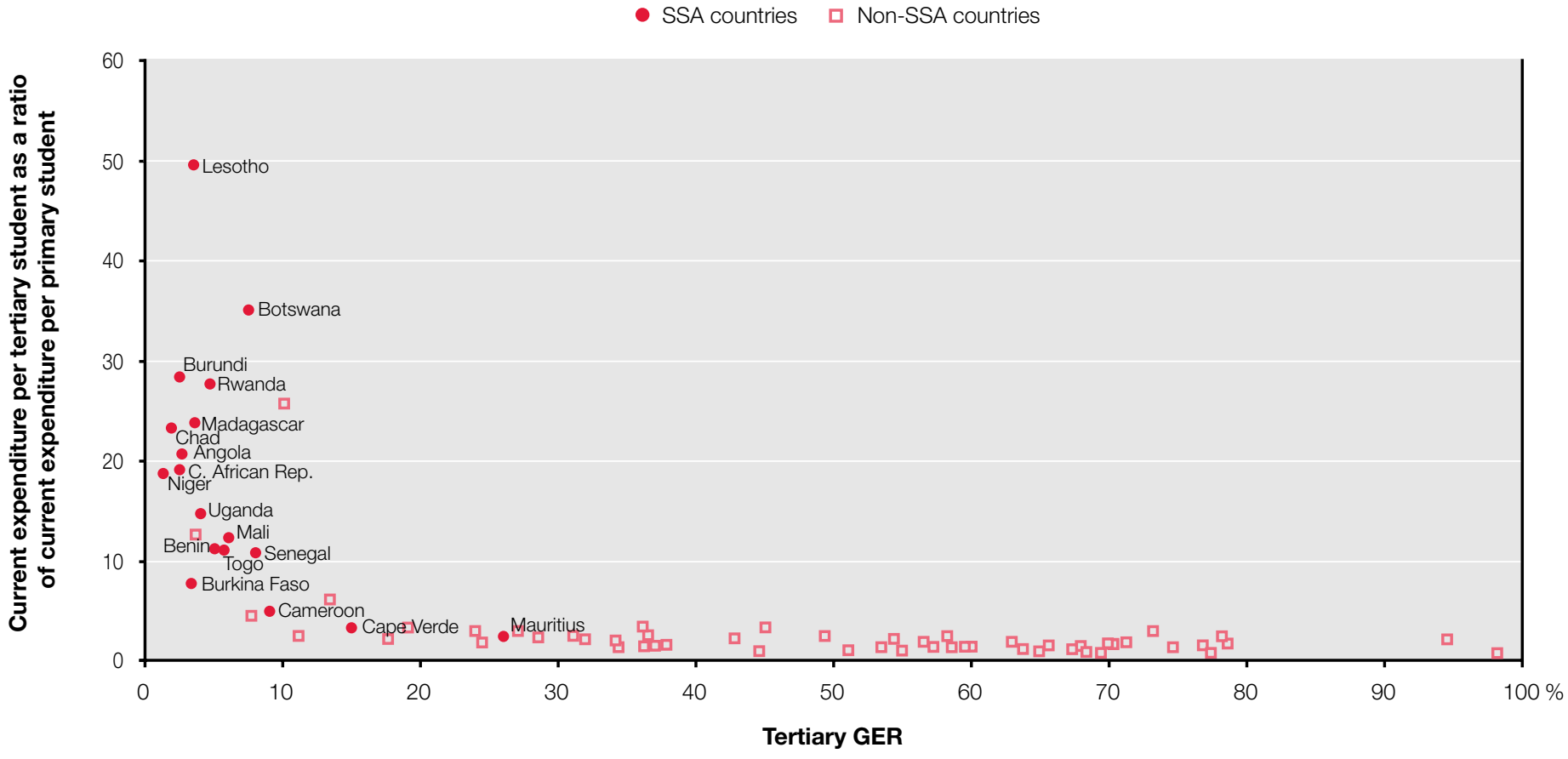

Note: Coverage includes 18 sub-Saharan African countries and 54 countries from other regions. Source: UNESCO Institute for Statistics, Statistical Table A6. 


\section{LORENZ CURVE OF STRUCTURAL DISTRIBUTION OF PUBLIC EXPENDITURE ON EDUCATION, 2008}

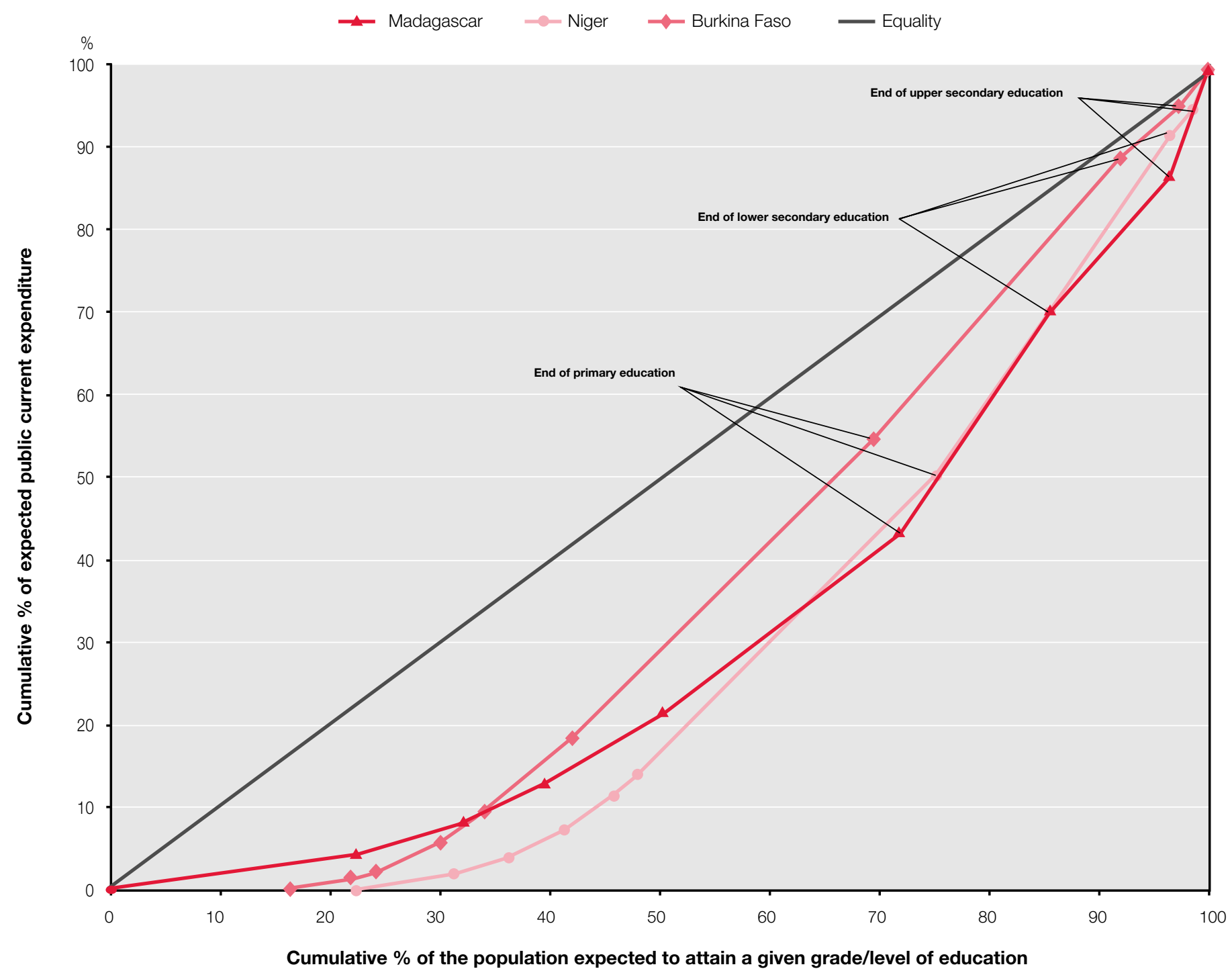

Notes: The data include current education expenditure on public institutions and public school enrolment.

They do not include expenditure other than for educational institutions or scholarships. Data for Burkina Faso refer to 2007.

Source: UNESCO Institute for Statistics calculations.

the curve from the beginning. In contrast, virtually all children attend primary school in Madagascar, so the distribution of resources is equitable at the beginning of school life.

However, as the level of education rises, the trend of resource allocation changes. Burkina Faso seems to exhibit the most equitable resource allocation among students at all levels because of the relatively lower cost of tertiary education. The Lorenz curve for this country moves closer to the equity line as the level of education goes up. The case is similar in Niger, where $55 \%$ of resources are consumed by pupils in primary school, who account for $75 \%$ of the student population. While costs for secondary education are higher than for primary education (as in the unit cost analysis), the low enrolment rate at upper levels of education results in relatively smaller gaps between the benefits received by primary and secondary education graduates and secondary and tertiary education graduates.

In Madagascar, the level of inequality increases as the level of education goes up. Since only about $25 \%$ of the student population reach the first grade of lower secondary, $75 \%$ leave school before or at completion of Grade 6. However, due to the relatively low expenditure per student at the primary level compared to upper levels of education, the $75 \%$ of school leavers have consumed only $44 \%$ of total education resources. 
At the lower secondary education level, however, $12 \%$ of the total student population will have completed their schooling (from primary to lower secondary) and consumed $27 \%$ of the total education resources. At the upper secondary education level, $9 \%$ of the student population will have completed their schooling (from primary to upper secondary) and received 15\% of education resources. As the case of Madagascar illustrates, all children may benefit from public resources at the beginning of primary school, but their relatively low survival rate to the last grade of primary education reduces the opportunity for most students to benefit from public resources at the secondary level. Hence, only the limited proportion of children who enrol in upper levels of education receive relatively large benefits from public resources.

\subsection{CONCLUSION}

This chapter has tried to address fundamental questions associated with education financing, such as funding and allocation. The analyses show that governments of SSA countries generally exhibit quite a strong commitment to educational development through financing. During the 2000s, real expenditure on education increased on average by $6.1 \%$ per annum among 26 countries with available data. This robust growth in education expenditure enabled many SSA countries to increase the expenditure per primary pupil while at the same time expanding primary education enrolment.

On average, SSA countries allocate $18.3 \%$ of public resources to the education sector. Some countries in the region that allocate a relatively smaller share of the government budget to education may have room to increase education expenditure, but this is probably an unrealistic option for many SSA countries. On the other hand, the contribution of donors to educational development is also significant in many SSA countries. The total amount of disbursed ODA to the education sector in the region was US\$2.6 billion in 2008 (OECD-DAC), indicating that $5.6 \%$ of education resources for SSA are financed by donors.

Despite these enormous national and international efforts, financing gaps still exist for achieving UPE in many SSA countries, especially those facing strong demographic pressure and increasing demand for quantitative and qualitative improvement to education. The data show that many SSA countries increased their resource allocations to educational development over the last decade, but the absolute amount of resources spent on the education sector is relatively small when compared to countries in other regions. While concerns of high aid dependency, sustainability and absorptive capacity remain, more resources will be needed to achieve EFA and ensure the quality of education and equity. The first step in securing more resources for educational development, however, is to make sure that committed amounts of ODA are effectively disbursed.

While more resources are required, it is not likely that domestic resources will increase rapidly through economic growth or that donors will provide even more financial support. In this context, one of the most important policy variables is the reallocation of resources within the education sector. There is no doubt about the importance of having balanced sector development at all levels of education, in both quantitative and qualitative terms. However, prioritisation of the resources, by levels of education and the nature of expenditure, is essential to reach national and international education targets. The reallocation of resources within the education sector can be an important option for countries that have not achieved UPE and that have allocated a relatively small share of resources to primary education. This issue will be discussed with the role of private expenditure in Chapter 4.

The reallocation of resources within the education sector can contribute to reducing the inequality of allocations among students of different levels of education. While a sector-wide national vision and support for comprehensive education sector development is important for the long term, it may be possible to overcome financial constraints in educational development in SSA for the short term by considering anew both the role that the public sector should play in the provision of educational services and the ways that education in the region can best be financed. 


\section{Chapter 3}

\section{FINANCING TEACHERS}

\section{Borel Foko and Guillaume Husson (Pôle de Dakar, UNESCO-BREDA) Saïd O. Voffal (UNESCO Institute for Statistics)}

Teacher remuneration often constitutes the single largest element of education expenditure, even if its share varies by country and level of education. As the demand for education is increasing steadily in the SSA region, the need for teachers is also continuously growing. It is estimated that more than 1 million additional teachers are needed in order to provide quality education in all SSA countries. Reviewing the effective and sustainable financing of teachers is thus of great interest to many SSA countries. This chapter discusses the financing of teachers from different angles: the level of remuneration that attracts quality teachers and maintains their motivation; the remuneration policy for different categories of teachers; the historical evolution and sustainability of teacher remuneration systems; teacher management; and trade-offs between teacher salaries and other current expenditure for education. In the SSA region, recruiting a sufficient number of teachers to achieve UPE, despite persistent financial constraints, is a necessity. In order to meet both short- and long-term education development goals, governments must first identify a sensible mix of short-term and sustainable recruitment and remuneration policies for teachers.

\subsection{INTRODUCTION ${ }^{33}$}

As part of the worldwide effort to attain EFA objectives, defining effective and sustainable national policies in recruitment, deployment, remuneration and management of teachers has become a priority in virtually all SSA countries. It has become necessary not only to continue massive recruitment of teachers to achieve UPE but also to address the pressures resulting from the inevitable expansion of secondary education.

Figure 27 shows that the number of primary and secondary school teachers in the region has increased nearly five-fold and eight-fold respectively over the last 40 years. In SSA, there were 2.8 million primary teachers in 2008 compared to only around 620,000 in 1970; in secondary education, there were 1.4 million teachers in 2008, compared to about 180,000 40 years earlier.
Despite this increase, the pace of growth in enrolment has surpassed growth in the number of teachers, especially at the primary level. The average pupil-teacher ratio (PTR) has risen from around 37 in 1990 to 45 in 2008. This indicates that the demand for teachers is still growing as SSA countries continue their progress towards UPE. The UIS (2010) estimates that approximately 1 million additional teachers will be needed in order to provide education of sufficient quality at the primary level in SSA.

Recruitment of a sufficient number of teachers to meet the demand of ever-increasing enrolment is not the only challenge confronting African policymakers. Once enough teachers have been recruited, efforts must continue in: i) deploying teachers to areas with the most need, particularly to rural and remote localities; ii) implementing pre- and in-service teachertraining programmes; and iii) effectively managing teachers and their careers in order to motivate them and improve their performance (Mulkeen, 2010). Commonly identified problems that affect the quality of teaching in SSA include: teacher absenteeism, under-utilisation of teachers, their deployment and retention in rural and remote areas, the lack of accurate data on the collective management of teachers, and the precarious status of certain categories of teachers (Göttelmann-Duret, 1998; Mulkeen, 2010).

From an education financing perspective, the financing and remuneration of teachers are at the core of educational planning in SSA, especially since budgetary constraints in the region are so severe. Chapter 2 showed that salaries compose the main recurrent expenditure in education in SSA. Salary expenditure comprises teacher salaries, salaries of support personnel in schools, and salaries of central and local administrative personnel. Teacher salaries are a key component because teaching is at the very heart of educational practices. Therefore, this chapter focuses on issues associated with the financing of teachers.

\footnotetext{
33 This chapter mainly uses data collected by Pôle de Dakar (UNESCO/BREDA). The focus is largely on primary education. Geographically, countries of Francophone Africa are most often presented as examples.
} 


\section{NUMBER OF PRIMARY AND SECONDARY EDUCATION TEACHERS IN SUB-SAHARAN AFRICA, 1970-2008}

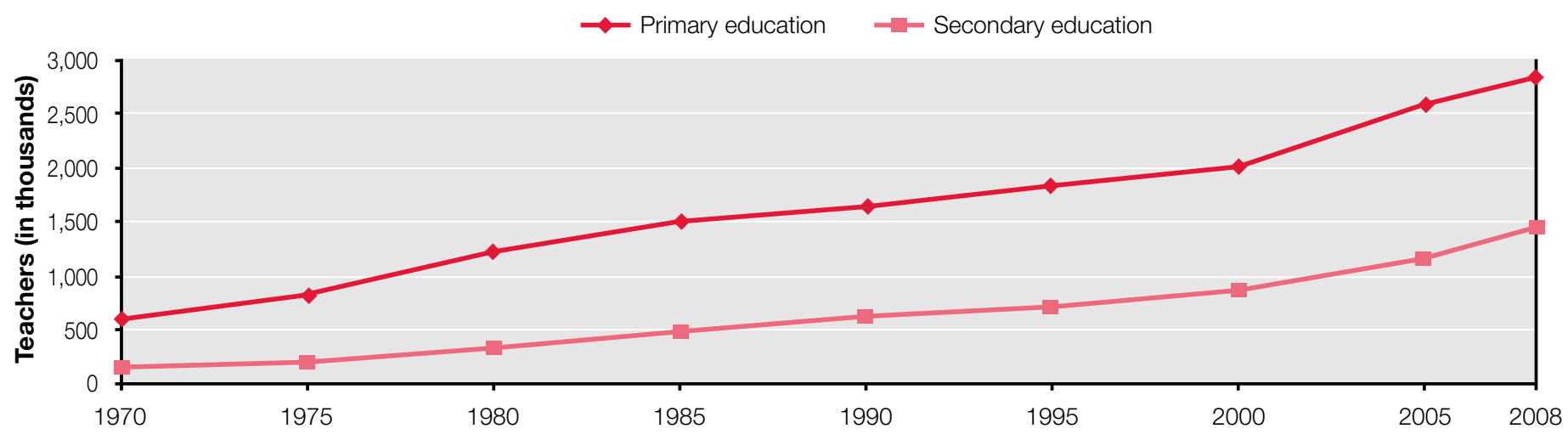

Source: UNESCO Institute for Statistics database.

First, the chapter discusses budgetary allocation to teacher salaries and the level of teacher remuneration. It is important to understand the current and historical policies of remuneration to attract good teachers, who are essential for providing quality education. The financing of teacher salaries will be considered in the context of trade-offs with other expenditure, including administrative and pedagogical expenditure, which are also crucial for building a sound education system. Finally, the issue of financing teachers is examined as a management challenge, especially with respect to the equitable distribution of public funds and their effective use.

\subsection{SPENDING ON TEACHING PERSONNEL}

In the most recent database available (2003 to 2008) for 34 SSA countries, expenditure on teaching personnel comprised slightly more than one-half of public spending on education. While differences exist across countries, the general trend by level of education is shown in Figure 28. The data show that the proportion of teacher salaries in recurrent expenditure decreases as the level of education goes up, from $69 \%$ in primary to $26 \%$ in higher education. In general, teacher salaries in secondary education (including lower and upper levels) comprised about 55\% of all education spending. In technical and vocational education and training (TVET), they comprised $38 \%$.

Obviously, as Figure 29 shows, these proportions vary by country. For example, in Nigeria, primary teacher salaries accounted for $91 \%$ of all spending on primary education, whereas in Congo, they accounted for only 34\%. ${ }^{34}$ Secondary teacher salaries as a proportion of the secondary school budget ranged from 34\% in the Central African Republic to $85 \%$ in Ghana for the lower secondary level, and from 25\% in Mali to $78 \%$ in Togo for the upper secondary level. In TVET, spending on teacher salaries ranged from $12 \%$ in Mali to $74 \%$ in Ghana. Finally, for tertiary education, it varied from $18 \%$ in GuineaBissau to $38 \%$ in Malawi.

The indicative framework of the Education for All Fast-Track Initiative (EFA FTI) recommended that one-third of recurrent spending on primary education be devoted to non-teacher salaries in order to achieve UPE (Bruns et al., 2003). According to this benchmark, some countries have made favourable budgetary trade-offs in terms of recurrent spending on items other than teacher salaries at various levels of education. Examples include primary education in Congo, lower secondary education in Central African Republic and upper secondary education in Mali.

\subsection{REMUNERATION OF TEACHERS: INTER- AND INTRA-COUNTRY DIVERSITY}

Since the amount spent on teacher salaries is quite high in the lower levels of the education pyramid, determining the average remuneration of teachers is a key aspect of any education policy. The amount spent on teacher salaries determines both the number of teachers that can be recruited given available funds and their qualifications at the time of recruitment.

This section aims to identify trends in teacher remuneration from cross-national samples. For the purpose of international comparison, teacher remuneration is expressed in a ratio to GDP per capita, which makes it possible to compare the

34 With regard to Congo, besides low teacher remuneration (0.9 times GDP per capita) in 2007, the PTR was high (63.2), resulting in a relatively low level of expenditure on primary teacher salaries. 


\section{Figure 28}

\section{TEACHER SALARIES AS A PERCENTAGE OF CURRENT EXPENDITURE BY EDUCATION LEVEL,}

2008 OR MOST RECENT YEAR

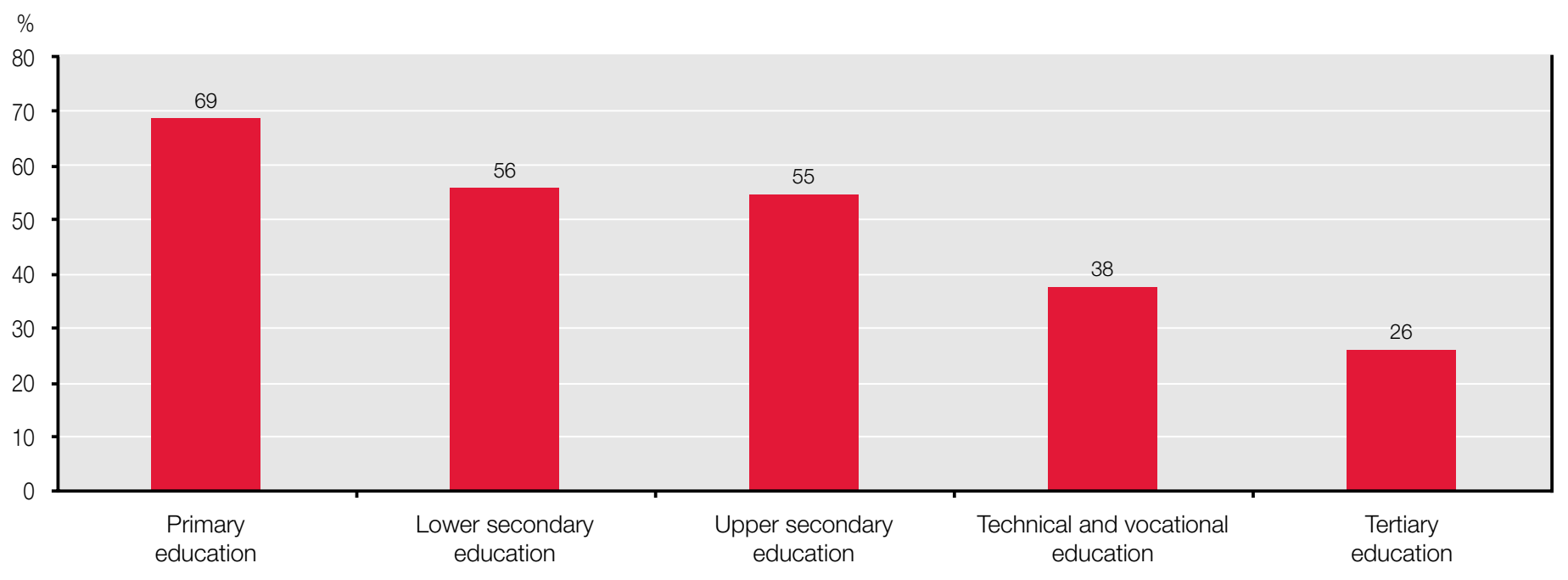

Notes: The proportion is calculated based on a simple average of 33 countries for primary education, 20 for secondary education,

12 for technical and vocational education and 11 for tertiary education. The reference year ranges from 2003 to 2008.

Source: Pôle de Dakar (UNESCO-BREDA) database.

\section{Figure 29}

TEACHER SALARIES AS A PERCENTAGE OF PUBLIC CURRENT EXPENDITURE ON PRIMARY EDUCATION, 2008 OR MOST RECENT YEAR

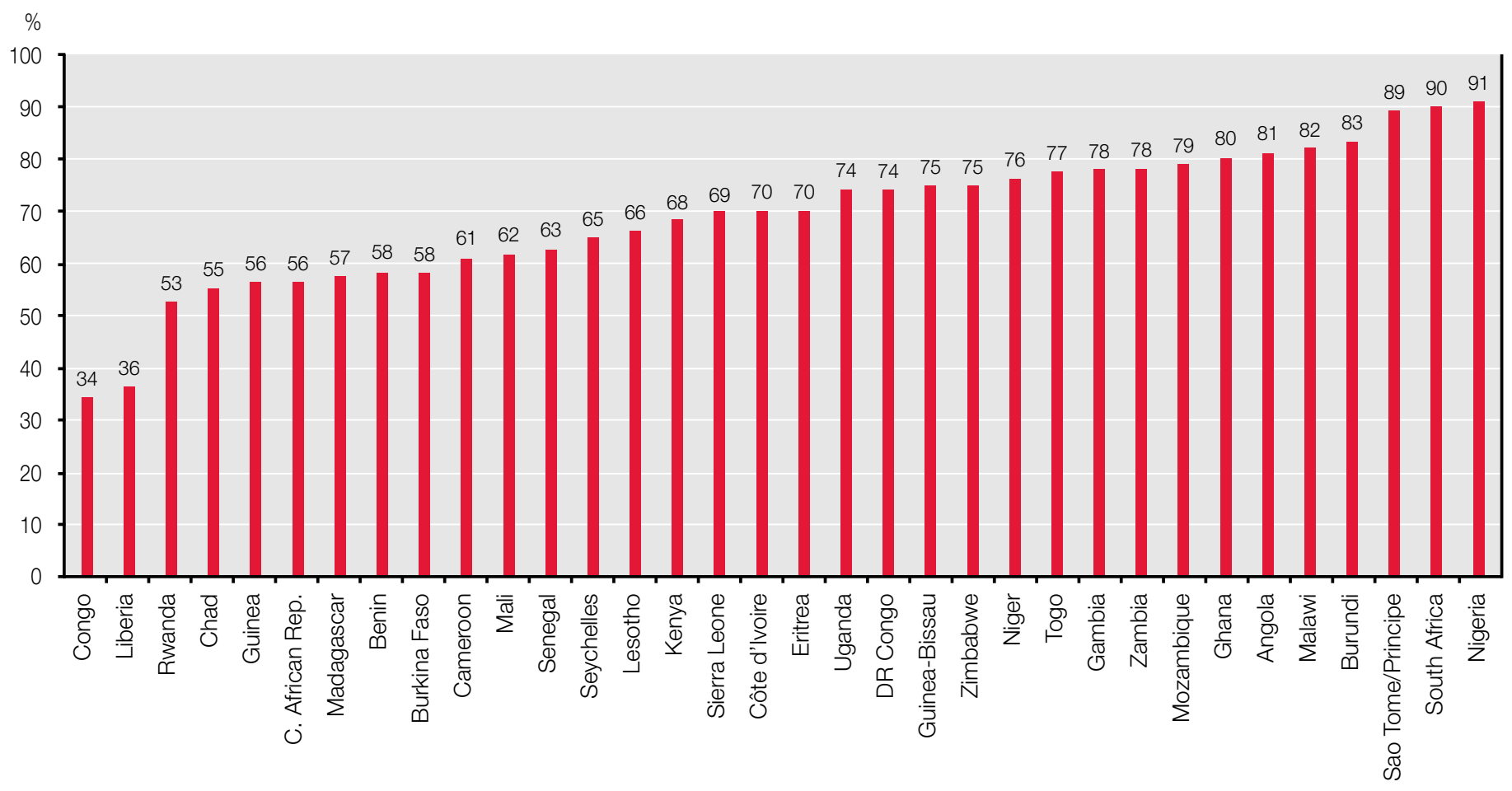

Notes: Coverage includes 33 sub-Saharan African countries. The reference year ranges from 2003 to 2008.

Sources: Pôle de Dakar (UNESCO-BREDA) and UNESCO Institute for Statistics databases. 
relative cost of teachers in a given country. Another possibility is to consider the cost of living and the attractiveness of teaching as a profession, and then expressing teacher salaries in terms of purchasing power parity.

\subsubsection{Variations in average teacher remuneration across countries}

The most recent data available include 34 SSA countries for the period ranging from 2003 to 2009 (the year varying by country)..$^{35}$ It is estimated that during this period the average cost of primary teacher salaries in SSA was 4.1 times the GDP per capita, while the average costs of lower and upper secondary teacher salaries were 6.3 and 7.2 times the GDP per capita respectively. As expected, it can be clearly seen that the cost of teacher salaries increases with the education level. Also, the data show that, although numerous countries had costs near these averages, significant differences exist among them (see Appendix III).

In primary education, average remuneration varied from slightly less than one multiple of GDP per capita in Congo to nearly 8 times GDP per capita in Burundi. In secondary education, teacher remuneration varied from 2 times GDP per capita in Congo to approximately 11.5 times GDP per capita in Malawi at the lower secondary level, and from nearly 2.5 times GDP per capita in Congo to about 12 times GDP per capita in Burundi at the upper secondary level. When these average salaries are compared to statutory salaries of primary and lower and upper secondary education teachers worldwide, ${ }^{36}$ the differences among remuneration levels of teachers in Africa and those of their peers in more developed countries are evident. On average, the ratio of teacher salaries to GDP per capita in OECD countries is 1.2, 1.2 and 1.3 respectively for primary, lower secondary and upper secondary teachers. It should be noted that similar to the average salary, the statutory salary is also influenced by the seniority of the teacher population and their weekly workload. However, the tendency that the relative cost of teachers is higher in countries with a low level of economic development still seems to exist.

In this regard, we can investigate whether there is a strong structural association between the relative cost of teacher salaries and a country's stage of economic development. The analysis suggests that the relative cost of teacher salaries, namely their salary level compared to the average wealth of their country, tends to decrease with economic growth. This phenomenon could indicate an association between structural change that occurs in the process of economic development, signified by a quantitative decrease in the portion of the population commonly categorised as less wealthy than teachers (e.g. labourers) and by a strong expansion of the population segment generally categorised as wealthier (e.g. executives, managers and intermediate professionals in the private sector). The result is that during a period of economic growth, teachers will generally see their relative incomes decrease or, more precisely, will see their salaries (in units of the local currency) increase at a rate that is lower than the overall economic growth rate.

Figure $\mathbf{3 0}$ indicates this general trend in SSA countries but also reveals its limitations. The diagonal line shows that the average associations between the relative cost of teacher salaries and GDP per capita decreases, but individual countries are relatively dispersed around the average trend. Further to the fact that this overall statistical association is rather moderate, its weak robustness leads to the conclusion that teacher salaries only have a slight association with the wealth of SSA countries. If Congo and Cape Verde were to be excluded from the figure, the association would be effectively cancelled out.

Considering the budget share that is allocated to salary expenditure, it is important to remember that a country's salary policy is theoretically a result of a direct trade-off between expenditure other than teacher salaries (administrative, pedagogical and social) and the PTR. Indeed, although teacher salaries should be an important element in discussions between policymakers and other stakeholders, trade-offs must be made among salaries, teaching conditions (e.g. class size, teacher workload, PTR) and other expenditure needed for the education system to function. In brief, for a given education budget, if a country decides to increase the average salary of teachers, it must make adjustments in two other areas, namely increase the average PTR, ${ }^{37}$ resulting in fewer teachers and/or reduce administrative, pedagogical and social expenditure. Thus, national policy on teacher salaries will have an impact on the learning experience of pupils and the pedagogical tools available for their education.

Figure 31 shows the relationship between the average salary of primary school teachers and the PTR, and Figure $\mathbf{3 2}$ shows average teacher salary and expenditure on items other than teacher salaries. Figure 31 suggests that there was no systematic or significant trade-off between teacher salaries and the PTR. In contrast, Figure 32 seems to indicate a correlation between expenditure for teacher salaries and other items. In countries with relatively high salary costs, there was a tendency to spend less on pedagogical, administrative and social costs, while countries with low teacher salaries tended to show

\footnotetext{
35 Data include remuneration of all public school teachers totally or partially financed by the government, whether they were civil service, contract or community teachers

${ }^{36}$ The statutory salary of teachers with 15 years experience was chosen for this comparison, because it represents the salary of teachers in mid-career.

37 For example, the average PTR in public primary schools in SSA was 44.8 in 2008, ranging from 12.5 in Seychelles to 90.7 in the Central African Republic.
} 


\section{Figure 30}

AVERAGE SALARY OF PUBLIC PRIMARY EDUCATION TEACHERS AS A RATIO OF GDP PER CAPITA, 2009 OR MOST RECENT YEAR

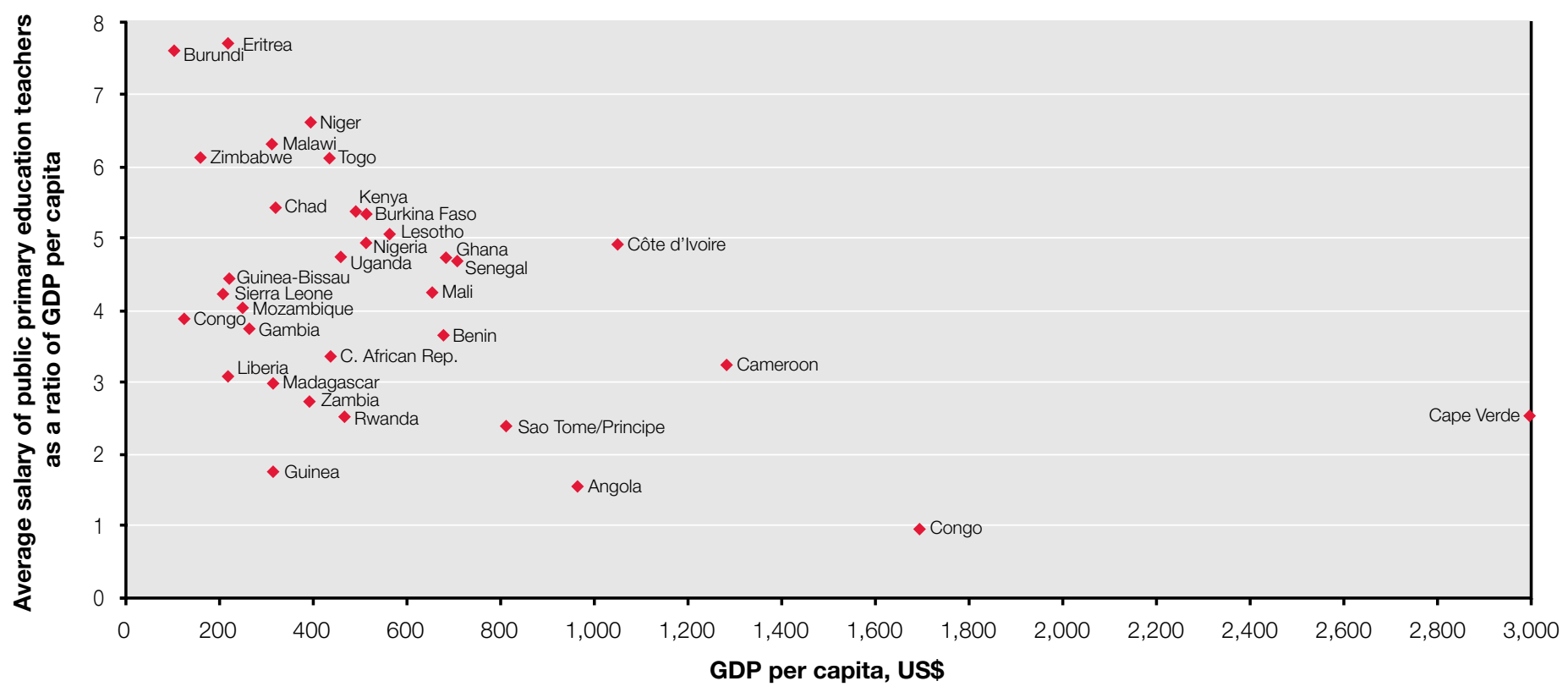

Source: Average primary teacher salary as a ratio of GDP per capita: Pôle de Dakar (UNESCO-BREDA). GDP per capita: International Monetary Fund.

\section{Figure 31}

\section{RELATIONSHIP BETWEEN AVERAGE SALARY OF PRIMARY EDUCATION TEACHERS AS A RATIO OF GDP} PER CAPITA AND THE PRIMARY PUPIL-TEACHER RATIO, 2009 OR MOST RECENT YEAR

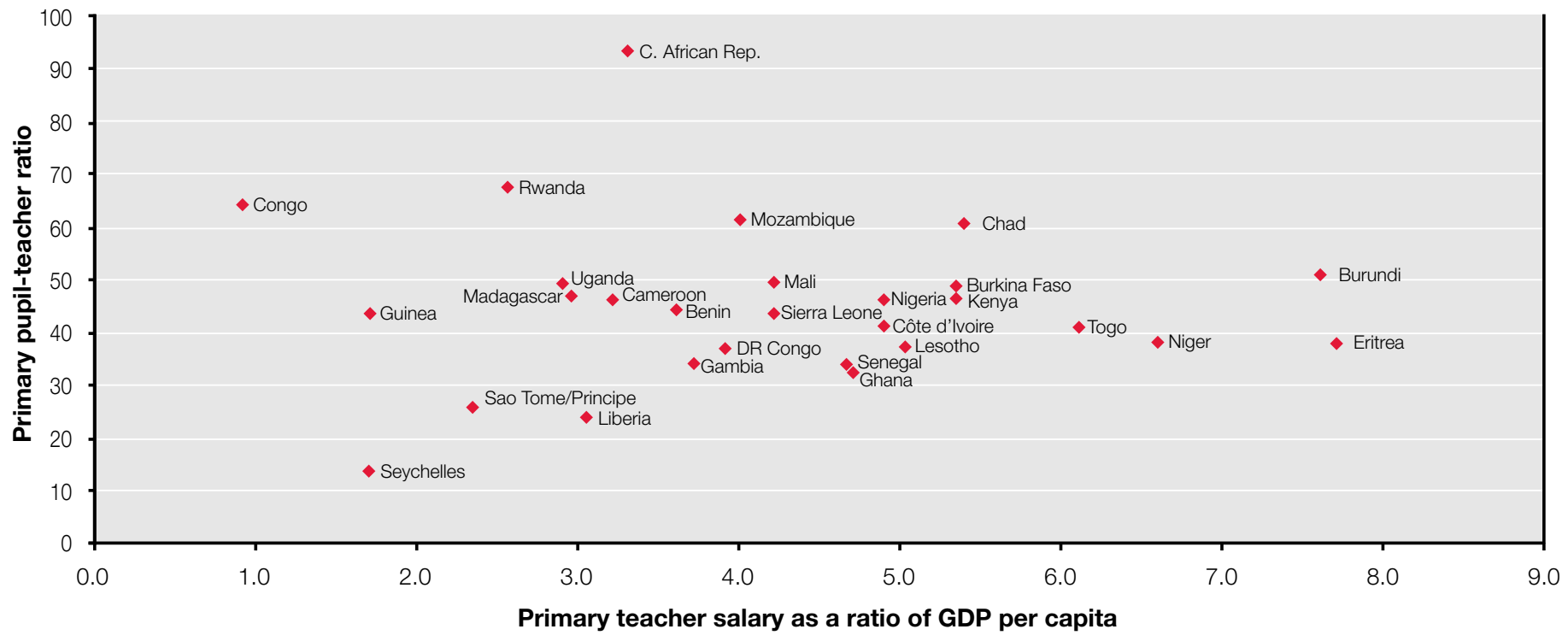

Sources: Average primary teacher salary as a ratio of GDP per capita: Pôle de Dakar (UNESCO-BREDA). 
increased spending in these areas. In particular, this trend held true in Congo and Liberia, where teacher salaries were relatively low at multiples of 0.9 and 3.0 of GDP per capita respectively, and expenditure on items other than teacher salaries were high. ${ }^{38}$

However, the trends suggested in Figures 31 and 32 were not systematic across countries, and a variety of situations can be observed. Neither of the two factors cited (PTRs and nonsalary expenditure) was the main adjustment variable following a given change in teacher salary policy. In short, this means that policymakers could use a combination of these factors as financial levers depending on the situation in their respective countries. Therefore, following an increase in the average teacher salary paid by the government, adjustments could be made by using teachers who are not paid by the government (as is the case for community teachers), by increasing the average number of pupils per teacher, and/or by lowering expenditure on budget items other than teacher salaries.

The analysis highlights the diversity of situations across African countries in terms of teacher remuneration. The observed differences in remuneration cannot simply be reduced to structural differences in development among countries.
They have more specific causes. It is clear that in the field of education financing, contrary to certain preconceived ideas, African countries are not all confronted with the same problems each country is characterised by its unique circumstance.

\subsubsection{Differences in teacher salaries by contract type and qualification}

As noted in the previous section, the average salary of teachers as a multiple of GDP per capita has been extremely varied across African countries. Particularly in recent years, average salaries have also varied greatly within a given country according to the category or training of teachers and, therefore, should be seen in a context of heterogeneity.

The publication entitled Universal Primary Education in Africa: The Teacher Challenge (Pôle de Dakar, 2009) distinguishes many categories of teachers. In Francophone countries in Africa these are: i) teachers who are civil servants; ii) contract teachers; and iii) community teachers (paid directly by the national government and/or individual communities). In Anglophone countries in Africa, the categories are: i) "qualified" teachers who have received pedagogical training; and ii) non-qualified teachers. The diversity of the teacher categories emerged during the 1990s and 2000s in a context

\section{Figure 32}

\section{RELATIONSHIP BETWEEN AVERAGE SALARY OF PUBLIC PRIMARY EDUCATION TEACHERS AS A RATIO OF GDP PER CAPITA AND THE PERCENTAGE OF EXPENDITURE ON ITEMS OTHER THAN TEACHER SALARIES IN RECURRENT PRIMARY EDUCATION EXPENDITURE, 2008 OR MOST RECENT YEAR}

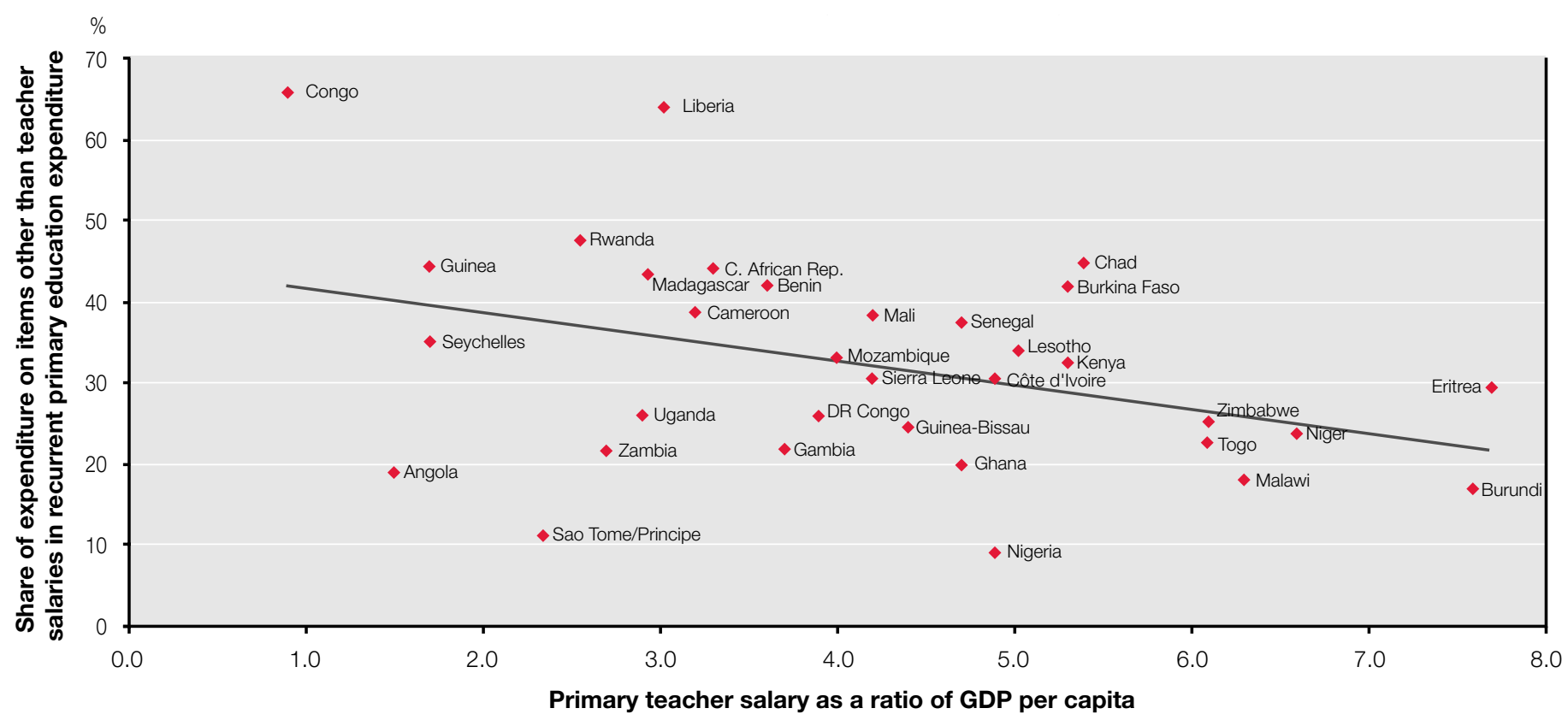

Source: Pôle de Dakar (UNESCO-BREDA) database.

38 In Liberia, in 2008, high expenditure on items other than teacher salaries were due to the fact that one-third of the recurrent primary education budget was transferred to schools to compensate for free education, thereby ensuring the ongoing operations of the schools. These transfers did not involve teacher salaries. Concerning Congo, please refer to footnote 34 . 
of national efforts to achieve financial sustainability and UPE.

Table 3 presents the differences in salaries and the distribution of teachers by these various categories.

The table clearly illustrates both the extreme variety of average salaries among SSA countries and the disparity of salaries, sometimes quite pronounced, within countries, according to teacher categories. In Niger in 2007, for example, a civil service teacher in primary education was paid 11 times GDP per capita, while a contract teacher only earned one-half of this (5.5 times GDP per capita). In contrast, this disparity was less pronounced in Togo in 2007, where a civil service teacher earned a multiple of 6.1 of GDP per capita, and a contract teacher 4.5 times GDP per capita. Of the 14 Francophone African countries shown in Table 3, the average civil servant teacher salary in primary school was 6.0 times GDP per capita, whereas it was only 3.2 for contract teachers - a difference of nearly $50 \%$.

In the case of community teachers, the differences in salary whether paid by the government or communities - were also quite marked. These teachers earned an even lower average wage than contract teachers, namely an average of 0.9 times GDP per capita in the 7 countries where data were available.

For the three Anglophone countries shown in Table 3, the differences in salaries are related to the amount of teacher training received. For example, qualified teachers in Malawi in 2008 were paid a multiple of 6.6 of GDP per capita, while their non-qualified peers were paid only 3.6 times GDP per capita. This difference was smaller in Rwanda in the same year, where qualified teachers were paid on average a multiple of 2.6 of GDP per capita, versus 2.1 for non-qualified teachers.

The composition of the teaching force and the different salary levels among teachers in different categories have an impact on the average teacher salary in a given country. In this regard, a variety of country-specific characteristics could be observed. In Francophone Africa, for example, the vast majority of primary school teachers in Mali in 2008 were contract or community teachers (48\% and $31 \%$ respectively) and only $21 \%$ were civil

\section{Table 3}

\section{AVERAGE TEACHER REMUNERATION AS A RATIO OF GDP PER CAPITA AND DISTRIBUTION OF TEACHERS BY CATEGORY IN PUBLIC PRIMARY EDUCATION, 2008 OR MOST RECENT YEAR}

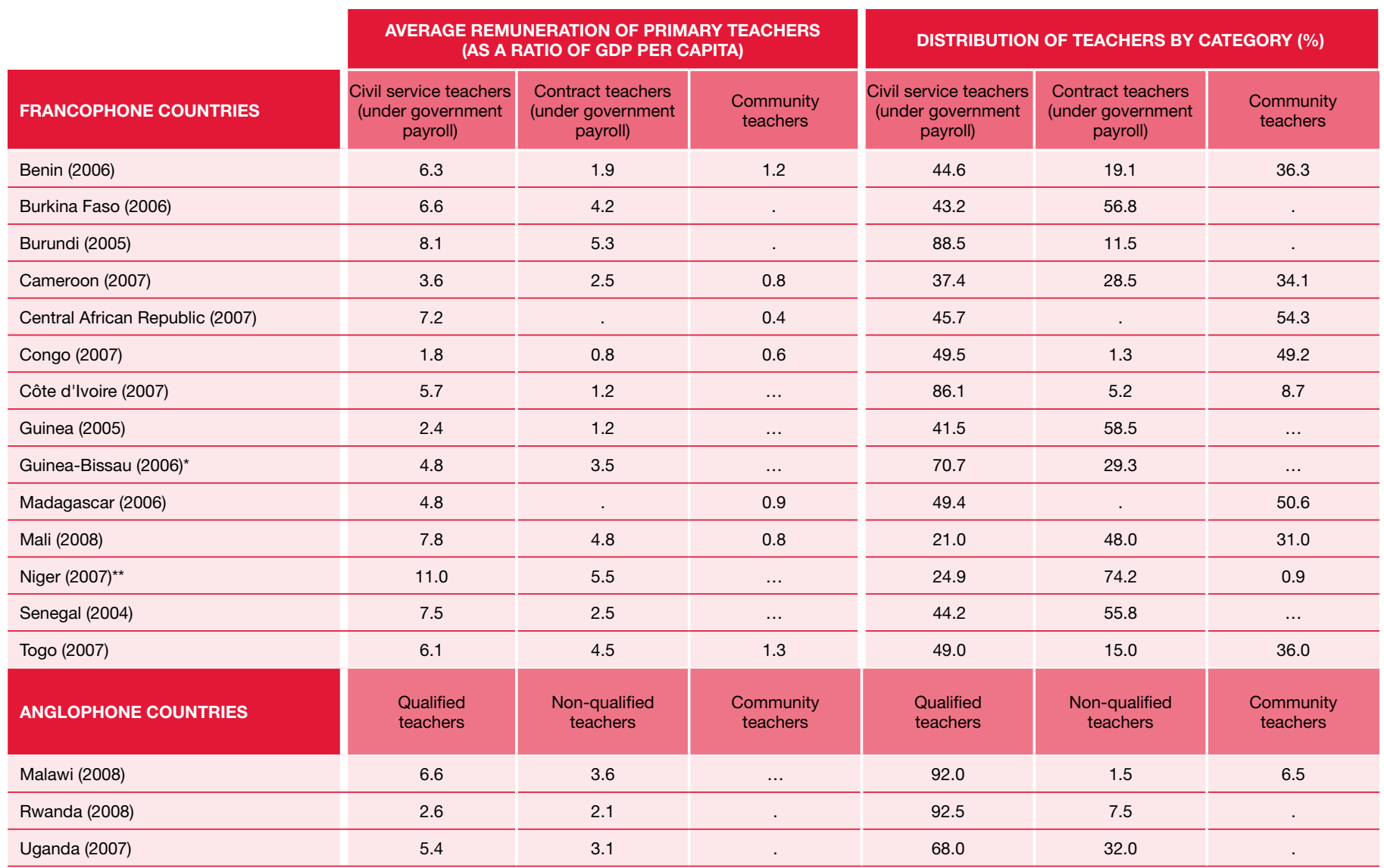

Notes: *Guinea-Bissau is a Lusophone country but is included here among Francophone countries since its teacher categories are similar ${ }^{\star \star}$ Niger: Remuneration data refer to 2008 and data on distribution of teachers by category refer to 2007. Source: Pôle de Dakar (UNESCO-BREDA) database. 
servant teachers. On the other hand, Côte d'Ivoire (2007) and Burundi (2005) had mostly civil service teachers (86\% and $88 \%$ respectively). In Anglophone countries, Malawi and Rwanda in 2008 had mostly qualified teachers in primary schools (92\% for both countries), compared to 68\% in Uganda (2007).

Diversified salaries among the various categories of teachers is commonly observed in a large number of African countries irrespective of geographic region or language. This raises the issue of social equity and long-term sustainability, particularly with regard to community teachers, whose low level of remuneration should be of concern in terms of a decent living wage. One important observation associated with community teachers is that their performance is not necessarily low. Community teachers are paid by the community, so they are directly accountable to the parents of their pupils. Their motivation is often high and that leads to good student learning, according to a study from the Programme on the Analysis of Education Systems (PASEC) (Bernard et al., 2004).

\subsection{TRENDS AND SUSTAINABILITY OF TEACHER SALARIES}

\subsubsection{Decrease in average primary teacher salaries}

As is the case in most professions, the salary levels of teachers are generally not frozen in time. Variations can result from exogenous factors, such as the average seniority of teachers, changes in salary policy or recruitment (inasmuch as there may be differences in salaries ${ }^{39}$ based on the category and/or qualifications of teachers). It is the combination of these various factors that ultimately affects the average salary of teachers.
Over the past 30 years, this has considerably decreased in SSA countries (see Table 4). According to data covering 39 African countries (including North Africa), the average salary of a primary school teacher dropped from 8.4 times GDP per capita in 1975 to 4.0 times GDP per capita during the period 2003-2009. ${ }^{40}$ During this period, real GDP per capita almost doubled, however. ${ }^{41}$ These two sets of data imply that the growth of the real value of average teacher salaries in Africa has been stagnant for over 30 years.

This dramatic decrease in remuneration was reported in both Anglophone and Francophone countries. ${ }^{42}$ Yet, even though the average level of remuneration of teachers is currently almost the same in both groups, overall trends were different. Thirty years ago, the average teacher salary in Francophone Africa was, in relative terms, almost twice that of teachers in Anglophone countries. Even across countries with comparable levels of economic development, salaries were approximately $60 \%$ higher in Francophone Africa than in Anglophone Africa (Mingat and Suchaut, 2000). These authors suggest that the specificity of Francophone African countries, especially in the 1970s, arose essentially from colonial practices. Teacher salaries were indexed to those of France, ${ }^{43}$ which was not the case in countries under British administration where education was mandated to missionaries receiving funds through government grants.

However, there has been a progressive convergence in salaries for the two groups of countries. In Francophone Africa, the decrease in the average salary of teachers was clearly the

\section{Table 4}

\section{TRENDS IN AVERAGE TEACHER SALARIES AS A RATIO OF GDP PER CAPITA IN PUBLIC PRIMARY SCHOOLS IN AFRICA, 1975-2009}

\begin{tabular}{|c|c|c|c|c|}
\hline & 1975 & 1985 & 1993 & $\begin{array}{l}2009 \text { OR MOST } \\
\text { RECENT YEAR }\end{array}$ \\
\hline Africa (including North Africa) & 8.4 & 6.0 & 5.7 & 4.0 \\
\hline Number of countries & 25 & 29 & 29 & 39 \\
\hline Francophone Africa & 11.5 & 8.0 & 6.3 & 4.2 \\
\hline Number of countries & 11 & 15 & 15 & 18 \\
\hline Anglophone Africa & 5.4 & 4.2 & 4.8 & 4.5 \\
\hline Number of countries & 10 & 10 & 9 & 13 \\
\hline Both Anglophone and Francophone Africa & 8.6 & 6.5 & 5.8 & 4.3 \\
\hline Number of countries & 21 & 25 & 24 & 31 \\
\hline
\end{tabular}

Sources: Mingat and Suchaut (2000) for the years 1975 to 1993; Pôle de Dakar for 2009 or most recent year (between 2003 and 2009 ).

\footnotetext{
39 Given that there are changes in the salary scale and benefits over time.

40 The latter figure is an average for 39 African countries (including North Africa) based on a database covering the years 2003-2009, according to data from each individual country. The average of 4.3 times GDP per capita is slightly different from the figure indicated previously (4.1 times GDP per capita), which was based on 34 SSA countries.

Real GDP per capita is calculated by authors using World Bank 2010 data.

42 The average for African countries includes Anglophone, Francophone and countries that do not belong to either group. Due to the availability of data, the coverage of countries varies by year.

43 This directly followed the passing of Bill No. 50-772, 30 June 1950, known as the Lamine Guèye Law "setting the conditions of allocating funds and benefits to civil servants and military personnel from the French Ministry responsible for overseas territories, and conditions of recruitment, layoffs or retirement of these same civil servants" (unofficial translation).
} 
most spectacular. In relative terms, the average salary for teachers in these countries essentially fell by a multiple of 3 between 1975 and 2005. Inasmuch as overall economic growth in these countries was flat, indeed negative during most of this period, the steep decrease in salary is an indicator of a significant loss in purchasing power on the part of African teachers.

However, this general trend did not result from any one phenomenon over the course of this period. It was the result of "structural adjustment" in the economies of African countries and, more recently, of policies reducing spending on salaries in order to "democratize" education, by making it available for all.

\subsubsection{Factors for the decrease in primary teacher salaries Economic downturn between 1980 and 1990}

Salary adjustments in numerous SSA countries were accentuated by the economic crisis that affected the continent in the 1980s. Indeed, from the very beginning of the decade, many African countries were confronted with macroeconomic problems - budget deficits, balance of payment deficits, inflation - notably following the oil shock of the 1970s. This resulted in structural adjustment programmes prescribed by the IMF and the World Bank. The size of the deficits meant that vigorous action was involved - external financing of recurrent expenditure was no longer sustainable and funding partners wished to see governments implement economic policies based on structural reform.

Forced to control and reduce government spending, some countries chose to freeze recruitment and/or promotion of civil servants, even to the point of revising salary scales. This may have involved all civil servants but, in certain cases, specific measures for teachers were implemented. For example, in Benin, all recruitment for the civil service was suspended between 1987 and 1994. Between 1986 and 1992, civil servant remuneration was based on the salary scale in force in 1986. In December of 1999, civil servants in the country were still being remunerated according to the pay scale in force in 1992 (World Bank, 2002).

\section{Voluntary recruitment in recent years}

Following the World Conference on Education for All in Jomtien in 1990, a new voluntary policy of lowering average salaries began to appear in some SSA countries in the late 1990s in the pursuit of increasing the number of teachers. The freeze on training and recruitment of civil service teachers since the late 1980s led to an insufficient number of teachers when the demand for education started to grow rapidly as a result of the EFA effort. Communities that were concerned with providing education to their children reacted and took action spontaneously, recruiting teachers and paying their salaries by themselves. At the national level, countries envisaged new solutions for increasing the recruitment of teachers while maintaining, or indeed reducing, the size of the civil service. These solutions differed according to the history and specific characteristics of each country.

Three types of responses were commonly identified during the period of 1995-2000. First, among non-Francophone countries, adjustments were made by lowering the level of qualifications required to teach and by recruiting teachers without professional training at a salary lower than that of their trained colleagues. Two different options were typically considered by Francophone and some other countries. One was assuming responsibility for community teachers ${ }^{44}$ through subsidies. The other entailed the government hiring contract teachers. Since teachers in this new category would no longer be members of the civil service, their salary scale could be based on criteria other than the pay scale of civil service teachers. The impact of this policy was rapidly felt, with massive recruitment of teachers occurring between 2000 and 2005. In a sample of 15 African countries, mostly Francophone, ${ }^{45}$ recent research by the Pôle de Dakar (UNESCO/BREDA) showed that the annual number of teachers recruited increased from 60,000 between 1995 and 2000 to nearly 140,000 between 2000 and 2005(Pôle de Dakar, 2009). ${ }^{46}$

A possible option for recruiting a sufficient number of teachers to reach UPE could be instituting or maintaining a salary policy that includes contract teachers. While a number of issues could arise as a result of this, such as sustainability and differences in salaries and qualifications (which will be discussed later), it can nonetheless be an effective interim policy for countries where teachers are severely lacking. Governments are responsible for providing UPE, but this is not possible without teachers. Every effort must be made for assembling available data on the economic pertinence of these teacher-related policies, including information on how an interim policy can be developed into a sustainable policy.

\subsubsection{Sustainability of salary policies}

The coexistence of different categories of teachers has led to protests in some SSA countries, and the sustainability of such salary policies is an ongoing issue. Some of the most common

44 This involved direct recruitment of teachers by communities or parents' associations.

45 It was not possible to draw a parallel between the trend in salaries and the pace of teacher recruitment in all African countries because of a lack of data from a large number of Anglophone countries. The 15 countries in the sample were: Benin, Burkina Faso, Burundi, Cameroon, Chad, Côte d'Ivoire, Guinea, Madagascar, Mali, Niger, Senegal, Togo and Tunisia. In these countries, the average salary of teachers went from 11.8 times GDP per capita in 1975 to 4.7 times GDP per capita in 2005.

46 To more precisely disaggregate the specific impact of these voluntary salary policies from other measures that could have affected teacher recruitment, it would have been necessary to draw on other sources of data (particularly macroeconomic) and to make a second parallel between the growth in recruitment and the trend in funds allocated to the education system. However, the lack of this additional analysis does not take away from the obvious impact that salary adjustment policies have had on trends in teacher numbers and recruitment in recent years. 
demands of protesters include that the national government assume responsibility for paying all or part of community teacher salaries and ensuring that teacher salaries increase progressively. However, finding a long-term, sustainable solution for meeting these demands means that the government must first of all find a way to reconcile budget constraints with the interests of different categories of teachers, whose work situation is not the same. Ultimately, this will require both a thorough examination of the best approach for ensuring the attractiveness of teaching as a profession and a complete review of the salary policy for teachers.

\section{Government financing of community teachers}

Recently, there has been an increase in the number of cases where governments finance a part of the salaries of community teachers, particularly in Francophone Africa. This has been true for Mali since 2001, Madagascar since 2005 and Benin since 2006. Action has also been taken to facilitate the conversion of community teachers to contract teachers of the national government as, for example, in Benin since 2008. ${ }^{47}$ In some countries, where a contract teacher scheme is not used, community teachers constitute an important pool of new teachers, as is the case in Madagascar.

\section{Increased teacher salaries}

In many SSA countries where salary differences are based on teacher qualifications, particularly in Anglophone Africa, professional training is a means to increase salaries of teachers who initially lacked qualifications. This association between training and salary premium, however, is not systematic. In the United Republic of Tanzania, ${ }^{48}$ for example, the difference in the base salary between qualified and nonqualified primary teachers is $10 \% .{ }^{49}$ Although this country had considerably reduced the proportion of teachers with no qualifications (from 42\% in 2000 to under 10\% in 2009), essentially due to an ambitious programme of having inservice teachers obtain qualifications, new teachers did not benefit from any salary increase (Pôle de Dakar, forthcoming). Nevertheless, as seen in most countries around the world, this type of programme will contribute to improving the skills of teachers, on the condition that their training was good in terms of process, content and duration, and adapted to the diversity of professional experience and academic levels (Pôle de Dakar, 2009).

In certain countries, such as Liberia and Uganda, different salary scales are used for qualified and non-qualified teachers.
In such situations, professional training is an obvious means for increasing the salaries of teachers who initially lacked qualifications. The financial implication of the professional training of teachers for the education budget depends on the amount of the premium that is given to qualified teachers.

Box 5 presents the case for Uganda.

In countries that have a large number of non-qualified teachers, in-service teacher qualification programmes could be used as a means to facilitate pay raises, including in private schools.

In fact, a number of countries seem to be re-examining teacher salaries and indeed increasing the overall salary scale as part of the civil service reform. These increases often follow discussions between governments and stakeholders, but also with development partners, since additional financial support, at least in the short term, is generally required.

In all cases, each country should carefully analyse these measures. Unsustainable salary increases will result in financial problems when countries need to hire a sufficient number of teachers to provide quality education with ever-increasing enrolment. This was foreseen in Liberia and Uganda. New and higher salary scales were not implemented there due to anticipated budget constraints (World Bank, 2007; Mulkeen, 2008).

\section{Attractiveness of salaries re-examined}

In order to achieve UPE, most African countries will have to recruit a significant number of teachers in the coming decade. According to estimates made in 2009 by the Pôle de Dakar (UNESCO/BREDA) for 41 African countries, the number of teachers would need to increase on average by 3.3\% per annum from 2006 to 2020.50 In nearly three-quarters of these countries, the annual pace of teacher growth would have to be $6 \%$ or higher. Beyond the logistical challenge posed by recruitment and training, there are also issues associated with attracting and maintaining competent and motivated teachers. In short, teacher remuneration is a key factor to better manage education systems.

The degree of attractiveness of teacher salaries is related to the specific context in a given country - knowing how to position the average teacher salary in light of the national labour market for jobs requiring comparable qualifications. This can also be understood from a regional perspective, in which the question is whether the same level of salary is offered for similar qualifications of teachers in neighbouring countries.

\footnotetext{
47 In late December 2007, the government decided to put under contract all 10,200 community teachers, comprising $38 \%$ of all teachers in public primary schools, who until then had received a modest subsidy from the government.

48 Not including Zanzibar.

${ }^{49}$ Qualified teachers begin in Category B of Level 2 in the Tanzania Government Teacher Scale (TGTS), whereas their peers without qualifications begin in Category B of Level 1 in the same scale.

${ }_{50}$ In their estimates, the year set for attaining UPE was adjusted according to the progress of individual countries towards achieving UPE. Thus, the target year was set at 2010 for countries with an achievement rate for primary school (ARPS) already higher than 90\% in 2006; 2015 for countries with an ARPS between 60\% and $90 \%$ in 2006 ; and 2020 for those who are the most behind (ARPS lower than $60 \%$ in 2006).
} 


\section{9 \\ COMPARISON OF THE BASE SALARY OF QUALIFIED AND NON-QUALIFIED TEACHERS AT THE BEGINNING AND END OF THEIR CAREERS IN UGANDA}

A comparison of the salaries of qualified and non-qualified teachers in Uganda in 2007 (see Table 5) shows that the salary premium that qualified teachers received is substantial from the beginning of their careers and continues to increase as their careers progress. From the start, qualified teachers benefit from a salary premium representing some $65 \%$ of the monthly salary of non-qualified teachers, and this premium increases to some $89 \%$ (the pay scale maximum) when they reach the end of their careers.

This should motivate non-qualified teachers to pursue the training they lacked in the first few years of their careers, but in a way that does not interrupt the continuity of their teaching. The magnitude of demand for such professional development should not be underestimated, since in 2006/2007 nearly one-third of all primary school teachers in the country were considered nonqualified (World Bank, 2007).

\section{Table 5}

\section{COMPARISON OF THE STATUTORY SALARY FOR QUALIFIED AND NON-QUALIFIED PUBLIC SCHOOL TEACHERS AT THE BEGINNING AND END OF THEIR CAREERS IN UGANDA, 2006-2007}

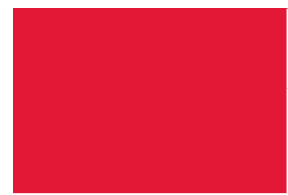

Non-qualified teachers

Qualified teachers

Relative difference in \%

Source: World Bank, 2007.

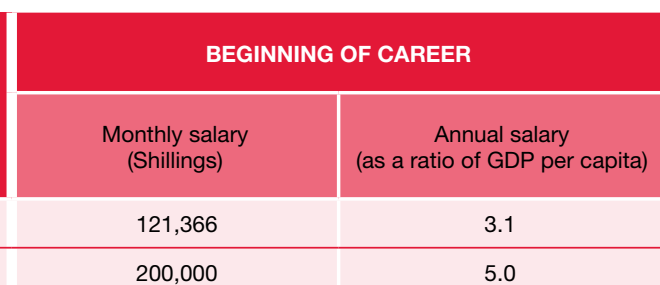

$64.8 \%$

\begin{tabular}{|c|c|}
\hline \multicolumn{2}{|c|}{ MAXIMUM IN SALARY SCALE } \\
\hline $\begin{array}{c}\text { Monthly salary } \\
\text { (Shillings) }\end{array}$ & $\begin{array}{c}\text { Annual salary } \\
\text { (as a ratio of GDP per capita) }\end{array}$ \\
\hline 121,366 & 3.1 \\
\hline 229,181 & 5.8 \\
\hline
\end{tabular}

Without a doubt, the country-level perspective is the most important, particularly for primary school teachers for whom the "potential market" is primarily in their respective country rather than in the region. That is why it is important to compare the salaries of teachers with those of other professions in the country that require comparable qualifications, as recommended in the joint report published by the ILO and UNESCO in 1966 on the working conditions of teachers (ILO/ UNESCO, 1966). The salary level of teachers in the first few years of their careers should be compared to that of workers in other economic sectors, who are also beginning their careers and have similar academic qualifications. In addition, increases in salaries over the course of a career for teachers and other workers in the "modern" labour force should be compared, including for teachers in the private sector where data are available.

A comparative study of salary scales is an interesting starting point for discussing the attractiveness of teacher salaries. In Rwanda and the United Republic of Tanzania, for example, teachers do not have the same salary scale as other civil servants. At the beginning of their careers, Tanzanian teachers
(Category B on their pay scale) have a base salary that is $11 \%$ higher than that of other civil servants. ${ }^{51}$ This salary premium stays in place but declines over the course of the career - it is no more than $4 \%$ when the teacher attains Category E, the maximum for primary teachers (Pôle de Dakar, forthcoming). Conversely, in Rwanda, teachers in general, and those in primary school in particular, are paid less than other civil servants with comparable qualifications. The salary of a certified primary school teacher in Category A2 is only one-third of the salary of another civil servant in the same category World Bank et al., 2010a)..$^{52}$

Household surveys are another valuable source of data on issues related to teachers, namely: employment; education levels and training; type of current job held (in the public, private or informal sector); number of years of experience; and salaries or income. They can provide a means of comparing the income of teachers with that of people working in other sectors with comparable levels of education, and show to what degree the teaching profession might be attractive for someone in terms of remuneration.

\footnotetext{
${ }^{51}$ Among non-teachers, health personnel with their own specific salary scale were not taken into account.

52 The average salary of secondary school teachers is $60 \%$ that of a non-teaching civil servant with similar academic qualifications (diploma or degree).
} 
From a regional perspective, one approach is to simply do a purchasing power comparison in each country related to the salary levels of teachers. For the purpose of international comparison, the average salaries of primary school teachers were converted into PPP dollars. Figure $\mathbf{3} 3$ presents the average salaries of primary school teachers in three large regions of Africa, converted to PPP dollars in 2005.

Among the three regions analysed, teachers in West Africa had the highest purchasing power, with a median annual salary of PPP $\$ 4,600$ (average of Benin and Togo), followed by teachers in Central Africa, with a median annual salary of PPP $\$ 3,300$ (Sao Tome and Principe), and teachers in East Africa, with a median annual salary of PPP $\$ 2,970$ (average of Mozambique). However, salaries in West Africa in 2005 were less homogeneous than in the other two regions (excluding Seychelles). ${ }^{53}$ Looking at these figures, it would seem that there may be an incentive for teachers or candidates to teach in West Africa, increasing their cross-border mobility. For example, the purchasing power of Guinean teachers in 2005 was less than one-quarter of that of teachers in neighbouring Senegal. Similarly, the purchasing power of teachers in Guinea-Bissau was around $60 \%$ of that of teachers in Senegal or Cape Verde. However, while cross-border mobility of teachers among neighbouring countries is possible in theory, not many cases have been observed, especially due to language barriers, labour market regulations that govern acceptance of foreign workers, and other various personal factors.

While no generalisation is possible, consolidating these different aspects clearly shows the great variety of country situations regarding the attractiveness of the teaching profession. Therefore, it is important that such data are collected from each country so that the relative situation of teachers in the labour market within countries and regions can be better understood.

\subsection{TEACHER MANAGEMENT}

The financing challenge is accompanied by a management challenge. African education systems should have mechanisms in place to ensure a coherent deployment of teachers to areas where they are most needed. In the interests of equity, it is important that rural, remote and disadvantaged areas are provided with a sufficient number of teachers so that communities are not obliged to recruit teachers on their own (community teachers). The analysis of the distribution of teachers in a country can reveal a great deal about the efficiency and equity of the national teacher deployment system.

\section{Figure 33}

\section{SALARIES OF PUBLIC PRIMARY EDUCATION TEACHERS IN PPP\$, 2009 OR MOST RECENT YEAR}

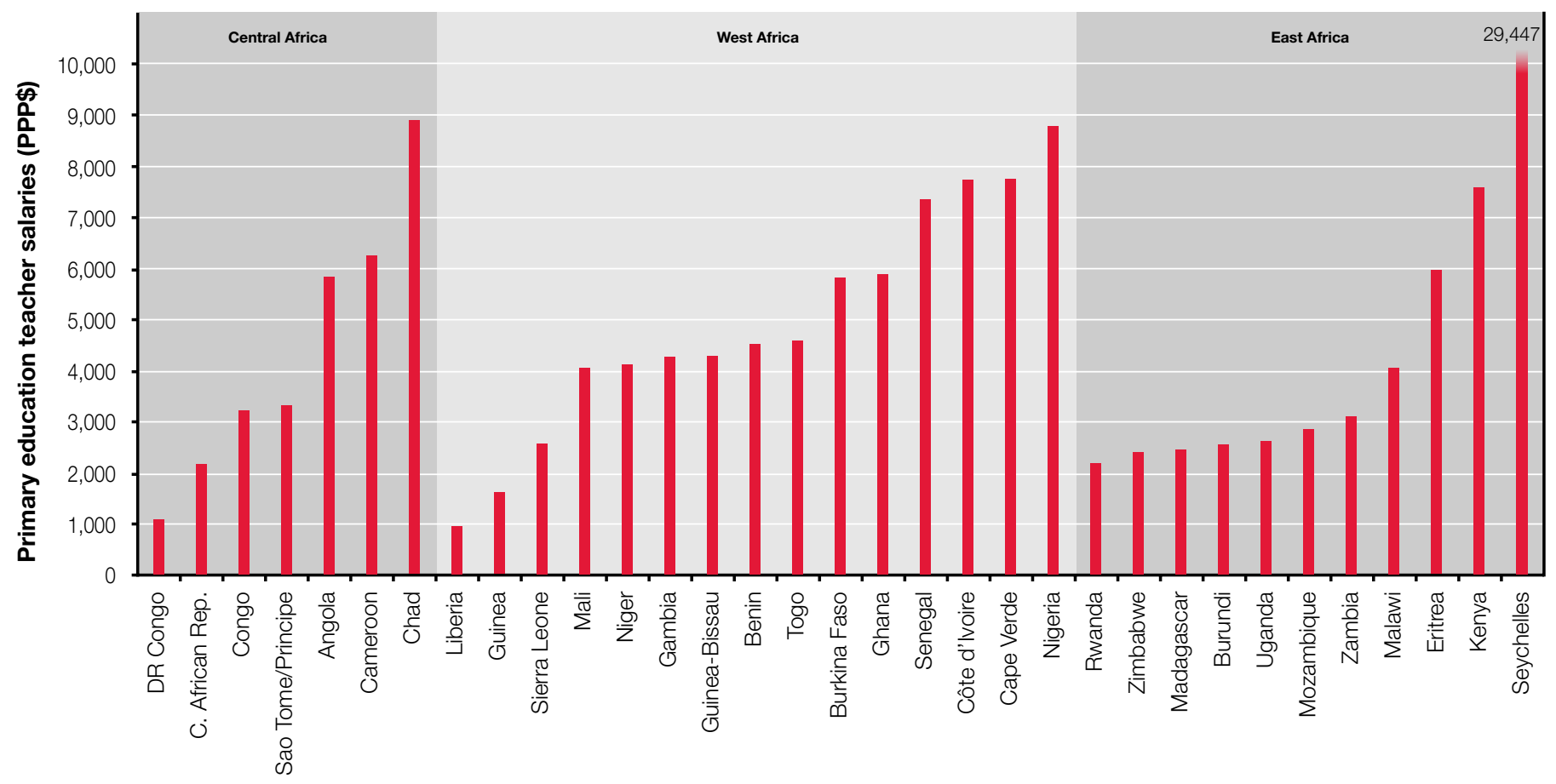

Source: Pôle de Dakar (UNESCO-BREDA) database.

53 The coefficient of variation of the salaries was 0.6 in Central Africa, 0.7 in East Africa (not including Seychelles) and 1.0 in West Africa. 
In many African countries, there is much room for improvement in this regard. Indeed, based on data from 11 SSA countries ${ }^{54}$ covering the period 2004-2007, it is estimated that on average one-third of teacher deployment to public primary schools is not carried out in relation to school size (i.e. student population). For these countries, the risk of inappropriate teacher deployment ranges from $7 \%$ in Guinea to $54 \%$ in Benin (where more than one-half of teacher deployment is determined by factors other than the number of pupils). This suggests that there is room for progress in making teacher allocations more equitable and coherent with regard to where teachers are assigned.

Furthermore, incoherent deployment of teachers leads to marked disparities among regions within countries. For example, in Mali in 2008, the PTR in primary schools ranged from 34.6 in the Kidal region to 73.1 in the Bamako district (World Bank et al., 2010b). This indicates that the assignment of teachers was not equitable throughout the country, creating great inequality from one region to another and certainly from one school to another in the same region. In the Gao region in Mali, ${ }^{55}$ only $1.9 \%$ of primary school teachers were community teachers, yet in the Ségou region, they accounted for $51.8 \%$ of the primary teacher workforce. As a result, the learning experience for pupils is not the same in one region compared to another.

Teacher management also includes encouraging the regular presence of teachers in the classroom and preventing teacher absenteeism, both to minimise the waste of public funds and to ensure that the teaching schedule is respected. In spite of the lack of complete data on teacher attendance, the available empirical data suggest that in certain countries the issue of absenteeism or "ghost teachers" is of significant concern. Absenteeism tends to greatly reduce the real number of hours of classroom teaching and ultimately compromises the quality of education. But it also results in considerable costs. In Zambia, for example, the estimated fiscal loss due to absenteeism is US\$17 million, or $0.31 \%$ of the country's GDP (Patrinos and Kagia, 2007). In general, "ghost teachers" draw a salary from the education budget without actually engaging in any teaching or administrative activity.

Examining the magnitude of this problem in certain countries including the administrative procedures associated with temporary postings or having teachers on call for assignment may provide valuable insight into the prevalence of teacher absenteeism in the SSA region. For example, in 2007 in Congo, $15 \%$ of the personnel in the Ministry of Primary and Secondary Education (Ministère des enseignements primaire et secondaire - MEPSA) continued to be paid without having actually worked in the Ministry, accounting for approximately $15 \%$ of MEPSA's total salary allocations.

Since the financing of teachers is always accompanied by a management challenge - the deployment and utilisation of teachers - it is essential to address these issues as an important dimension of education policy.

\subsection{TRADE-OFFS IN EDUCATION POLICYMAKING}

Needless to say, teacher remuneration is not the only issue for education policy. Due to budget constraints, which all governments face, trade-offs must be made among the major elements of education policy - quantitative, qualitative and organizational. Furthermore, these trade-offs must be made for each level of the education system in order to maintain coherence and consistency in the sector.

Policymakers must, therefore, consider each of these aspects and extract the real issues in terms of developing the education system, identifying the various options for addressing these issues, and estimating the costs in order to match spending with the funds available. They must then determine the best balance. In order to make policy decisions among various options, the use of a financial simulation model for the sector is generally practical, since it facilitates the trade-off process by testing the feasibility of various scenarios. It also provides a means of estimating the funds needed to implement the policy in the education sector and, thereby, helps to evaluate the level of the country's dependence on international sources of funding specifically in the field of education.

Integrating all the sub-sectors in the same model also provides a means of checking the "compatibility" of subsector policies. In general, the education sector is managed by several ministries, each with a specific perspective on the development of the sub-sector under their responsibility. Therefore, an integrated model provides a means of validating an all-encompassing education development policy that is both coherent and shared by all.

Nevertheless, discussions surrounding an issue as sensitive as the policy on teacher salaries cannot be confined to analyses based on financial sustainability. As recommended in the guide to analysing teacher issues produced by UNESCO (UNESCO and UNESCO-BREDA, 2010), analyses should involve multiple discussions at various levels and among diverse actors: i) between technical personnel and politicians in the ministry of education, the former analysing the impacts of measures envisaged by the latter; ii) between the ministry of education

\footnotetext{
${ }_{54}$ These countries are: Benin, Burkina Faso, Burundi, Chad, Central African Republic, Congo, Guinea, Guinea-Bissau, Malawi, Mali and Niger.
}

55 Community teachers in Mali are subsidised by the government. Therefore, they are taken into account in the overall management of teachers. 
and its partner ministries (finance, development plan and departments in charge of implementing initiatives described in poverty reduction strategy papers, that participate in intersector trade-offs or compete for public funds); iii) between the ministry of education and other education stakeholders (parents of students, teacher unions, civil society), insofar as a sector development programme often involves conflicting rights and interests of the various actors concerned; and iv) between the ministry of education and external partners in development so that the country can attract additional funding.

Final trade-offs are related to the powers exercised by the various actors in the system. They should take into account the aspirations, often divergent, of each actor. But a balance must be established, based on explicit consideration of the consequences of various development scenarios. The transparent sharing of simulation models, in particular, can help to position social dialogue at the core of education policy, thereby facilitating the building of consensus, which is indispensable for implementing ambitious policies of education system development.

\subsection{CONCLUSION}

Considering the key role teachers play in the process of developing education systems, salaries of teaching personnel constitute a major proportion of education budgets. Taking into account the lag in enrolment seen in most SSA countries and the dramatic increase in the population of school-aged children, these countries will need to recruit a massive number of teachers in order to provide wider access to education for their young populations.

To enable this under persistent resource constraints, one of the options can be the use of contract teachers as an interim policy. While there are issues associated with contract teachers (including sustainability, qualification and the gap in salary levels), education cannot be effectively provided without teachers. As the story of community teachers during the period of structural adjustment tells us, communities often take matters into their own hands, even if it means finding and financing their own teachers.

In addition to the issue of recruitment, the real achievement of education goals in a country, which must be accompanied by quality of teaching and learning, depends on the capacity of a country to attract and maintain competent and motivated teachers. The average teacher salary as a ratio of GDP per capita declined across SSA countries during the last 30 years. While this may have rendered the education system more sustainable, the issue of the attractiveness of teaching as a profession should not be ignored, especially since a part of the salary decrease may be the effect of the creation of different categories of teachers with precarious status. For the long term, the national policy of teacher recruitment and remuneration must be both sustainable and attractive to retain qualified teachers.

The emergence of community teachers led to a re-composition of the teaching force and a rethinking about traditional requirements for pre- and in-service professional training. This fostered the creation of new categories of teachers. The heterogeneity of government responses to this new order is matched by the heterogeneity of the pool of teachers in each country in terms of categories, professional designations, salaries and careers. Although this heterogeneity seems to have resulted in notable progress in terms of enrolment, the current situation calls for veritable teacher-specific policies and a real career path for this profession that should be attracting people to join its ranks. In order to optimise the funds and resources allocated to the education sector, it is essential to address issues associated with the management of teachers, particularly in their deployment to schools and their utilisation.

Finally, though the matter of financing teachers is a key for sustainable financing of education systems, it is clear that certain other elements must be considered. A major one is the trade-offs between expenditure related to teachers and that related to other items which affect teaching conditions and the quality of education (e.g. PTR and teaching resources per student), as well as administrative, special needs and supervision expenditure. The use of financing simulation models is generally helpful in decisions regarding these tradeoffs by testing the logistic feasibility and financial sustainability of various scenarios in education policy. They can provide a transparent basis for discussions among the various actors (technical personnel, policymakers, societal stakeholders, development partners, etc.) by processing information based on needs and national and international funding possibilities. Such models can, therefore, help place the teacher issue in the context of the overall needs related to education policy. 


\section{Chapter 4}

\section{PRIVATE FINANCING OF EDUCATION}

\section{Serge Peano (UNESCO's International Institute for Educational Planning)}

Government financing of education is often complemented by inputs from external partners, students and households, and private entities. In fact, the contribution of households, the largest private financier, covers around one-fourth of all education expenditure in the countries studied in this report. As part of the EFA effort, a number of countries have abolished school fees at the primary education level in order to alleviate the financial burden on households, especially among the poor. At the same time, enrolment in private schools has increased in a number of countries, implying that the growing urban middle class is sending a greater number of its children to private schools in the hope that they will receive a better education. Lately, the growth in private financing has led to a greater diversification of government and private sector partnerships. While the motivation and modalities of these partnerships vary, the rise of private sector involvement brings new opportunities to education financing.

\subsection{INTRODUCTION}

In general, governments are the main funders of education systems in every country in the world, but they are not the only source. The financing of education derives from partnerships that are regulated to varying degrees. These partnerships are often complex and related to the particular history of each country. Government funding is also complemented by inputs from external partners, users and beneficiaries of school systems (students and their families), private entities such as non-governmental organizations (NGOs), associations, religious institutions, communities and private companies. Private financing can complement government funding in public education institutions. Private funders can also finance private schools that are created and managed by private operators.

From a statistical point of view, characteristics of nongovernmental funders are scarcely known, since the most widely used statistical indicators are often limited to public financing of education. Therefore, it is currently impossible to provide a complete description of private expenditure on education in SSA countries. Furthermore, this is not limited to Africa, and it is only in recent years that the Organisation for
Economic Co-operation and Development (OECD) has been in a position to provide such indicators for developed countries. While it is not possible to provide a complete picture of private expenditure on education in Africa, this chapter will try to give an overview based on particular cases and various studies conducted on the topic. ${ }^{56}$

First, the chapter will examine the current funding mechanisms of education in some African countries, illustrating the role of parents' associations. Second, it will focus on household inputs which, after the government, are the principal source of funds for education systems in Africa. The current issue of free education and the abolition of tuition fees will be covered in the third part of this chapter. The particular topic of private schools will then be discussed in the fourth part. Although private schools can make useful contributions to national efforts in education, their development may also reveal the poor state of public schools. Other forms of public-private partnerships will be covered in the last part of this chapter.

\subsection{PRIVATE COMMITMENTS TO EDUCATIONAL DEVELOPMENT}

Funds that originate from private sources can take on a variety of forms depending on the types of financiers, the level of education, the status of the institution receiving the funds, and the nature of expenditure. It is a productive exercise, therefore, to situate private financing within the framework of funding mechanisms of various types of educational institutions.

Little research is available to produce a comprehensive overview of the financing and costs associated with education systems that includes public, private and external funding, for all public or private institutions at all levels of education. Only all-inclusive studies would provide the means to sketch the proportion of the total amount spent on education that is covered by private expenditure. Figure $\mathbf{3 4}$ shows the distribution of funding by source in two African countries, where funds from households and private organizations accounted for $25 \%$ to $35 \%$ of all expenditure on education.

\footnotetext{
56 The data provided come mainly from the UNESCO Institute for Statistics (UIS), the Pôle de Dakar (UNESCO/BREDA) and UNESCO's International Institute for Educational Planning (IIEP).
} 


\section{SOURCES OF EDUCATION FINANCING IN MADAGASCAR AND BENIN FOR ALL LEVELS OF EDUCATION}

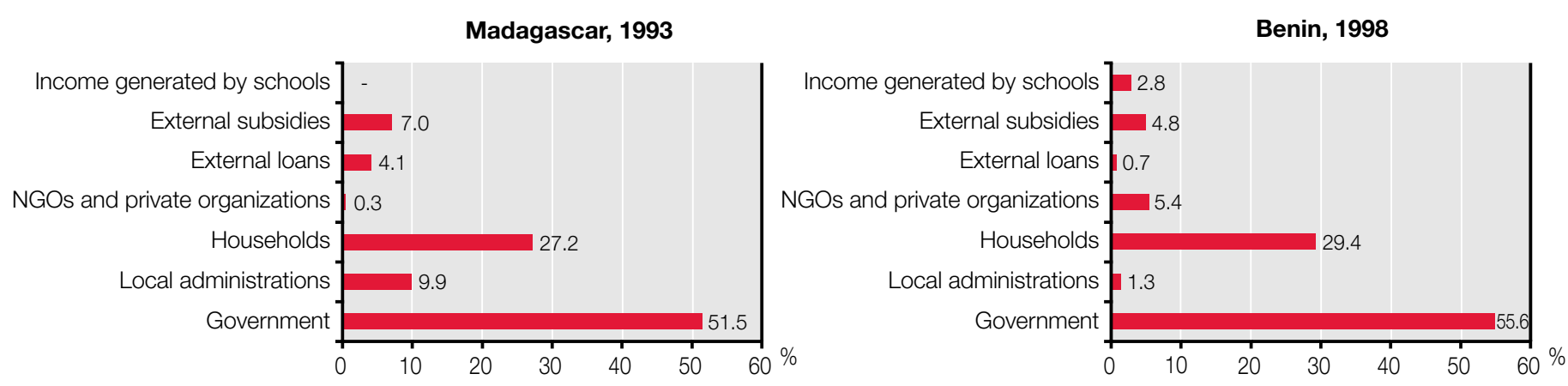

Source: UNESCO-IIEP.

The largest proportion of private funding came from households - students, families, individuals and community inputs. This proportion from families comprises: registration or tuition fees for public institutions; dues or contributions to parents' associations; tuition fees for private institutions; and direct spending on textbooks, school supplies and uniforms associated with attending school. The proportion of financing from households was higher in countries with more private schools and where private schools do not receive state funding. Family expenditure on education is described in more detail in Section 4.3.

This situation has been corroborated by a number of studies on household expenditure conducted by the Pôle de Dakar (UNESCO/BREDA) comparing private expenditure (based on household surveys) with public expenditure on education.

There is much diversity in this regard. In the years 2001 to 2008 , household expenditure on education in a majority of African countries comprised between one-quarter and one-third of what the government spent on education. As shown in Table 6, extreme situations have been observed in Rwanda and Zambia, where household expenditure on education is very low, and in Benin, Burkina Faso, Chad, Côte d'Ivoire, Gabon, Madagascar and Sierra Leone, where they accounted for more than one-third of all education expenditure (private and public).

The proportion of household spending in total education expenditure also varies across levels of education. As presented in Figure 35, the proportion of household contributions in the total education expenditure in SSA is on average $29.2 \%$ at the primary education level. This means that the household contribution is still significant, despite an ongoing trend of school fee abolition in primary education (see Section 4.4). The household contribution rises to $49 \%$ and $44 \%$ respectively for lower and upper secondary education. On the other hand, the household contribution goes down to $22 \%$ at tertiary level.
The high unit cost at the tertiary education level, as discussed in Chapter 2, means high public subsidies to tertiary students. This is an important point when equity of public resource allocation is a concern.

NGOs and private organizations - including religious institutions, national or international NGOs, and various associations may also make substantial contributions to the development of education in SSA. Financing by religious organizations is most often related to the establishment and management of schools. Their contribution to the financing of schools is often low. NGOs tend to work in local development and bring funding or resources in kind (construction materials, equipment, etc.) to the schools they support. National NGOs are often funded by their international counterparts, which themselves receive funds from public or private donors. They may also serve as intermediaries in distributing funds from development agencies. In some countries, NGOs provide significant funding. In Benin, for example, they account for $5 \%$ of education expenditure.

The most in-depth surveys on education spending provide information on income which is generated by schools themselves. This may stem from selling articles made in vocational and technical schools, or other income-producing activities of a commercial nature, such as renting rooms or halls. In Benin, parents' associations receive the fees for business permits sold to vendors who sell food within the schools.

Inputs from parents and private organizations vary according to the public or private nature of the institution and education level. In private institutions that do not receive funding from the government, tuition fees paid by students and their families constitute the main, indeed the only, source of income for these schools. Therefore, households cover the entire cost of education. These institutions sometimes receive funds from religious organizations, donations or NGOs. This model of 
HOUSEHOLD AND GOVERNMENT EXPENDITURE ON EDUCATION AS A PERCENTAGE OF GDP AND HOUSEHOLD EXPENDITURE AS A PROPORTION OF ALL EXPENDITURE ON EDUCATION, MOST RECENT YEAR

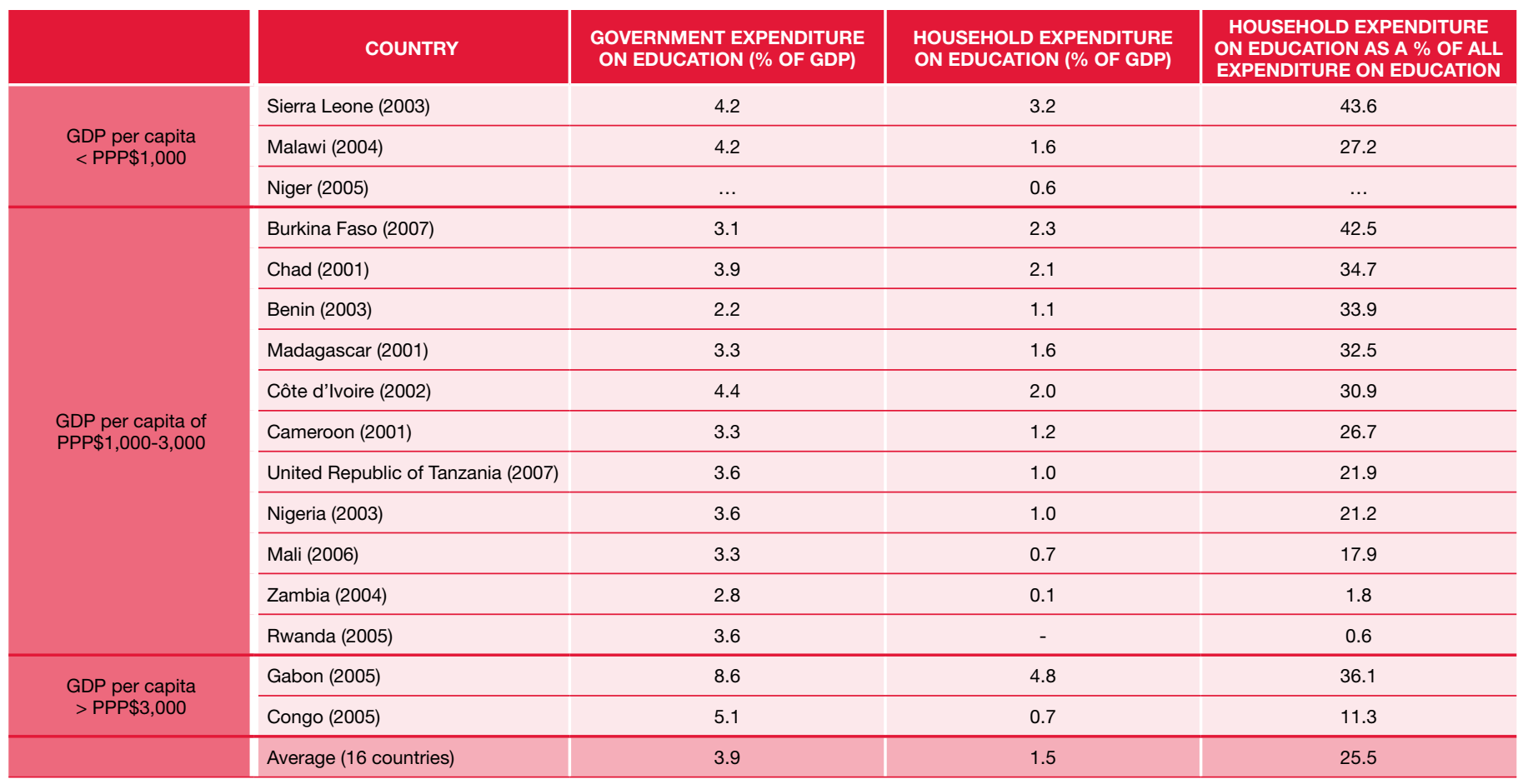

Note: Countries are listed in descending order of household expenditure as a percentage of all expenditure on education.

Source: Pôle de Dakar (UNESCO-BREDA) database.

\section{Figure 35}

\section{PROPORTION OF HOUSEHOLD CONTRIBUTIONS TO EDUCATION EXPENDITURE BY LEVEL, 2001-2006}

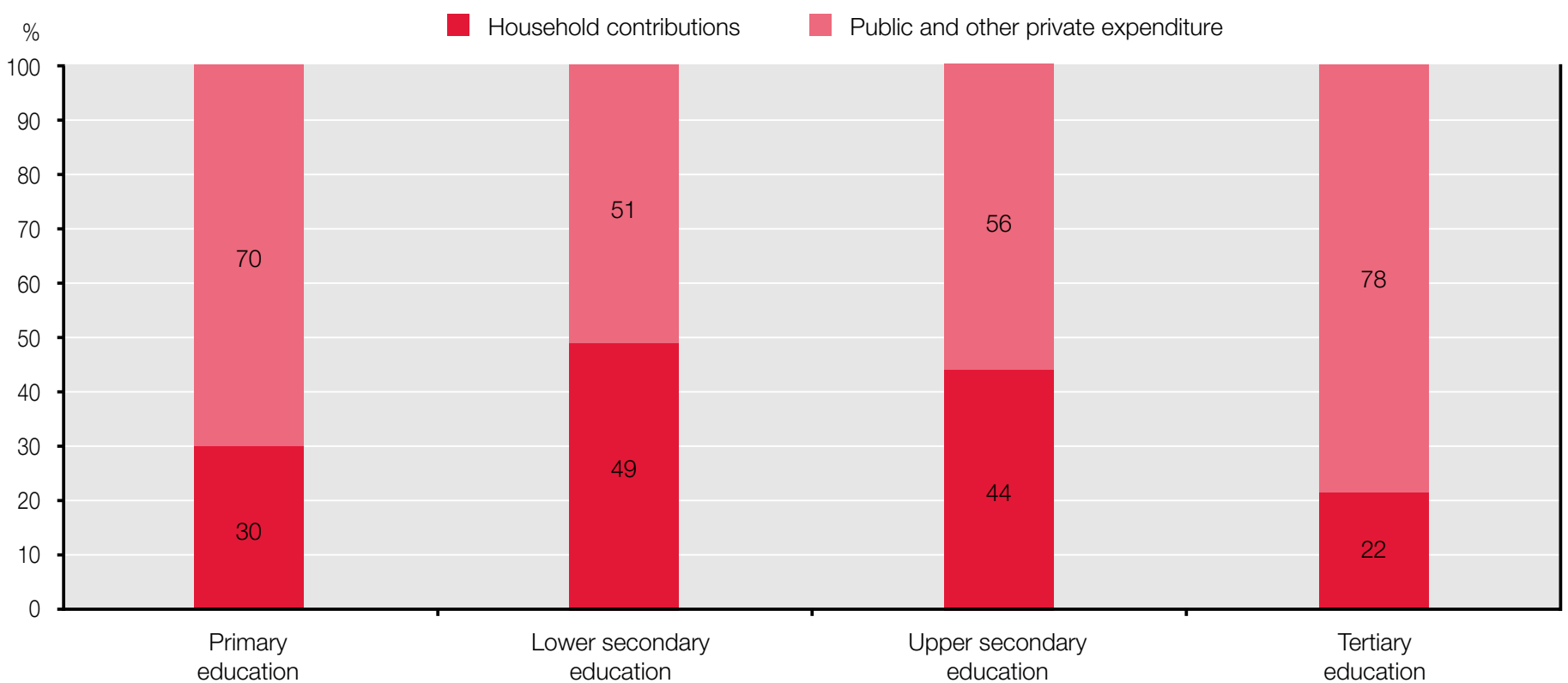

Note: The indicator is calculated based on a simple average of 16 sub-Saharan African countries. Source: Pôle de Dakar (UNESCO-BREDA) database. 
private schools financed quasi-exclusively by parents exists in numerous African countries.

Some private schools receive assistance or subsidies from the government, which can take a variety of forms - civil service teachers paid by the government and assigned to private schools (Chad), reimbursement for part of teacher salaries (Catholic schools in Mali that have a contract with the government), or operating grants (private schools in Cameroon). This assistance or financial support helps reduce the costs of schooling for families.

In general, public primary schools have very little financial autonomy. They are provided with either teachers or goods and services in kind. Financial management in a primary school is often limited to local resources, with parents' associations playing an important role as the local manager of the school and sometimes acting as the employer of teachers recruited locally. This role is perhaps changing in light of policies abolishing tuition fees; in a number of countries, public funds are now directly transferred to schools. The examples of Ghana (see

Figure 36) and Benin (see Figure 37) show both the similarities in cost-sharing between public administrations and parents, and the differences proper to each country.

The example of Ghana illustrates the complexity of the financing mechanisms applied to a public primary school:
- The highest level of funding comes from the central government, but from a diversity of sources in the budget. Teacher salaries come from the Ghana Education Services budget, which also covers operating expenses. Capital investments and equipment expenditure are paid by the Ghana Education Trust Fund or the Social Investment Fund. Utilities, such as water, electricity and telephone, are paid directly by the Ministry of Finance. The Ministry of Manpower, Youth and Employment is responsible for support personnel.

- District assemblies are the local public administrations. They provide for equipment in schools, canteen programmes and bursaries given to families.

- External partners are involved through the national public administration or district assemblies, which act as intermediaries.

- Up to 2004, parents paid dues to their local Parents of Students Association, which managed the everyday affairs of the school. Since 2005, these dues have been replaced by a subsidy per student from the government. Families continue to pay for uniforms, textbooks and school supplies.

- NGOs may provide direct funding but most often their support is "in kind".

\section{Figure 36}

\section{SOURCE AND FLOWS OF FUNDING FOR A PRIMARY SCHOOL IN GHANA}

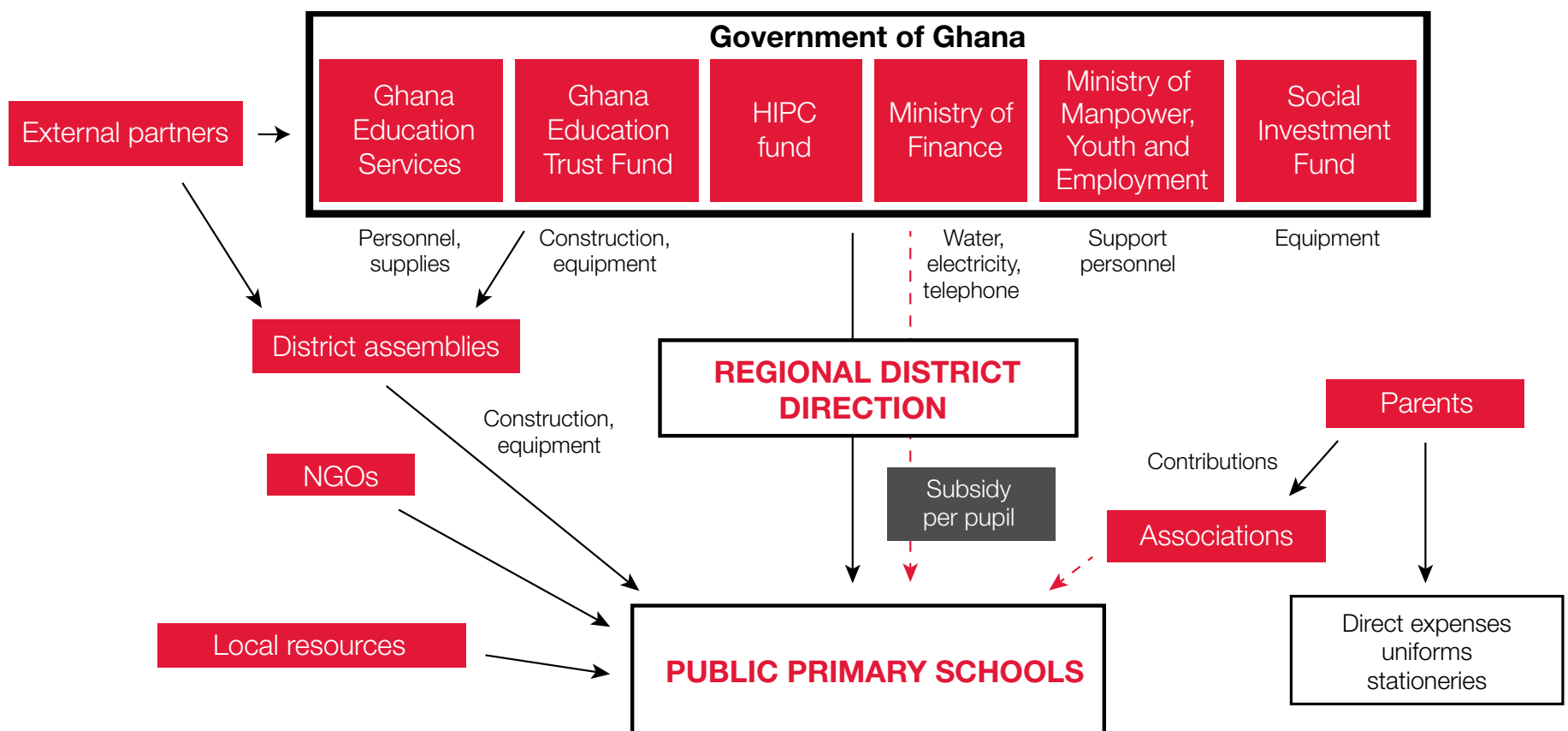

Source: UNESCO-IIEP 
The only funds managed by the school are those from the subsidy per student received from the government, contributions from parents and those generated locally.

The example of Benin illustrates similarities in the financing mechanisms of a public primary school:

- The largest sums come from the Ministry of Pre-primary and Primary Education. They cover the salaries of personnel, operations and capital investment. Before 2005, there was no financial transfer of funds to schools by the government.

- Communes are administrative geographic areas in the country, below departments. They receive an allocation from the government and cover certain operational and capital costs of schools. They can also provide their own additional funding.

- External partners use these communes as intermediaries.

- Up to 2005, parents paid dues to their local parents' association, which was responsible for the everyday management of the school. The association hired and paid local contract teachers. With the implementation of tuition-free education in the beginning of the school year in 2006, the income from these dues was replaced by two new sources from the national government a subsidy by class (for school fees) to pay for the recurrent operational expenses of the school and payment of the salaries of local contract teachers, who remained employees of the parents' association. The current plan is to progressively integrate local contract teachers into the body of teachers under contract with the government. Families continue to pay directly for uniforms, textbooks and school supplies.

- NGOs may provide direct funding but most often their support is "in kind".

The only financial resources that schools manage by themselves are the government subsidies for school fees and funds raised locally. This comprised all funds contributed by parents until 2005.

Public institutions in secondary or higher education generally benefit from greater financial autonomy. Funds that are raised from families or other local sources are recorded in school accounts with the subsidies from the government. Parents' contributions come in the form of registration fees, tuition fees and funds for specific services (photocopying, laboratories, etc.). This financial autonomy is not always complete, since the majority of personnel are most commonly paid directly by the government.

Where there is greater financial autonomy, as is sometimes seen in universities, the government gives an operating subsidy to cover all expenses, on occasion including those of personnel. Further to the income they receive from the government, these autonomous institutions add revenues from their own sources, such as student fees.

\section{Figure 37}

\section{SOURCE AND FLOWS OF FUNDING FOR A PRIMARY SCHOOL IN BENIN}

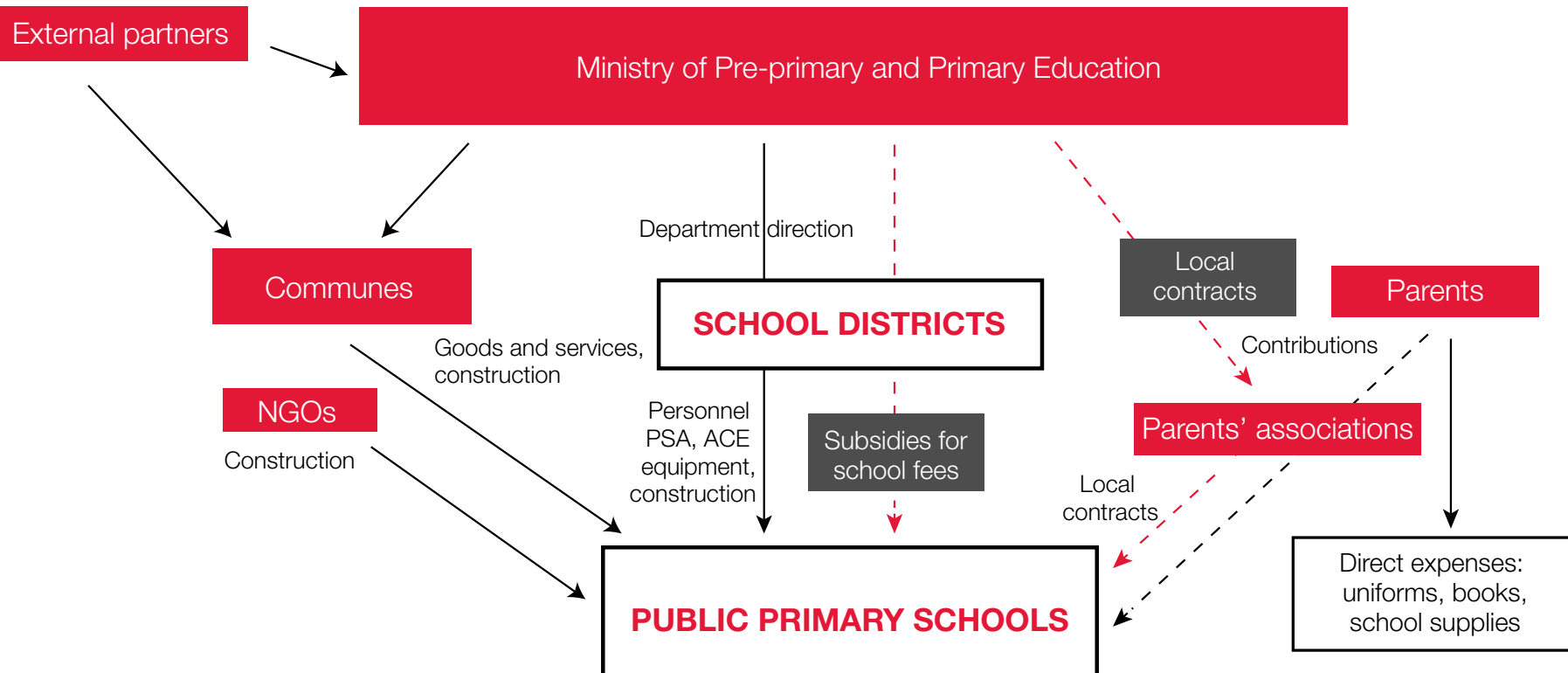

Source: UNESCO-IIEP 


\subsection{HOUSEHOLD EXPENDITURE ON EDUCATION}

Before presenting some results of studies on household expenditure on education in SSA, it should be indicated that these are difficult to discern both for conceptual and practical factors associated with data collection.

In terms of a conceptual approach, the difficulty is to define the precise limits of what can be considered household spending on education. Although payments to schools can be clearly considered as expenditure on education, other types of expenditure may be more difficult to categorise. Table $\mathbf{7}$ is based on the application of current statistical classifications. It presents a classification of types of expenditure, distinguishing those for education from others related to attending school. Any payment made to an educational institution and any expenditure made at the request of an educational institution or required for enrolment are considered to be an expenditure on education. However, expenditure of a complementary nature is not considered as spending on education. This definition originates from the operational perspective of educational institutions.
In terms of data collection, family expenditure can be ascertained from sources such as line items in the accounts of public or private educational institutions that show income from households or surveys based on samples of households. Household surveys can provide information on a wider range of expenditure and are a virtual necessity in terms of assessing the direct spending of families on education. The difficulty with household surveys is that information on spending is based on what is reported from memory and a varying understanding of what is included in the definition of expenditure on education.

The Pôle de Dakar (UNESCO/BREDA) has processed responses to household surveys in 16 SSA countries, which provides a slightly more precise overview of expenditure on education. Two types of analysis were conducted: educationrelated spending on all household children in school that could be linked to household income and characteristics; and education-related spending per child and thus per education level.

\section{Table 7}

\section{CONCEPTUAL FRAMEWORK FOR CLASSIFYING HOUSEHOLD EDUCATION EXPENDITURE}
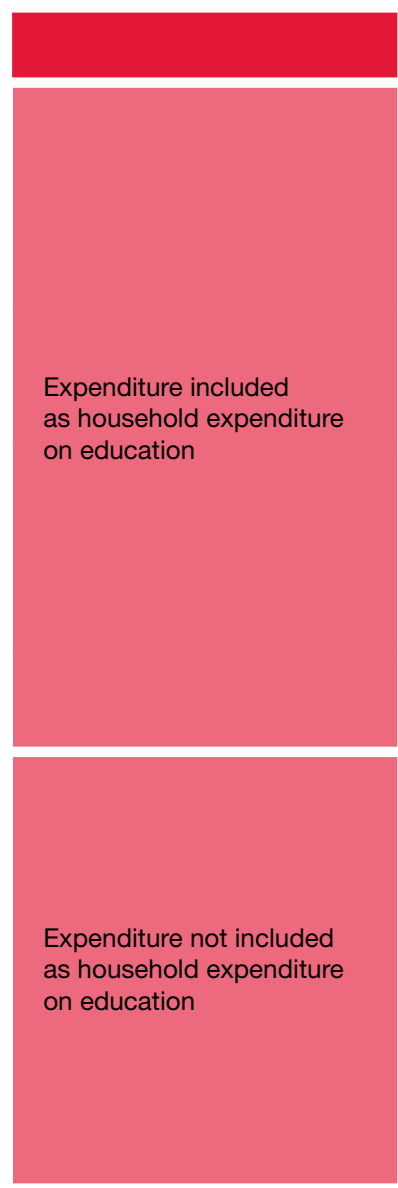

Payments to public and private educational institutions

\section{CHARACTERISTICS OF EXPENDITURE}

TYPES OF EXPENSES

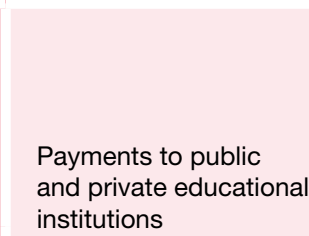

Expenditure on educational activities

Purchases required to attend an educational institution

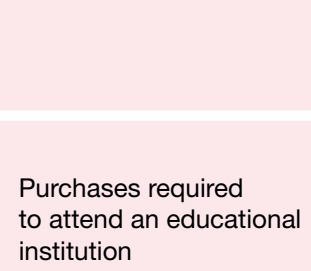

Purchases of services complementary to education

Direct expenditure related to attending school

\section{Expenditure on ancillary services}

Direct expenditure related
to attending school

Additional expenditure related to attending school
Registration fees or any school or tuition fees in public or private schools

- Fees, dues and contributions to schools or parents' associations, compulsory or not

- Examination fees

- For boarding schools, university residences

- For canteens and cafeterias

- For transportation to and from school

- Uniforms

- Textbooks

- School supplies

- Sports clothing

- Transportation to school requiring payment

- Tutoring

- Special classes

Expenses:

- Lodging away from the family home

- Meals outside of school

- Transportation (other than that requiring payment)

- Engaging in a sport

\section{Purchases:}

- Educational books other than those

required by educational institutions

- Educational games

- Bicycle, means of transportation

- Computer 
Overall, in the years between 2001 and 2008, the average household spending on education as a proportion of all household expenditure was 4.4\% This proportion, however, can vary considerably from country to country, ranging from 1.2\% in Chad to $15.3 \%$ in Benin (see Table 8). In some countries, the figures may apply to a time before tuition-free education was introduced.

Differences by income level also show how situations can vary by country. The proportion of spending on education was not systematically higher for the top $20 \%$ of households in terms of wealth compared to the poorest $40 \%$. However, income variations resulted in marked differences in the monetary amounts spent: $4 \%$ of all expenditure for wealthier families represents a much higher actual amount spent on education than $4 \%$ for families with lower income.

Great variation in spending on education among families can also be observed. This is mainly related to the number of children in a household who are in school, the education level of the children and the type of institution (public or private) they attend. Country averages, even for the most homogeneous groups, hide marked differences. A household survey conducted by the IIEP on 79 households with children in primary school in Burkina Faso shows the average household spending on education was CFA 6,114 (approximately US\$13). However, only one-quarter of the families surpassed this average. In fact, all families do not "consume" education in the same way, and differences can be observed in the type of expenditure by household income.

\section{Spending by high- and low-income families}

Families with the lowest income spend more on materials and school supplies - nearly $50 \%$ of all their expenditure on education - and less on tuition fees (see Table 9). The education of children in the lowest-income families is often limited to primary school and rarely extends to higher levels of education. Children from these families also tend to attend public or community schools where tuition, registration and parents' association fees are lower. Therefore, education expenditure among poor families is mainly on unavoidable items such as materials associated with attending school and school supplies.

The wealthiest families spend more on tuition fees, most likely because they have children enrolled in secondary or higher education, and they tend to send their children to private schools. These families also spend more on items other than tuition and school supplies, such as tutoring or special classes.

\section{Table 8}

\section{PROPORTION OF HOUSEHOLD EXPENDITURE DEVOTED TO EDUCATION BY INCOME QUINTILE, MOST RECENT YEAR}

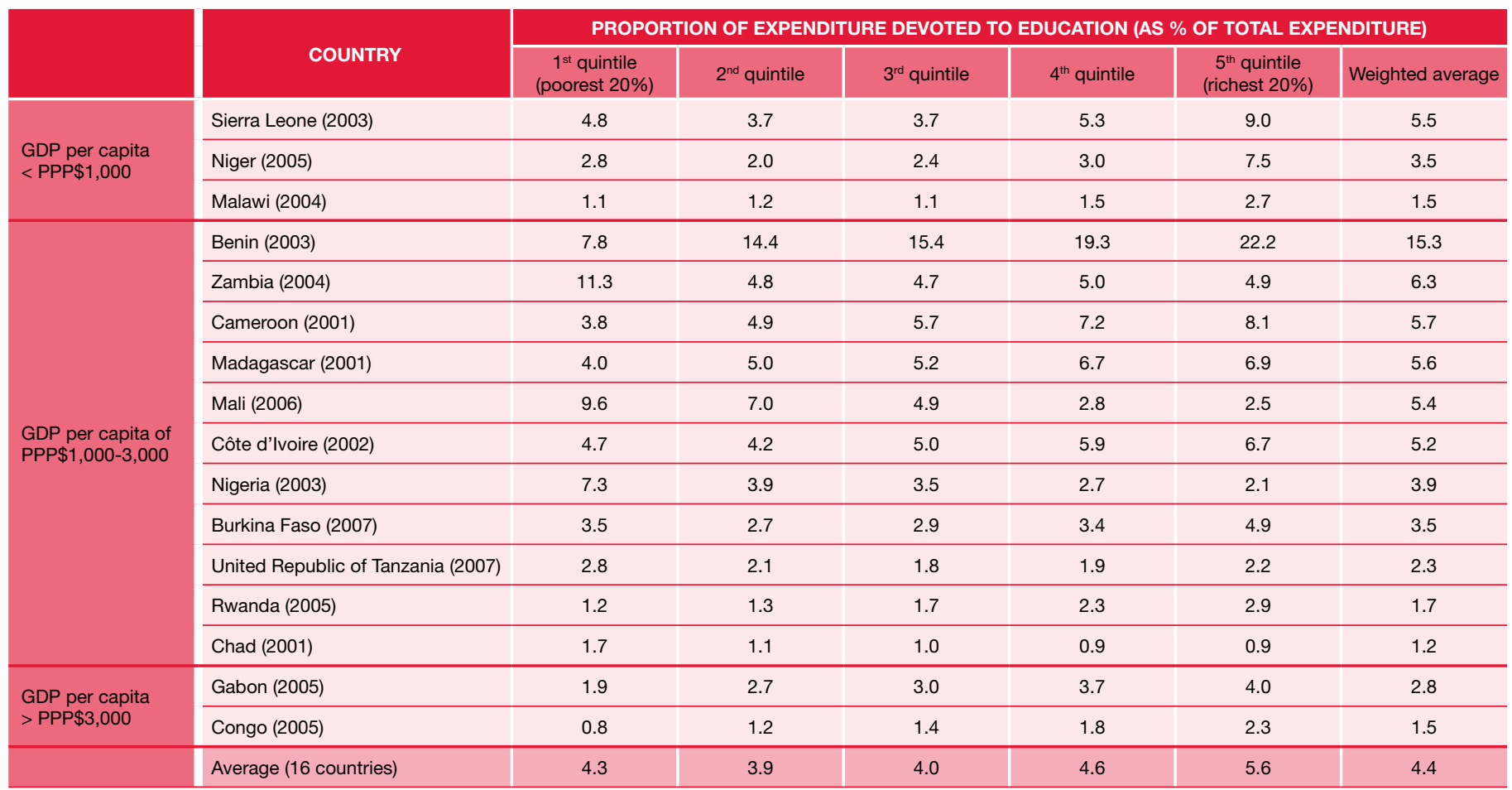

Note: Countries are listed in descending order of weighted average of household expenditure as a percentage of all expenditure on education. Source: Pôle de Dakar (UNESCO-BREDA) database. 
Table 9

\section{DISTRIBUTION OF HOUSEHOLD EXPENDITURE ON EDUCATION BY INCOME LEVEL, MOST RECENT YEAR}

\begin{tabular}{|c|c|c|c|c|c|c|c|c|c|}
\hline \multirow{3}{*}{ COUNTRY } & \multicolumn{9}{|c|}{ HOUSEHOLD EXPENDITURE ON EDUCATION BY TYPE OF EXPENDITURE (\%) AND INCOME QUINTILE } \\
\hline & \multicolumn{3}{|c|}{ Tuition fees } & \multicolumn{3}{|c|}{ Learning materials and school supplies } & \multicolumn{3}{|c|}{ Other expenditure } \\
\hline & Poorest 40\% & Middle $40 \%$ & Richest 20\% & Poorest $40 \%$ & Middle $40 \%$ & Richest 20\% & Poorest $40 \%$ & Middle $40 \%$ & Richest $20 \%$ \\
\hline Burkina Faso (2007) & 55 & 61 & 64 & 42 & 34 & 23 & 2 & 5 & 13 \\
\hline Côte d'Ivoire (2002) & 16 & 20 & 43 & 78 & 65 & 29 & 6 & 15 & 28 \\
\hline Madagascar (2001) & 42 & 33 & 40 & 54 & 56 & 27 & 4 & 11 & 33 \\
\hline Malawi (2004) & 5 & 8 & 9 & 49 & 37 & 34 & 47 & 56 & 57 \\
\hline Mauritania (2008) & 46 & 49 & 64 & 43 & 34 & 27 & 11 & 17 & 10 \\
\hline Niger (2005) & 12 & 22 & 58 & 72 & 60 & 31 & 15 & 18 & 11 \\
\hline Rwanda (2005) & 53 & 48 & 58 & 26 & 31 & 19 & 21 & 21 & 23 \\
\hline Sierra Leone (2003) & 20 & 18 & 17 & 52 & 41 & 30 & 28 & 42 & 53 \\
\hline Tanzania (2007) & 77 & 71 & 74 & 22 & 25 & 23 & 1 & 3 & 3 \\
\hline Average (9 countries) & 36 & 37 & 48 & 49 & 43 & 27 & 15 & 21 & 26 \\
\hline
\end{tabular}

Source: Pôle de Dakar (UNESCO-BREDA), data processed from various household surveys.

\section{Table 10}

AVERAGE HOUSEHOLD EXPENDITURE ON EDUCATION (IN LCU) PER CHILD IN GHANA, 2007

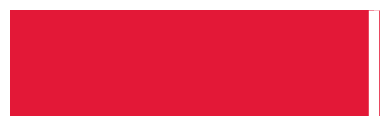

TUITION FEES FOR
SCHOOL OR DUES
FOR PARENTS'
ASSOCIATION

\begin{tabular}{c|c}
$\begin{array}{c}\text { ROOM AND } \\
\text { BOARD }\end{array}$ & $\begin{array}{c}\text { TEXTBOOKS } \\
\text { AND SCHOOL } \\
\text { SUPPLIES }\end{array}$
\end{tabular}

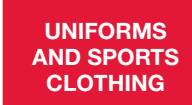
TRANSPORTATION
TO AND FROM SCHOOL

\begin{tabular}{|c|c|c|c|c|c|c|c|}
\hline & $\begin{array}{l}\text { TUITION FEES FOR } \\
\text { SCHOOL OR DUES } \\
\text { FOR PARENTS' } \\
\text { ASSOCIATION }\end{array}$ & $\begin{array}{l}\text { ROOM AND } \\
\text { BOARD }\end{array}$ & $\begin{array}{l}\text { TEXTBOOKS } \\
\text { AND SCHOOL } \\
\text { SUPPLIES }\end{array}$ & $\begin{array}{l}\text { UNIFORMS } \\
\text { AND SPORTS } \\
\text { CLOTHING }\end{array}$ & $\begin{array}{l}\text { TRANSPORTATION } \\
\text { TO AND FROM } \\
\text { SCHOOL }\end{array}$ & $\begin{array}{l}\text { TUTORING, } \\
\text { SPECIAL } \\
\text { CLASSES }\end{array}$ & TOTAL \\
\hline Pre-primary & $3.6^{*}$ & 24.9 & 1.1 & 3.7 & 1.0 & 0.8 & 35.1 \\
\hline Primary & $4.1^{*}$ & 28.3 & 4.2 & 5.3 & 1.2 & 2.4 & 45.5 \\
\hline Secondary $-1^{\text {st }}$ cycle & $10.5^{*}$ & 45.0 & 9.5 & 7.4 & 4.4 & 8.8 & 85.6 \\
\hline Secondary $-2^{\text {nd }}$ cycle & 128.4 & 104.8 & 37.4 & 12.8 & 27.6 & 27.2 & 338.2 \\
\hline Vocational/technical & 85.6 & 93.7 & 23.7 & 11.3 & 15.5 & 10.5 & 240.3 \\
\hline Teacher training & 133.5 & 95.3 & 57.0 & 15.7 & 14.7 & 6.7 & 322.8 \\
\hline University & 433.1 & 334.3 & 159.7 & 7.1 & 71.8 & 5.4 & $1,011.4$ \\
\hline $\begin{array}{l}\text { Post-secondary } \\
\text { technical education }\end{array}$ & 196.6 & 218.6 & 129.4 & 7.8 & 44.2 & 22.8 & 619.4 \\
\hline Pre-primary & 48.3 & 54.5 & 5.5 & 8.7 & 15.4 & 4.0 & 136.4 \\
\hline Primary & 63.1 & 66.6 & 16.0 & 10.7 & 16.3 & 16.2 & 188.8 \\
\hline Secondary - $1^{\text {st }}$ cycle & 94.6 & 86.1 & 26.8 & 12.6 & 19.0 & 29.5 & 268.5 \\
\hline Secondary $-2^{\text {nd }}$ cycle & 238.8 & 105.2 & 41.0 & 14.8 & 25.1 & 23.9 & 448.7 \\
\hline Vocational/technical & 211.6 & 100.4 & 68.6 & 11.7 & 57.2 & 1.7 & 451.1 \\
\hline Higher education & 605.7 & 411.1 & 194.1 & 8.1 & 138.7 & 0.0 & $1,357.8$ \\
\hline
\end{tabular}

Notes: The estimates do not take into account the effects of the abolition of tuition fees in the beginning of the school year in 2006 . Tuition fees abolished in 2006 are indicated by *. Levels of education are not based on ISCED. Estimates for 2007 are based on data from the Ghana Living Standard Survey 5 (2004-2005).

Source: UNESCO-IIEP, based on data from the Ghana Living Standard Survey, Ghana Statistics. 


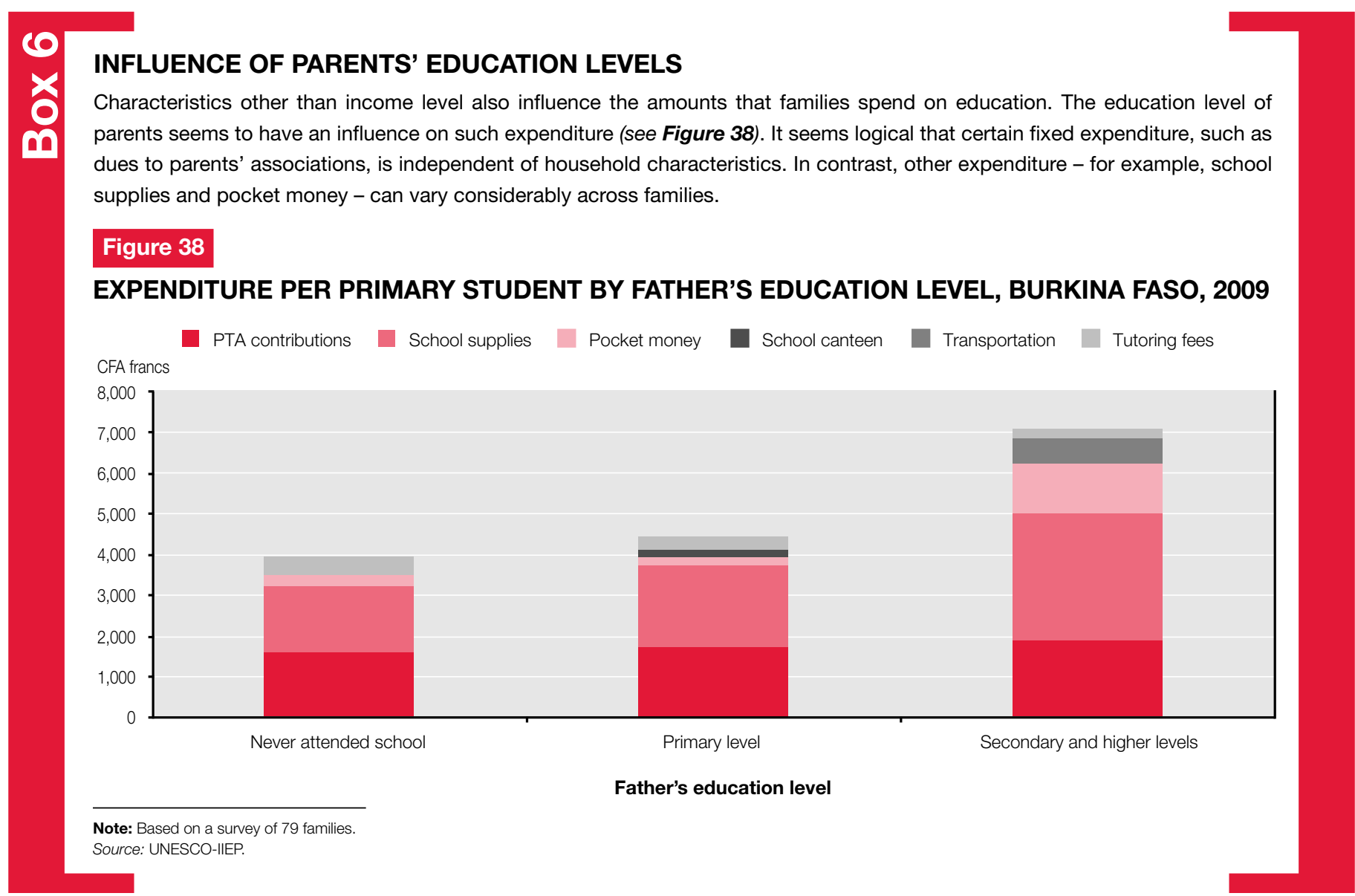

\section{Factors affecting household expenditure}

Certain household surveys conducted by government statistical organizations show household spending on education per child, as well as per education level and category of institution. A notable example is the Ghana Living Standard Survey 5, conducted in 2004-2005. Estimates from this survey were based on 12,000 children in school, of which 2,800 were in private school (see Table 10). The sample size provides good quality statistics.

Average household spending per student increased with the education level for almost all types of expenditure. From an average household expenditure per child of 45 Ghana Cedis $(\mathrm{GHC})^{57}$ for public primary school, the expenditure almost doubled for the first cycle of secondary school, then rose to 7 times the primary cost in the second cycle of secondary school, and was 20 times greater for higher education (than for primary education). The increase was mainly due to tuition fees but also to increased expenditure required for higher levels of education.

Families with children in private schools were obviously paying higher tuition fees, particularly for higher levels of education. But families who chose a private school also spent more on other items. In all, it was estimated that families who had a child attending private school in Ghana in 2007 were spending more on education, namely from GHC 100 to 300 more.

This trend of higher household spending according to higher levels of education and for private schooling appears to hold true when based on household spending per child. However, the picture changes when the data are examined from the perspective of the aggregate of all households.

It is estimated that in Ghana in 2007 there were more children in primary schools or public schools, and this resulted in some re-shifting in spending by education level and type of school.

Table 11 presents essentially the same situation as Table 10 but shows that household spending for children in public school was twice that for children in private school, or that spending on primary school - public or private - was nearly one-third of total household spending on education.

These data also show the relative impact of abolishing tuition fees for public education (numbers with asterisks). In the context of free public education, expenditure on public education comprises only a small amount of total household spending on education.

\footnotetext{
57 The currency for Ghana: US $\$ 1.00=$ GHC 0.936 in 2007.
} 


\subsection{ABOLISHING TUITION FEES FOR PRIMARY SCHOOLS}

Expenditure on education can be a heavy burden for families with little money. In a study conducted by the IIEP on the cost of education for households in Burkina Faso, 48 out of 79 parents reported that it was difficult or very difficult to pay school fees.

The cost of school attendance can lead some families to decide not to send all or some of their children to school. This is the primary reason reported by families to explain why their children are not enrolled in school, the second reason being the absence of a school located near them. A strong reaction to tuition fees on the part of families has been observed in a number of SSA countries. The introduction of tuition fees in the 1990s was followed by a period of stagnation in terms of education indicators, whereas eliminating these fees has led to an immediate increase in school enrolment. For example, after progressively instituting tuition-free education, the United Republic of Tanzania saw an increase of 26 percentage points in its net enrolment rate in the five years between 2002 and 2006. Significant impacts on enrolment have also been observed in Ethiopia, Malawi, Mozambique and most countries that have introduced tuition-free schooling.
Reducing expenses related to schooling can, therefore, be a catalyst for action on public policy to increase school attendance among children from families with the least financial resources. From the perspective of UPE, tuition and other school fees requested directly from families are now considered to cause a brake on enrolment and present a financial barrier to children's schooling. Education for all children means also educating children of the poorest families for whom the issue of fees constitutes an important factor in their decisionmaking.

To facilitate and allow for the schooling of all children, many SSA countries have already adopted policies of tuition-free education. Governments have assumed responsibility for the operational expenses of schools, replacing the income of schools previously derived from payments made by parents or parents' associations. These policies have been encouraged by development partners. In 2005, the World Bank, jointly with UNICEF, launched the School Fee Abolition Initiative (SFAl).

Public authorities also need to determine which fees they would like to reduce or abolish. The key abolition measure should certainly address fees paid by families to schools,

\section{Table 11}

\section{AGGREGATED EXPENDITURE ON EDUCATION BY HOUSEHOLDS (IN THOUSANDS LCU) IN GHANA, 2007}

\begin{tabular}{|c|c|c|c|c|c|c|c|c|}
\hline & & $\begin{array}{l}\text { TUITION FEES FOR } \\
\text { SCHOOL OR DUES } \\
\text { FOR PARENTS' } \\
\text { ASSOCIATION }\end{array}$ & $\begin{array}{c}\text { ROOM AND } \\
\text { BOARD }\end{array}$ & $\begin{array}{l}\text { TEXTBOOKS } \\
\text { AND SCHOOL } \\
\text { SUPPLIES }\end{array}$ & $\begin{array}{l}\text { UNIFORMS } \\
\text { AND SPORTS } \\
\text { CLOTHING }\end{array}$ & $\begin{array}{c}\text { TRANSPORTATION } \\
\text { TO AND FROM } \\
\text { SCHOOL }\end{array}$ & $\begin{array}{l}\text { TUTORING, } \\
\text { SPECIAL } \\
\text { CLASSES }\end{array}$ & TOTAL \\
\hline \multirow{10}{*}{$\begin{array}{l}\text { Public } \\
\text { school }\end{array}$} & Pre-primary & 3,520 * & 24,449 & 1,105 & 3,620 & 957 & 815 & 34,466 \\
\hline & Primary & 11,872 * & 81,354 & 12,028 & 15,326 & 3,471 & 6,854 & 130,905 \\
\hline & Secondary - $1^{\text {st }}$ cycle & 10,177 * & 43,776 & 9,266 & 7,195 & 4,297 & 8,585 & 83,296 \\
\hline & Secondary $-2^{\text {nd }}$ cycle & 49,059 & 40,052 & 14,272 & 4,886 & 10,540 & 10,404 & 129,213 \\
\hline & Vocational/technical & 1,565 & 1,714 & 434 & 206 & 283 & 192 & 4,394 \\
\hline & Teacher training & 3,495 & 2,496 & 1,493 & 410 & 384 & 174 & 8,452 \\
\hline & University & 39,099 & 30,182 & 14,422 & 643 & 6,482 & 488 & 91,316 \\
\hline & Higher technical & 5,660 & 6,295 & 3,726 & 226 & 1,273 & 657 & 17,837 \\
\hline & Other higher education & 3,027 & 612 & 612 & 470 & 213 & 62 & 4,996 \\
\hline & Sub-total public & 127,474 & 230,930 & 57,358 & 32,982 & 27,900 & 28,231 & 504,875 \\
\hline \multirow{8}{*}{$\begin{array}{l}\text { Private } \\
\text { school }\end{array}$} & Pre-primary & 15,846 & 17,882 & 1,798 & 2,867 & 5,040 & 1,323 & 44,756 \\
\hline & Primary & 35,917 & 37,892 & 9,089 & 6,089 & 9,273 & 9,199 & 107,459 \\
\hline & Secondary - $1^{\text {st }}$ cycle & 17,932 & 16,333 & 5,079 & 2,388 & 3,595 & 5,584 & 50,911 \\
\hline & Secondary $-2^{\text {nd }}$ cycle & 9,606 & 4,231 & 1,649 & 593 & 1,007 & 961 & 18,047 \\
\hline & Vocational/technical & 1,223 & 580 & 396 & 68 & 331 & 10 & 2,608 \\
\hline & Higher & 10,504 & 7,129 & 3,366 & 141 & 2,406 & 0 & 23,546 \\
\hline & Sub-total private & 91,028 & 84,047 & 21,377 & 12,146 & 21,652 & 17,077 & 247,327 \\
\hline & Total & 218,502 & 314,977 & 78,735 & 45,128 & 49,552 & 45,308 & 752,202 \\
\hline
\end{tabular}

Notes: The estimates do not take into account the effects of the abolition of tuition fees in the beginning of the school year in 2006 . Tuition fees abolished in 2006 are indicated by *. Levels of education are not based on ISCED. Estimates for 2007 are based on data from the Ghana Living Standard Survey 5 (2004-2005).

Source: UNESCO-IIEP, based on data from the Ghana Living Standard Survey, Ghana Statistics. 
parents' associations or school management committees. This parental expenditure, meant to cover the material costs of operating a school and sometimes paying for teacher salaries, is in reality registration fees. In most African countries, the first measures being taken are those designed to eliminate these fees. But other measures are also being taken to supply textbooks, subsidise meals in school or provide direct assistance to families.

Policies of reducing tuition fees for families should also determine whether these should take into account all families, those who are the poorest, those living in certain geographic areas generally judged to be disadvantaged, or those living in areas where enrolment is lower than the national average. It can be observed that the policies implemented in recent years have focused on the elimination of public school fees and the provision of free textbooks for all children. Policies related to school meals often target specific geographic areas.

Tuition-free measures can be immediately implemented for all primary schools or introduced gradually beginning in Grade 1. Malawi and Uganda, which were among the first African countries to commit to such policies, opted to abolish school fees immediately and simultaneously for all grades in primary school. Other countries, such as Lesotho and the United Republic of Tanzania, decided to progressively introduce tuition-free measures, thereby preventing a sudden increase in school enrolment.

Government expenditure, replacing that of families, often takes the form of a subsidy or grant per student to cover operating expenses, which is managed at the local level by each school. In certain countries, such as Benin, a subsidy is given per class and only covers material expenses. Again in Benin, the government has directly assumed responsibility for local contract teachers, who were previously paid by parents. Contract teachers have been progressively integrated into the government's pool of contract workers. In Chad, the partial responsibility for paying community teachers has been implemented through the intermediary of the Parents' Federation and, therefore, has not altered the employer role played by parents' associations.

There have been problems in setting up financing mechanisms to replace fees that parents were paying before. In particular, there have been significant delays in releasing funds from the public purse on the part of governments. This has pushed schools with empty coffers to ask parents to contribute financially. Management of state funding by school principals can also lead to less community involvement in the running of schools.

\subsection{PRIVATE SCHOOLS}

The issue of private schools in Africa, as in other regions of the world, can be examined from various perspectives. Private schools can contribute to children's education and, therefore, complement the efforts of governments through the public school system. In the context of large populations and limited financial resources in SSA, governments are not in a position to harness sufficient funds to educate all children in favourable conditions. Given this, schooling by private entrepreneurs provides a means of attenuating the pressure on government education budgets and increasing the overall supply of education.

From the point of view of parents, private schools provide an alternative to the public school system. Family decisions on where to send their children to school can be driven by religious reasons, family traditions, discipline, the quality of instruction and sometimes by the language of instruction. Attending a private school most often means increased expenditure in the form of registration and tuition fees. Families opting for a private school, therefore, accept to spend more on their children's education, because it is different or the quality of instruction fulfils their expectations.

Private schools do not comprise a uniform category and often present a variety of educational situations. The four schools briefly described in Box $\mathbf{7}$ provide only a snapshot of the diversity of private schools in Cameroon in terms of their students and families, the motivation for their creation, and their level of financial resources.

In addition to public and private schools, the development of community schools has been observed in a number of countries (e.g. Chad, Mali and Togo). These fulfil a collective need for education that is not guaranteed by the public school system, especially in rural areas. Often established without the knowledge of the government and without any means at hand, these schools recruit teachers from the community with limited, if any, qualifications. Community schools are gradually being recognised by ministries of education. In Togo, a specific statute was created (Écoles d'Initiative Locale) to provide a legal framework for these local initiatives.

Non-public schools show a typology that seems to include a variety of opposites - religious and lay schools, rural and urban schools, schools that are complementary to or in competition with public schools, community or individual-initiative schools, for- or not-for-profit schools, those that target urban middle classes and those that target disadvantaged families, and so on. Other contrasts occur with regard to tuition fees. Some schools demand high tuition fees and benefit from a certain amount of affluence, while others function with very limited 


\section{EXAMPLES OF THE TYPES OF PRIVATE SCHOOLS IN CAMEROON}

Collège Vogt (Catholic secondary school): Established in 1951, this was the first private Catholic secondary school in the country. This large institution (2,050 students), close to downtown Yaoundé, has undergone important renovations under the guidance of church-affiliated expatriates. It recruits students from the middle class, who have a favourable perception of the school. With funding of 80,000 CFA per student for the first cycle and 90,000 CFA for the second cycle, the institution has a total budget of 200 million CFA, which certainly renders it affluent and financially independent. The priests who run the institution manage both the education and financing components, and are open to modernising the facilities and acquiring new technologies. The faculty mainly comprises temporary or substitute teachers, who are paid 1,500 CFA an hour in addition to their regular employment in public primary and secondary schools. This ensures that they have a regular, and indeed comfortable, monthly income.

École franco-arabe de Maroua (Muslim primary school): In a neighbourhood close to the city center, with narrow streets and family businesses, this long-established school dating from the colonial period is located not far from the mosque. Relatively rundown, with four classrooms surrounding a large central square courtyard used for recreation, the school has only 176 students. Most are from the local neighbourhood, coming from "traditionally uneducated", large families with modest means, who do not understand why they have to pay school fees, though these are minimal. Their opinion is that the government should still be in charge of education in the Arabic language. Faced with a deteriorating financial situation, with many months in arrears, we can sense that the principal, feeling a little impoverished, is waiting for a grant from the Ministry. "Parents pay when they can," she says. Contributions from families are irregular and are immediately used to buy chalk or small supplies. Ministry grants are used to pay the teachers, only once a year.

Collège Matamfen (lay secondary school): This is a typical example of an institution run by the firm hand of an individual founder, a veritable boss of a small business, who is as concerned with good management as he is with good education. He would have loved to have been a teacher himself. This school's name means "mother of the father of the chief" and its slogan is "the temple of knowledge," which (in French - "le temple du savoir") is printed on the T-shirts most of the students wear. All of this helps forge a group identity. Located in downtown Yaoundé, the institution opened in 1976 with 500 students and has approximately 1,700 today. This is a sign of its success, along with cramped space due to the need to expand. However, the school can only increase its capacity by adding a new floor to the building. Business-oriented in its first few years, the school progressively shifted to provide education in other, more wide-ranging fields. The technical-business stream has 450 students of rather modest backgrounds, whose studies lead to a vocational diploma (Certificat d'aptitude professionnelle (C.A.P.)) costing 55,000 CFA or to a general baccalaureate (Bac G) costing 70,000 CFA. The majority of the students (who are for the most part girls and children of civil servants) take general first and second cycle secondary education courses. While the initial investment for starting the school was a heavy burden for the founder, establishing it today would be even more difficult because of the current value of the land. The teachers are paid 80,000 CFA monthly over 12 months, slightly less than what they would earn in the public school system. As one teacher says, conscious of the quality of his work: "We have a boss who is ready to yell if work is poorly done. Students in the public system do not benefit from the same rigour". The founder says: "I do not need to advertise - it is the students and parents who do that. They are the judge of what I do". His concern is to be able to award bursaries to the best students so that they do not go to the public system, and also to further establish his institution's reputation.

École PNEU (Parents National Educational Union) (Anglophone community school): Located in a suburb of Yaoundé, this primary school with kindergarten was founded in 1976 by a group of Anglophone parents. The parents, who had come from the northwest region of the country, formed an association. They purchased land and funded the school's construction and its expansion over the years. Indeed, new construction is currently under way. The school receives much support, both from the founding parents' association PNEU and the Parents of Current Students (APE). Much sought after in spite of the existence of Anglophone public schools in Yaoundé, the school has 711 students, 239 in kindergarten and 472 in primary grades. The children mainly come from comparatively wealthy families, though not exclusively. The principal, who is a friend of the chairman of the board of directors and is very well-connected, ensures his school uses motivating and effective teaching methods. The results speak for themselves - the graduation rate is $100 \%$. Parents pay a tuition fee of 80,000 CFA and pay for textbooks and uniforms. The school's 43 teachers are paid approximately 70,000 CFA a month and are employed by PNEU. Though the school does not produce a profit, it has a comfortable existence and even receives a grant of 3 million CFA from the government annually. Somewhat critical of the official primary level programme, the principal trains primary teachers in teaching a subject or conducting a class, and is trying a few experiments, such as having several teachers in the same classroom.

Source: Based on excerpts from R. Djamé (2000). 
financial resources. Finally, there are well-organized and academically successful non-public schools, as well as low-performance non-public schools operating in very poor conditions.

\section{Growing enrolment in private schools}

The proportion of children attending private schools is extremely variable, ranging from a small percentage in Burundi, South Africa and the United Republic of Tanzania, to more than 30\% in Congo, Equatorial Guinea and Mali in 2009 (see Figure 39). In these latter countries, community schools play a particular role in the provision of education.

The number of private schools is on the increase in numerous countries, for both primary and secondary education. In the 25 countries indicated in Figure 39, the proportion of private schools in primary education rose from $9 \%$ to $9.9 \%$ between 2000 and 2008. It appreciably increased in about 10 countries and significantly decreased in 4 (Cameroon, Côte d'Ivoire and Madagascar).

Growth in private schools has also been observed in secondary education. From 2000 to 2008, 7 of the 16 countries in

Figure $\mathbf{4 0}$ experienced an increase in the proportion of children attending private schools for secondary education. In 2008, the proportion was particularly high, surpassing 40\%, in Burkina Faso and Madagascar and 50\% in Liberia and Mauritius.

The growth of private school education can also be interpreted as an indicator that public schools are functioning poorly, as perceived by families, particularly in urban areas. The perception is that public schools are too big and have overloaded classes, poor discipline and a lack of rigour on the part of teachers. This perception leads families with financial means, namely those in the urban middle and upper classes, to seek an alternative judged to be better for the future of their children. The most commercial forms of private schools are, therefore, finding a clientele and benefiting from the deficiencies observed in public schools.

If the abandonment of public schools by the urban middle class becomes a massive phenomenon, there is the risk that large structural inequalities will develop: on one side, poorly funded public schools that focus on rural areas and families with modest means; on the other side, private schools operating in a highly (socially and economically) segmented market and servicing families which are seeking a better quality education for their children.

\section{Figure 39}

\section{SHARE OF ENROLMENT IN PRIVATE PRIMARY SCHOOLS IN SUB-SAHARAN AFRICA, 1999 AND 2009 OR MOST RECENT YEAR}

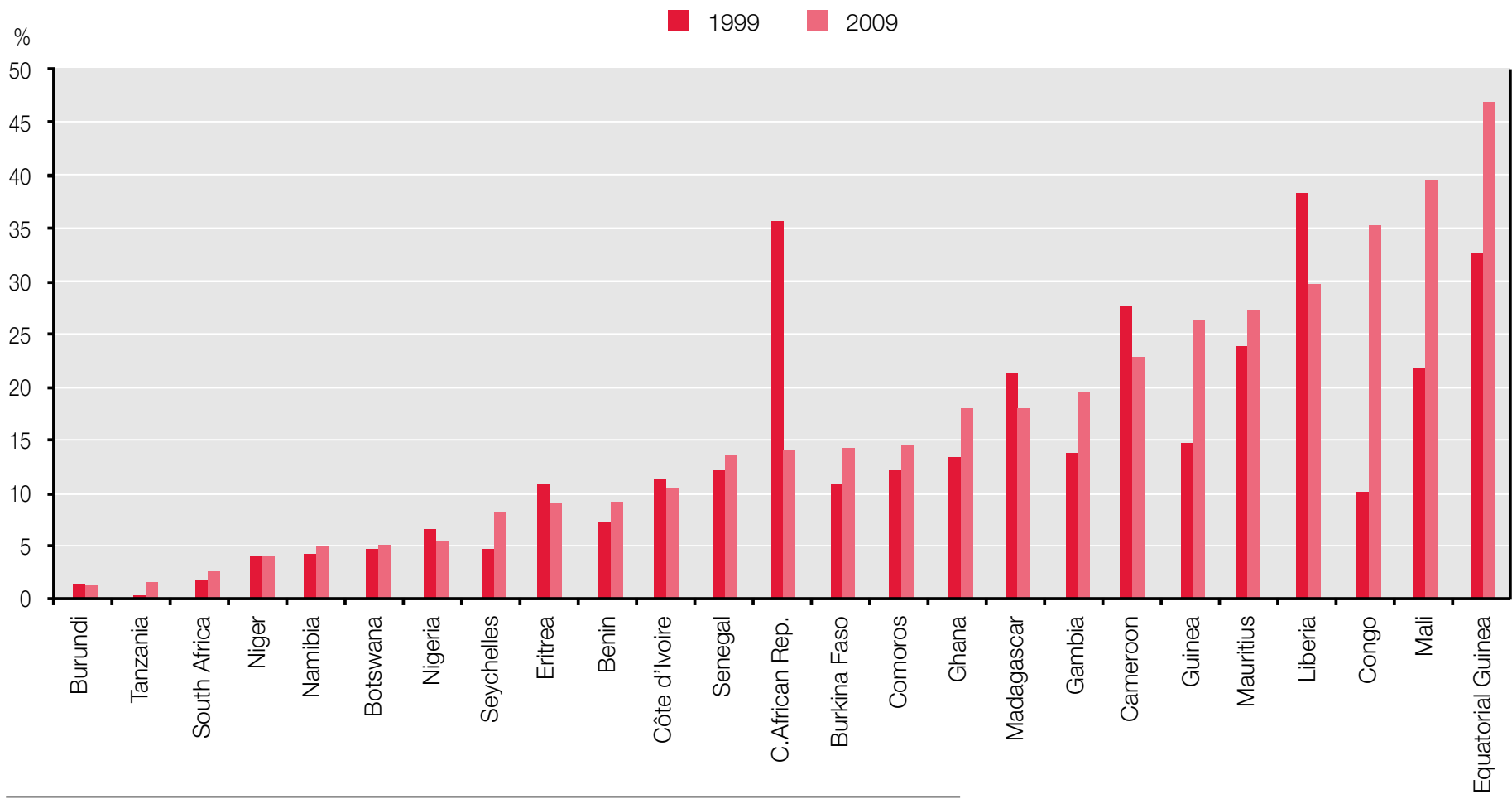

Notes: Included are government-dependent private institutions (which receive more than $50 \%$ of operating resources from the government) and independent private institutions. See glossary for a more detailed definition of private institutions. Source: UNESCO Institute for Statistics, Statistical Table A2. 


\section{SHARE OF ENROLMENT IN PRIVATE SECONDARY SCHOOLS IN SUB-SAHARAN AFRICA, 1999 AND 2009 OR MOST RECENT YEAR}

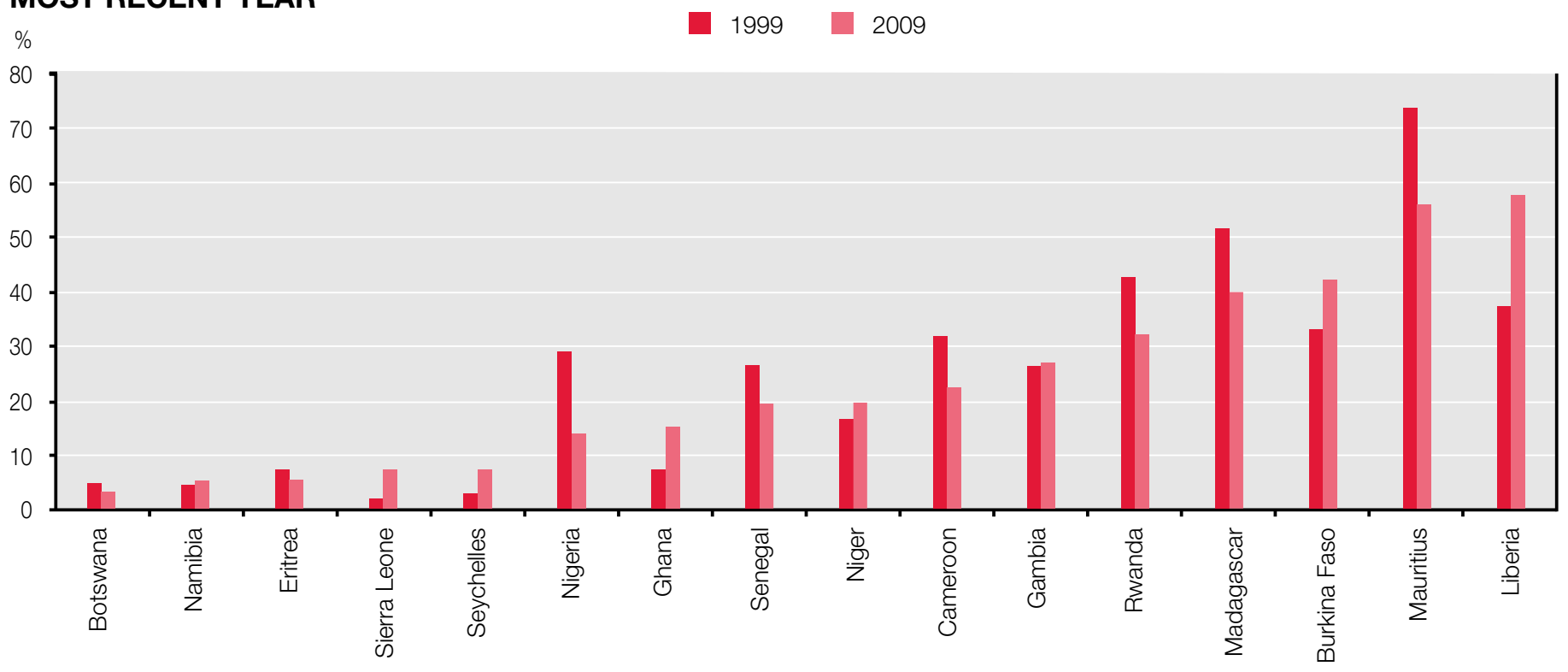

Notes: Included are government-dependent private institutions (which receive more than $50 \%$ of operating resource from the government) and independent private institutions. See glossary for a more detailed definition of private institutions.

Source: UNESCO Institute for Statistics, Statistical Table A2.

\subsection{PUBLIC-PRIVATE PARTNERSHIPS}

The increased diversification in the types of public-private partnerships stems from: heavy constraints on government budgets; the desire to open schools to the external world; the notion of bringing market mechanisms to the field of education; and the idea that education involves all of society.

The range of public-private partnerships in education can be quite wide and involve a variety of actors - businesses, foundations, religious organizations, NGOs, communities, parents' associations and parents themselves (see Figure 41). The motivation for involvement in education can derive from many different factors, from financial interest to philanthropy. Involvement can mean providing infrastructure or teaching services, or financing them. Examples, commonly seen in SSA, are the construction of a classroom by a community, the management of a school by a private operator, or the provision of equipment by a company or an NGO.

Certain partnerships can address the demand for education by encouraging and accompanying families with limited means or in disadvantaged regions. This can take the form of financial aid or in kind assistance for families, or by acting at the level of overall management and monitoring of the education system.

The modalities of partnerships can also vary a great deal, ranging from very formal contracts to very informal arrangements. Some partnerships arise from forms of privatisation, such as sub-contracting or outsourcing of certain activities to private operators who are paid by the government.

As previously noted in this report, parents are certainly the primary partners in education systems, since they are directly involved in the education of their children. Particularly in SSA, parents are collectively the primary financial partner of governments. The role of parents as economic agents is extended through the communities in which they live. They are often involved in the management and funding of schools, the construction of buildings or the administration of current operations.

Another form of partnership that is very common is the management of schools by private operators. The government oversees these promoters and operators through regulations that establish the legal framework, the accreditation procedures, and the pedagogical, safety and security norms to be respected. In addition, governments sometimes provide financial support to certain private schools.

Partnerships with NGOs are another form of public-private arrangements that are very common in SSA. The work of NGOs can be coordinated by governments, resulting in projects based on agreements with bilateral or multilateral agencies. Their work, however, can also be conducted in a rather uncoordinated manner. 


\section{DIMENSIONS OF PUBLIC-PRIVATE PARTNERSHIPS IN EDUCATION}

\begin{tabular}{l}
\multicolumn{1}{c|}{ Actors } \\
Business \\
Foundations \\
NGOs \\
Communities \\
Parent associations
\end{tabular}

Type of involvement
Resource provider
Service provider
Expertise

\begin{tabular}{l} 
Motivation \\
Social responsibility \\
Philanthropy \\
Business interest \\
\hline
\end{tabular}

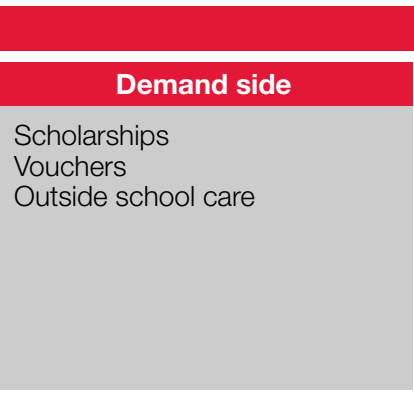

\section{Purpose/contents}

\section{Education delivery}

Private management of public schools

Funding of private school Infrastructure

Equipment, textbooks

Pedagogy

Opening to outside

Monitoring \& evaluation

\section{Nature of intervention}

Funding

Technical

Management

Advocacy

Modalities
Contract
Outsourcing
Soft agreement
Unregulated

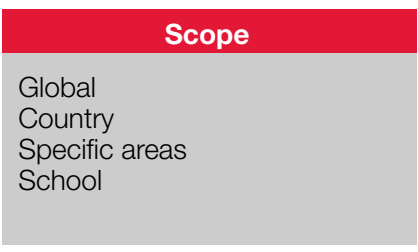

Levels of education

Early childhood

Basic education

Secondary education

TVET

Higher education

Adult education
The increasing involvement of private actors and the growing variety of their activities result in bringing effective competition for governments that face constraints in their capacity to ensure the quantitative and qualitative development of education systems. However, this also raises the issue of the capacity of SSA governments to provide a framework to regulate and monitor these partnerships in a way that will ensure that their activities contribute to the country's development goals.

\subsection{CONCLUSION}

In general, governments are the main funders of education systems in every country in the world, but they are not the only source. Government funding is often complemented by inputs from external partners, students and households, and private entities. Private financing can complement government funding in public education institutions and it can also finance private schools. However, despite its importance for financing education provision across all levels, private contributions to education remains a neglected area of research and policy. Data on this are scarce, and the statistical indicators often focus only on the public financing of education.

The largest proportion of private funding comes from households in the form of registration or tuition fees for public and private institutions, contributions to parents' associations, and direct spending on textbooks, school supplies and uniforms associated with attending school. Household contributions represent around $25 \%$ of total education expenditure among the 16 SSA countries where data were available. This proportion differs according to level of education, with the smallest proportion going to tertiary education.

Spending on education accounts for a significant part of household spending in general. On average, $4.4 \%$ of household expenditure in the 16 countries studied is for educational purposes. Wealthier households tend to allocate a larger share of household expenditure to education because they are more likely to send their children to private schools and their children are more likely to enrol in upper levels of education where tuition fees are usually higher.

To alleviate the burden of education expenditure on households, especially for the poor, school fees have been abolished in many SSA countries since the 1990s. Significant impacts on enrolment have been observed, proving that school fee abolition is an important measure for increasing the enrolment of children, especially for poor families.

At the same time, the number of private schools is growing in most SSA countries. While the proportion of enrolment in private schools varies across countries, appreciable increases have been observed at both primary and secondary education levels during the 2000s. This increase in private school education can be interpreted as an indicator of the poor quality 
of public schools, as perceived by families, particularly in urban areas. Urban middle-class families are increasingly opting for alternatives that they consider to be beneficial for the future of their children. One key policy option can be to restore sufficient quality in the public primary school system so that public education does not become a programme solely for poor households.

Heavy constraints on government budgets, the desire to open schools to the external world, the notion of bringing market mechanisms to the field of education, and the idea that education involves all segments of society have led to increased diversification in the types of partnerships between governments and the private sector for providing education. While the motivation and modalities of these partnerships vary, the rise of private sector involvement in education brings new opportunities to education financing. Nonetheless, it is necessary that governments provide a framework to regulate and monitor these partnerships in such a way that their activities contribute to the country's development goals. 


\title{
Chapter 5
}

\section{FINANCING THE QUALITY OF EDUCATION}

\author{
Laurence Wolff (Consultant) \\ Shinsaku Nomura (UNESCO Institute for Statistics)
}

\begin{abstract}
As previously explained, SSA countries are faced with persistent resource constraints and a rising demand for education. In this context, it is crucial that countries choose the best approaches to improve the quality of education. This chapter seeks to support this process by placing issues related to quality in the context of financing and costs. It begins with a review of definitions of quality and then presents recent evidence on learning achievement and essential inputs into basic education in SSA countries. It concludes with a discussion of ways to identify the key policy interventions needed to improve the quality of education.
\end{abstract}

\subsection{INTRODUCTION}

Over the last decade, SSA countries as well as donors have focused on ensuring that all children complete primary education. Funds have been allocated to pay for increased numbers of teachers, schools and teaching materials, as well as to reduce the financial burdens poor families face in order to keep their children in school. As a result, the number of primary pupils has expanded rapidly, especially since 2000; more students are completing primary education; and increasing numbers are continuing their education at secondary and higher levels (see Chapter 1).

The region, however, still has not achieved its quantitative goals of ensuring that all children complete primary education.

Figure $\mathbf{4 2}$ shows the survival rates to the last grade of primary education and to Grade 5. Only a few SSA countries are graduating $90 \%$ of children. In Ethiopia and Mozambique, less than $60 \%$ of those who enter Grade 1 will reach Grade 5 , and less than $40 \%$ will continue to the last grade of primary education. The low survival rate is attributed to various factors, including demand-side reasons, incomplete schools (i.e. schools that do not offer the last grades, cost of schooling, and the low quality of education which results in children not understanding the subject matter and repeating grades.

While the quantitative task remains challenging, there is a growing recognition that children can stay in school and not learn very much, making completion of primary school a hollow achievement. UNESCO's 2004 EFA Monitoring Report, The Quality Imperative, put this issue into perspective, and numerous recent reports and analyses have focused on the need to improve education quality in Africa and the rest of the world. This new focus is in line with the consensus that the learning achievement of school graduates, rather than simply years of schooling, is of critical importance to economic growth and development. Knowledge and skills - not educational attainment - are the keys to reducing poverty and building wealth (OECD, 2010a).

Today, SSA countries are increasingly aware of issues related to education quality, even though many are still overwhelmed by the large number of students in their school systems and by the inadequacy of their budgets, making it difficult for them to come to grips with quality issues. In this context, measuring learning achievement has become essential. All countries in the region that receive $\mathrm{FTI}$ support are committed to national learning assessments. Fifteen countries participate in the Southern and Eastern African Consortium for Measuring Educational Quality (SACMEQ): Botswana, Kenya, Lesotho, Malawi, Mauritius, Mozambique, Namibia, Seychelles, South Africa, Swaziland, the United Republic of Tanzania, Uganda, Zambia, Zanzibar ${ }^{58}$ and Zimbabwe. Under the Programme on the Analysis of Education Systems (PASEC), which was launched in 1991, 13 individual country evaluations have been carried out in Francophone Africa, including panel studies following primary pupils from Grade 2 to Grade 6 in several countries. ${ }^{59}$

\subsection{THE DEFINITION OF EDUCATION QUALITY}

The UNESCO report, The Quality Imperative, examines the question of the definition of education quality from a number of different points of view. A major objective of all education systems is the cognitive development of learners. Besides fostering cognitive development, schools aim to promote commonly shared values, along with creative and emotional development. These objectives are more difficult to assess

\footnotetext{
58 SACMEQ conducted a survey for mainland Tanzania and Zanzibar. Therefore, this chapter reports on Zanzibar separately when discussing the SAQMEQ results.

59 A number of countries are also developing Early Grade Reading Assessments (EGRA) as a tool for identifying reading problems in $1^{\text {st }}$ and $2^{\text {nd }}$ grades.
} 


\section{SURVIVAL RATE TO GRADE 5 AND THE LAST GRADE OF PRIMARY EDUCATION, 2009 OR MOST RECENT YEAR}

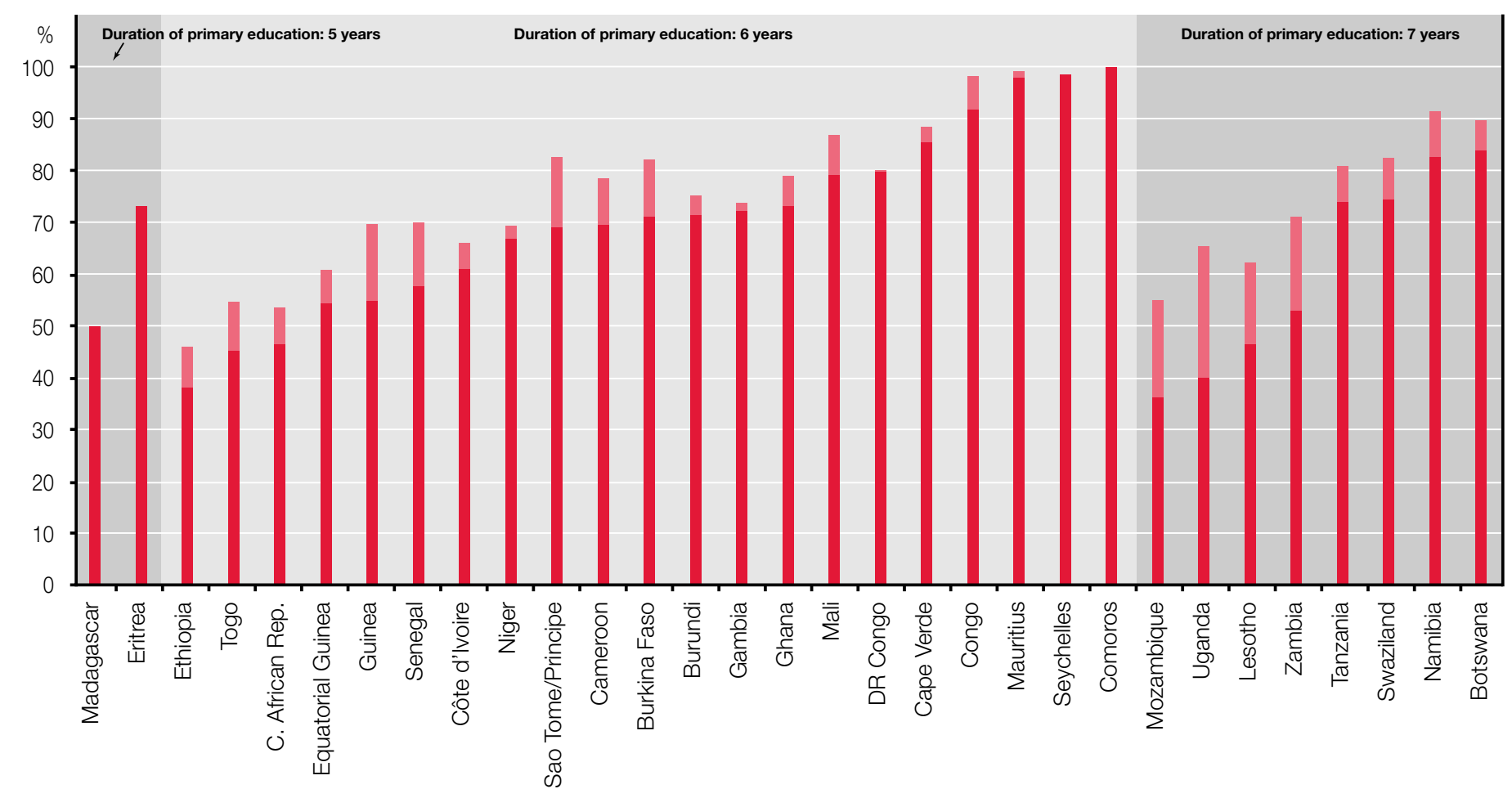

Source: UNESCO Institute for Statistics database.

than learning achievement. Five dimensions influence the core processes of teaching and learning: learner characteristics; context; enabling inputs; teaching and learning; and outcomes.

The first dimension, learner characteristics, is about student capacities and experiences that influence how much and how quickly they learn. These include aptitude, school readiness and prior knowledge (which are largely determined by socioeconomic background), health, place of residence, cultural and religious background, etc. While it is not easy to examine the innate ability of students, tests almost inevitably identify correlations between learning achievement and the socioeconomic status of children. ${ }^{60}$

The second dimension, context, sheds light on the links between education and society. Education can help change society by improving and strengthening skills, values, communications, etc., but education usually also reflects the values and attitudes that are dominant in a society. Economic and labour market conditions may affect the motivation of students and influence learning standards. The availability of public resources and the private sector's role in education are also important elements.

The success of teaching and learning is likely to be strongly influenced by the resources made available to support the process and by how these resources are managed. Key enabling inputs can be divided into material resources, human resources and enabling governance. The material resources can be further broken down by teaching and learning materials and physical infrastructure and facilities. It is obvious that schools without teachers, textbooks or learning materials will not be effective, but management, oversight, commitment and accountability are equally critical.

While the debates on what constitutes an adequate learning environment and how to improve it continue, it is clear that a focus on inputs (such as building classrooms, hiring teachers and purchasing textbooks) alone is not enough, as this covers only some of the elements of a successful education system. The ability of an education system to transform available resources into learning for all depends on its capacity for

\footnotetext{
60 An example from Kenya is presented in Postlethwaite (2004).
} 
policy formulation and implementation, planning, finance, student assessment, human resource management, and intergovernmental and external partnerships.

With more solid assessment and applied research results, public authorities increasingly need to make decisions on where to invest based on "what works" rather than on opinions or unfounded expectations. Evolving research suggests that time on task, especially actual teaching time, has a major impact on learning. Teachers are critical to the learning process, but the quality of teacher training appears to be more important than the number of years of teacher training. Yet, how the level of teacher training and classroom size affect learning varies considerably from one country to another. Putting textbooks and other pedagogical materials into the classroom, especially in resource-poor environments, has an impact on learning.

There is also considerable interaction between learning achievement and school retention. When children learn more, they are more likely to remain in school, since both they and their parents recognize the value added resulting from the education process.

\subsection{MEASURING EDUCATION QUALITY IN SUB-SAHARAN AFRICA}

A small number of African countries (including Botswana, Ghana and South Africa) have participated in international testing programmes, such as the Progress in Reading
Literacy Survey (PIRLS) and the Trends in Mathematics and Science Survey (TIMSS) of the International Association for Educational Assessment (IEA). In both of these programmes, the participating African countries scored at or near the lowest scores of the participating countries, from 1.5 to 2 standard deviations below the average. This poor performance is not surprising, given the context in many SSA countries of poverty, illiteracy, management and governance weaknesses, and inadequate levels of enabling inputs.

More data are available from studies undertaken by SACMEQ, which has benefited greatly from the support of and partnership with national education ministries. Two rounds of testing of $6^{\text {th }}$ graders (1995-1998 and 1999-2004) have been completed to test their language and mathematics skills. The most recent SACMEQ test is standardized at 500 points for both reading and mathematics, with a standard deviation of 50. According to the distribution, Kenya, Mauritius and Seychelles performed highest among the participating countries, both in terms of mathematics and reading scores, while Lesotho, Malawi, Namibia and Zambia performed lowest among the group (see Figure 43).

A simpler measure of learning achievement is literacy, defined as the ability to read fluently and understand a simple sentence. The ability to read is considered by many as the fundamental building block for future learning. If children do not learn to read, then they cannot continue to build their capacity. SACMEQ

\section{Figure 43}

\section{SACMEQ SCORES IN READING AND MATHEMATICS, 2005}

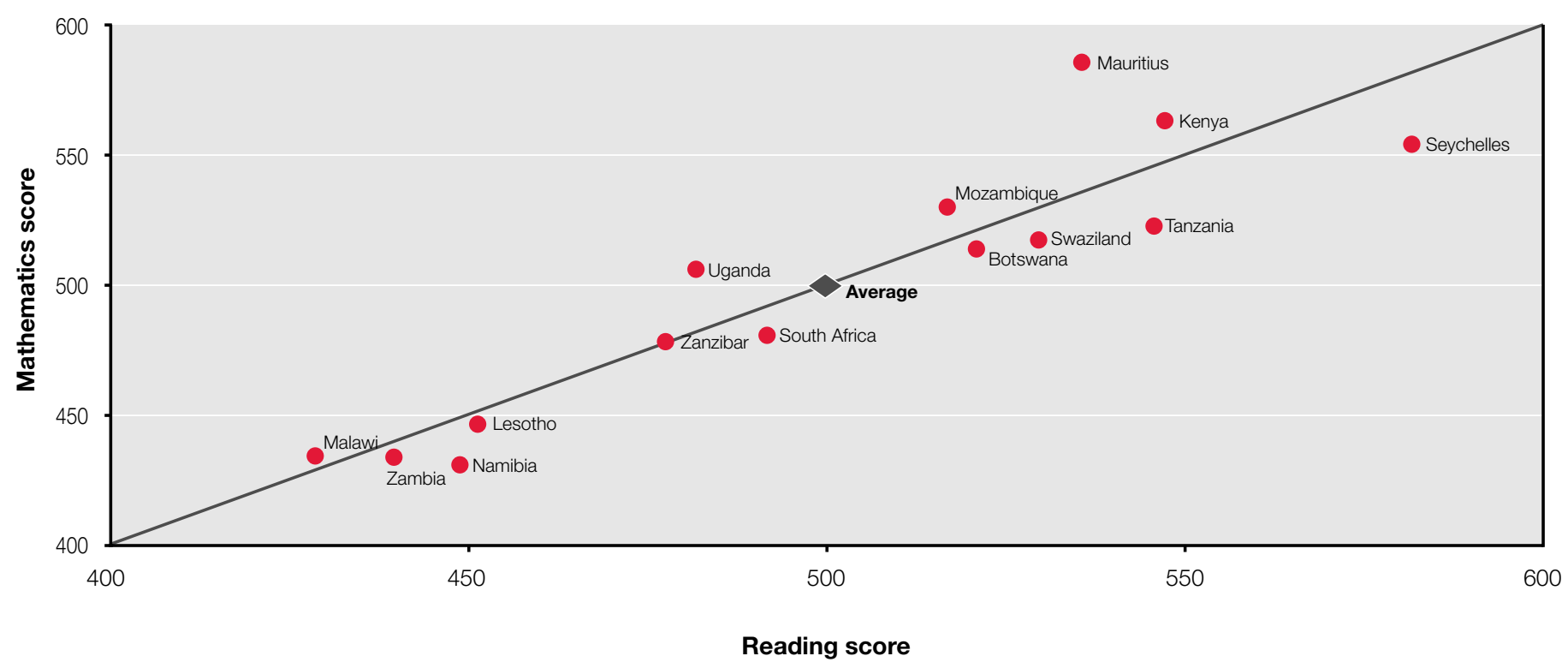

Source: SACMEQ.

61 SACMEQ presents a similar framework for numeracy 
bases its assessments on eight levels of reading fluency ${ }^{61}$

(see Appendix IV for details). According to SACMEQ evaluations, $78 \%$ of $6^{\text {th }}$ graders are able to read at least at the "basic" level (Level 3 or above), ranging from 98\% in Swaziland to 52\% in Zambia and $56 \%$ in Malawi (see Figure 44). It should be pointed out that reading at the "basic" level is not the expected level of achievement at Grade 6 according to country curriculum guides and standards. Benchmarks of the minimum and desirable levels of mastery are set by each country in order to group children by pre-functional, functional and independent levels of literacy. By Grade 6, however, higher levels of mastery are expected.

The primary objective of PASEC evaluations is not the comparison of student achievement across countries but the analysis of key factors relevant to fostering educational quality. It does not provide explicit, desired achievement levels. PASEC standardizes its tests and reports scores on common items, as in Figure $\mathbf{4 5}$.

Performance ranges from over $45 \%$ in Madagascar and Cameroon to less than 30\% in Côte d'Ivoire. To get a practical idea of the levels of achievement expected, fewer than one-half of low achievers (the bottom 25\%) in Grade 5 could correctly perform the following task:

Sort the numbers from highest to lowest value $\begin{array}{llll}35.7 & 25.9 & 35.8 & 35.6\end{array}$
Analyses of household surveys also point out weaknesses in the mastery of subject matter among primary school completers. Pôle de Dakar of UNESCO-BREDA has tested literacy of adults aged 22 to 44 years who have completed six years of schooling. Then, based on the results of a short reading test, it estimated the percentage of those in the group who could read at present (see Figure 46).

These results show that many primary school completers in the sample are not able to read. In the case of Niger, less than $40 \%$ of primary school completers are able to read today. There are limitations to the use of this data, however. Literate $6^{\text {th }}$ graders can lose their levels of literacy if they do not use written materials in their daily life. Alternatively, some $6^{\text {th }}$ graders who could not read at the end of their schooling could become literate through non-formal education programmes. Finally, measuring the literacy of 22 to 44 -yearolds today is measuring the quality of the primary school system some 10 to 30 years ago. Nonetheless, the results clearly indicate the inadequacy of the quality of education in the countries studied.

Currently, the monitoring of EFA is done by completion rate only, under the assumption that primary school graduates are functionally literate. But the studies described earlier confirm that this is not necessarily the case. There is a need for a new indicator that can show real mastery of critical reading skills.

\section{Figure 44}

\section{PERCENTAGE OF CHILDREN WHO ARE ABLE TO READ AT LEAST AT THE BASIC LEVEL, 2005}

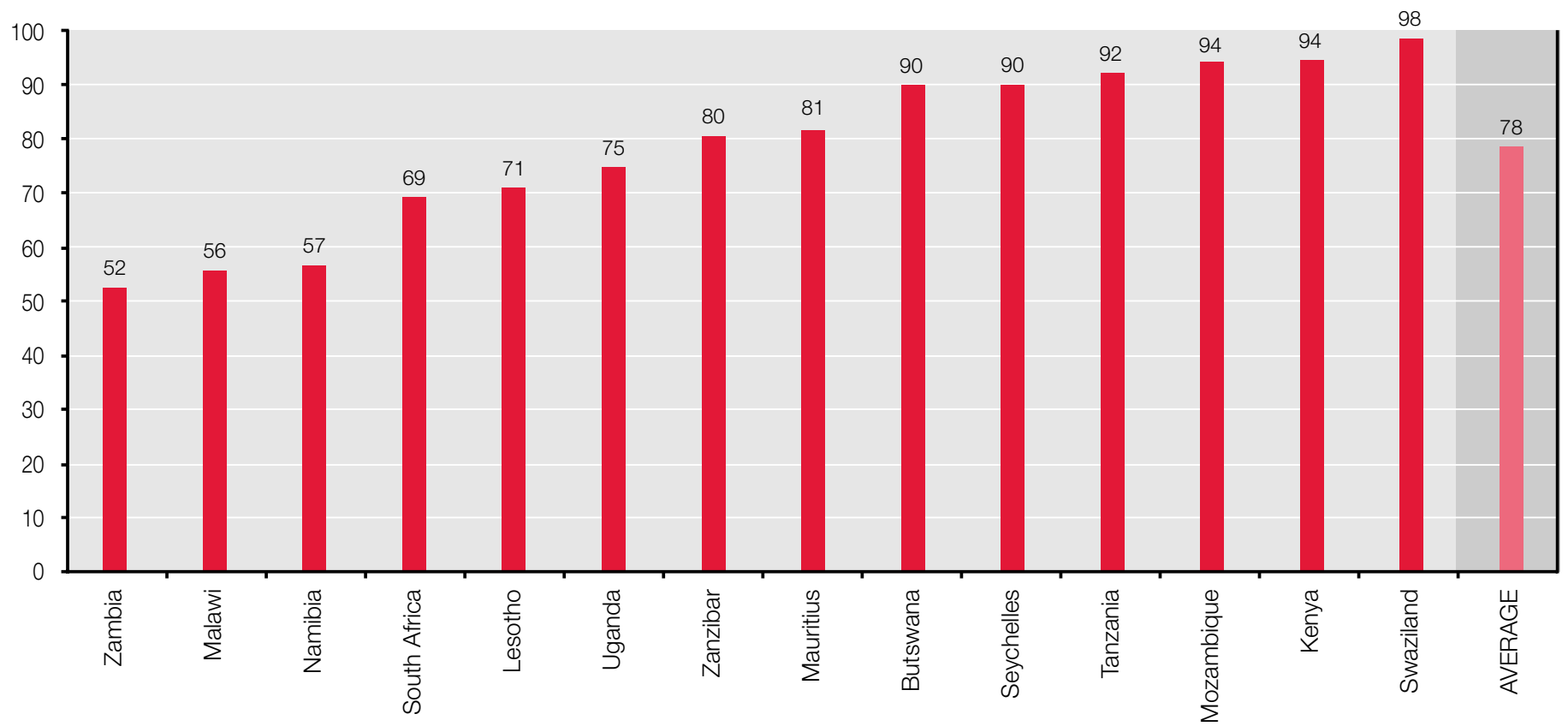

Note: The basic level is the third lowest out of 8 literacy levels defined by SACMEQ.

Source: SACMEQ. 


\section{Figure 45}

\section{PERCENTAGE OF STUDENTS WHO ANSWER CORRECTLY ON MORE THAN 40\% OF COMMON FRENCH}

LANGUAGE TEST ITEMS, 2004-2009

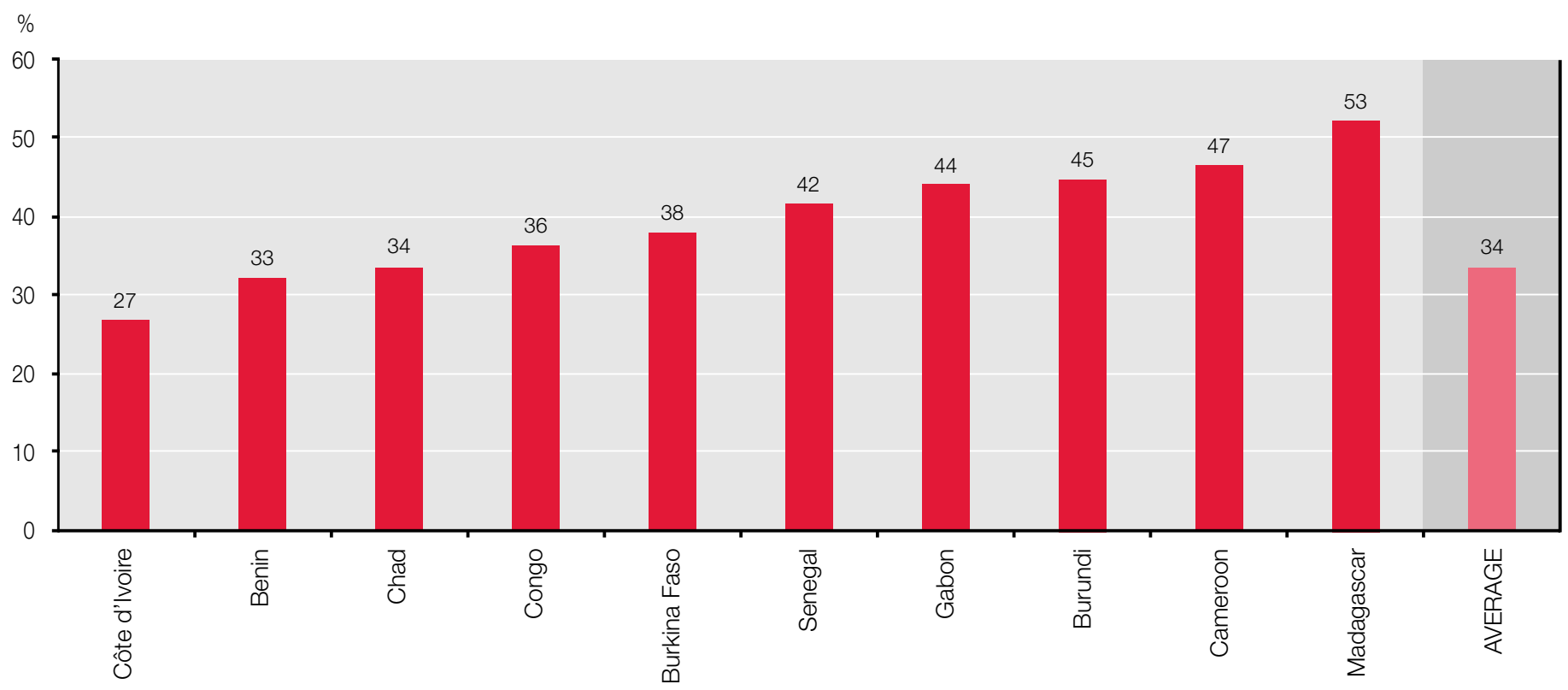

Source: PASEC.

\section{Figure 46}

\section{ESTIMATED LITERACY RATE AMONG 22 TO 44-YEAR-OLDS WITH SIX YEARS OF EDUCATION}

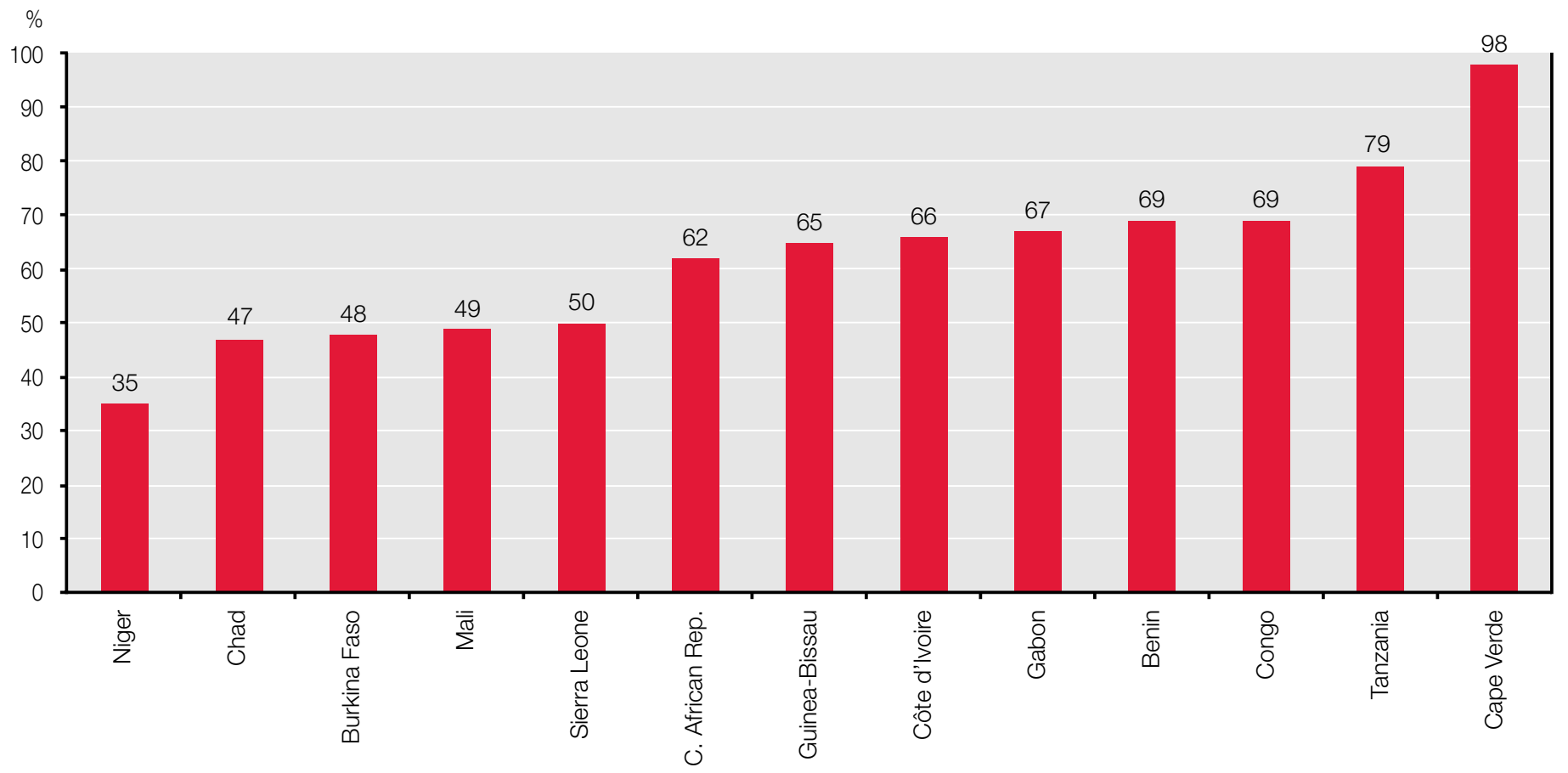

Notes: Estimated literacy rates are calculated by using different household surveys from 2000 to 2006. 
A new indicator combining completion rates and learning achievement would make it possible to identify the percentage of children who reach Grade 5 or 6 and are also able to read. ${ }^{62}$ This is important because many authorities believe that literacy is the key to unlocking access to the modern world, ${ }^{63}$ and because this single indicator could have an impact on the policy dialogue. Figure 47 summarizes data on countries that participated in SACMEQ, and shows how using this new indicator would impact on our understanding of education quality. It is based on SACMEQ estimates of the number of students who reach the basic level of reading (as shown in Figure 44). This indicator, however, would not account for dropouts who are literate or become literate through alternative programmes. In addition, literacy estimates are based on sample surveys with a range of confidence intervals, which means that minor differences from one country or period to another may not be significant.

These results change our understanding of how countries are doing in terms of reaching the goals of quality education for all. For example, Namibia has a very good record in providing schooling to its children, with $86 \%$ of children reaching Grade 6. But it appears to be doing poorly in terms of learning achievement, since only $55 \%$ of its $6^{\text {th }}$ graders are able to read at the basic level. This means that only $49 \%$ of its children reach Grade 6 and are able to read. In contrast, in Swaziland, $78 \%$ of children reach $6^{\text {th }}$ grade, but $98 \%$ of them are able to read. On this basis, $77 \%$ of Swaziland's children reach Grade 6 and are able to read, which is a significantly better outcome than in Namibia.

This gap between reaching $6^{\text {th }}$ grade of primary education and desired learning outcomes can be used to deepen the traditional argument of cost efficiency. The coefficient of efficiency estimates the percentage of expenditure spent to produce a graduate compared to expenditure spent on dropouts and repeaters. It has been pointed out by a number of observers that the coefficient of efficiency implies that all expenditure in primary education spent on dropouts or repeaters are "wasted," which may not be the case. Yet, increasingly research is finding that illiterates cannot compete in today's world, and so there appears to be more truth to the "wastage" argument than previously thought.

Figure $\mathbf{4 8}$ shows a revised coefficient of efficiency, based on costs for producing a literate graduate, in eight SACMEQ countries for which literacy data are available.

\section{Figure 47}

\section{ESTIMATED PERCENTAGE OF STUDENTS WHO SURVIVE TO END OF PRIMARY EDUCATION AND WHO ARE ABLE TO READ IN SACMEQ COUNTRIES}

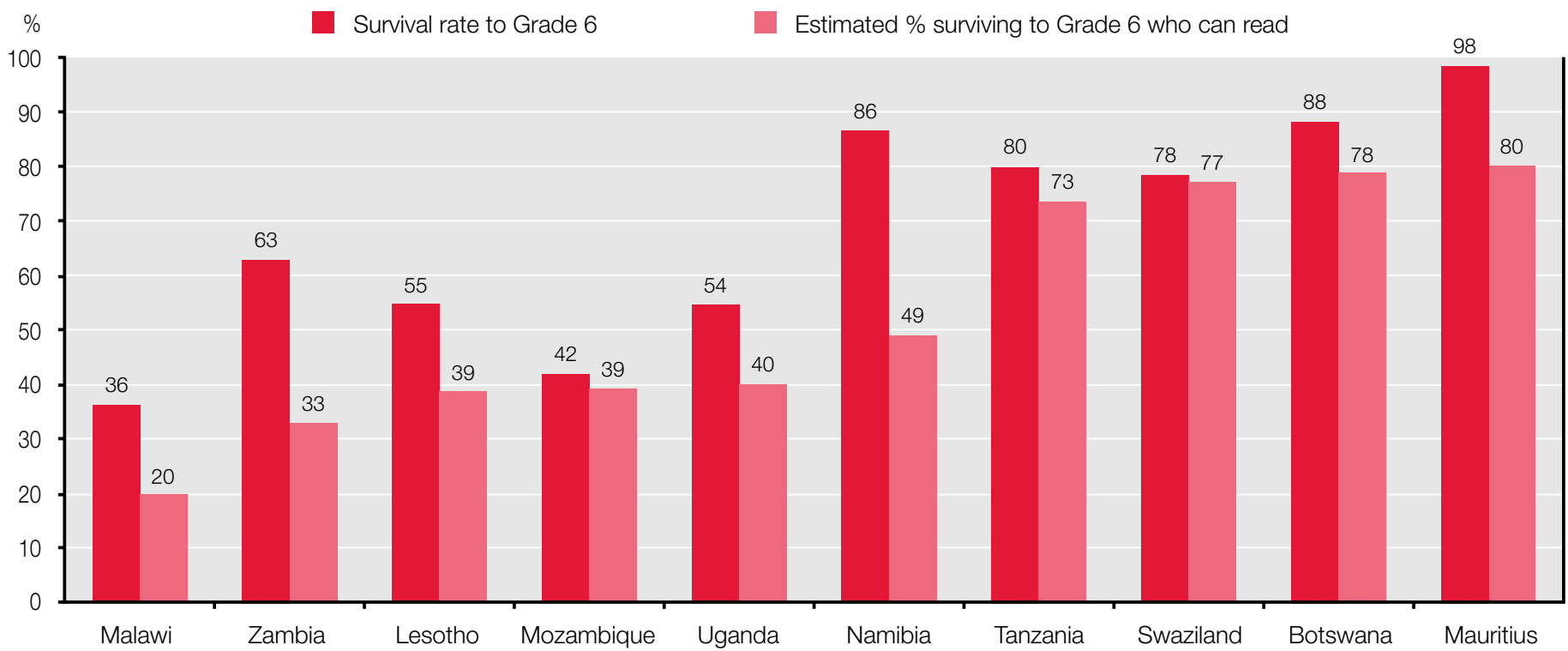

Sources: UNESCO Institute for Statistics estimates based on SACMEQ data (2005) and estimated survival rate (2009 or most recent year), Figure 5.1.

62 This approach has also been suggested by Michaelowa (2000).

63 Literacy is the key to future learning because it modifies the brain's architecture. Nerve endings that are disconnected in illiterate people develop in literate people to connect various parts of the brain for faster processing of information. See Abadzi, (2006) for a more detailed discussion. 
This figure shows that in Lesotho, Malawi, Namibia, Uganda and Zambia, less than 50\% of expenditure goes toward producing a literate graduate, with the remaining funds "wasted" on dropouts, repeaters and illiterates.

One reason for the low coefficient of efficiency is the high rate of repetition in primary education. Reported repetition in SSA averages $15 \%$, which is the highest in the world. In 11 SSA countries, $20 \%$ or more students are repeaters, with a high of $37 \%$ in Burundi, while a few countries - such as Kenya and Mozambique - have repetition rates of $6 \%$ or lower.

The high repetition rate is a result of multiple factors, including issues related to the quality of educational services and household environment. Children from disadvantaged backgrounds are more likely to drop out or repeat grades. Schools sometimes do not have the resources to focus on children with special learning needs. Research suggests that repeaters score lower on achievement tests than non-repeaters, despite their increased number of learning hours. One of the studies on SACMEQ results showed that repeaters performed lower than non-repeaters at Grade 6 on the SACMEQ reading test in 13 out of 14 countries (Lee, Zuze and Ross, 2005).

It has been suggested that reducing repetition would liberate some funds for increasing the quality of education. Since more children would, nonetheless, remain in school, overall costs would probably not change. The automatic promotion of children from one grade to the next without complementary measures has occurred around the world, including in some Francophone SSA countries (for example, in Equatorial Guinea and Gabon) (Ndaruhutse, 2007). This practice has had mixed results, leading in some cases to hidden and unreported repetition, as well as to higher numbers of illiterate primary school graduates.

The region has made significant progress in measuring learning outcomes. But much still remains to be done. In the first place, it will be important for individual countries to strengthen their analytical and technical capacities, including training good psychometricians, developing reliable criterion-referenced tests, and ensuring that results can be compared from one year to the next. Countries, as well as both SACMEQ and PASEC, will need to improve the timely dissemination of results to key stakeholders. Some possibilities include the design of common test items, which would permit comparison of results between PASEC and SACMEQ, including aligning PASEC's research design with IEA-type criterion-based objectives.

Selective participation in international assessments may also be an option, especially if the agencies involved - the IEA and the Program for International Student Assessment (PISA) design their assessment instruments in a way that would be more helpful for lower-performing countries. It may also be appropriate, on a pilot basis and in conjunction with developed countries, to begin to measure non-cognitive outcomes, such as citizenship and work habits.

\section{Figure 48}

\section{COEFFICIENT OF EFFICIENCY FOR PRIMARY COMPLETION AND FOR COMPLETION WITH READING SKILLS}

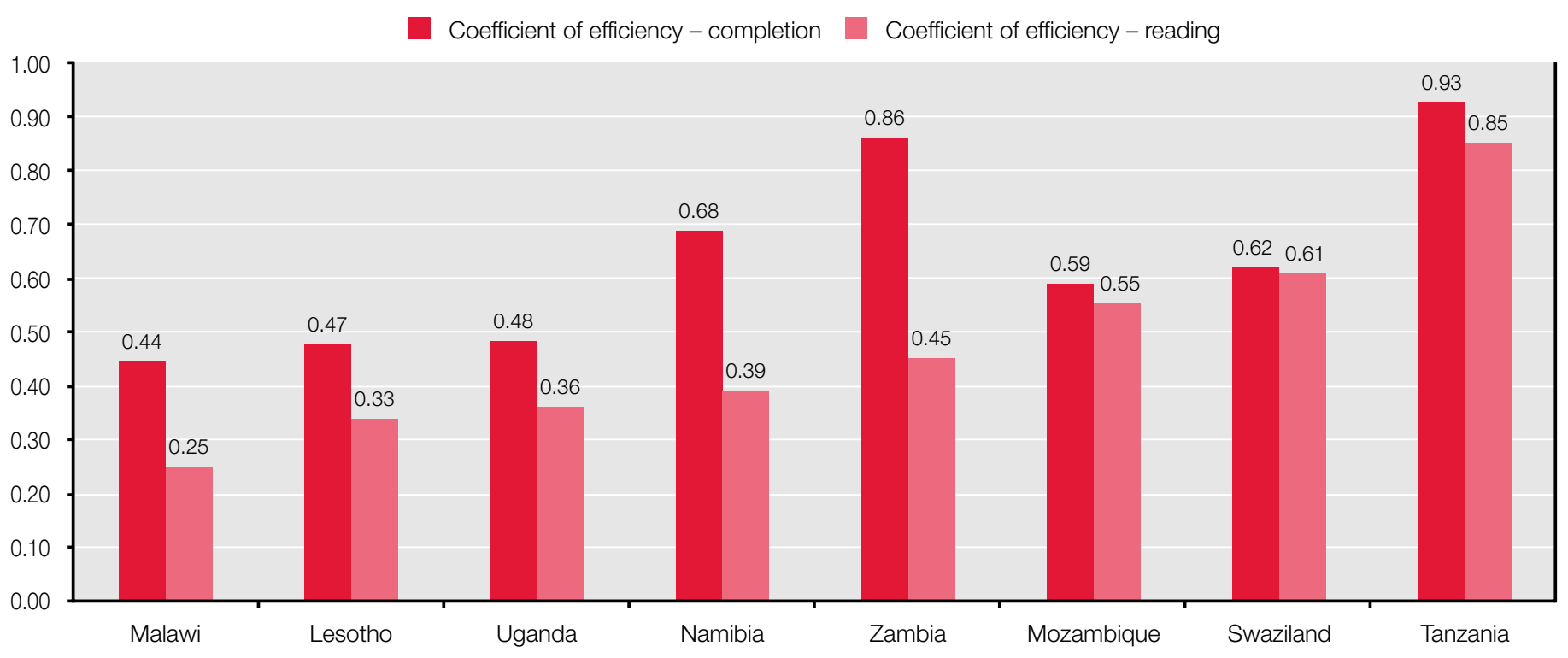

Sources: UNESCO Institute for Statistics estimates based on SACMEQ data (2005) and UIS database. 
Finally, one way to focus more attention on learning outcomes is to develop more informative and meaningful indicators.

A single indicator linking completion and learning achievement, as shown in Figures 47 and 48, for example, might encourage policymakers to focus on learning rather than simply on school completion rates.

\subsection{DATA ON ENABLING INPUTS}

While the debates on what constitutes an adequate learning environment and how to improve it are still open, it is clear that a focus on inputs alone (such as building classrooms, hiring teachers and purchasing textbooks) is not enough. Nonetheless, adequate inputs continue to be important for achieving education quality. The UIS collects data on some but not all indicators in this area.

PTRs are one critical element for which relatively complete data are available, as can be seen in Figure 49.

While the PTRs of most countries fall between 30 and 50, there are some extreme cases. In the Central African Republic, Chad, Congo, Guinea-Bissau, Mozambique, Rwanda and Zambia, PTRs exceed 60 . Since there are also variations within countries, it is possible that some schools have only 1 teacher for more than 100 pupils. While empirical studies have shown mixed findings worldwide regarding the impact of PTRs on student learning (Hanushek, Rivkin and Taylor, 1996), ${ }^{64}$ the teaching process cannot be effective in the African context if the number of students in the classroom is too high.

Another critical element is expenditure on textbooks and learning materials. Data are available for 16 countries, as seen in Table 12.

Reported public expenditure on learning materials appear to vary enormously from one country to another, with Chad and Guinea spending over $14 \%$ of their primary education budgets on teaching materials, compared to less than $2 \%$ in Togo, Madagascar and Uganda. Guinea and Chad spend PPP\$11.3 and PPP\$20.7 per primary pupil respectively, while Comoros spends the highest amount per pupil (PPP\$33) and Togo the lowest amount (PPP\$0.7). It is possible that reporting anomalies make this indicator difficult to evaluate.

The UIS also collects data on the qualifications of teachers. The definition of a qualified teacher varies from one country to another but usually requires completion of a teacher-training programme at the upper secondary or post-secondary level or completion of a comparable in-service training programme (see Figure 50).

\section{Figure 49}

\section{PUPIL-TEACHER RATIO IN PRIMARY EDUCATION, 2009 OR MOST RECENT YEAR}

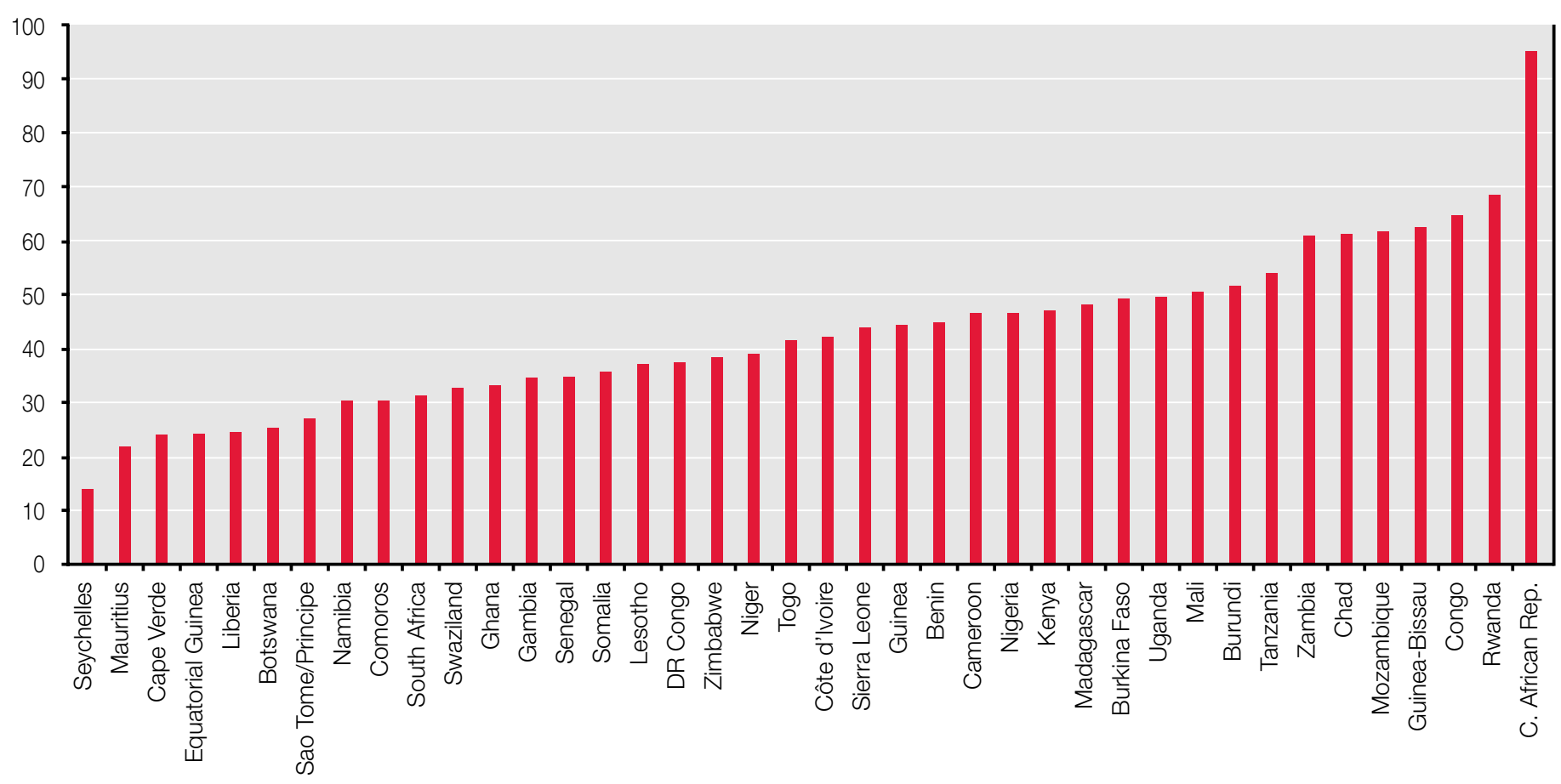

Source: UNESCO Institute for Statistics, Statistical Table A4.

${ }_{64}$ They reviewed 277 studies on the impact of PTRs and found a statistically significant and positive impact in $15 \%$ of the studies and a statistically significant and negative impact in $13 \%$ of the studies. The rest of the studies showed statistically insignificant results. 
The share of qualified teachers in primary education exceeds 95\% in Botswana, Côte d'Ivoire, Kenya, Mauritius, Namibia, Niger, Seychelles and Tanzania. The median of 33 SSA countries is $86.1 \%$. As noted in Chapter 3 , there is some evidence that the level of teacher qualifications has gone down as more teachers have been hired on a contractual basis to manage higher numbers of students. In addition, research on the subject suggests that formal qualifications of teachers are less important than the quality of teacher-training programmes.

Pre-school enrolment ratios have an important implication for the quality of primary education, although varying definitions of the length of the pre-school cycle make comparison across countries difficult. Figure $\mathbf{5 1}$ summarises currently available data on GERs in pre-schooling in the SSA region. Cape Verde, Equatorial Guinea, Ghana, Kenya, Mauritius, Seychelles and South Africa report pre-school enrolment ratios of over $50 \%$, compared to ratios of less than $5 \%$ mainly in low-income countries (e.g. Burkina Faso, Chad, Côte d'Ivoire, Democratic Republic of Congo, Ethiopia, Mali and Niger).

A final key indicator of inputs concerns expenditure per pupil in primary education, as shown in Figure 52. This expenditure varies widely across SSA countries and correlates to a great extent with per capita income. High-income SSA countries, such as Botswana, Mauritius, Namibia and South Africa, spend PPP $\$ 950$ or more per primary pupil, compared to less than PPP\$100 in poorer countries, such as Burundi, Madagascar, Sierra Leone and Zambia. As noted earlier, worldwide per student expenditure does not necessarily result in higher learning achievement. In this respect it is interesting to note that some SSA countries that do not spend much per student, such as Kenya and Mozambique, score relatively better on SACMEQ tests than, for instance, Namibia and South Africa, which spend around 5 times more.

As previously noted, there are many inadequacies in the reporting of internationally comparable variables related to education quality. For example, the breakdown of expenditure by salary and non-salary costs is often unclear, since transfers to communities are usually not reported by type of expenditure. Ministries of education rarely have good data on the quantities or costs of textbooks and other teaching materials. Also, data on pre-schooling are inadequate because of varying definitions of pre-school ages, and repetition is considered by some observers to be under-estimated. Much work is needed to regularise the reporting of these standard indicators.

\section{Table 12}

\section{PUBLIC EXPENDITURE ON TEXTBOOKS AND LEARNING MATERIALS IN PRIMARY AND SECONDARY EDUCATION AS A SHARE OF TOTAL CURRENT EXPENDITURE, 2009 OR MOST RECENT YEAR}

\begin{tabular}{|c|c|c|c|c|c|}
\hline & \multirow[t]{2}{*}{ COUNTRY } & \multicolumn{2}{|c|}{$\begin{array}{l}\text { EXPENDITURE ON TEXTBOOKS } \\
\text { AND LEARNING MATERIALS AS A \% } \\
\text { OF TOTAL CURRENT EXPENDITURE }\end{array}$} & \multicolumn{2}{|c|}{$\begin{array}{l}\text { EXPENDITURE ON TEXTBOOKS AND } \\
\text { LEARNING MATERIALS PER STUDENT (PPP\$) }\end{array}$} \\
\hline & & Primary & Secondary & Primary & Secondary \\
\hline \multirow[b]{2}{*}{ GDP per capita $<$ PPP $\$ 1,000$} & Eritrea & $\ldots$ & $\ldots$ & 1.2 & 4.3 \\
\hline & Malawi & 11.3 & 6.9 & $\ldots$ & $\ldots$ \\
\hline \multirow{7}{*}{ GDP per capita of PPP $\$ 1,000-3,000$} & Burkina Faso & 4.8 & 0.7 & 15.8 & 2.5 \\
\hline & Cameroon & 7.1 & 0.4 & 11.1 & 2.5 \\
\hline & Chad & 14.8 & 9.1 & 20.7 & 24.2 \\
\hline & Comoros & 10.3 & $\ldots$ & 33.0 & $\ldots$ \\
\hline & Mali & 10.2 & 12.8 & 16.2 & 51.0 \\
\hline & Rwanda & 10.8 & 5.0 & $\ldots$ & $\ldots$ \\
\hline & Uganda & 1.7 & $\ldots$ & 1.3 & - \\
\hline GDP per capita $>$ PPP $\$ 3,000$ & South Africa & 2.9 & 2.9 & $\ldots$ & $\ldots$ \\
\hline
\end{tabular}

Notes: For countries with 2009 data, GDP per capita in 2008 PPP is used to calculate the approximate expenditure per student. These countries include Burundi, Cameroon, Chad, Mali, Niger, South Africa, Togo and Uganda. Expenditure per student (PPP\$) is not available for some countries due to a lack of corresponding enrolment data. Sources: UNESCO Institute for Statistics database and Statistical Table A7. 


\section{Figure 50}

COMPARISON OF THE PERCENTAGE OF TRAINED PRIMARY TEACHERS, 2009 OR MOST RECENT YEAR

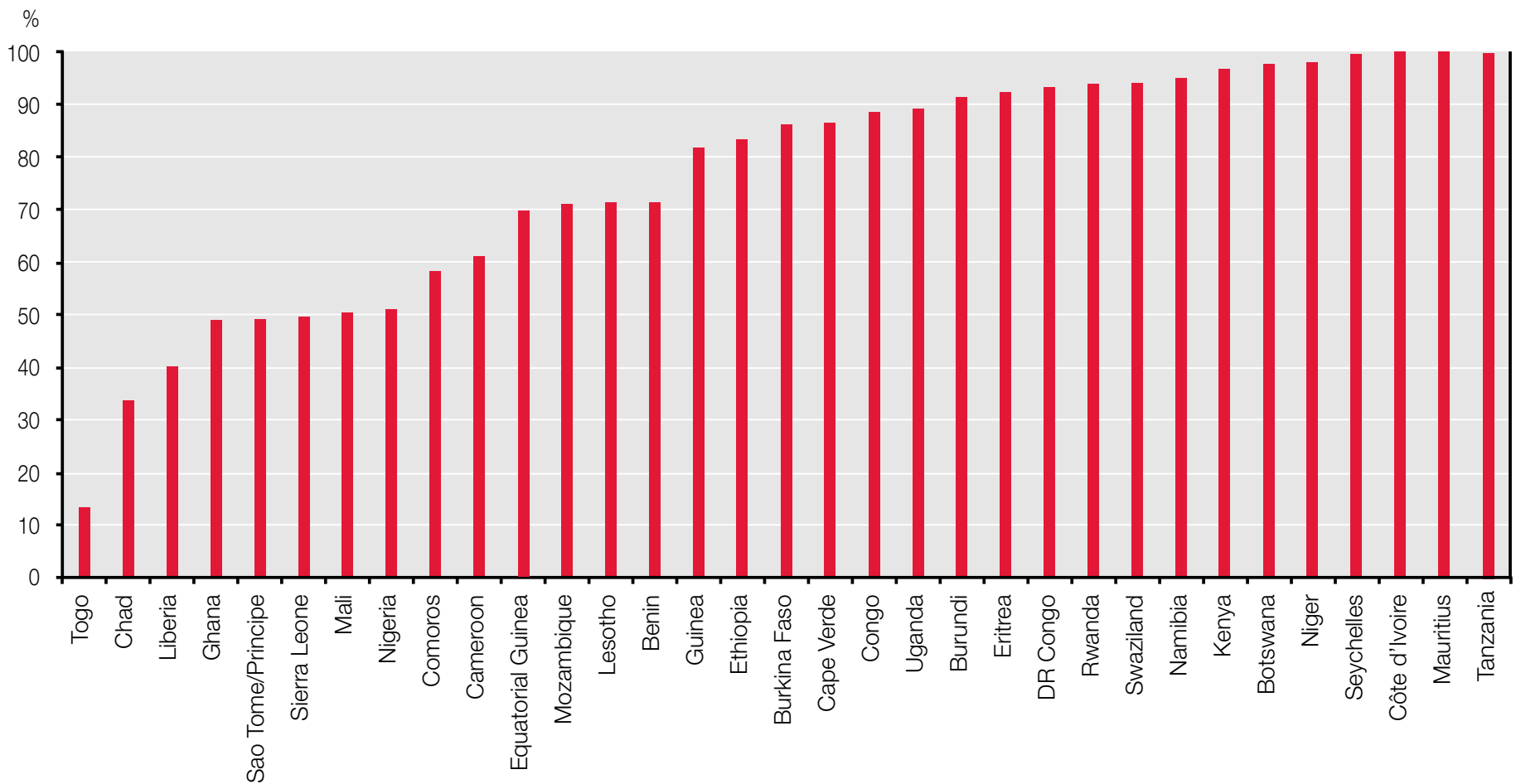

Source: UNESCO Institute for Statistics, Statistical Table A4.

\section{Figure 51}

GROSS ENROLMENT RATIO FOR PRE-PRIMARY EDUCATION, 2009 OR MOST RECENT YEAR

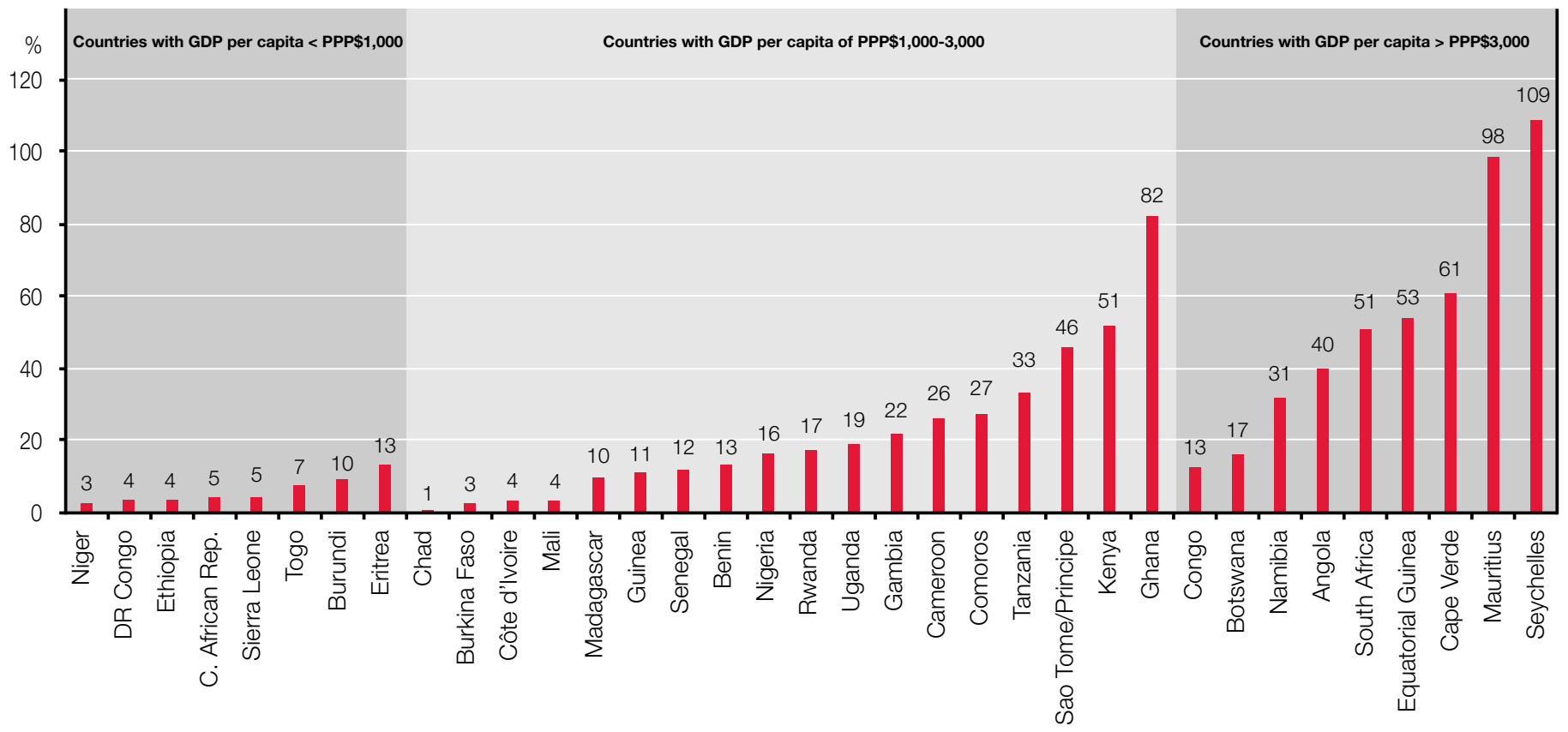

Source: UNESCO Institute for Statistics, Statistical Table A2. 


\section{PUBLIC EXPENDITURE ON PRIMARY EDUCATION PER PUPIL IN PPP\$, 2009 OR MOST RECENT YEAR}

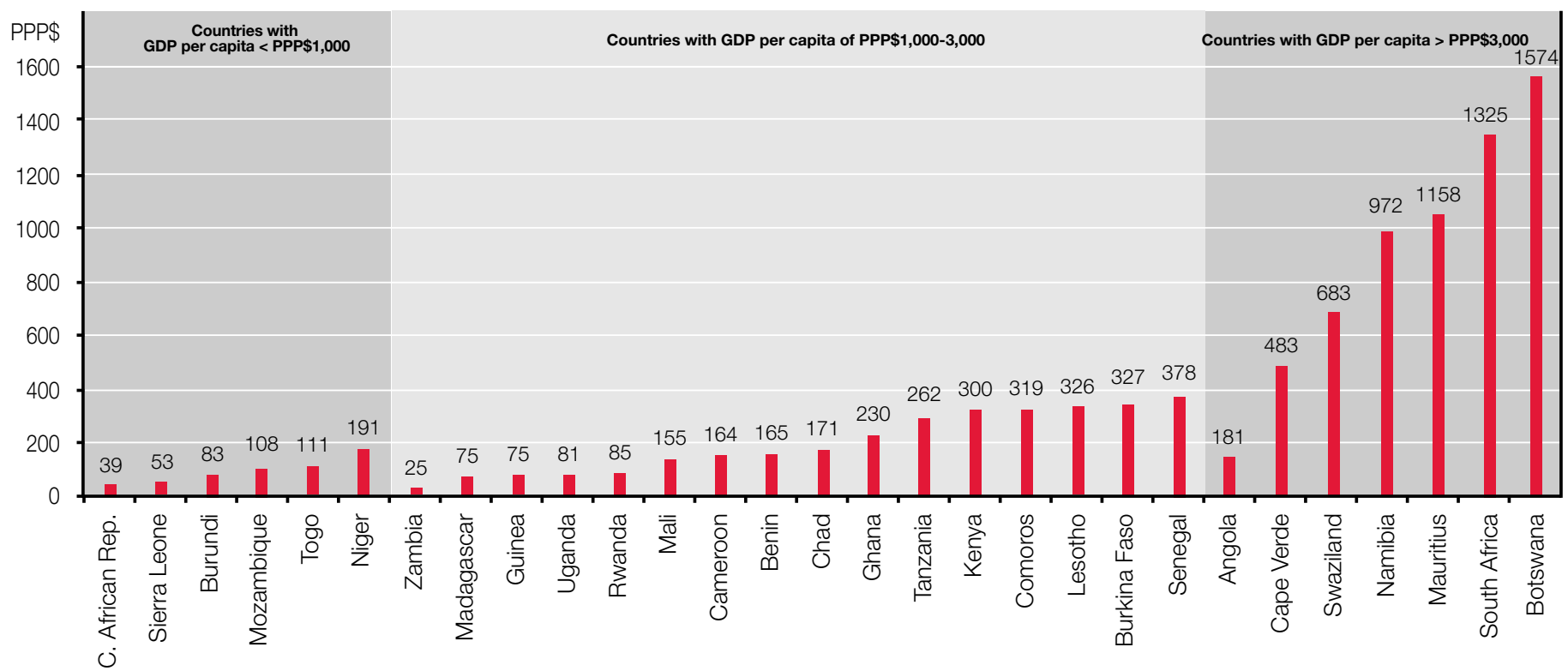

Source: UNESCO Institute for Statistics, Statistical Table A6.

In many SSA countries work is underway to measure other key elements impacting on education quality, including: the number of days and hours that schools are open; student time spent learning; teacher attendance and absenteeism; student attendance; assessment methods for monitoring student progress; classroom methodology and management; issues related to language of instruction; and actual use of textbooks in the classroom. Up to now, measurement of these key elements has been undertaken at the country level rather than for international comparative purposes. Continued and strengthened collection of data of this sort will be essential.

\subsection{ALLOCATION OF RESOURCES FOR IMPROVED LEARNING}

All countries in the region face resource constraints, especially since they are struggling with expanding access in order to reach EFA goals. In this context, it is crucial that each country allocates resources to the activities that yield the largest impact but require the least resources. This involves careful thought about financing options and trade-offs.

There is no single theory on how the quality of education can be improved in Africa. One recent study (Fehler et al., 2006) summarises what is known about the impact of interventions in basic education in Africa. Another study (Scheerens, 2004) examines worldwide research on the subject. These and other reports suggest an evolving consensus on what works.
Time on task, especially actual teaching time, is considered to have a major impact on learning. While teachers are critical to the learning process, the quality of teacher training is more important than the number of years of training.

Yet, how the level of teacher training and the size of the classroom affect learning vary considerably from one country to another. Putting textbooks and other pedagogical materials into the classroom, especially in resource-poor environments, has an impact on learning (as long as they are actually being used!). Pre-schooling also has an impact on school retention and learning achievement. As noted earlier, the ability of an education system to efficiently transform available resources into learning for all, especially for the poor, depends not only on inputs but also on its capacity for policy formulation and implementation, planning, finance, student assessment, human resource management, and intergovernmental and external partnerships. In contrast with more developed regions, the effectiveness of schools is relatively more important in SSA than the socio-economic background of students.

In any event, SSA countries need to determine what their key priorities and trade-offs will be for investing in education quality. Cost effectiveness research can be helpful when deciding how to invest in quality. This approach uses sample surveys to estimate the extent to which particular interventions increase learning achievement, estimates the costs of these 
interventions, and then calculates the "cost effectiveness" of each intervention (see Levin and McEwan, 2001). A study of basic education in northeast Brazil (Harbison and Hanushek, 1992) pioneered this approach. Since then its use has been rare, considering the large amounts of money that have been devoted to meeting EFA goals and MDGs. The fact is that most decisions on investments in basic education are based on consensus agreement rather than on analysis and data. The lack of good analytical work is in part due to the complexity and cost of these studies. However, increased information on student achievement now provides a stronger basis for identifying the priorities for investing in the quality of basic education, and a number of efforts are currently underway to more systematically identify the costs and effectiveness of policy options.

SACMEQ countries have made some progress in this respect. Country analyses identify the status quo of learning achievement among students and then make a variety of recommendations for policy interventions that are expected to have an impact, based on a survey attached to the SACMEQ tests. The country analyses also offer rough estimates of the costs of these interventions, categorising them as "low", "medium" or "high", and indicate whether the interventions are for the short, medium or long term. The policy recommendations are based in part on SACMEQ research but also on analyses of issues in individual countries. For example, the Malawi study makes 50 policy recommendations in all, divided into five categories: consultations with staff and experts; reviews of existing planning and policy procedures; data collection for planning purposes; education policy research projects; and investment in infrastructure and human resources (Chimombo et al., 2005).
Attempts have also been made recently to link the impact of interventions as identified by test scores with the costs of these interventions. Table $\mathbf{1 3}$ provides such an analysis based on the results of the primary school leaving certificate (CEPD) test in Togo.

The analysis reveals that textbooks, teacher qualifications, level of education of teachers and building quality all impact primary school leaving examination scores. However, the PTR does not appear to have any significant relationship with such scores. Increasing the level of education of teachers from primary to lower secondary level has a big impact, but there is only a small increase in scores when the level of education of teachers increases from lower to upper secondary level. According to the analysis, the distribution of textbooks is by far the most cost-effective of the five interventions. ${ }^{65}$ Distributing textbooks to an additional $10 \%$ of students increases scores by $0.44 \%$, at a cost of only 200 CFA $^{66}$ per student. Higher teacher qualifications increase the score by $9.6 \%$, but the cost is 9,300 CFA per student.

To overcome the inadequacies of cost effectiveness research in the SSA region, Schiefelbein and Wolff (2007) take a different approach. The authors created a list of 46 possible primary school interventions on learning and estimated impact based on a survey of expert opinion. ${ }^{67}$ These interventions can be placed into 12 categories: time on task; academic management; salary levels; management and decentralisation; testing; textbooks and learning materials; school meals and health interventions; pre-schooling; teacher training;

\section{Table 13}

\section{COST EFFECTIVENESS ANALYSIS OF THE IMPACT ON LEARNING ACHIEVEMENT BASED ON PRIMARY SCHOOL LEAVING CERTIFICATE (CEPD) EXAMINATION IN TOGO, 2003}

\begin{tabular}{|c|c|c|c|c|}
\hline INTERVENTION & VARIATION & $\begin{array}{l}\text { IMPACT ON TEST } \\
\text { SCORE (\%) }\end{array}$ & $\begin{array}{c}\text { ASSOCIATED } \\
\text { COST PER } \\
\text { STUDENT (CFA) }\end{array}$ & $\begin{array}{l}\text { IMPACT ON SCORE } \\
\text { (\%) PER } 1000 \text { CFA }\end{array}$ \\
\hline Textbooks & Additional $10 \%$ of students with textbooks & 0.44 & 200 & 2.20 \\
\hline Students per teacher & Reduction of the number of students per class by 10 & 0.00 & 8,470 & 0.00 \\
\hline \multirow{2}{*}{ Level of qualification of teacher } & From CEPD to BEPC & 9.60 & 9,300 & 1.03 \\
\hline & From BEPC to Bac & 0.30 & 12,000 & 0.03 \\
\hline Initial professional training of teacher & Additional $10 \%$ of teachers receiving initial professional training & 0.41 & 930 & 0.44 \\
\hline Building quality & Improve the quality of the classroom & 1.20 & 5,000 & 0.24 \\
\hline
\end{tabular}

Notes: CEPD: Certificat d'études du premier degré or primary school leaving certificate. BEPC: Brevet d'études du premier cycle or lower secondary leaving certificate. Bac: Baccalauréat or upper secondary leaving certificate.

Source: World Bank, 2003.

65 Fehrler, Michaelowa and Wechtler (2006) also conclude from PASEC data that textbook possession for mathematics in all grades and for French in Grade 2 has a significant impact on learning achievement. They also find that the availability of a classroom library has a positive impact on learning.

66 Exchange rate is US $\$ 1=581.20$ CFA in 2003.

${ }_{67}$ The survey was conducted among 23 ainternational education planners and economists, mainly working in universities and international agencies, all of whom were well acquainted with educational research and had an understanding of attempts at educational reform in the SSA region. 
curriculum reform; use of technology; and packages of linked interventions. Each respondent was asked to quantify the potential impact of each intervention, as well as indicate the probability that it would be adequately implemented. The authors then estimated the incremental unit costs of these interventions, which ranged from almost nothing to 20\%-50\% of unit costs.

Based on this expert opinion, the authors created an index ranking the cost effectiveness of each of the 46 interventions. As shown in Table 14, a number of interventions could have a significant impact on learning at almost no cost. These include: assigning the best teachers (for reading and writing) to Grade 1; enforcing regulations on the official length of the school year; enforcing student attendance policies; paying teachers regularly; and ending the practice of switching teachers during the school year and rotating teachers and principals among schools. Most of these interventions require improved management, which could be difficult to achieve and may incur additional costs. Interventions of moderate to high cost, but with a significant estimated impact, include: testing students and training teachers based on the test results; making textbooks available to each student; producing learning materials for individualised instruction; and so on.

Furthermore, the survey identified some expensive interventions that appear to have a low impact on learning achievement and, therefore, have very low cost effectiveness. These interventions include computers, school feeding programmes for all children, major decreases in student-teacher ratios without changing teaching methodology, and major increases in teacher salaries without better training.

It is also known that many school inputs have a diminishing rate of return. The marginal impact of the input is high when it is offered for the first time, but the impact becomes smaller as the input becomes more available (Orivel, 2004).

In short, while more money is absolutely needed to improve education quality in SSA countries, these funds should be spent carefully and effectively. Applied research can identify promising avenues for investment and then confirm if the desired impact has been achieved. With the improvement of technical quality and reliability of student assessments, it is increasingly feasible to estimate the impact of education investments. But to inform policy decisions, the costs of proposed quality improvement programmes must be made clear and alternatives analysed. At the same time, research will have an impact only if it is used. Therefore, a major task in the region is to make policymakers, opinion leaders and politicians aware of the need to identify options and potential trade-offs when investing in the quality of education.

\section{Table 14}

\section{KEY COST-EFFECTIVE AND HIGH-IMPACT INTERVENTIONS}

INTERVENTIONS WITH VERY LOW COST AND HIGH COST EFFECTIVENESS

Assign best teachers to $1^{\text {st }}$ grade

Enforce official length of school year

Enforce school attendance policies

Pay teachers regularly

Do not rotate teachers during the year

INTERVENTIONS WITH MODERATE COST AND HIGH ESTIMATED IMPACT ON LEARNING ACHIEVEMENT

Test $4^{\text {th }}$ graders and train all teachers for one week on results

Give students two standard textbooks and train teachers for one week in their use

Learning materials for individualized instruction

Interactive instruction by radio

Train teachers in cooperative learning

Source: Prepared by the authors, based on Schiefelbein and Wolff (2007)

\subsection{CONCLUSION}

This chapter has reviewed a number of critical issues related to making quality the main focus of dialogue and priority-setting in basic education. This includes increased attention to monitoring learning outcomes, collecting better data on key enabling inputs, undertaking applied research to identify the best mix of policy interventions, and bringing these results to the attention of policy- and decisionmakers. An additional challenge will be to go beyond basic education and begin examining issues related to quality in secondary and higher education.

The SSA region has made significant progress in measuring learning outcomes. All SSA countries that receive FTI support are committed to developing national learning assessments, and 22 have already implemented them. Fifteen countries in southern and eastern Africa now participate in SACMEQ, and 13 countries (mainly Francophone) participate in PASEC. A number of countries are also developing Early Grade Reading Assessments (EGRA) as a tool for identifying reading problems in Grades 1 and 2. But much still needs to be done in order to strengthen analytical capacity, comparability, data dissemination and use. One way to focus more attention on learning outcomes is to develop more informative and meaningful indicators. A single indicator linking completion rates and learning achievement will encourage policymakers to focus on learning rather than simply on completion rates.

Basic education inputs vary greatly from one country to another. For instance, student-teacher ratios are inordinately high and expenditure per student is very low in some SSA countries, while in others the opposite is true. Much work is needed to regularise the reporting of standard indicators and to address 
the many inadequacies in the reporting of internationally comparable input variables related to education quality in the region. In many SSA countries, work is underway to measure other key factors impacting on education quality. Up to now, data collection for these indicators has been undertaken at the country level rather than for international comparative purposes. Continued and strengthened collection of key data of this sort will be essential.

While more money is absolutely needed to improve education quality, these funds should be spent carefully and effectively. Applied research can identify promising avenues for investment and then confirm if the desired impact has been achieved. With the improvement of technical quality and reliability of student assessments, it is increasingly feasible to estimate the impact of education investments. But to inform policy decisions, the costs of proposed quality improvement programmes must be made clear and alternatives analysed. However, research will have an impact only if it is used. Therefore a major task in the region is to make policymakers, opinion leaders and politicians aware of the need to identify options and potential trade-offs when investing in the quality of education.

This chapter has not sought to review the issue of quality in post-primary education. Nonetheless, as SSA increasingly faces the complex issues of expanding and improving secondary, vocational/technical and higher education, countries in the region will inevitably have to consider how to improve quality at these levels and what it will cost. The task will be difficult because of the financial implications of meeting social demand for expansion at these levels and the risks that quantitative growth will negatively impact on quality. It appears that in secondary education quality can be measured through learning achievement tests at the end of each cycle, which are already given. Until recently, these examinations have been used solely to evaluate students and not to assess the performance of the secondary school system. While they have many weaknesses in terms of reliability and validity (see Kellaghan et al., 2009), these tests can be improved to better identify the minimum skills and knowledge expected of a secondary school graduate. Another option is to participate in international programmes such as PISA, which conducts learning assessments of 15-year-olds.

Measures of quality in secondary, vocational/technical and higher education are often related to performance in the labour market. An effective means of measuring the quality of vocational/technical education and training is to conduct tracer studies, which confirm whether graduates have jobs, are performing adequately in the areas in which they were trained, and/or have higher salaries. In addition, tests of knowledge of college graduates are increasingly being discussed in OECD and other countries. The OECD is currently developing the Assessment of Higher Education Learning Outcomes (AHELO) in order to test the knowledge of college graduates on generic and discipline-specific skills (OECD, 2010b). 


\title{
Chapter 6
}

\section{EDUCATION FINANCING IN SUB-SAHARAN AFRICA: REAL GAINS BUT MANY CHALLENGES}

\author{
Shinsaku Nomura (UNESCO Institute for Statistics) \\ Laurence Wolff (Consultant)
}

\subsection{INTRODUCTION}

Notable progress has been made in educational development in SSA, especially during the last decade. Enrolment in primary education increased from 87 million to 129 million (48\% growth) between 2000 and 2008; enrolment in pre-primary, secondary and tertiary education increased respectively from 6.6 million to 10.9 million (65\% growth), 22 million to 36 million (65\% growth), and 2.5 million to 4.5 million (82\% growth). This achievement in enrolment expansion was accompanied by increased levels of expenditure on education in most countries and increased commitments of national and international stakeholders since the World Education Forum (WEF) in 2000. Real expenditure on education increased on average by $6.1 \%$ per annum since 2000 among 26 countries with available data. Expenditure per primary pupil also increased in 13 out of 15 countries. ODA for education in the region increased from US\$1.1 billion in 2002 to US\$2.6 billion in 2008. Nonetheless, SSA countries continue to face the dilemma of how best to balance scarce available resources with growing demands for improving the region's education systems.

This report has aimed to provide policymakers of SSA countries with a solid platform of data on education financing, as well as analytical discussions of policy issues related to financing. This concluding chapter synthesises the issues related to the costs and financing of education and discusses the challenges ahead. It begins by outlining the key findings and conclusions that have emerged in preceding chapters. This is followed by a synthesis of findings, especially in terms of setting priorities. To set priorities, it is essential for policymakers to recognise that there are external constraints, as well as opportunities, and to pursue evidence-based decisionmaking supported by regular use of solid educational and financial data.

\subsection{SUMMARY OF KEY FINDINGS}

\section{The external environment}

Supported by increased national and international commitments under MDGs and EFA initiatives, SSA countries experienced rapid enrolment growth during the past decade. Primary enrolment increased by 42 million between 2000 and 2008, and the primary GER increased from $82.2 \%$ to $101.6 \%$. However, the region still faces particular challenges in meeting EFA goals and ensuring sustainable educational development because of many constraints inherent in the external environment. These include economic vulnerability that could undermine growth, weak resource mobilisation and disbursement, demographic pressure due to a $2.4 \%$ population growth, and weak governance. Ongoing conflicts in some SSA countries, a prevalence of HIV/AIDS and other health concerns are also important external issues impacting on educational development in the region.

To achieve rapid educational development during the 2000s, governments of SSA countries and development partners have increased commitments and efforts. In some countries, the level of commitment is already very high, as can be seen from the large share of the government budget allocated to the education sector. Therefore, it may be difficult for them to raise additional funds for educational development in the context of persisting external challenges. At the same time, the international community has witnessed the emergence of new regional initiatives and the more active role being played by civil society organizations. Similarly to the first decade of the 2000s during which strengthened partnerships and political will led to enrolment expansion, these new initiatives offer new opportunities for educational development.

\section{Progress and challenges in enrolment, funding and equity} Funding and allocation are two important aspects of education financing. As evident from the annual $6.1 \%$ growth in real education expenditure among 26 countries during the 2000s, most SSA countries are increasingly committed to providing more resources for educational development. On average, SSA countries allocate $18.3 \%$ of public resources to the education sector. The contribution of donors to educational development is also significant in many SSA countries. The total amount of disbursed ODA to the education sector in the region was US\$2.6 billion in 2008 (OECD-DAC, 2010), indicating that $5.6 \%$ of education resources for SSA are financed by donors. 
Expenditure per student also increased in 13 out of 15 countries with available data. This indicates that the increased public education expenditure was not only used to accommodate the rising number of new pupils but to maintain or possibly improve the quality of education.

Despite these major efforts, financing gaps still exist for achieving EFA targets in many SSA countries, especially those under strong demographic pressure and increasing demand for quantitative and qualitative improvement of education. While more resources are required for educational development in SSA countries, it is not likely that domestic resources will increase rapidly through economic growth or that donors will provide ever more financial support. Therefore, an important means for securing more funds is to first make sure that all committed amounts of ODA are effectively disbursed. Between 2002 and 2008, the discrepancy between donor commitment and disbursement was around 9\% (or US\$221 million) every year.

It is also important to strategically reallocate resources within the education sector. There is no doubt about the necessity of having balanced sector development at all levels of education, in both quantitative and qualitative terms; yet, prioritising resources by level and nature of expenditure is essential to reach EFA targets. This reallocation of resources within the education sector can be a real option for countries that have not achieved UPE and that have assigned a relatively small share of resources to primary education. The reallocation of resources within the education sector can also contribute to reducing inequality among students at different levels of education.

\section{Teacher remuneration - Finding the right balance to ensure motivation, quality and sustainability}

Teacher remuneration usually constitutes the single largest component of education expenditure by accounting for more than one-half of recurrent expenditure. While the average for the SSA region is 69\%, the share taken up by teacher salaries varies by country and level of education; Nigeria and South Africa, for example, spend more than $90 \%$ of recurrent expenditure on teacher salaries at the primary education level. Under these circumstances, the issue of teacher remuneration is particularly important when considering the sustainability of education financing in SSA. It is estimated that the region will need 1 million additional teachers by 2015 in order to provide education of sufficient quality at the primary level.

A good teacher remuneration policy is important for two key reasons. First, it can help to make the profession attractive and motivate teachers. The policy also determines how many teachers with what types of qualifications can be hired within a limited budget. Over the last 30 years, average teacher salaries have decreased in relation to national wealth across SSA countries from 8.4 fold of GDP per capita in 1975 to
4.0 in the 2000s. This decrease reflects various financial constraints and efforts to overcome such constraints. New categories of teachers with different pay scales, such as contract teachers, have emerged, as well as new management procedures, such as community-based recruitment and payment. In order to ensure sustainable development of education in SSA, it is essential to also achieve sustainable financing of teachers, including a good balance between reasonable levels of pay and provision of professional development paths for teachers.

Teacher remuneration, recruitment and management issues, however, have to be considered in relation to other expenditure, including teaching and learning materials, administrative and supervision costs, maintenance of buildings, and capital expenditure. Because the resources for education are limited, they must be allocated wisely to provide students with adequate teaching services.

\section{Rising private sector involvement - Potential and pitfalls}

Governments are usually the main funders of education in SSA and elsewhere, but they are not the only source. Government funding is often complemented by inputs from external partners, students and households, and private entities. Private financing can complement government funding in public education institutions and it can also finance private schools. Yet, private contribution to education remains a neglected area of research and policy. Data on private contributions are scarce, and statistical indicators often focus on the public financing of education.

The largest proportion of private funding for education in SSA comes from households. Their contribution to total education expenditure is around $25 \%$, according to 16 countries with available data. To alleviate the financial burden on households, especially for the poor, school fees at primary schools have been abolished in a number of SSA countries since the 1990s. This has resulted in a rapid increase of primary school enrolment but has also created overcrowded classrooms and insufficient numbers of teachers. Affluent and middle-class families living in urban areas are aware of this trend and are gradually opting for private - rather than public - education. In a number of SSA countries, private school enrolment has been gradually rising since 2000. Sixteen out of 26 countries with data reported an increase at the primary level. At the same time, there was an increase in 8 out of 16 countries with data for the secondary education level.

Private sector contributions also vary by level of education. The proportion of household contributions increases from $29 \%$ at primary to $46 \%$ at the lower secondary level and to $41 \%$ at the upper secondary level. However, this proportion decreases to $22 \%$ in tertiary education, implying a very large government contribution to this level. The same phenomenon is observed for 
expenditure per tertiary student, which is also high. Considering the issue of equity in resource allocation, this distribution pattern might warrant being reviewed by many SSA countries, since most students who can enrol in a higher education institution tend to have relatively wealthy families.

Heavy constraints on government budgets, the desire to open schools to the external world, the notion of bringing market mechanisms to the field of education, and the idea that education involves all of society have led to increased diversification in the types of partnerships between governments and the private sector. While the motivation and modalities of their involvement vary, the growing role of private contributors brings a new opportunity for education financing in SSA. However, governments need to provide a framework to regulate and monitor these partnerships so that they coincide with national development goals.

Improving the quality of education while expanding access Because of persistent resource constraints, SSA countries face the dilemma of allocating more resources to improve the quality of education while also expanding access to education. Despite notable enrolment growth during the 2000s in SSA, the quality of education - as measured by students' learning achievement has remained relatively low. More than $20 \%$ of students in Grade 6 of primary education still do not master basic reading skills. This suggests a need for urgent action to improve the quality of education. There is growing recognition that children can stay in school and not learn much, making completion of primary school a hollow achievement. It is, therefore, crucial that national and international partners work together to put into place the right mechanisms to monitor the quality of education in SSA.

The region has made significant progress in measuring learning outcomes. The growing concern with education quality may be reflected by the greater participation of SSA countries in learning assessment programmes, such as SACMEQ and PASEC, as well as PIRLS and TIMSS. As a result, there is more data about the quality of education in the SSA region. Applied research is being conducted to use these learning achievement tests to assess the quality of education, including such aspects as enabling inputs and the learning environment.

\subsection{POLICY IMPLICATIONS FOR FINANCING EDUCATION IN SUB-SAHARAN AFRICA}

\subsubsection{Recognising persistent external constraints, growing educational demands and emerging opportunities}

Policymakers need to be aware of the impacts of external environments and opportunities on the development of education. This sector is not immune to external constraints, which include vulnerable economic growth, weak resource mobilisation and disbursement, demographic pressure (with $2.4 \%$ population growth in SSA), and weak governance.
Since the national government is usually the largest financier of education, financing is greatly affected by the economic growth and resource mobilisation of the country. In the context of already high commitments to educational development, allocating more resources to the education sector may not be realistic for some SSA countries because of the trade-offs this would require with other sectors. Effectively disbursing all the committed resources and delivering educational services to students under good governance are key for meeting education challenges successfully despite limited resources.

Policymakers should also be aware that the demand for education will continue to grow regardless of resource availability. The immediate challenge for SSA countries is the intake of 32 million out-of-school children of primary school age and the achievement of UPE. However, due to demographic pressure, these countries will need to expand access to primary school for an additional 77 million pupils between 2010 and 2030. At the same time, demand for upper levels of education will also grow rapidly. Secondary and tertiary enrolment grew respectively by $65 \%$ and $82 \%$ between 2000 and 2008.

Fortunately there are emerging opportunities which can facilitate progress in education. Since the Millennium Summit in 2000, governance of international aid has improved. The Paris Declaration of 2005 and the subsequent Accra Agenda for Action of 2008 have established a platform to accelerate aid harmonisation for all donors. A number of new initiatives and schemes for sustainable development in education have also been launched. Civil society organizations are playing a greater role in fostering good governance and accountability, and the private sector has become a stronger partner of development through innovative financing schemes and public-private partnerships.

\subsubsection{Addressing trade-offs by setting priorities}

Decisionmakers will need to choose a mix of policy options that enables them to reach the neediest populations and promote innovative opportunities for those who are capable and willing. In short, the central role of policymakers is to address difficult trade-offs and strategic choices. In particular, as more and more children complete primary education, demands for post-primary education will increase, and each country will face some difficult decisions, including:

- how much to spend on different levels of education;

- how much to spend on quantitative growth compared to qualitative improvement; and

- the extent to which policies should encourage the private sector and households to increase their financial participation in education. 


\section{How much to spend by level of education}

There are no simple formulas for deciding how much to spend by level of education. Nonetheless, there does appear to be an international consensus that the achievement of the EFA goals is essential. Although it is still uncertain, there is increasing evidence that many countries in the SSA region will not attain these goals by the year 2015. Therefore, a major effort must be made to fund primary education and find the right mix of inputs and programmes which will achieve quality education for all.

Redressing inequities, to the extent possible, continues to be a concern at all levels of education in the SSA region. Keeping children from disadvantaged backgrounds in school often means significant direct and indirect financial burdens for their families. Given the extent of poverty in the region, equity-enhancing policies will be able to address this issue only partially. Particularly important are the interventions that target marginalised and disadvantaged populations.

While achieving EFA is the priority that cannot be compromised, a more complex challenge in the region will be to design and implement appropriate policies for financing secondary, vocational/technical and higher education. As increasing numbers of children complete primary education, they will have an expectation to enter secondary education, and graduates of secondary education can naturally have the wish to enter tertiary education. Policies of expanding upper levels of education must be considered in terms of balancing resource requirements and availability, social demands and economic needs for a more highly skilled labour force. Policymakers should also consider to what extent the government is responsible for providing educational services to meet all the needs from society.

\section{How much to spend on quantitative growth compared to improving quality of education}

Providing UPE of adequate quality is not a simple task. While paying attention to the total amount of resources available to education and their allocation to different education levels are important, it is also essential to examine how resources are spent. Policies will need to be implemented on the basis of best practices in the region and worldwide. This will likely include increasing time on task for students, providing adequate textbooks and learning materials, and ensuring quality teaching and learning practices. Teacher salary and recruitment policies will need to be calibrated to encourage higher academic levels of entering teachers and ensure commitment, which should at least include regular classroom attendance. Salary incentives could be provided selectively for teachers working in rural or underprivileged areas, and salary ladders could reward competence and results.
Despite resource constraints, efficiency gains are possible without compromising the quality and quantity of services if the right interventions are chosen. By taking into account evidence on cost effectiveness, policymakers can become aware of the options to reach intended results. The right choice of interventions is possible by clearly addressing the expected result of the action taken, determining whether goals are being achieved, and then revising programmes and policies as needed.

\section{The extent to which policies should encourage the private sector and households to increase their financial participation in education}

A critical policy question revolves around private expenditure on education. Improvement of public educational services has been achieved through increased accountability as a result of involving civil society. Also, without expansion of private expenditure, including household expenditure, governments will simply not be able to meet social demands for education. Therefore, it is inevitable that policymakers consciously develop policies, with adequate oversight to ensure transparency, for the provision of private educational services. In particular, it is essential that these policies specifically address the equity issues that will accompany growth in the private education sector.

Policymakers should think flexibly about options for providing post-primary educational services by allowing diversification of funding sources. Considering that in the SSA region households provide $22 \%$ of tertiary education resources, which is less than their contribution for primary education (29\%), there is room for reconsidering the role of the private sector in financing upper levels of education. Regulation of private education is important, but it should be of the right type, creating an enabling environment and encouraging both quality and equity. By allowing the private sector to finance upper levels of education, limited public resources for education can be effectively directed towards priority areas. The elements of an effective policy with regard to private and household expenditure in post-primary education could include the following: co-financing and co-management with industry of vocational/technical training; increased public sector tuition and fees; and provision of loan and scholarship programmes in higher education ${ }^{68}$.

\subsection{EVIDENCE-BASED PLANNING USING EDUCATION AND FINANCE DATA}

\section{Programme-based budgeting and use of sector-wide financial simulation models}

Many SSA countries use traditional line item budgeting, which specifies the amount of money a particular agency or sub-unit

\footnotetext{
68 Effective loan schemes require a strong and independent implementation agency, as well as a functioning tax and reporting system. Many SSA countries currently lack these prerequisites, but this should not hamper initiating loan schemes on a pilot basis and building the necessary institutional infrastructure.
} 
will spend on personnel, fringe benefits, travel, equipment, etc. The strength of such a system lies in its relative simplicity, clarity and potential for control of expenditure through easy comparison with prior years and through detailed specification of inputs (World Bank, 1998). However, this budgeting system is often too rigid to allow strategic shifts of resources to priority areas, and it gives no information about why money was spent or about the efficiency and effectiveness of programmes. It is often oriented more towards short-term rather than longterm planning. If decisions are made on the basis of politics, social pressures and lobbying, rather than on the basis of strategic and long-term visions, then everything becomes a priority to please all stakeholders. But in effect, nothing is a priority.

Programme-based budgeting, built upon medium- to longterm development plans, has the advantage of focusing on budgetary choices among competing policies and offers an alternative to the traditional manner of budgeting, which focuses on marginal adjustments to the status quo (World Bank, 1998). In particular, education ministries could begin by adopting a financial simulation model for modelling the impact of different policy options. This approach permits testing of the feasibility of different policy options and provides a means of estimating the funds needed to implement the chosen policy in the education sector. Integrating all the sub-sectors in the same model provides a way of confirming the compatibility of subsector policies. Usually several ministries manage the education sector, each with a different perspective on the development of the sub-sector under their responsibility. Therefore, a major advantage of integrated financial simulation models is that they provide a means of validating an overall education development policy that is both coherent and shared by all.

\section{Need for credible education finance data}

Adopting programme budgeting, as well as any evidencebased decisionmaking, requires credible information. It is rare that education statistical reports cover the assessment or cost implications of different policy options that can be used for strategic decisionmaking. This is partly because education ministries are often implementers of educational services, while finance ministries have the main responsibility for planning and allocating budgets, as well as monitoring expenditure.

In making and implementing policies, SSA governments need to strengthen the quality of their education statistics, with particular reference to collecting, publishing and utilising data on education expenditure and financing that are relevant for policymaking. Planning offices in ministries of education will need to ensure that they know how much they are spending, through developing and designing data-sharing procedures with the ministry of finance, other ministries and regional authorities. It will be particularly important for countries with more decentralised administrative systems - such as Ethiopia, Nigeria and the United Republic of Tanzania to monitor and review regional and local expenditure, and to design financing policies that help to reduce inequities between and within provinces and regions. Much more data are needed to understand and measure the growth of household expenditure on education and private provision of educational services. More effective monitoring of learning outcomes, as well as more research on what works (by linking costs and effectiveness), are also needed.

Effective information-sharing at the international level will increase the mutual benefits of neighbouring countries. All SSA countries are struggling with demands placed on their education systems. International and historical comparisons can help these countries to understand how their systems compare with others, as well as help to identify the problems that can be anticipated as they progress through stages of educational development.

In sum, to make the most efficient and effective use of limited resources, it is essential for SSA countries to have comprehensive education finance data for strategic planning and decisionmaking, as well as for monitoring progress. 


\section{REFERENCES}

Abadzi, H. (2006). Efficient Learning for the Poor. Washington, D.C.: World Bank.

African Development Bank (AfDB) (2008). African Development Report 2008/09: Conflict Resolution, Peace and Reconstruction in Africa. New York: Oxford University Press.

African Development Bank (AfDB) and OECD (2009). African Economic Outlook 2009. Paris: OECD.

African Growth and Opportunity Act (AGOA) (2010). Accessed at: http://www.agoa.info/index.php?view=trade_stats\&story=agoa_trade on 16 March 2010.

Bernard, J. M., B. K. Tiyab and K. Vianou (2004). "Profils enseignants et qualité de l'éducation primaire en Afrique subsaharienne francophone : Bilan et perspectives de dix années de recherche du PASEC". Dakar: PASEC/CONFEMEN.

Brossard, M. and B. Foko (2007). "Les acquisitions scolaires et la production d'alphabétisation de l'école primaire en Afrique: Approches comparatives". Note théma n², avril 2007. Dakar: Pôle de Dakar.

Brossard, M., B. Ledoux and F. Ndem (2006). "Eléments d'analyse du secteur éducatif au Togo." Dakar: Pôle de Dakar.

Bruns, B., A. Mingat and M. Rakotomalala (2003). Achieving Universal Primary Education by 2015: A Chance for Every Child. Washington D.C.: World Bank.

Chimombo, J., D. Kunje, T. Chimuzu and C. Mchikoma (2005). "The SACMEQ II Project in Malawi: A Study of the Conditions of Schooling and the Quality of Education". Harare: SACMEQ.

Djamé, R. et al. (2000). "Les écoles privées au Cameroun". Working paper series "Mécanismes et stratégies de financement de l'éducation". Paris: UNESCO-IIEP.

Fehrler, S., K. Michaelowa and A. Wechtler (2006). "The cost-effectiveness of inputs in primary education: Insights from recent student surveys for sub-Saharan Africa”. Dakar: Pôle de Dakar.

Göttelmann-Duret, G. (1998). "La gestion des enseignants de premier cycle au Bénin, Burkina Faso, Mali et Sénégal”. Working paper. Paris: UNESCO-IIEP.

Hanushek, E. A., S. G. Rivkin and L. L. Taylor (1996). "Aggregation and the estimated effects of school resources."

The Review of Economics and Statistics. Vol. 78(4): 611-627.

Harbison, R. W. and E. A. Hanushek (1992). Educational Performance of the Poor: Lessons from Rural Northwest Brazil.

New York: Oxford University Press.

International Labour Organization (ILO)/UNESCO (1966). "Recommendation concerning the Status of Teachers". Adopted by the Special Intergovernmental Conference on the Status of Teachers, Paris, 5 October 1966. Paris: ILO/UNESCO. Accessed at: http://portal.unesco.org/en/ev.php-URL_ID=13084\&URL_DO=DO_TOPIC\&URL_SECTION=201.html

International Monetary Fund (IMF) (2010). "Debt Relief under the Heavily Indebted Poor Countries (HIPC) Initiative".

Factsheet. Washington, D.C.: IMF.

Kaufmann, D., A. Kraay and M. Mastruzzi (2008). "Governance Matters VIII: Aggregate and Individual Governance Indicators, $1996-$ 2008”. World Bank Policy Research Working Paper No. 4978. Washington D.C.: World Bank.

Kellaghan, T., V. Greaney and T. Scott Murray (2009). Using the Results of a National Assessment of Educational Achievement. Washington, D.C.: World Bank. 
Lee, V. E., T. Zuze and K. Ross (2005). "School effectiveness in 14 Sub-Saharan African countries: Links with 6 $6^{\text {th }}$ graders' reading achievement”. Studies in Educational Evaluation, Vol. 31(2-3): 207-246.

Levin, H. M. and P. J. McEwen (2001). Cost Effectiveness Analysis: Methods and Applications. New York: Sage Publications.

Michaelowa, K. (2000). "Nouvelles approches aux indicateurs éducatifs: Les indicateurs «traditionnels» de quantité et le défi de la qualité". In J.-J. Friboulet, V. Liechti and P. Meyer-Bisch (eds), Les Indicateurs du droit à l'éducation: la mesure d'un droit culturel, facteur du développement, pp.135-161. Switzerland: Fribourg.

Mingat, A., B. Ledoux and R. Rakotomalala (2010). Developing Post-Primary Education in Sub-Saharan Africa: Assessing the Financial Sustainability of Alternative Pathways. Africa Human Development Series. Washington D.C.: World Bank.

Mingat, A and B. Suchaut (2000). Les systèmes éducatifs africains: Une analyse économique comparative.

Brussels: De Boeck Université.

Mulkeen, A. (2008). "Teacher issues in Liberia: Africa Region Human Development”. Working Paper. Washington, D.C.: World Bank. Mulkeen, A. (2010). Teachers in Anglophone Africa: Issues in Teacher Supply, Training, and Management. Development Practice in Education. Washington, D.C.: World Bank.

Ndaruhutse, S. (2007). Grade Repetition in Primary Schools in Sub-Saharan Africa: An Evidence Base for Change. London: CfBT Education Trust.

OECD (2006). 2005 Development Co-operation Report. Vol. 7(1). Paris: OECD.

OECD (2008). "Is it ODA?" OECD Factsheet, November 2008. Accessed at: http://www.oecd.org/dataoecd/21/21/34086975.pdf on 18 November 2010.

OECD (2010a). The High Cost of Low Educational Performance: The Long-Run Economic Impact of Improving PISA Outcomes. Paris: OECD.

OECD (2010b). "Testing student and university performance globally: OECD AHELO". Accessed at: http://www.oecd.org/edu/ahelo on 14 September 2010.

OECD-DAC (2010). Query Wizard for International Development Statistics (QWIDS). Accessed at: www.oecd.org/dac/stats/qwids on 23 July and 17 November 2010.

Orivel, F. (2004). Preface to: Monitoring Educational Achievement, by T.N. Postlethwaite. Paris: UNESCO-IIEP.

PASEC (2008). "Indicateurs PASEC sur la qualité de l'éducation". Working Paper. Dakar: PASEC/CONFEMEN.

Patrinos, H. A. and R. Kagia (2007). "Maximizing the Performance of Education Systems: The Case of Teacher Absenteeism". In J.E. Campos and S. Pradham (eds.), The Many Faces of Corruption: Tracking Vulnerabilities at the Sector Level. Washington, D.C.: World Bank.

Pôle de Dakar (2009). Universal Primary Education in Africa: The Teacher Challenge. Dakar: UNESCO-BREDA.

Pôle de Dakar (forthcoming). "Education Sector Country Status Report: Tanzania”. Dakar: UNESCO-BREDA.

UN Population Division (2010). World Population Prospects: The 2008 Revision. Accessed at: http://esa.un.org/unpp on 16 March 2010.

Postlethwaite, T.N. (2004). Monitoring Educational Achievement. Paris: UNESCO-IIEP.

Psacharopoulos, G. and H. A. Patrinos (2002). "Returns to investment in education: A further update". Policy Research Working Paper No. WPS2881. Washington, D.C.: World Bank.

Rajkumar, A.S. and V. Swaroop (2008). "Public spending and outcomes: Does governance matter?" Journal of Development Economics. Vol. 86(1): 96-111. Washington, D.C.: World Bank. 
Republic of South Africa (2000). "South African Languages Bill, 19 July 2000". Department of Arts and Culture website.

Assessed at: http://www.dac.gov.za/bills/sa_language_bill.pdf

Scheerens, J. (2004). "Review of School and Instructional Effectiveness Research". Contribution to Chapter 3 of the 2004 EFA Global Monitoring Report. Paris: UNESCO.

Schiefelbein, E. and L. Wolff (2007). "Cost-Effectiveness of Primary School Interventions in English Speaking East and West Africa: A Survey of Opinion by Education Planners and Economists". Accessed at: http://www.educationfasttrack.org/themes/learningoutcomes/

UNAIDS (2009). AIDS Epidemic Update, December 2009. Geneva: UNAIDS.

UNDP (2009). Human Development Report 2009. Overcoming Barriers: Human Mobility and Development. New York: UNDP. UNESCO (2000). The Dakar Framework for Action, Education for All: Meeting our collective commitments, including six regional frameworks for action. Adopted by the World Education Forum, Dakar, Senegal, 26-28 April 2000. Paris: UNESCO.

UNESCO (2004). EFA Global Monitoring Report 2005. Education for All: The Quality Imperative. Paris: UNESCO.

UNESCO (2005). EFA Global Monitoring Report 2006. Education for All: Literacy for Life. Paris: UNESCO.

UNESCO (2008). EFA Global Monitoring Report 2009. Education for All: Overcoming Inequality: Why Governance Matters.

Paris: Oxford University Press.

UNESCO (2010a). Atlas of the World's Languages in Danger. Third edition. Paris: UNESCO:

UNESCO (2010b). EFA Global Monitoring Report 2010. Education for All: Reaching the Marginalized. Paris: Oxford University Press.

UNESCO and UNESCO-BREDA (Pôle de Dakar) (2010). Analysing Teacher Issues in Africa: A Methodological Guide.

Preliminary version, January 2010. Paris: UNESCO; Dakar: UNESCO-BREDA.

UNESCO Institute for Statistics (UIS) (2005). Children Out of School: Measuring Exclusion from Primary Education. Montreal: UIS.

UNESCO Institute for Statistics (UIS) (2007). Global Education Digest 2007: Comparing Education Statistics Across the World. Montreal: UIS.

UNESCO Institute for Statistics (UIS) (2010). "The Global Demand for Primary Teachers - 2010 Update". UIS Information Sheet No. 5. Montreal: UIS.

UN-HABITAT (2010). "Balanced Development for Africa: The Cities of the Future - Beyond Chaotic Urbanization". Statement by Mrs Anna Tibaijuka, Under Secretary-General and Executive Director of UN-HABITAT at the $1027^{\text {th }}$ Wilton Park Conference, West Sussex, United Kingdom, 5 February 2010.

UNICEF (2006). The State of the World's Children 2007. New York: UNICEF.

UNECA and African Union (AU) (2008). Assessing Regional Integration in Africa 2008: Towards Monetary and Financial Integration in Africa. Addis Ababa: UNECA.

Verspoor, A.M. with the SEIA Team (2008). At the Crossroads: Choices for Secondary Education in Sub-Saharan Africa. Africa Human Development Series. Washington, D.C.: World Bank.

Wolfe, B.L. and S. Zuvekas (1997). "Non-Market Effects of Education". International Journal of Education Research. Vol. 27(6): 491-502.

Woodhall, M. (2004). Cost-Benefit Analysis in Educational Planning, $4^{\text {th }}$ Edition. Paris: UNESCO-IIEP.

World Bank (1998). Public Expenditure Management Handbook. Washington, D.C.: World Bank.

World Bank (2000). Global Development Finance 2000. Washington, D.C.: World Bank.

96 References 
World Bank (2002). "Le système éducatif béninois : Performances et espaces d'amélioration pour la politique éducative”. Working Paper. Washington, D.C.: World Bank.

World Bank (2003). "Le système éducatif togolais : Éléments d'analyse pour une revitalisation". Working Paper. Africa Human Development Series. Washington, D.C.: World Bank.

World Bank (2004). African Development Indicators 2004. Washington, D.C.: World Bank.

World Bank (2007). "The Challenges of Ensuring Quality Teaching in Every Classroom in Africa: Teacher Issues in Uganda." Workshop Background Paper. Regional Workshop on Teacher Matters (Nairobi, 24-28 September 2007).

World Bank (2008). Public Finance for Poverty Reduction: Concepts and Case Studies from Africa and Latin America.

Edited by B. Moreno-Dodson and Q. Wodon. Washington, D.C.: World Bank.

World Bank (2009). Courage and Hope: Stories from Teachers Living with HIV in Sub-Saharan Africa. Edited by D. Bundy et al. Washington, D.C.: World Bank.

World Bank (2010). World Development Indicators 2010. World Bank DataBank. Accessed at: http://data.worldbank.org/data-catalog/ world-development-indicators on 28 October 2010.

World Bank, Pôle de Dakar (UNESCO-BREDA), Rwanda Ministry of Education and EFA Fast Track Initiative Secretariat (2010a). "Rwanda Education Country Status Report: Toward Quality Enhancement and Achievement of Universal Nine Year Basic Education". Washington, D.C.: World Bank.

World Bank, Pôle de Dakar (UNESCO-BREDA) and EFA Fast Track Initiative Secretariat (2010b). "Le système éducatif Malien: Analyse sectorielle pour une amélioration de la qualité et de l'efficacité du système". World Bank Working Paper No. 198.

Washington, D.C.: World Bank.

World Bank, Pôle de Dakar (UNESCO-BREDA) and EFA Fast Track Initiative Secretariat (2010c). "Le système éducatif congolais : Diagnostic pour une revitalisation dans un contexte macroéconomique plus favorable". World Bank Working Paper No. 183. Washington, D.C.: World Bank.

Xaba, J., P. Horn and S. Motala. (2002). "The Informal Sector in Sub-Saharan Africa". Working Paper on the Informal Economy. Geneva: ILO. 


\section{READER'S GUIDE}

The following symbols are used throughout the report and in the statistical tables:

\begin{tabular}{|c|c|}
\hline SYMBOL & INTERPRETATION \\
\hline$\ldots$ & No data available \\
\hline * & National estimation \\
\hline ** & UIS estimation \\
\hline- & Magnitude nil or negligible \\
\hline . & Not applicable \\
\hline$+n$ & Data refer to the school or financial year $n$ years after the reference year \\
\hline$-n$ & Data refer to the school or financial year $n$ years prior to the reference year \\
\hline
\end{tabular}

\section{REFERENCE PERIOD}

The reference period for education and finance data presented in the statistical tables is the academic or financial year ending in 2009 or the most recent year available within the period 2006-2009.

Literacy indicators refer to the most recent data available within the period 2005-2008. When observed data are older than 2005, the UIS Global Age-Specific Literacy Projections Model (GALP) estimates for 2008 are used.

Socio-economic indicators and official development assistance (ODA) data refer to 2008 unless otherwise indicated.

Where a given reference period is spread across two calendar years, the later year is cited. For example, the school year 2008/2009 is presented as 2009 .

Data presented in the analytical chapter are complemented by data for other reference periods or additional indicators not included in the statistical tables. These are available online at the UIS Data Centre at: http://stats.uis.unesco.org.

\section{DATA SOURCES}

\section{UIS Annual Education Survey}

UIS education questionnaires are sent to UNESCO Member States annually. The questionnaires are based on international standards, classifications and measures that are regularly reviewed and modified by the UIS in order to address emerging statistical issues and improve the quality of data. They can be downloaded at: http://www.uis.unesco.org/surveys/education

\section{Literacy}

Literacy statistics for youth aged 15 to 24 years and adults aged 15 years and older are obtained from national population censuses, household surveys and estimates using the UIS Global Age-Specific Literacy Projections Model (GALP). The UIS literacy questionnaire can be downloaded at: http://www.uis.unesco.org/surveys/literacy

Data sources, reference years and national definitions are available online at the UIS Data Centre. For more information regarding literacy estimates and projections, please refer to the report Global Age-Specific Literacy Projections Model (GALP): Rationale, Methodology and Software, available at http://www.uis.unesco.org/publications/GALP

\section{Population estimates}

Population data are based on the 2008 revision of the World Population Prospects by the United Nations Population Division. The UN Population Division does not provide data by single year of age for countries with a total population of less than 100,000 inhabitants. In such cases, national data or UIS estimates are used. National population data refer to population data obtained by the UIS directly 
from national sources, such as the national statistical office in a country. Where only national population totals are available, UIS estimates are used to approximate the age distribution whenever possible. These estimates are based on national population age distributions from previous years. For more information on UN Population Division estimates, please visit http://www.un.org/esa/population/unpop.htm

\section{Socio-economic statistics}

Socio-economic data such as gross domestic product (GDP), purchasing power parity (PPP) and HIV prevalence rate are World Bank estimates as of September 2010.

\section{Official development assistance (ODA) statistics}

Data on official development assistance are estimates from the Organisation for Economic Co-operation and Development Development Assistance Committee (OECD-DAC) as of October 2010.

\section{Pôle de Dakar (UNESCO BREDA) database}

Pôle de Dakar (UNESCO BREDA) collects data through diagnostic studies in sub-Saharan African countries. The dataset used in this report include average teacher salaries, PASEC scores and analysis, and household expenditure on education.

\section{IIEP studies}

The UNESCO International Institute for Educational Planning (IIEP) produces policy studies using household surveys. Their data on private expenditure are used in this report.

\section{TECHNICAL NOTES}

\section{Expenditure on education by level of education}

Expenditure by level of education is sometimes estimated when national data are converted to the ISCED classification. For example, expenditure on eight-year primary education or nine-year basic education is split by the amount allocated to ISCED 1 and ISCED 2 respectively.

Most analyses in this report are based on ISCED classification. The case studies in Chapters 3 and 4 use education levels based on national systems. In such cases, footnotes are provided.

\section{Expenditure on education by nature of spending}

Data on expenditure by nature of spending is sometimes under- or over-estimated when reported to the UIS. Under-estimating salary expenditure can occur when a school grant scheme exists and it is used to pay some of the teacher remuneration. Capital expenditure may also be under-estimated. When schools cover multiple ISCED levels, in theory the capital expenditure must be split for each level. However, sometimes the total amount of capital expenditure is recorded under expenditure not allocated by level.

\section{Enrolment in private institutions}

Private institutions include both government-dependent and independent private schools. Changes in reporting of these data may occur, e.g. community schools may be reclassified from government-dependent private to public schools. Such changes may affect the data presented in the time series for enrolment in private institutions.

\section{Actual expenditure and budget allocation}

The UIS aims to collect data on actual expenditure. However, in cases where these are not available, budget allocation data are used. The data are continually revised as detailed actual expenditure by category becomes available. 


\section{GLOSSARY}

Capping. Indicators that surpass a theoretical maximum of 100\% are adjusted using a capping factor. Net enrolment rates in primary education are capped using a factor that takes into account the enrolment of primary school-age children in pre-primary, primary and secondary education by sex. For all other indicators regarding male, female and both sexes combined, the highest value (whether for male or female) is set to $100 \%$. The other two indicators are then re-calculated so that the gender parity index of the new set of values remains the same as for the original values.

Duration. The number of grades or years in a given level of education.

Educational institutions (public and private). Educational institutions are defined as entities that provide instructional or educationrelated services to individuals and other educational institutions. Whether or not an entity qualifies as an educational institution is not contingent upon which public authority (if any) has responsibility for it.

Educational institutions are classified as either public or private according to whether a public agency or a private entity has the ultimate power to make decisions concerning the institution's affairs.

An institution is classified as public if it is controlled and managed directly by a public education authority or agency; or controlled and managed either by a government agency directly or by a governing body (council, committee, etc.), most of whose members are either appointed by a public authority or elected by public franchise.

An institution is classified as private if it is controlled and managed by a non-governmental organization (e.g. a church, trade union or business enterprise), or if its governing board consists mostly of members not selected by a public agency. In general, the ultimate management control over an institution rests with who has the power to determine the general activity of the school and appoint the managing officers. The extent to which an institution receives its funding from public or private sources does not determine the classification status of the institution.

A distinction is made between government-dependent and independent private institutions on the basis of the degree of a private institution's dependence on funding from government sources. A government-dependent private institution is one that receives more than $50 \%$ of its core funding from government agencies. An independent private institution is one that receives less than $50 \%$ of its core funding from government agencies. Core funding refers to the funds that support the basic educational services of the institution. It does not include funds provided specifically for research projects, payments for services purchased or contracted by private organizations, or fees and subsidies received for ancillary services such as lodging and meals. Additionally, institutions should be classified as government-dependent if their teaching staff are paid by a government agency, either directly or indirectly.

Enrolment. The number of pupils or students officially enrolled in a given grade or level of education, regardless of age. Typically, these data are collected at the beginning of the school year.

Entrance age (theoretical). The age at which pupils or students have entered a given programme or level of education assuming they had started at the official entrance age for the lowest level of education, studied full-time throughout and progressed through the system without repeating or skipping a grade.

\section{Expenditure on education}

Total public expenditure on education. The sum of all expenditure on education and education administration made by local, regional and national/central governments, including municipalities. Intergovernmental transfers are excluded.

Current expenditure on education. Expenditure for goods and services consumed within the current year and which would be renewed if needed in the following year. It includes expenditure on staff salaries, pensions and benefits; contracted or purchased services; other resources, including books and teaching materials; welfare services; and other current expenditure, such as subsidies for students and households, minor equipment, minor repairs, fuel, telecommunications, travel, insurance and rent. 
Capital expenditure on education. Expenditure for assets that last longer than one year. It includes expenditure for construction, renovation and major repairs of buildings and the purchase of heavy equipment or vehicles.

Public subsidies. Public subsidies to households and other private entities consist of transfers to the private sector for educational institutions and transfers for student living costs and other education-related costs that occur outside educational institutions.

Public subsidies to households and other private entities for educational institutions are composed of government transfers and certain other payments to students or households, insofar as these translate into payments to educational institutions for educational services (for example, fellowships, financial aid or student loans for tuition). They also include government transfers and other payments (mainly subsidies) to private entities other than households, including, for example, subsidies to firms or labour organizations that operate apprenticeship programmes and interest subsidies to private financial institutions that provide student loans, etc.

Public subsidies to households that are not attributable to payments to educational institutions include subsidies for student living costs and the value of special subsidies provided to students, either in cash or in kind, such as free or reduced-price travel on public transport or family allowances that are contingent on student status.

Graduate. A person who has successfully completed the final year of a level or sub-level of education. In some countries, completion occurs as a result of passing an examination or a series of examinations. In other countries, it occurs after a requisite number of course hours have been accumulated. Sometimes both types of completion occur within a country. For UOE survey participating countries, graduations - instead of graduates - are used to calculate percentages by field of education (due to the UOE instrument design). Graduations refer to the number of qualifications obtained during the reference period; one graduation is counted once for every qualification obtained.

Gross domestic product (GDP). The sum of gross value added by all resident producers in the economy, including distributive trades and transport, plus any product taxes and minus any subsidies not included in the value of the products.

GDP per capita. The gross domestic product divided by the mid-year population.

International Standard Classification of Education (ISCED). A classification system that provides a framework for the comprehensive statistical description of national education systems and a methodology that translates national education programmes into internationally comparable levels of education. The basic unit of classification in ISCED is the education programme. ISCED also classifies programmes by field of study, programme orientation and destination.

Literacy. The ability to read and write, with understanding, a simple statement related to one's daily life. It involves a continuum of reading and writing skills, and often includes basic arithmetic skills (numeracy).

New entrants. Pupils or students entering a given level of education, grade or programme for the first time.

Official development assistance (ODA). Flows of official financing administered with the promotion of the economic development and welfare of developing countries as the main objective, and which are concessional in character with a grant element of at least $25 \%$. In addition to financial flows, technical cooperation is included in aid.

ODA for education. The aid activity that is designed to assist the education sector of the recipient's economy.

Total ODA disbursement. Disbursements record the actual international transfer of financial resources or goods and services valued at the cost to the donor.

Out-of-school children. Children in the official primary school-age range who are not enrolled in either primary or secondary school.

Private institutions. See Educational institutions (public and private).

Public institutions. See Educational institutions (public and private). 
Public-private partnership. Arrangements whereby the private sector provides infrastructure assets and services that traditionally have been provided by the government, such as: hospitals, schools, prisons, roads, bridges, tunnels, railways, and water and sanitation plants.

Purchasing power parity (PPP). Purchasing power parities (PPPS) are the currency exchange rates that equalise the purchasing power of different currencies. This means that a given sum of money, when converted into U.S. dollars at the PPP rate (PPP dollars), will buy the same basket of goods and services in all countries. In other words, PPPs are the rates of currency conversion which eliminate the differences in price levels among countries. Thus, comparisons between countries reflect only differences in the volume of goods and services purchased.

Repeater. Pupil enrolled in the same grade for a second or further year.

School-age population. Population of the age group theoretically corresponding to a given level of education, as indicated by theoretical entrance age and duration.

School life expectancy. The number of years a person of school entrance age can expect to spend within the specified levels.

Students/ pupils. Pupils refer to children enrolled in an educational programme, whereas children or adults enrolled at more advanced levels are students.

\section{Teachers}

Teaching staff. Persons employed full-time or part-time in an official capacity for the purpose of guiding and directing the learning experience of pupils and students, irrespective of their qualification or the delivery mechanism (i.e. whether face-to-face or at a distance). This definition excludes educational personnel who have no active teaching duties (e.g. headmasters, headmistresses or principals who do not teach) or who work occasionally or in a voluntary capacity in educational institutions.

Trained teachers. Teachers who have received the minimum organised teacher training (pre-service or in-service) required for teaching at the relevant level in a given country. 


\section{DEFINITION OF INDICATORS}

Average remuneration of teachers as a ratio of GDP per capita. Average annual remuneration of teachers expressed as a ratio of GDP per capita. The calculation of average remuneration includes teachers who are civil servants and those who are employed by the government on a contract basis.

Child dependency ratio. Ratio of the child population (aged 0-14 years) defined as dependent to the working-age population (aged 15-64 years).

Current expenditure on education per student. Public current expenditure on education per student in a specific education level expressed in U.S. dollars and adjusted in terms of purchasing power parity.

Distribution of public current expenditure on education. Proportion of public current expenditure on education allocated to a specific level of education. This indicator aims to estimate the proportion of annual operational costs by level of education.

Distribution of total public expenditure on education. Proportion of total public expenditure (current and capital) on education allocated to a specific education level. This indicator aims to estimate the proportion of total resources allocated to each level of education.

Public revenue as a percentage of GDP. Public revenue that is domestically generated (excluding official development assistance) mainly through taxes - in a given year, expressed as a percentage of GDP.

Education expenditure by nature of spending as a percentage of total education expenditure on public institutions. Spending by nature (salaries, other current, total current or capital) expressed as a percentage of the expenditure for public education institutions at a specific education level. Salaries should be included in the total current expenditure, while public subsidies to the private sector and administrative costs should be excluded.

Expenditure on learning materials as a percentage of public current expenditure on education. Expenditure on learning materials expressed as a percentage of the total current expenditure for public educational institutions at a specific education level.

Gross enrolment ratio (GER). Number of students enrolled in a given level of education, regardless of age, expressed as a percentage of the population in the theoretical age group for the same level of education. For the tertiary level, the population for the five-year age group following the official secondary school graduation age is used.

Gross intake ratio (GIR). Total number of new entrants in the first grade of primary education, regardless of age, expressed as a percentage of the population at official primary school entrance age.

Gross intake ratio to the last grade of primary (GIRLG ). Total number of new entrants in the last grade of primary education, regardless of age, expressed as a percentage of the population of theoretical entrance age to the last grade.

HIV prevalence in adults aged 15-49 (\%). Estimated number of adults aged 15-49 years with HIV infection, whether or not they have developed symptoms of AIDS, expressed as percent of total population in that age group.

Life expectancy at birth. Average number of years that a newborn is expected to live if current mortality rates continue to apply. Life expectancy at birth summarises the overall mortality level of a population across all age groups.

Literacy rate. Total number of literate persons in a given age group, expressed as a percentage of the population in that age group. The adult literacy rate includes persons aged 15 years and older, while the youth literacy rate covers the 15 to 24 -year-old population. 
Primary net enrolment rate (adjusted) (ANER). Total number of pupils of the official primary school age who are enrolled in primary or secondary education, expressed as a percentage of the corresponding population. It assesses the level of achievement of the universal primary education (UPE) goal and measures school participation among the official primary school-age population.

\section{Official development assistance (ODA).}

ODA for education as a percentage of total ODA. Proportion of total ODA that is allocated to the education sector in a given year.

ODA for education per population aged 5-24 years (in PPP\$). ODA for education in a given year divided by a recipient country's population aged 5-24 years, expressed in U.S. dollars and adjusted in terms of purchasing power parity.

Ratio of ODA for education to total public expenditure on education. Ratio of the amount of ODA for education in a given year to a recipient country's total public expenditure on education, which in theory includes a part of ODA that goes through the public account. If a fiscal cycle is different from the calendar year in a country, the latter year is used as a reference year. It is not a percentage of ODA in the total public education expenditure on education, because ODA for education includes activities carried out in donor countries and activities that are implemented by non-governmental organizations.

Percentage of private enrolment. Total number of students at a given level of education enrolled in institutions that are controlled and managed, whether for profit or not, by a private body (e.g. non-governmental organization, religious body, special interest group, foundation or business enterprise), expressed as a percentage of the total number of students enrolled at that level of education.

Percentage of trained teachers. Total number of teachers who have received the minimum, organized teacher training (preservice or in-service) required for teaching at the relevant level of education according to current national standards, expressed as a percentage of the total number of teachers at that level of education.

Pupil-teacher ratio. Average number of pupils per teacher at a level of education specified in a given school year, based on headcounts of pupils and teachers.

Ratio between current expenditure per secondary (or tertiary) student and per primary pupil. Current expenditure per secondary (or tertiary) student expressed as a ratio to current expenditure per primary pupil. A ratio of 1 means that current spending per secondary (or tertiary) student is the same as current spending per primary pupil.

Salaries as a percentage of public current expenditure on education. Expenditure on salaries expressed as a percentage of the total current expenditure for public education institutions of a specific education level. This indicator is calculated for salaries of teaching staff and all staff.

School life expectancy. Number of years a person of school entrance age can expect to spend within a specific level of education.

School survival rate. Percentage of a cohort of students enrolled in the first grade of a given level or cycle of education who are expected to reach a given grade, regardless of repetition. The school survival rate is calculated on the basis of the reconstructed cohort method, which uses data on enrolment by grade for two consecutive years and repeaters by grade.

Total public expenditure on education as a percentage of GDP. Current and capital expenditure on education by local, regional and national governments, including municipalities, expressed as a percentage of GDP.

Total public expenditure on education as a percentage of total government expenditure. Current and capital expenditure on education by local, regional and national governments, including municipalities, expressed as a percentage of total government expenditure on all sectors (e.g. health, education, social services, etc.).

Total public expenditure per student (PPP\$). Total public expenditure per student at a specific education level, expressed in U.S. dollars and adjusted in terms of purchasing power parity.

Total public expenditure per student as a percentage of GDP per capita. Total public expenditure per student at a specific education level, expressed as a percentage of GDP per capita. 
Transition rate from primary to secondary education. The number of new entrants into the first grade of secondary education (general programmes only) in a given year, expressed as a percentage of the number of pupils enrolled in the final grade of primary education in the previous year.

For more definitions, please refer to the UIS multilingual online glossary at: www.uis.unesco.org/glossary 


\section{APPENDIX I}

\section{SUB-SAHARAN AFRICAN COUNTRIES GROUPED BY GDP PER CAPITA, 2008}

\begin{tabular}{|c|c|c|c|c|c|}
\hline \multicolumn{2}{|c|}{$\begin{array}{l}\text { COUNTRIES WITH A GDP } \\
\text { PER CAPITA }<\text { PPP } \$ 1,000\end{array}$} & \multicolumn{2}{|c|}{$\begin{array}{l}\text { COUNTRIES WITH A GDP } \\
\text { PER CAPITA OF PPP } \$ 1,000-3,000\end{array}$} & \multicolumn{2}{|c|}{$\begin{array}{l}\text { COUNTRIES WITH A GDP } \\
\text { PER CAPITA > PPP } \$ 3,000\end{array}$} \\
\hline Country & $\begin{array}{l}\text { GDP per capita } \\
\text { (PPP\$) }\end{array}$ & Country & $\begin{array}{l}\text { GDP per capita } \\
\text { (PPP\$) }\end{array}$ & Country & $\begin{array}{l}\text { GDP per capita } \\
\text { (PPP\$) }\end{array}$ \\
\hline Burundi & 383 & Benin & 1,473 & Angola & 5,820 \\
\hline Central African Republic & 741 & Burkina Faso & 1,160 & Botswana & 13,574 \\
\hline Democratic Republic of the Congo & 314 & Cameroon & 2,195 & Cape Verde & 3,202 \\
\hline Eritrea & 642 & Chad & 1,337 & Congo & 3,949 \\
\hline Ethiopia & 869 & Comoros & 1,170 & Equatorial Guinea & 33,899 \\
\hline Guinea-Bissau & 537 & Côte d'Ivoire & 1,652 & Gabon & 14,575 \\
\hline Liberia & 388 & Gambia & 1,363 & Mauritius & 12,356 \\
\hline Malawi & 805 & Ghana & 1,463 & Namibia & 6,398 \\
\hline Mozambique & 838 & Guinea & 1,056 & Seychelles & 21,392 \\
\hline Niger & 683 & Kenya & 1,551 & South Africa & 10,116 \\
\hline Sierra Leone & 782 & Lesotho & 1,564 & Swaziland & 4,927 \\
\hline Somalia & - & Madagascar & 1,054 & & \\
\hline Togo & 830 & Mali & 1,129 & & \\
\hline \multirow[t]{7}{*}{ Zimbabwe } & - & Nigeria & 2,099 & & \\
\hline & & Rwanda & 1,027 & & \\
\hline & & Sao Tome and Principe & 1,748 & & \\
\hline & & Senegal & 1,793 & & \\
\hline & & United Republic of Tanzania & 1,264 & & \\
\hline & & Uganda & 1,166 & & \\
\hline & & Zambia & 1,357 & & \\
\hline
\end{tabular}

Note: GDP per capita (PPP\$) is not available for Somalia and Zimbabwe for the reference year. They are included in the GDP per capita of less than PPP\$1,000 group.

Source: World Bank WDI database. 


\section{APPENDIX II}

\section{EDUCATION SYSTEMS IN SUB-SAHARAN AFRICA MAPPED TO ISCED, 2009}

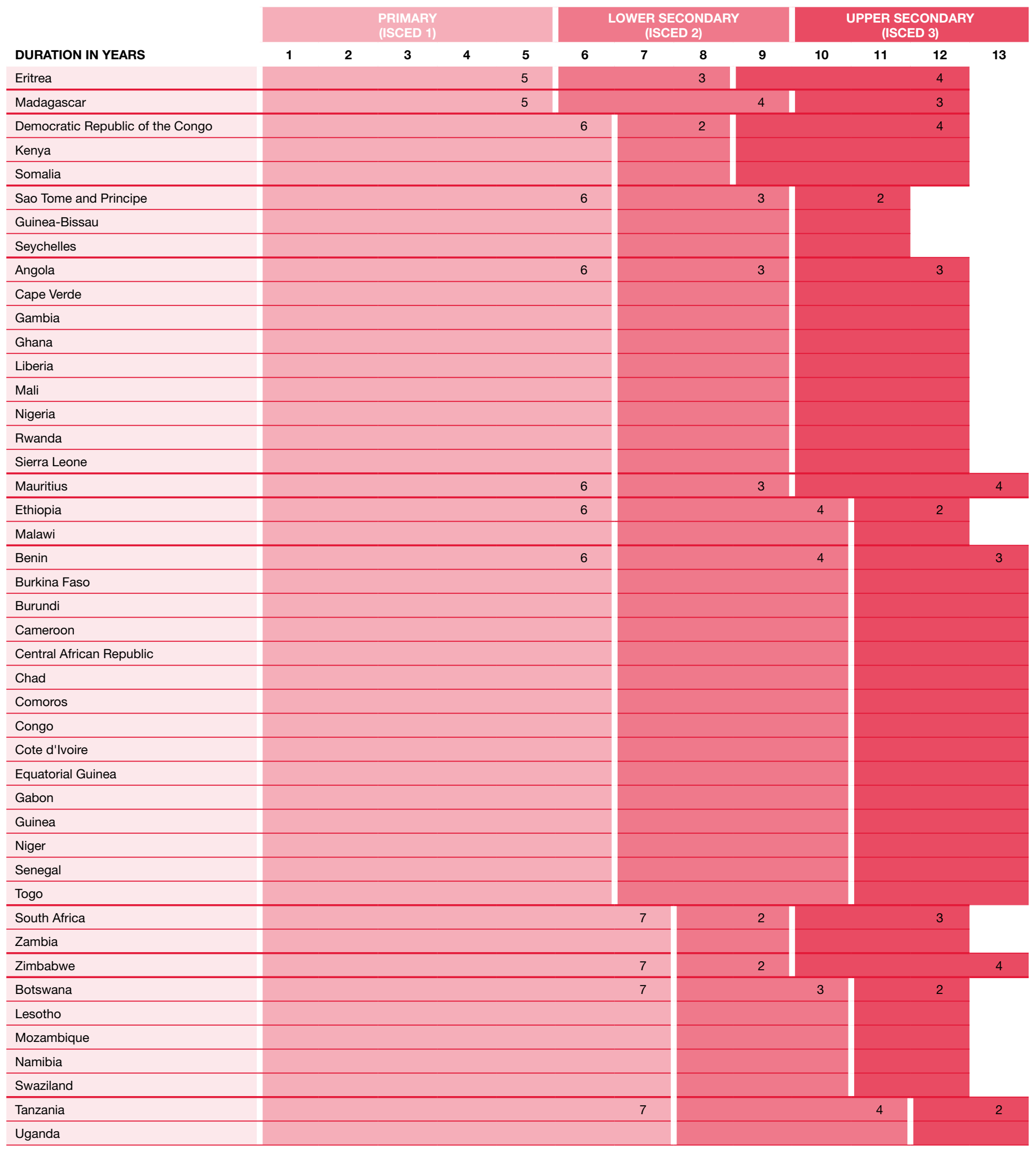

Note: Only the main education structure within ISCED 1, 2A and 3A programmes have been presented. For more detailed mappings of national education systems, please see 


\section{APPENDIX III}

\section{AVERAGE TEACHER REMUNERATION}

\section{AVERAGE REMUNERATION OF PRIMARY AND SECONDARY EDUCATION TEACHERS FINANCED FULLY OR IN PART BY THE GOVERNMENT, AS A RATIO OF GDP PER CAPITA, 2009 OR MOST RECENT YEAR}

\begin{tabular}{|c|c|c|c|}
\hline & PRIMARY EDUCATION & LOWER SECONDARY EDUCATION & UPPER SECONDARY EDUCATION \\
\hline Angola (2003) & 1.5 & $\ldots$ & $\ldots$ \\
\hline Benin (2006) & 3.6 & 6.0 & 8.2 \\
\hline Burkina Faso (2006) & 5.3 & 8.8 & 9.6 \\
\hline Burundi (2007) & 7.6 & 8.4 & 12.2 \\
\hline Cameroon (2007) & 3.2 & 5.2 & 5.5 \\
\hline Cape Verde (2009) & 2.5 & 3.0 & 3.2 \\
\hline Central African Republic (2007) & 3.3 & 6.9 & 7.1 \\
\hline Chad (2003) & 5.4 & 8.8 & 9.8 \\
\hline Congo (2007) & 0.9 & 2.0 & 2.5 \\
\hline Côte d'Ivoire (2007) & 4.9 & 8.8 & 9.4 \\
\hline Democratic Republic of the Congo (2005) & 3.9 & 2.4 & 2.4 \\
\hline Eritrea (2003) & 7.7 & $\cdots$ & $\cdots$ \\
\hline Gambia (2003) & 3.7 & $\cdots$ & $\ldots$ \\
\hline Ghana (2007) & 4.7 & 4.7 & 4.8 \\
\hline Guinea (2005) & 1.7 & 2.9 & 2.9 \\
\hline Guinea-Bissau (2006) & 4.4 & 6.6 & 6.6 \\
\hline Kenya (2004) & 5.3 & 7.6 & 7.6 \\
\hline Lesotho (2004) & 5.0 & 10.4 & 10.4 \\
\hline Liberia (2008) & 3.0 & 3.1 & 3.3 \\
\hline Madagascar (2006) & 2.9 & 5.1 & 8.1 \\
\hline Malawi (2008) & 6.3 & 11.6 & 11.6 \\
\hline Mali (2008) & 4.2 & 5.6 & 6.6 \\
\hline Mozambique (2003) & 4.0 & $\cdots$ & $\cdots$ \\
\hline Niger (2008) & 6.6 & 7.4 & 8.6 \\
\hline Nigeria (2003) & 4.9 & $\cdots$ & $\cdots$ \\
\hline Rwanda (2008) & 2.6 & 6.4 & 7.3 \\
\hline Sao Tome and Principe (2006) & 2.3 & $\cdots$ & $\cdots$ \\
\hline Senegal (2004) & 4.7 & 5.5 & 6.6 \\
\hline Seychelles (2003) & 1.7 & $\cdots$ & $\cdots$ \\
\hline Sierra Leone (2004) & 4.2 & 5.9 & 5.9 \\
\hline Sudan (2003) & 2.2 & $\cdots$ & $\cdots$ \\
\hline Togo (2007) & 6.1 & 8.9 & 11.6 \\
\hline Uganda (2007) & 4.7 & $\ldots$ & $\ldots$ \\
\hline Zambia (2003) & 2.7 & $\cdots$ & $\cdots$ \\
\hline Zimbabwe (2003) & 6.1 & $\cdots$ & $\ldots$ \\
\hline Average (35 countries) & 4.1 & 6.3 & 7.2 \\
\hline Minimum & 0.9 & 2.0 & 2.4 \\
\hline Maximum & 7.7 & 11.6 & 12.2 \\
\hline
\end{tabular}

Note: Reference year varies from 2003 to 2009

Sources: Pôle de Dakar (UNESCO-BREDA) and UNESCO Institute for Statistics database. 


\section{APPENDIX IV}

\section{SACMEQ READING LEVELS}

The SACMEQ II Project presents literacy and numeracy performance of pupils based on descriptive accounts of competency levels. For each test, Rasch scaling procedures permitted the performance of pupils to be aligned along a single dimension that could be broken into eight groups or levels - each being named according to the skills required to successfully complete the items within the group. This approach provides meaningful descriptive information about the tasks that pupils can currently manage, and the knowledge and skills that pupils require if they are to move to higher levels of competence.

\section{LEVEL 1. PRE-READING}

Matches words and pictures involving concrete concepts and everyday objects, and follows short, simple, written instructions.

\section{LEVEL 2. EMERGENT READING}

Matches words and pictures involving prepositions and abstract concepts; uses cuing systems (by sounding out, using simple sentence structure, and familiar words) to interpret phrases by reading on.

\section{LEVEL 3. BASIC READING}

Interprets meaning (by matching words and phrases, completing a sentence, or matching adjacent words) in a short and simple text by reading on or reading back.

\section{LEVEL 4. READING FOR MEANING}

Reads on or reads back in order to link and interpret information located in various parts of the text.

\section{LEVEL 5. INTERPRETIVE READING}

Reads on and reads back in order to combine and interpret information from various parts of the text in association with external information (based on recalled factual knowledge) that 'completes' and contextualises meaning.

\section{LEVEL 6. INFERENTIAL READING}

Reads on and reads back through longer (narrative, document or expository) texts in order to combine information from various parts of the text so as to infer the writer's purpose.

\section{LEVEL 7. ANALYTICAL READING}

Locates information in longer (narrative, document or expository) texts by reading on and reading back in order to combine information from various parts of the text so as to infer the writer's personal beliefs (value systems, prejudices and/or biases).

\section{LEVEL 8. CRITICAL READING}

Locates information in a longer (narrative, document or expository) texts by reading on and reading back in order to combine information from various parts of the text so as to infer and evaluate what the writer has assumed about both the topic and the characteristics of the reader - such as age, knowledge and personal beliefs (value systems, prejudices and/or biases). 



\section{APPENDIX V}

\section{STATISTICAL TABLES}

Table A1. SOCIO-ECONOMIC INDICATORS | 2008

Table A2. EDUCATION SYSTEMS AND ENROLMENT | 1999 AND 2009

Table A3. SCHOOL LIFE EXPECTANCY, COMPLETION RATE AND TRANSITION RATE | 1999 AND 2009

Table A4. TEACHING STAFF | 1999 AND 2009

Table A5. PUBLIC EXPENDITURE ON EDUCATION | 1999 AND 2009

Table A6. PUBLIC EXPENDITURE ON EDUCATION PER STUDENT | 1999 AND 2009

Table A7. EDUCATION EXPENDITURE BY NATURE OF SPENDING | 2009

Table A8. OFFICIAL DEVELOPMENT ASSISTANCE (ODA) | 2008 
Table A1. SOCIO-ECONOMIC INDICATORS | 2008

\begin{tabular}{|c|c|c|c|c|c|c|}
\hline \multirow{3}{*}{ COUNTRY } & \multicolumn{2}{|c|}{ GROSS DOMESTIC PRODUCT (GDP) } & \multicolumn{4}{|c|}{ POPULATION } \\
\hline & \multirow{2}{*}{$\begin{array}{l}\text { GDP per capita } \\
\text { (PPP\$) }\end{array}$} & \multirow{2}{*}{$\begin{array}{c}\text { GDP annual } \\
\text { growth rate }(\%)^{a}\end{array}$} & \multicolumn{2}{|c|}{ Total } & \multicolumn{2}{|c|}{ Aged $0-14$} \\
\hline & & & $(000)$ & Growth rate $(\%)^{a}$ & $(000)$ & Growth rate $(\%)^{a}$ \\
\hline Angola & 5,829 & 13.2 & 18,021 & 2.7 & 8,161 & 1.9 \\
\hline Benin & 1,476 & 5.1 & 8,662 & 3.2 & 3,743 & 2.8 \\
\hline Botswana & 13,885 & 2.9 & 1,921 & 1.5 & 647 & 0.2 \\
\hline Burkina Faso & 1,168 & 4.5 & 15,234 & 3.5 & 7,032 & 3.9 \\
\hline Burundi & 384 & 4.5 & 8,074 & 3.0 & 3,147 & 1.1 \\
\hline Cameroon & 2,188 & 3.9 & 19,088 & 2.3 & 7,844 & 1.8 \\
\hline Cape Verde & 3,539 & 2.8 & 499 & 1.4 & 184 & -0.7 \\
\hline Central African Republic & 742 & 2.2 & 4,339 & 1.9 & 1,775 & 1.3 \\
\hline Chad & 1,339 & -0.2 & 10,914 & 2.7 & 4,999 & 2.6 \\
\hline Comoros & 1,172 & 1.0 & 661 & 2.3 & 252 & 2.2 \\
\hline Congo & 3,955 & 5.6 & 3,615 & 1.8 & 1,470 & 1.4 \\
\hline Côte d'Ivoire & 1,655 & 2.2 & 20,591 & 2.3 & 8,413 & 1.8 \\
\hline Democratic Republic of the Congo & 314 & 6.2 & 64,257 & 2.8 & 30,172 & 2.2 \\
\hline Equatorial Guinea & 33,953 & 11.3 & 659 & 2.6 & 272 & 1.9 \\
\hline Eritrea & 643 & 2.0 & 4,927 & 3.0 & 2,046 & 3.0 \\
\hline Ethiopia & 869 & 11.3 & 80,713 & 2.6 & 35,402 & 1.8 \\
\hline Gabon & 14,598 & 2.3 & 1,448 & 1.8 & 532 & 0.1 \\
\hline Gambia & 1,368 & 5.9 & 1,660 & 2.8 & 705 & 2.4 \\
\hline Ghana & 1,465 & 7.3 & 23,351 & 2.1 & 9,040 & 1.3 \\
\hline Guinea & 1,058 & 4.7 & 9,833 & 2.3 & 4,223 & 1.9 \\
\hline Guinea-Bissau & 538 & 3.3 & 1,575 & 2.2 & 672 & 2.3 \\
\hline Kenya & 1,553 & 1.7 & 38,765 & 2.7 & 16,576 & 2.8 \\
\hline Lesotho & 1,566 & 3.9 & 2,049 & 0.9 & 803 & 0.1 \\
\hline Liberia & 389 & 7.1 & 3,793 & 4.6 & 1,629 & 4.1 \\
\hline Madagascar & 1,056 & 7.3 & 19,111 & 2.7 & 8,272 & 1.9 \\
\hline Malawi & 807 & 9.7 & 14,846 & 2.8 & 6,892 & 2.4 \\
\hline Mali & 1,146 & 5.0 & 12,706 & 2.4 & 5,621 & 2.2 \\
\hline Mauritius & 12,441 & 4.5 & 1,280 & 0.7 & 297 & -1.7 \\
\hline Mozambique & 839 & 6.8 & 22,383 & 2.3 & 9,861 & 2.3 \\
\hline Namibia & 6,408 & 2.9 & 2,130 & 2.0 & 796 & 0.5 \\
\hline Niger & 684 & 9.5 & 14,704 & 4.0 & 7,308 & 4.6 \\
\hline Nigeria & 2,102 & 6.0 & 151,212 & 2.4 & 64,545 & 2.0 \\
\hline Rwanda & 1,029 & 11.2 & 9,721 & 2.8 & 4,102 & 2.9 \\
\hline Sao Tome and Principe & 1,751 & 5.8 & 160 & 1.6 & 66 & 1.0 \\
\hline Senegal & 1,796 & 3.3 & 12,211 & 2.7 & 5,346 & 2.2 \\
\hline Seychelles & 21,123 & 2.8 & 84 & 0.5 & 21 & -1.1 \\
\hline Sierra Leone & 784 & 5.5 & 5,560 & 2.6 & 2,405 & 3.0 \\
\hline Somalia & $\ldots$ & $\ldots$ & 8,926 & 2.2 & 4,004 & 2.4 \\
\hline South Africa & 10,416 & 3.1 & 49,668 & 1.0 & 15,278 & 0.1 \\
\hline Swaziland & 4,935 & 2.4 & 1,168 & 1.4 & 467 & -0.2 \\
\hline Togo & 837 & 1.1 & 6,459 & 2.5 & 2,599 & 1.6 \\
\hline Uganda & 1,157 & 9.5 & 31,657 & 3.3 & 15,512 & 3.1 \\
\hline United Republic of Tanzania & 1,303 & 7.5 & 42,484 & 2.9 & 18,974 & 3.0 \\
\hline Zambia & 1,356 & 6.0 & 12,620 & 2.5 & 5,837 & 2.6 \\
\hline Zimbabwe & $\ldots$ & $\ldots$ & 12,463 & 0.1 & 5,015 & -0.6 \\
\hline
\end{tabular}

a Data refer to the period 2007 to 2008 . ${ }^{\text {b }}$ Data refer to 2007. 


\begin{tabular}{|c|c|c|c|c|c|c|}
\hline \multicolumn{2}{|c|}{ POPULATION } & \multicolumn{4}{|c|}{ SOCIAL INDICATORS } & \multirow{3}{*}{ COUNTRY } \\
\hline Aged 15-24 & \multirow{2}{*}{$\begin{array}{l}\text { Child } \\
\text { dependency } \\
\text { ratio }\end{array}$} & \multirow{2}{*}{$\begin{array}{l}\text { HIV prevalence } \\
\text { in adults aged } \\
15-49(\%)^{\mathrm{b}}\end{array}$} & \multirow{2}{*}{$\begin{array}{l}\text { Life expectancy } \\
\text { at birth } \\
\text { (years) }\end{array}$} & \multirow{2}{*}{$\begin{array}{l}\text { Literacy rate } \\
\text { of youth } \\
\text { aged } 15-24\end{array}$} & \multirow{2}{*}{$\begin{array}{l}\text { Literacy rate } \\
\text { of adults } \\
\text { aged } 15-49\end{array}$} & \\
\hline$(000)$ & & & & & & \\
\hline 3,670 & 86.7 & 2.1 & 47.0 & 72.9 & 69.6 & Angola \\
\hline 1,693 & 80.7 & 1.2 & 61.4 & 53.3 & 40.8 & Benin \\
\hline 434 & 53.9 & 23.9 & 54.2 & 95.1 & 83.3 & Botswana \\
\hline 3,032 & 89.1 & 1.6 & 53.0 & 39.3 & 28.7 & Burkina Faso \\
\hline 1,877 & 66.9 & 2.0 & 50.4 & 75.9 & 65.9 & Burundi \\
\hline 3,998 & 74.2 & 5.1 & 51.1 & 85.8 & 75.9 & Cameroon \\
\hline 114 & 62.9 & $\ldots$ & 71.0 & 98.0 & 84.1 & Cape Verde \\
\hline 879 & 74.1 & 6.3 & 47.0 & 64.2 & 54.6 & Central African Republic \\
\hline 2,152 & 89.2 & 3.5 & 48.7 & 45.4 & 32.7 & Chad \\
\hline 134 & 65.0 & 0.1 & 65.3 & 84.9 & 73.6 & Comoros \\
\hline 754 & 73.3 & 3.5 & 53.6 & 80.5 & $\ldots$ & Congo \\
\hline 4,101 & 73.8 & 3.9 & 57.4 & 66.1 & 54.6 & Côte d'Ivoire \\
\hline 12,859 & 93.2 & $\cdots$ & 47.6 & 65.3 & 66.6 & Democratic Republic of the Congo \\
\hline 131 & 73.9 & 3.4 & 50.2 & 97.8 & 93.0 & Equatorial Guinea \\
\hline 1,024 & 74.1 & 1.3 & 59.5 & 87.8 & 65.3 & Eritrea \\
\hline 16,349 & 82.8 & 2.1 & 55.2 & 49.9 & 35.9 & Ethiopia \\
\hline 302 & 62.4 & 5.9 & 60.4 & 97.4 & 87.0 & Gabon \\
\hline 310 & 77.6 & 0.9 & 55.9 & 64.1 & 45.3 & Gambia \\
\hline 4,761 & 67.1 & 1.9 & 56.6 & 79.3 & 65.8 & Ghana \\
\hline 1,944 & 79.8 & 1.6 & 57.8 & 58.7 & 38.0 & Guinea \\
\hline 287 & 79.1 & 1.8 & 47.8 & 69.6 & 51.0 & Guinea-Bissau \\
\hline 8,290 & 78.3 & $\ldots$ & 54.2 & 92.3 & 86.5 & Kenya \\
\hline 480 & 69.8 & 23.2 & 45.0 & 91.9 & 89.5 & Lesotho \\
\hline 750 & 79.5 & 1.7 & 58.3 & 74.8 & 58.1 & Liberia \\
\hline 3,749 & 80.7 & 0.1 & 60.3 & 70.2 & 70.7 & Madagascar \\
\hline 2,902 & 91.9 & 11.9 & 53.1 & 85.7 & 72.8 & Malawi \\
\hline 2,671 & 82.8 & 1.5 & 48.4 & 38.8 & 26.2 & Mali \\
\hline 202 & 33.2 & 1.7 & 72.6 & 96.4 & 87.5 & Mauritius \\
\hline 4,371 & 83.6 & 12.5 & 47.9 & 69.9 & 54.0 & Mozambique \\
\hline 459 & 63.3 & 15.3 & 61.0 & 92.9 & 88.2 & Namibia \\
\hline 2,642 & 102.9 & 0.8 & 51.4 & 36.5 & 28.7 & Niger \\
\hline 30,442 & 78.7 & 3.1 & 47.9 & 71.5 & 60.1 & Nigeria \\
\hline 2,222 & 76.3 & 2.8 & 50.1 & 77.1 & 70.3 & Rwanda \\
\hline 35 & 74.5 & $\ldots$ & 65.5 & 95.2 & 88.3 & Sao Tome and Principe \\
\hline 2,553 & 81.4 & 1.0 & 55.6 & 50.9 & 41.9 & Senegal \\
\hline 14 & $\cdots$ & $\cdots$ & 73.2 & 99.1 & 91.8 & Seychelles \\
\hline 1,082 & 78.8 & 1.7 & 47.6 & 55.7 & 39.8 & Sierra Leone \\
\hline 1,642 & 85.6 & 0.5 & 49.8 & $\cdots$ & $\ldots$ & Somalia \\
\hline 10,052 & 47.4 & 18.1 & 51.5 & 96.8 & 89.0 & South Africa \\
\hline 288 & 70.4 & 26.1 & 45.8 & 93.2 & 86.5 & Swaziland \\
\hline 1,334 & 71.5 & 3.3 & 62.5 & 83.5 & 64.9 & Togo \\
\hline 6,458 & 101.2 & 5.4 & 52.7 & 87.3 & 74.6 & Uganda \\
\hline 8,486 & 85.5 & 6.2 & 55.6 & 77.5 & 72.6 & United Republic of Tanzania \\
\hline 2,546 & 91.2 & 15.2 & 45.4 & 74.8 & 70.7 & Zambia \\
\hline 3,156 & 72.2 & 15.3 & 44.2 & 98.9 & 91.4 & Zimbabwe \\
\hline
\end{tabular}


Table A2. EDUCATION SYSTEMS AND ENROLMENT | 1999 AND 2009

\begin{tabular}{|c|c|c|c|c|c|c|c|c|c|c|c|c|}
\hline \multirow{3}{*}{ COUNTRY } & \multicolumn{12}{|c|}{ GROSS ENROLMENT RATIO } \\
\hline & \multicolumn{2}{|c|}{$\begin{array}{l}\text { Pre-primary } \\
\text { (ISCED 0) }\end{array}$} & \multicolumn{2}{|c|}{$\begin{array}{l}\text { Primary } \\
\text { (ISCED 1) }\end{array}$} & \multicolumn{2}{|c|}{$\begin{array}{l}\text { Lower secondary } \\
\text { (ISCED 2) }\end{array}$} & \multicolumn{2}{|c|}{$\begin{array}{l}\text { Upper secondary } \\
\text { (ISCED 3) }\end{array}$} & \multicolumn{2}{|c|}{$\begin{array}{l}\text { Total secondary } \\
\text { (ISCED 2-3) }\end{array}$} & \multicolumn{2}{|c|}{$\begin{array}{c}\text { Tertiary } \\
\text { (ISCED 5-6) }\end{array}$} \\
\hline & 1999 & 2009 & 1999 & 2009 & 1999 & 2009 & 1999 & 2009 & 1999 & 2009 & 1999 & 2009 \\
\hline Angola & $26.8^{* *}$ & $40.1^{-1}$ & $\ldots$ & $127.7^{-1}$ & 15.8 & $30.6^{* *},-1$ & 7.4 & $15.7^{* *},-2$ & 12.5 & $15.2^{* *},-3$ & 0.6 & $\ldots$ \\
\hline Benin & 4.4 & $13.2^{-1}$ & 83.1 & $116.6^{-1}$ & 29.8 & $\ldots$ & 9.6 & $\cdots$ & 21.7 & $\cdots$ & 3.3 & $\cdots$ \\
\hline Botswana & $\ldots$ & $16.6^{-2}$ & 105.5 & $109.4^{-2}$ & 89.0 & $91.1^{-2}$ & 53.2 & $67.1^{-2}$ & 75.0 & $81.5^{-2}$ & 5.3 & $\ldots$ \\
\hline Burkina Faso & 1.8 & 2.9 & 43.9 & 78.3 & 13.1 & 26.5 & 4.7 & 9.7 & 9.7 & 19.8 & 1.0 & 3.4 \\
\hline Burundi & 0.8 & 9.5 & 48.6 & 146.6 & $\ldots$ & 28.9 & $\cdots$ & 10.8 & $\cdots$ & 21.2 & 1.0 & 2.7 \\
\hline Cameroon & 11.2 & 26.2 & 83.6 & 113.8 & $23.1^{* *}$ & 50.3 & $28.0^{* *}$ & 29.1 & $25.1^{* *}$ & 41.5 & 4.7 & 9.0 \\
\hline Cape Verde & $\cdots$ & 60.9 & 120.7 & 98.1 & 83.3 & 100.7 & $\cdots$ & $\cdots$ & $\cdots$ & 81.5 & 1.7 & 14.9 \\
\hline Central African Republic & $\cdots$ & 4.5 & $\cdots$ & 88.6 & $\ldots$ & 17.6 & $\cdots$ & 7.7 & $\cdots$ & 13.6 & 1.9 & 2.5 \\
\hline Chad & $\ldots$ & 0.7 & 63.1 & 89.7 & 12.3 & 28.8 & 6.1 & 17.0 & 9.9 & 24.1 & $\ldots$ & 2.0 \\
\hline Comoros & 3.0 & $26.6^{-1}$ & 98.7 & $119.4^{-1}$ & 39.4 & $\ldots$ & 16.9 & $\cdots$ & 30.0 & $\cdots$ & 1.2 & $5.2^{*}$ \\
\hline Congo & 2.3 & 12.7 & 57.1 & 119.5 & 34.3 & $\cdots$ & $\ldots$ & $\cdots$ & $\cdots$ & $\cdots$ & 3.8 & $\cdots$ \\
\hline Côte d'Ivoire & 2.4 & 3.6 & 73.0 & 73.6 & $28.5^{\star *}$ & $\ldots$ & $13.9^{* *}$ & $\ldots$ & $22.6^{* *}$ & $\ldots$ & 6.2 & $8.4^{-2}$ \\
\hline Democratic Republic of the Congo & $\ldots$ & 3.8 & 47.0 & 90.3 & 39.2 & 47.5 & 6.6 & 30.6 & 18.4 & 36.7 & $1.4^{* *}$ & 6.0 \\
\hline Equatorial Guinea & 25.6 & $53.4^{-1}$ & 108.9 & 81.9 & 43.4 & $\ldots$ & 9.1 & $\ldots$ & 31.6 & $\ldots$ & $\ldots$ & $\ldots$ \\
\hline Eritrea & 5.3 & 13.3 & 52.1 & 48.3 & 36.0 & 45.7 & 13.6 & 21.0 & 21.3 & 31.8 & 1.0 & 2.0 \\
\hline Ethiopia & 1.5 & 4.0 & 50.4 & 102.5 & 15.9 & 43.5 & 7.3 & 14.6 & 13.3 & 34.4 & 1.0 & $3.6^{-1}$ \\
\hline Gabon & $\cdots$ & $\ldots$ & 138.9 & $\ldots$ & 61.5 & $\ldots$ & 28.6 & $\cdots$ & 48.2 & $\cdots$ & 7.1 & $\cdots$ \\
\hline Gambia & 19.0 & $22.0^{-2}$ & 92.4 & $86.2^{-1}$ & 44.8 & $61.7^{-1}$ & 18.0 & $38.5^{-1}$ & 32.0 & $50.8^{-1}$ & 1.1 & $4.6^{-1}$ \\
\hline Ghana & $40.1^{* *}$ & 81.8 & 78.9 & 105.2 & 58.5 & 78.2 & 18.7 & 35.0 & 39.4 & 57.2 & $\ldots$ & $6.2^{-2}$ \\
\hline Guinea & $\ldots$ & $11.4^{*},-1$ & 56.0 & $89.9^{-1}$ & 18.5 & $43.0^{-1}$ & $6.5^{* *}$ & $25.1^{-1}$ & $13.7^{* *}$ & $35.8^{-1}$ & $\cdots$ & $9.2^{-1}$ \\
\hline Guinea-Bissau & $3.7^{\star *}$ & $\ldots$ & $80.1^{* *}$ & $\ldots$ & $\ldots$ & $\ldots$ & $\ldots$ & $\ldots$ & $\ldots$ & $\ldots$ & $0.4^{\text {*n }}$ & $2.9^{-3}$ \\
\hline Kenya & 42.4 & 51.4 & 91.1 & 112.7 & 64.5 & 89.9 & 24.0 & 43.3 & 38.4 & 59.5 & $\cdots$ & 4.1 \\
\hline Lesotho & $20.9^{\star *}$ & $\ldots$ & 101.6 & $107.7^{-2}$ & 38.4 & $50.7^{-2}$ & 18.2 & $23.3^{* *},-2$ & 30.6 & $39.9^{* *},-2$ & 2.1 & $\ldots$ \\
\hline Liberia & 47.4 & $\ldots$ & 98.0 & $90.6^{-1}$ & 38.9 & $39.2^{-1}$ & 27.5 & $23.3^{-1}$ & 33.5 & $31.6^{-1}$ & 9.0 & $\ldots$ \\
\hline Madagascar & $3.4^{* *}$ & 10.2 & 98.0 & 160.4 & $\ldots$ & 42.7 & $\cdots$ & $14.8^{* *}$ & $\ldots$ & $31.5^{* *}$ & 2.2 & 3.6 \\
\hline Malawi & $\ldots$ & $\ldots$ & 135.6 & 119.3 & 59.3 & 51.7 & 24.1 & 17.0 & 36.3 & 29.5 & 0.3 & $0.5^{-2}$ \\
\hline Mali & 1.6 & 3.9 & 56.5 & 94.7 & 19.3 & 49.9 & 11.0 & 25.9 & 15.3 & 38.3 & 2.0 & 6.0 \\
\hline Mauritius & 93.5 & 98.3 & 103.4 & 100.0 & 88.8 & 96.5 & 66.5 & $80.5^{* *}$ & 75.8 & $87.2^{* *}$ & $10.3^{* *}$ & $\ldots$ \\
\hline Mozambique & $\ldots$ & $\ldots$ & 69.6 & 114.5 & 7.2 & 31.8 & 1.9 & 9.5 & 5.2 & 23.3 & 0.6 & $\ldots$ \\
\hline Namibia & 33.6 & $\cdots$ & 116.4 & 112.1 & 75.7 & $\cdots$ & 29.9 & $\cdots$ & 58.1 & $\cdots$ & $\cdots$ & $8.9^{-1}$ \\
\hline Niger & 1.1 & 3.2 & 30.4 & 62.4 & 8.4 & 16.6 & 3.9 & 3.8 & 6.7 & 11.7 & $\ldots$ & 1.4 \\
\hline Nigeria & $\ldots$ & $16.0^{-2}$ & 91.0 & $93.1^{-2}$ & $26.0^{* *}$ & $34.2^{-2}$ & $21.6^{* *}$ & $26.5^{-2}$ & $23.9^{* *}$ & $30.5^{-2}$ & 6.0 & $\ldots$ \\
\hline Rwanda & $\cdots$ & 16.7 & 100.4 & 150.7 & 11.2 & 35.8 & 8.0 & 17.4 & 9.7 & 26.7 & 1.0 & 4.8 \\
\hline Sao Tome and Principe & 25.0 & 51.3 & 107.6 & 131.2 & $\cdots$ & 68.9 & $\ldots$ & 19.8 & $\ldots$ & 50.1 & $\ldots$ & 4.1 \\
\hline Senegal & 2.7 & 11.5 & 65.3 & 83.7 & 18.9 & $40.4^{-1}$ & 10.0 & $16.2^{-1}$ & 15.3 & $30.1^{-1}$ & 3.3 & 8.0 \\
\hline Seychelles & 106.2 & 108.8 & 110.5 & 106.2 & 111.5 & 109.8 & 94.8 & 98.2 & 104.7 & 105.0 & $\ldots$ & $\ldots$ \\
\hline Sierra Leone & $\cdots$ & $4.9^{-2}$ & $\ldots$ & $157.7^{-2}$ & $\ldots$ & $49.9^{-2}$ & $\ldots$ & $18.3^{-2}$ & $\cdots$ & $34.6^{-2}$ & $\ldots$ & $\cdots$ \\
\hline Somalia & $\ldots$ & $\ldots$ & $\ldots$ & $32.6^{-2}$ & $\ldots$ & $10.1^{* *},-2$ & $\ldots$ & $6.4^{* *},-2$ & $\ldots$ & $7.7^{* *},-2$ & $\ldots$ & $\ldots$ \\
\hline South Africa & 20.7 & $51.1^{-2}$ & 113.2 & $104.5^{-2}$ & 99.6 & $94.4^{-2}$ & 81.1 & $95.5^{* *},-2$ & 88.7 & $95.1^{* *},-2$ & $\cdots$ & $\ldots$ \\
\hline Swaziland & $\ldots$ & $\ldots$ & 94.0 & $107.9^{-2}$ & 51.5 & $63.9^{-2}$ & 31.6 & $37.2^{-2}$ & 44.1 & $53.3^{-2}$ & 4.7 & $\ldots$ \\
\hline Togo & 2.5 & 7.5 & 116.4 & 115.2 & 37.5 & $51.3^{* *},-2$ & 15.1 & $26.7^{* *},-2$ & 28.5 & $41.3^{-2}$ & $\ldots$ & $5.3^{-2}$ \\
\hline Uganda & $\cdots$ & $\ldots$ & 126.5 & 121.6 & $11.0^{* *}$ & 33.1 & $6.8^{* *}$ & $14.6^{* *}$ & $9.7^{* *}$ & $27.4^{* *}$ & 1.9 & $3.7^{-1}$ \\
\hline United Republic of Tanzania & $\ldots$ & 33.1 & 66.6 & 104.9 & $7.7^{* *}$ & $\ldots$ & $2.6^{* *}$ & $\ldots$ & $6.1^{\text {*** }}$ & $\ldots$ & 0.6 & $\ldots$ \\
\hline Zambia & $\ldots$ & $\ldots$ & 82.2 & 112.9 & 27.0 & 73.4 & 16.6 & 30.5 & 20.9 & 48.7 & $2.3^{* *}$ & $\ldots$ \\
\hline Zimbabwe & $41.0^{* *}$ & $\ldots$ & 100.1 & $\ldots$ & 66.1 & $\ldots$ & 30.9 & $\cdots$ & 43.1 & $\ldots$ & $3.2^{\star \star}$ & $\ldots$ \\
\hline
\end{tabular}




\begin{tabular}{|c|c|c|c|c|c|c|c|c|c|c|c|c|}
\hline \multicolumn{2}{|c|}{$\begin{array}{c}\text { PRIMARY } \\
\text { EDUCATION SYSTEM }\end{array}$} & \multirow{2}{*}{\multicolumn{2}{|c|}{$\begin{array}{l}\text { NET ENROLMENT } \\
\text { RATE (ADJUSTED) } \\
\text { Primary } \\
\text { (ISCED 1) }\end{array}$}} & \multirow{2}{*}{\multicolumn{2}{|c|}{$\begin{array}{l}\text { GROSS INTAKE } \\
\text { RATIO TO } \\
\text { THE FIRST GRADE } \\
\text { (PRIMARY) }\end{array}$}} & \multirow{2}{*}{\multicolumn{2}{|c|}{$\begin{array}{l}\text { OUT-OF-SCHOOL } \\
\text { CHILDREN OF } \\
\text { PRIMARY SCHOOL } \\
\text { AGE (000) }\end{array}$}} & \multicolumn{4}{|c|}{$\begin{array}{l}\text { ENROLMENT IN PRIVATE } \\
\text { SCHOOL }(\%)\end{array}$} & \multirow{3}{*}{ COUNTRY } \\
\hline \multirow{2}{*}{$\begin{array}{l}\text { Entrance } \\
\text { age } \\
2009\end{array}$} & \multirow{2}{*}{$\begin{array}{c}\begin{array}{c}\text { Duration } \\
\text { (years) }\end{array} \\
2009\end{array}$} & & & & & & & \multicolumn{2}{|c|}{$\begin{array}{l}\text { Primary } \\
\text { (ISCED 1) }\end{array}$} & \multicolumn{2}{|c|}{$\begin{array}{l}\text { Secondary } \\
\text { (ISCED 2-3) }\end{array}$} & \\
\hline & & 1999 & 2009 & 1999 & 2009 & 1999 & 2009 & 1999 & 2009 & 1999 & 2009 & \\
\hline 6 & 6 & $\ldots$ & $\ldots$ & $\ldots$ & $\ldots$ & $\ldots$ & $\ldots$ & $\ldots$ & $2.0^{-1}$ & $\ldots$ & $\ldots$ & Angola \\
\hline 6 & 6 & $\ldots$ & $92.8^{-1}$ & $104^{* x},+1$ & $164^{-1}$ & $\ldots$ & $99^{-1}$ & 7.2 & $9.1^{-1}$ & 18.3 & $\ldots$ & Benin \\
\hline 6 & 7 & $81.5^{* *}$ & $87.1^{* *},-2$ & 115 & $113^{-2}$ & $56^{* *}$ & $39^{* * *},-2$ & 4.7 & $5.0^{-2}$ & 4.1 & $3.0^{-1}$ & Botswana \\
\hline 7 & 6 & 35.2 & 64.4 & 46 & 87 & 1,205 & 866 & 10.8 & 14.2 & 33.1 & 42.0 & Burkina Faso \\
\hline 7 & 6 & $36.1^{* *}$ & 99.1 & 69 & 149 & $732^{* *}$ & 10 & $1.3^{+2}$ & 1.1 & $\ldots$ & 8.8 & Burundi \\
\hline 6 & 6 & $\ldots$ & 91.6 & $74^{* *}$ & 126 & $\ldots$ & 248 & 27.7 & 22.8 & 31.6 & 22.2 & Cameroon \\
\hline 6 & 6 & $99.4^{* *}$ & $82.8^{* *}$ & $102^{* *}$ & 87 & $\cdots$ & $13^{* *}$ & $\ldots$ & 0.4 & $\ldots$ & 12.5 & Cape Verde \\
\hline 6 & 6 & $\ldots$ & 66.9 & $\cdots$ & 97 & $\ldots$ & 227 & 35.5 & 13.8 & $\ldots$ & 9.7 & Central African Republic \\
\hline 6 & 6 & 51.5 & $\cdots$ & 72 & 115 & 646 & $\cdots$ & 25.0 & 8.6 & 14.0 & $\ldots$ & Chad \\
\hline 6 & 6 & $67.6^{* *}$ & $87.3^{-2}$ & 95 & $96^{-1}$ & $27^{* *}$ & $12^{-2}$ & 12.4 & $14.8^{-1}$ & 46.2 & $\cdots$ & Comoros \\
\hline 6 & 6 & $\cdots$ & $\cdots$ & 38 & 113 & $\cdots$ & $192^{* *},-3$ & 10.0 & 35.4 & 8.7 & $\cdots$ & Congo \\
\hline 6 & 6 & $56.3^{*}$ & 57.2 & 67 & 72 & $1,143^{* *}$ & 1,384 & 11.6 & 10.7 & 36.2 & $\cdots$ & Côte d'Ivoire \\
\hline 6 & 6 & $32.6^{* *}$ & $\cdots$ & 49 & 112 & $5,768^{* *}$ & $\cdots$ & $\ldots$ & $\cdots$ & $\cdots$ & $\cdots$ & Democratic Republic of the Congo \\
\hline 7 & 6 & $\ldots$ & 53.5 & $104^{+2}$ & 87 & $22^{* *++1}$ & 47 & 32.8 & 47.1 & 23.2 & $\cdots$ & Equatorial Guinea \\
\hline 7 & 5 & 33.4 & 36.9 & 55 & 42 & 335 & 392 & 11.1 & 9.0 & 6.5 & 5.2 & Eritrea \\
\hline 7 & 6 & 36.7 & $83.5^{* *}$ & 81 & 150 & 6,481 & $2,184^{* *}$ & $\cdots$ & 6.0 & $\cdots$ & 8.7 & Ethiopia \\
\hline 6 & 6 & $\cdots$ & $\cdots$ & $92^{* *},+2$ & $\cdots$ & $37^{* *},+2$ & $\cdots$ & 17.2 & $\cdots$ & 29.3 & $\cdots$ & Gabon \\
\hline 7 & 6 & 76.8 & $71.6^{-1}$ & $85^{* *}$ & $93^{-1}$ & 43 & $73^{-1}$ & 13.7 & $19.5^{-1}$ & 26.1 & $26.7^{-1}$ & Gambia \\
\hline 6 & 6 & $60.2^{* *}$ & $76.2^{* *}$ & 88 & $110^{* *}$ & $1,198^{* *}$ & $828^{* *}$ & 13.3 & 18.0 & 7.1 & 14.9 & Ghana \\
\hline 7 & 6 & 43.6 & $72.3^{* *},-1$ & 51 & $92^{-1}$ & 732 & $420^{* *},-1$ & 14.7 & $26.3^{-1}$ & $\ldots$ & $23.3^{-1}$ & Guinea \\
\hline 7 & 6 & $52.1^{* *}$ & $\cdots$ & $107^{* *}$ & $\cdots$ & $87^{* *}$ & $\cdots$ & 19.4 & $\cdots$ & $12.8^{+1}$ & $\cdots$ & Guinea-Bissau \\
\hline 6 & 6 & $63.0^{* *}$ & $83.8^{* *}$ & 100 & $\cdots$ & $1,942^{* *}$ & $1,029^{* *}$ & $\cdots$ & 10.6 & $\cdots$ & 12.7 & Kenya \\
\hline 6 & 7 & 57.5 & $73.0^{* *},-2$ & 99 & $97^{-2}$ & 153 & $101^{* *},-2$ & 0.1 & $\ldots$ & $\ldots$ & $\ldots$ & Lesotho \\
\hline 6 & 6 & $48.5^{* *}$ & $\ldots$ & 68 & $112^{-1}$ & $208^{* *}$ & $\ldots$ & 38.4 & $29.8^{-1}$ & 37.2 & $57.6^{-1}$ & Liberia \\
\hline 6 & 5 & 66.5 & 99.0 & 111 & 197 & 688 & 27 & 21.9 & 18.0 & $51.4^{+1}$ & 40.3 & Madagascar \\
\hline 6 & 6 & 98.8 & 91.3 & 173 & 140 & 23 & 236 & $\ldots$ & $\ldots$ & $\cdots$ & $\cdots$ & Malawi \\
\hline 7 & 6 & $44.7^{* *}$ & 76.9 & $57^{* *}$ & 96 & $939^{* *}$ & 469 & 21.9 & 39.7 & $\ldots$ & 32.3 & Mali \\
\hline 5 & 6 & 90.5 & $94.0^{* *}$ & 96 & 99 & 12 & $7^{* *}$ & 23.8 & 27.2 & 73.5 & 55.8 & Mauritius \\
\hline 6 & 7 & 52.4 & 82.3 & 103 & 160 & 1,575 & 785 & $\cdots$ & 1.7 & $\ldots$ & 11.5 & Mozambique \\
\hline 7 & 7 & 88.9 & $90.1^{* *}$ & 108 & 98 & 37 & $36^{* *}$ & 4.1 & 4.8 & 4.4 & 5.1 & Namibia \\
\hline 7 & 6 & $25.9^{*}$ & 54.0 & 42 & 90 & $1,291^{* *}$ & 1,147 & 4.0 & 3.9 & 16.4 & 20.0 & Niger \\
\hline 6 & 6 & $61.3^{* *}$ & $62.8^{* *},-2$ & $103^{* *}$ & $\cdots$ & $7,611^{* *}$ & $8,650^{* *},-2$ & $6.5^{+1}$ & $5.4^{-2}$ & 28.9 & $13.7^{-2}$ & Nigeria \\
\hline 7 & 6 & $\ldots$ & 99.0 & 142 & 191 & $343^{* * *},+2$ & 16 & $\ldots$ & 2.5 & 42.5 & 31.9 & Rwanda \\
\hline 7 & 6 & $87.6^{* *}$ & 97.8 & 106 & 130 & $3^{* *}$ & 1 & $\cdots$ & 0.3 & $\cdots$ & 1.8 & Sao Tome and Principe \\
\hline 7 & 6 & $55.5^{* *}$ & 75.0 & 67 & 99 & $705^{* *}$ & 494 & 12.1 & 13.5 & $26.3^{+1}$ & $19.8^{-1}$ & Senegal \\
\hline 6 & 6 & 92.9 & 94.4 & 111 & 107 & 1 & 0 & 4.7 & 8.2 & 3.2 & 7.1 & Seychelles \\
\hline 6 & 6 & $\cdots$ & $\cdots$ & $88^{+1}$ & $192^{-2}$ & $\cdots$ & $\ldots$ & $1.1^{+1}$ & $\cdots$ & $1.9^{+2}$ & $6.9^{-2}$ & Sierra Leone \\
\hline 6 & 6 & $\ldots$ & $\cdots$ & $\cdots$ & $\cdots$ & $\cdots$ & $\cdots$ & $\cdots$ & $\cdots$ & $\cdots$ & $\cdots$ & Somalia \\
\hline 7 & 7 & $96.6^{* *}$ & $92.8^{* *},-2$ & 116 & $108^{* *},-2$ & $236^{* *}$ & $503^{* *},-2$ & 1.7 & $2.5^{-2}$ & 2.3 & $\ldots$ & South Africa \\
\hline 6 & 7 & 70.6 & $82.9^{-2}$ & 94 & $103^{-2}$ & 67 & $37^{-2}$ & $\cdots$ & $\cdots$ & $\cdots$ & $\cdots$ & Swaziland \\
\hline 6 & 6 & 86.3 & 93.5 & 96 & 105 & 112 & 65 & 35.6 & $\cdots$ & 17.7 & $\cdots$ & Togo \\
\hline 6 & 7 & $\ldots$ & $98.0^{* *}$ & $173^{* *},+1$ & 153 & $\ldots$ & $135^{* *}$ & $\ldots$ & 13.4 & $\ldots$ & $51.5^{-1}$ & Uganda \\
\hline 7 & 7 & $49.4^{* *}$ & $96.7^{* *}$ & 73 & 99 & $3,186^{* *}$ & $268^{* *}$ & 0.2 & 1.5 & $\cdots$ & 11.1 & United Republic of Tanzania \\
\hline 7 & 7 & $69.7^{* *}$ & $92.2^{* *}$ & 86 & 117 & $574^{* *}$ & $197^{* *}$ & $\ldots$ & 2.3 & $\ldots$ & 2.6 & Zambia \\
\hline 6 & 7 & 83.8 & $\ldots$ & 112 & $\ldots$ & 398 & $224^{-3}$ & 88.1 & $\ldots$ & 71.7 & $\cdots$ & Zimbabwe \\
\hline
\end{tabular}


Table A3. SCHOOL LIFE EXPECTANCY, COMPLETION RATE AND TRANSITION RATE | 1999 AND 2009

\begin{tabular}{|c|c|c|c|c|c|c|}
\hline \multirow{3}{*}{ COUNTRY } & \multicolumn{6}{|c|}{ SCHOOL LIFE EXPECTANCY } \\
\hline & \multicolumn{2}{|c|}{$\begin{array}{l}\text { Primary } \\
\text { (ISCED 1) }\end{array}$} & \multicolumn{2}{|c|}{$\begin{array}{l}\text { Secondary } \\
\text { (ISCED 2-3) }\end{array}$} & \multicolumn{2}{|c|}{$\begin{array}{l}\text { Total primary and secondary } \\
\text { (ISCED 1-3) }\end{array}$} \\
\hline & 1999 & 2009 & 1999 & 2009 & 1999 & 2009 \\
\hline Angola & $\cdots$ & $7.7^{-1}$ & $0.9^{* *}$ & $1.1^{\star \star},-1$ & $\cdots$ & $8.4^{* *},-1$ \\
\hline Benin & $5.4^{* *}$ & $7.0^{* *},-1$ & $1.6^{* *}$ & $\ldots^{-1}$ & $7.0^{* *}$ & $\ldots$ \\
\hline Botswana & 7.4 & $7.6^{-2}$ & $3.9^{* *}$ & $4.1^{* *},-2$ & $11.3^{* *}$ & $11.7^{* *},-2$ \\
\hline Burkina Faso & 2.7 & 4.7 & 0.7 & 1.4 & 3.4 & 6.1 \\
\hline Burundi & 3.0 & 8.8 & $\ldots$ & 1.5 & $\ldots$ & 10.3 \\
\hline Cameroon & $5.1^{* \star}$ & 6.9 & $1.8^{* *}$ & 2.9 & $6.9^{* *}$ & 9.8 \\
\hline Cape Verde & $7.3^{* *}$ & 5.9 & $\ldots$ & $4.9^{* *}$ & $\ldots$ & $10.8^{* *}$ \\
\hline Central African Republic & $\ldots$ & 5.4 & $\cdots$ & 1.0 & $\ldots$ & 6.4 \\
\hline Chad & 3.9 & 5.4 & $0.8^{* *}$ & 1.7 & $4.6^{* *}$ & 7.1 \\
\hline Comoros & 5.9 & $7.2^{-1}$ & $2.2^{* *}$ & $\ldots$ & $8.1^{* *}$ & $\ldots$ \\
\hline Congo & $3.6^{* *}$ & $7.2^{* *}$ & $\cdots$ & $\ldots$ & $\cdots$ & $\ldots$ \\
\hline Côte d'Ivoire & $4.4^{\text {*** }}$ & 4.5 & $1.6^{* *}$ & $\ldots$ & $6.0^{* *}$ & $\ldots$ \\
\hline Democratic Republic of the Congo & 3.0 & 5.4 & $1.2^{* *}$ & 2.2 & $4.3^{* *}$ & 7.6 \\
\hline Equatorial Guinea & $6.0^{* *}$ & 5.0 & $2.5^{* *}$ & $\cdots$ & $8.5^{* *}$ & $\cdots$ \\
\hline Eritrea & 2.7 & 2.5 & $1.3^{* *}$ & 2.2 & $4.0^{* *}$ & 4.7 \\
\hline Ethiopia & 3.2 & 6.3 & 0.8 & $2.1^{\text {** }}$ & 4.0 & $8.4^{* *}$ \\
\hline Gabon & $8.9^{* *}$ & $\ldots$ & $3.3^{* *}$ & $\cdots$ & $12.2^{*}$ & $\cdots$ \\
\hline Gambia & 5.7 & $5.3^{-1}$ & 2.0 & $3.1^{-1}$ & 7.6 & $8.4^{-1}$ \\
\hline Ghana & $4.9^{* *}$ & 6.5 & $2.4^{* *}$ & $3.5^{\star * *}$ & $7.3^{* *}$ & $10.0^{* *}$ \\
\hline Guinea & 3.5 & $5.5^{-1}$ & $1.0^{* *}$ & $2.6^{* *},-1$ & $4.5^{* *}$ & $8.1^{* *},-1$ \\
\hline Guinea-Bissau & $5.1^{* *}$ & $7.2^{-3}$ & $\cdots$ & $1.8^{-3}$ & $\cdots$ & $9.0^{-3}$ \\
\hline Kenya & 5.6 & 7.1 & $2.3^{* *}$ & $3.6^{\star *}$ & $7.9^{* *}$ & $10.7^{\star *}$ \\
\hline Lesotho & 7.3 & $7.6^{-2}$ & $1.7^{* *}$ & $2.0^{\star * *},-2$ & $9.0^{* *}$ & $9.7^{* *},-2$ \\
\hline Liberia & 6.5 & $6.0^{* *},-1$ & $2.1^{* *}$ & $2.1^{* *},-1$ & $8.6^{* *}$ & $8.2^{* *},-1$ \\
\hline Madagascar & 5.2 & 8.2 & $\ldots$ & $2.3^{* *}$ & $\ldots$ & $10.5^{\star *}$ \\
\hline Malawi & 8.6 & 7.4 & 2.2 & 1.8 & 10.8 & 9.2 \\
\hline Mali & $3.4^{\text {*x }}$ & 5.6 & $1.0^{* *}$ & 2.3 & $4.4^{* *}$ & 7.9 \\
\hline Mauritius & 6.3 & 6.0 & $5.3^{* *}$ & $6.1^{* *}$ & $11.6^{* *}$ & $12.1^{* *}$ \\
\hline Mozambique & 5.1 & 8.5 & 0.3 & 1.3 & 5.4 & 9.8 \\
\hline Namibia & 8.4 & 7.9 & 3.0 & $3.3^{* *}$ & 11.4 & $11.2^{* *}$ \\
\hline Niger & 1.8 & 3.7 & $0.5^{* *}$ & 0.8 & $2.3^{* *}$ & 4.5 \\
\hline Nigeria & $5.7^{* *}$ & $5.8^{* *},-2$ & $1.5^{* \prime}$ & $1.8^{* * *},-2$ & $7.2^{* *}$ & $7.7^{* *},-2$ \\
\hline Rwanda & $6.2^{* *}$ & 9.3 & $0.6^{* *}$ & 1.6 & $6.8^{* *}$ & 10.9 \\
\hline Sao Tome and Principe & 6.5 & 8.0 & $\ldots$ & 2.6 & $\ldots$ & 10.6 \\
\hline Senegal & 3.9 & 5.0 & $1.1^{* *}$ & 2.1 & $5.1^{* *}$ & 7.1 \\
\hline Seychelles & 6.6 & 6.4 & 5.2 & 5.2 & 11.9 & 11.6 \\
\hline Sierra Leone & $\cdots$ & $9.6^{* *},-2$ & $\cdots$ & $2.1^{-2}$ & $\ldots$ & $11.7^{* *},-2$ \\
\hline Somalia & $\cdots$ & $2.1^{* *},-2$ & $\cdots$ & $0.5^{\star *},-2$ & $\ldots$ & $2.5^{* *},-2$ \\
\hline South Africa & 8.0 & $7.3^{* *},-2$ & $4.5^{* *}$ & $4.8^{\star * *},-2$ & $12.4^{* *}$ & $12.1^{* *},-2$ \\
\hline Swaziland & 6.8 & $7.5^{-2}$ & 2.4 & $2.8^{-2}$ & 9.1 & $10.3^{-2}$ \\
\hline Togo & 7.2 & 7.0 & 2.0 & $3.0^{* *}$ & 9.2 & $9.3^{* *}$ \\
\hline Uganda & $9.5^{* *}$ & 8.8 & $0.6^{* *}$ & $1.7^{* *}$ & $10.1^{* *}$ & $10.5^{* *}$ \\
\hline United Republic of Tanzania & 4.9 & 7.4 & $0.4^{* *}$ & $\ldots$ & $5.3^{* *}$ & $\cdots$ \\
\hline Zambia & 5.9 & 8.2 & $1.1^{* *}$ & $2.4^{* *}$ & $7.0^{* *}$ & $10.6^{\star *}$ \\
\hline Zimbabwe & 7.1 & $7.2^{-3}$ & 2.6 & $2.5^{-3}$ & 9.6 & $9.7^{-3}$ \\
\hline
\end{tabular}




\begin{tabular}{|c|c|c|c|c|c|c|}
\hline \multirow{2}{*}{\multicolumn{2}{|c|}{$\begin{array}{c}\text { SCHOOL LIFE } \\
\text { EXPECTANCY } \\
\text { Tertiary } \\
\text { (ISCED 5-6) }\end{array}$}} & \multicolumn{4}{|c|}{ PRIMARY COMPLETION AND TRANSITION RATES } & \multirow{3}{*}{ COUNTRY } \\
\hline & & \multicolumn{2}{|c|}{$\begin{array}{l}\text { Gross intake ratio to the } \\
\text { last grade (primary) }\end{array}$} & \multicolumn{2}{|c|}{$\begin{array}{l}\text { Transition rate from } \\
\text { primary to secondary }\end{array}$} & \\
\hline 1999 & 2009 & 1999 & 2009 & 1999 & 2009 & \\
\hline$\ldots$ & $0.1^{-3}$ & $\ldots$ & $\ldots$ & $\ldots$ & $\ldots$ & Angola \\
\hline 0.2 & $0.3^{-3}$ & $\cdots$ & $65.1^{-1}$ & $\cdots$ & $\cdots$ & Benin \\
\hline 0.3 & $0.4^{-3}$ & 91.1 & $95.5^{-2}$ & $96.2^{\star \star}$ & $97.3^{* *},-3$ & Botswana \\
\hline$\ldots$ & 0.2 & 23.2 & 43.0 & 38.4 & $48.9^{-1}$ & Burkina Faso \\
\hline$\cdots$ & 0.1 & 22.2 & 52.4 & $\ldots$ & $35.8^{-1}$ & Burundi \\
\hline 0.2 & 0.5 & $48.6^{* *}$ & 73.4 & $22.7^{\star \star}$ & $43.4^{-1}$ & Cameroon \\
\hline 0.1 & 0.7 & $105.3^{* *}$ & 86.6 & $\cdots$ & $86.0^{-1}$ & Cape Verde \\
\hline 0.1 & 0.1 & $\ldots$ & 38.0 & $\ldots$ & $44.7^{-1}$ & Central African Republic \\
\hline$\cdots$ & 0.1 & 20.1 & 33.5 & 47.2 & $64.2^{* *,-3}$ & Chad \\
\hline 0.1 & $0.3^{*}$ & 48.9 & $81.0^{-1}$ & $\ldots$ & $52.9^{-2}$ & Comoros \\
\hline 0.2 & $\cdots$ & $\cdots$ & 74.1 & $\ldots$ & $63.7^{-1}$ & Congo \\
\hline 0.3 & $0.4^{-2}$ & 41.3 & 46.5 & 35.2 & $46.1^{-1}$ & Côte d'Ivoire \\
\hline $0.1^{* *}$ & 0.3 & 30.9 & $53.2^{-1}$ & $\ldots$ & $79.8^{*},-2$ & Democratic Republic of the Congo \\
\hline$\cdots$ & $\ldots$ & 51.7 & 46.5 & 84.8 & $\cdots$ & Equatorial Guinea \\
\hline$\cdots$ & 0.1 & 34.3 & 47.8 & 84.5 & $83.5^{-1}$ & Eritrea \\
\hline$\cdots$ & $0.2^{-1}$ & 20.7 & 55.2 & 98.3 & $85.3^{-1}$ & Ethiopia \\
\hline 0.4 & $\cdots$ & $\cdots$ & $\ldots^{-2}$ & $\cdots$ & $\cdots$ & Gabon \\
\hline 0.1 & $0.2^{-1}$ & $79.7^{* *}$ & $79.1^{-1}$ & $62.5^{\star \star}$ & $79.6^{* *},-2$ & Gambia \\
\hline$\ldots$ & $0.3^{-2}$ & 66.5 & $82.7^{* *}$ & 92.6 & $91.5^{-1}$ & Ghana \\
\hline$\cdots$ & $0.5^{-1}$ & 29.0 & $54.7^{-1}$ & 51.5 & $\cdots$ & Guinea \\
\hline$\cdots$ & $0.1^{-3}$ & $30.6^{* *}$ & $\ldots$ & $63.4^{\star \star}$ & $\ldots$ & Guinea-Bissau \\
\hline$\cdots$ & 0.2 & $\cdots$ & $\ldots$ & $\cdots$ & $\cdots$ & Kenya \\
\hline 0.1 & $0.2^{-3}$ & 61.5 & $72.7^{-2}$ & 53.0 & $67.2^{-3}$ & Lesotho \\
\hline 0.5 & $\ldots$ & $\ldots$ & $57.6^{-1}$ & $\ldots$ & $\ldots$ & Liberia \\
\hline 0.1 & 0.2 & $34.8^{* *}$ & 78.8 & 47.5 & $56.0^{-1}$ & Madagascar \\
\hline$\ldots$ & $\ldots$ & 67.2 & 59.2 & 74.4 & $\ldots$ & Malawi \\
\hline 0.1 & 0.3 & $\cdots$ & 59.4 & $52.7^{\star \star}$ & $70.2^{-1}$ & Mali \\
\hline $0.5^{* *}$ & $1.3^{* *},-1$ & 99.9 & 89.4 & 60.4 & $69.3^{-1}$ & Mauritius \\
\hline 0.0 & $\ldots$ & 14.0 & 56.8 & 42.2 & $53.0^{-1}$ & Mozambique \\
\hline$\cdots$ & $0.5^{-1}$ & 95.5 & 87.1 & 89.4 & $81.4^{-1}$ & Namibia \\
\hline$\cdots$ & 0.1 & 18.8 & 40.3 & 29.6 & $47.3^{-1}$ & Niger \\
\hline 0.3 & $\ldots$ & $\ldots$ & $\ldots$ & $\ldots$ & $\ldots$ & Nigeria \\
\hline$\cdots$ & 0.2 & 28.5 & $\cdots$ & $\ldots$ & $\cdots$ & Rwanda \\
\hline$\ldots$ & 0.2 & 46.4 & 83.2 & $\ldots$ & $50.0^{-1}$ & Sao Tome and Principe \\
\hline 0.2 & 0.4 & 42.6 & 56.9 & 35.0 & $59.5^{-1}$ & Senegal \\
\hline$\cdots$ & $\cdots$ & 114.2 & 105.1 & 94.7 & $98.2^{-1}$ & Seychelles \\
\hline$\cdots$ & $\cdots$ & $\cdots$ & $87.7^{-2}$ & $\ldots$ & $\cdots$ & Sierra Leone \\
\hline$\ldots$ & $\ldots$ & $\ldots$ & $\ldots$ & $\ldots$ & $\ldots$ & Somalia \\
\hline$\cdots$ & $\cdots$ & 85.0 & $85.8^{* *},-2$ & 91.9 & $93.5^{* *},-3$ & South Africa \\
\hline 0.2 & $0.2^{-3}$ & 59.4 & $72.0^{-2}$ & 76.3 & $84.8^{-3}$ & Swaziland \\
\hline$\ldots$ & $0.3^{-2}$ & 54.9 & 61.4 & 67.6 & $53.2^{-3}$ & Togo \\
\hline 0.1 & $0.2^{-1}$ & $\ldots$ & 72.5 & 42.0 & $56.9^{-1}$ & Uganda \\
\hline$\ldots$ & $0.1^{-2}$ & 57.2 & 102.3 & $15.6^{\star \star}$ & $\ldots^{-1}$ & United Republic of Tanzania \\
\hline $0.1^{* *}$ & $\ldots$ & 64.0 & 87.1 & 43.8 & $66.4^{-1}$ & Zambia \\
\hline $0.2^{* *}$ & 0.2 & 90.8 & $\cdots$ & $74.6^{\star \star}$ & $\cdots$ & Zimbabwe \\
\hline
\end{tabular}


Table A4. TEACHING STAFF | 1999 AND 2009

\begin{tabular}{|c|c|c|c|c|c|c|}
\hline \multirow{3}{*}{ COUNTRY } & \multicolumn{6}{|c|}{ PUPIL/TEACHER RATIO } \\
\hline & \multicolumn{2}{|c|}{ Primary (ISCED 1) } & \multicolumn{2}{|c|}{ Secondary (ISCED 2-3) } & \multicolumn{2}{|c|}{ Tertiary (ISCED 5-6) } \\
\hline & 1999 & 2009 & 1999 & 2009 & 1999 & 2009 \\
\hline Angola & $\ldots$ & $\ldots$ & $18.3^{* *}$ & $\ldots$ & 9.9 & $\ldots$ \\
\hline Benin & 53.4 & $44.6^{-1}$ & $23.8^{* *}$ & $\ldots$ & $29.4^{* *}$ & $\ldots$ \\
\hline Botswana & 27.0 & $25.2^{-2}$ & 17.6 & $13.9^{-2}$ & $20.1^{* *}$ & $\ldots$ \\
\hline Burkina Faso & 49.0 & 48.9 & $27.9^{* *}$ & 25.6 & 12.8 & 18.9 \\
\hline Burundi & 46.0 & 51.4 & $\cdots$ & 26.5 & 13.3 & 16.3 \\
\hline Cameroon & 51.9 & 46.3 & $23.8^{* *}$ & $\ldots$ & 25.3 & $38.5^{-1}$ \\
\hline Cape Verde & $28.7^{\star \star}$ & 23.9 & $\cdots$ & 18.2 & $\ldots$ & 9.5 \\
\hline Central African Republic & $\ldots$ & 94.6 & $\ldots$ & 80.1 & 20.8 & 30.7 \\
\hline Chad & 67.9 & 60.9 & 34.1 & 32.3 & $\ldots$ & 8.6 \\
\hline Comoros & 34.8 & $30.2^{-1}$ & $\ldots$ & $\ldots$ & 9.7 & $\cdots$ \\
\hline Congo & 61.2 & 64.4 & $\ldots$ & $\ldots$ & $24.2^{* *}$ & $\ldots$ \\
\hline Côte d'Ivoire & 42.7 & 42.1 & $29.4^{* *}$ & $\ldots$ & $\ldots$ & $\ldots$ \\
\hline Democratic Republic of the Congo & 26.0 & 37.3 & 13.8 & 16.0 & $15.9^{* *}$ & 16.5 \\
\hline Equatorial Guinea & 56.7 & 24.2 & 23.4 & $\ldots$ & $\cdots$ & $\ldots$ \\
\hline Eritrea & 47.0 & 38.5 & 50.7 & 42.7 & 21.7 & 16.0 \\
\hline Ethiopia & $\cdots$ & 57.9 & $\cdots$ & 47.9 & 23.5 & $31.7^{-1}$ \\
\hline Gabon & 44.0 & $\ldots$ & $28.1^{* *}$ & $\ldots$ & 12.8 & $\cdots$ \\
\hline Gambia & 37.0 & $34.4^{-1}$ & 23.2 & $24.1^{-1}$ & 13.8 & $17.9^{-1}$ \\
\hline Ghana & 29.6 & 33.1 & 19.6 & 18.3 & $\cdots$ & $34.9^{-2}$ \\
\hline Guinea & 46.8 & $44.1^{-1}$ & $\ldots$ & $33.3^{-1}$ & $\ldots$ & $37.1^{-1}$ \\
\hline Guinea-Bissau & $44.1^{\star \star}$ & $\ldots$ & $\ldots$ & $\ldots$ & $15.1^{* *}$ & $147.6^{-3}$ \\
\hline Kenya & 32.2 & $46.8^{* *}$ & $\ldots$ & $29.7^{* *}$ & $\ldots$ & $\ldots$ \\
\hline Lesotho & 44.4 & $37.0^{-2}$ & $\ldots$ & $16.9^{* *},-2$ & 9.3 & $\ldots$ \\
\hline Liberia & 39.3 & $24.3^{-1}$ & 17.2 & $13.3^{-1}$ & 32.9 & $\ldots$ \\
\hline Madagascar & 47.2 & 47.9 & $\ldots$ & $23.5^{* *}$ & 20.9 & 16.3 \\
\hline Malawi & $\ldots$ & $\ldots$ & $\ldots$ & $\ldots$ & 6.2 & $7.5^{-2}$ \\
\hline Mali & $62.1^{*}$ & 50.1 & $28.4^{*}$ & $23.5^{-1}$ & 19.4 & $\ldots$ \\
\hline Mauritius & 26.1 & 21.6 & 19.6 & $16.0^{* *}$ & $\ldots$ & $\ldots$ \\
\hline Mozambique & 61.5 & 61.3 & $\ldots$ & 37.9 & $\ldots$ & $\ldots$ \\
\hline Namibia & 31.8 & 30.1 & 23.8 & $\ldots$ & $\cdots$ & $16.4^{-1}$ \\
\hline Niger & 41.1 & 38.8 & 24.4 & 27.6 & $\cdots$ & 13.6 \\
\hline Nigeria & 41.4 & $46.3^{-2}$ & $29.4^{* *}$ & $28.4^{-2}$ & 13.3 & $\ldots^{-2}$ \\
\hline Rwanda & 54.3 & 68.3 & 22.5 & $17.9^{-1}$ & 13.8 & 44.9 \\
\hline Sao Tome and Principe & 36.0 & 26.2 & $\ldots$ & $\ldots$ & $\cdots$ & $\ldots$ \\
\hline Senegal & 48.6 & 34.7 & $27.3^{+1}$ & $\ldots$ & $\cdots$ & $\ldots$ \\
\hline Seychelles & 14.7 & 13.8 & 14.0 & 12.6 & $\ldots$ & $\ldots$ \\
\hline Sierra Leone & $\cdots$ & $43.7^{-2}$ & $\cdots$ & $23.9^{-2}$ & $\cdots$ & $\cdots$ \\
\hline Somalia & $\cdots$ & $35.5^{-2}$ & $\ldots$ & $19.3^{* *},-2$ & $\ldots$ & $\ldots$ \\
\hline South Africa & 35.0 & $31.0^{-2}$ & 29.2 & $29.0^{* *},-2$ & $\cdots$ & $\cdots$ \\
\hline Swaziland & 33.2 & $32.4^{-2}$ & $\ldots$ & $19.1^{-2}$ & 21.3 & $\ldots$ \\
\hline Togo & 41.3 & 41.3 & 35.2 & $35.5^{* * *},-2$ & $\ldots$ & $69.2^{-2}$ \\
\hline Uganda & 57.3 & 49.3 & $\ldots$ & $18.1^{* *}$ & 18.3 & $30.1^{-1}$ \\
\hline United Republic of Tanzania & 40.3 & 53.7 & $\ldots$ & $\ldots$ & 9.1 & $18.4^{-2}$ \\
\hline Zambia & $60.9^{\star \star}$ & $\ldots$ & $16.6^{* *}$ & $23.2^{* *},-1$ & $\ldots$ & $\ldots$ \\
\hline Zimbabwe & 41.0 & $\ldots$ & 27.3 & $\ldots$ & $\ldots$ & 24.0 \\
\hline
\end{tabular}


TRAINED TEACHERS (\%)

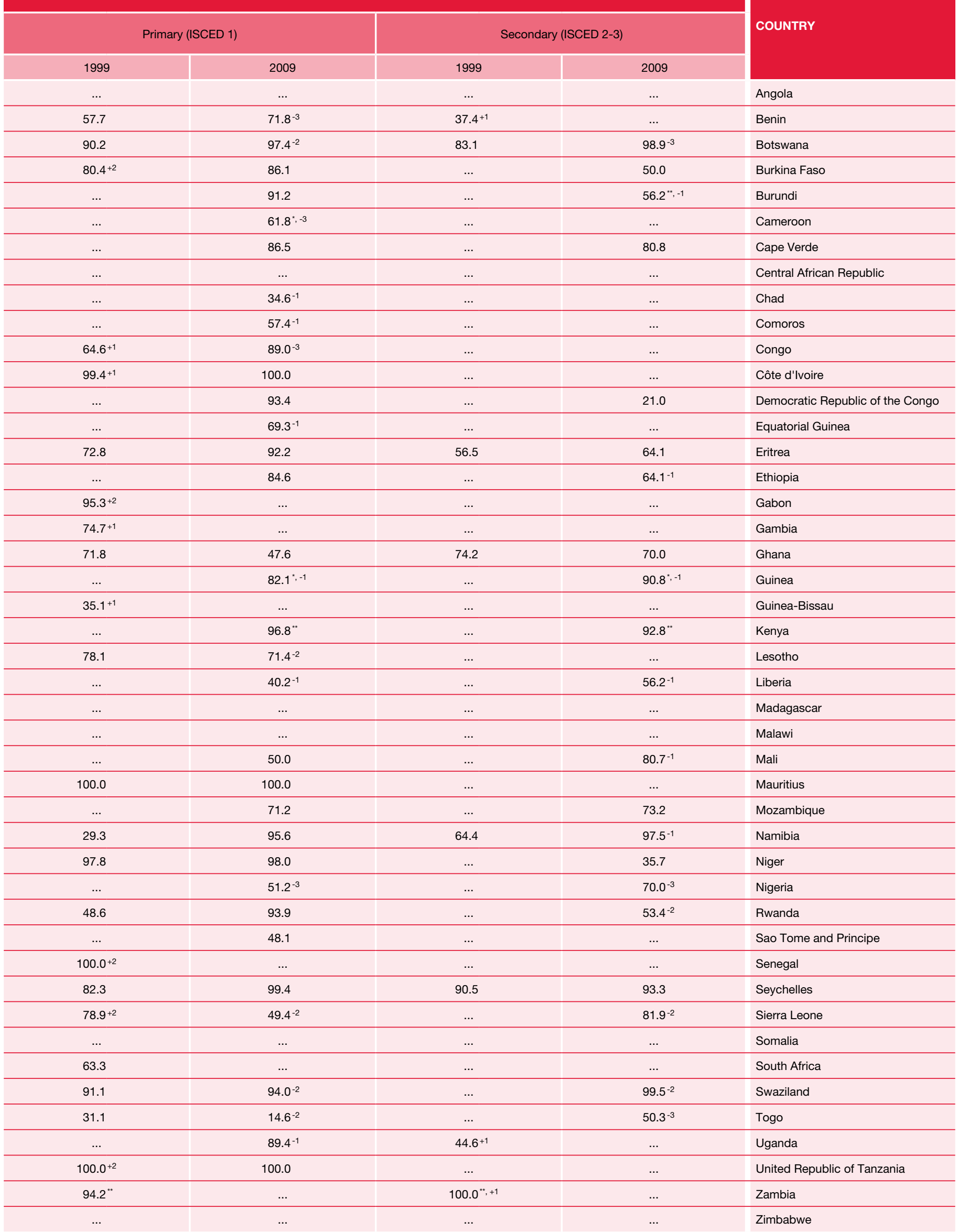


Table A5. PUBLIC EXPENDITURE ON EDUCATION | 1999 AND 2009

\begin{tabular}{|c|c|c|c|c|c|c|c|c|c|c|}
\hline \multirow{3}{*}{ COUNTRY } & \multicolumn{4}{|c|}{ TOTAL PUBLIC EXPENDITURE ON EDUCATION } & \multicolumn{6}{|c|}{$\begin{array}{l}\text { DISTRIBUTION OF PUBLIC CURRENT } \\
\text { EXPENDITURE ON EDUCATION (\%) }\end{array}$} \\
\hline & \multicolumn{2}{|c|}{ as a $\%$ of GDP } & \multicolumn{2}{|c|}{$\begin{array}{l}\text { as a \% of total } \\
\text { government expenditure }\end{array}$} & \multicolumn{2}{|c|}{$\begin{array}{l}\text { Primary } \\
\text { (ISCED 1) }\end{array}$} & \multicolumn{2}{|c|}{$\begin{array}{l}\text { Secondary } \\
\text { (ISCED 2-3) }\end{array}$} & \multicolumn{2}{|c|}{$\begin{array}{l}\text { Tertiary } \\
\text { (ISCED 5-6) }\end{array}$} \\
\hline & 1999 & 2009 & 1999 & 2009 & 1999 & 2009 & 1999 & 2009 & 1999 & 2009 \\
\hline Angola & 2.6 & $2.6^{-3}$ & $6.4^{* *}$ & $\ldots$ & $\cdots$ & $27.6^{-3}$ & $\cdots$ & $42.7^{-3}$ & $\cdots$ & $8.2^{-3}$ \\
\hline Benin & 3.0 & $3.5^{-2}$ & 16.0 & $15.9^{-2}$ & $52.1^{+1}$ & $57.6^{-2}$ & $27.0^{+1}$ & $19.0^{-2}$ & $19.6^{+1}$ & $20.0^{-2}$ \\
\hline Botswana & $\ldots$ & 7.9 & $\ldots$ & 16.2 & $\ldots$ & 19.2 & $\ldots$ & 31.3 & $\ldots$ & 43.5 \\
\hline Burkina Faso & $\ldots$ & $4.6^{-2}$ & $\cdots$ & $21.8^{-2}$ & $\ldots$ & $65.7^{-3}$ & $\ldots$ & $12.2^{-3}$ & $\ldots$ & $11.0^{-3}$ \\
\hline Burundi & 3.4 & 8.3 & 13.3 & 23.4 & 38.9 & 50.8 & 36.5 & 25.1 & 24.4 & 20.0 \\
\hline Cameroon & $1.9^{+1}$ & 3.7 & $9.8^{+1}$ & 16.6 & $\cdots$ & 29.9 & $\cdots$ & 58.6 & $\cdots$ & 7.4 \\
\hline Cape Verde & $\ldots$ & 4.9 & $\ldots$ & 13.8 & $\ldots$ & 42.9 & $\ldots$ & 39.0 & $\ldots$ & 16.1 \\
\hline Central African Republic & 1.6 & $1.3^{-1}$ & 14.5 & $11.7^{-1}$ & $\cdots$ & $48.4^{-2}$ & $\cdots$ & $28.6^{-2}$ & $\cdots$ & $21.2^{-2}$ \\
\hline Chad & 3.2 & 3.2 & 17.1 & 12.6 & 44.6 & 56.8 & 33.3 & 27.1 & 18.6 & 16.1 \\
\hline Comoros & $\ldots$ & $7.6^{-1}$ & $\cdots$ & $\cdots$ & $\ldots$ & $60.5^{-1}$ & $\cdots$ & $4.8^{-1}$ & $\cdots$ & $34.6^{-1}$ \\
\hline Congo & $\cdots$ & $\cdots$ & $\cdots$ & $\cdots$ & $\cdots$ & $\cdots$ & $\cdots$ & $\cdots$ & $\cdots$ & $\cdots$ \\
\hline Côte d'Ivoire & 4.0 & $4.6^{-1}$ & 20.6 & $24.6^{-1}$ & 43.4 & $\cdots$ & 36.4 & $\ldots$ & 20.1 & $21.2^{-2}$ \\
\hline Democratic Republic of the Congo & $\cdots$ & $\cdots$ & $\cdots$ & $\cdots$ & $\cdots$ & $\cdots$ & $\cdots$ & $\cdots$ & $\cdots$ & $\cdots$ \\
\hline Equatorial Guinea & $0.7^{+1}$ & $\cdots$ & $1.6^{+2}$ & $\cdots$ & $\cdots$ & $\cdots$ & $\cdots$ & $\ldots$ & $\cdots$ & $\cdots$ \\
\hline Eritrea & 5.3 & $2.0^{-3}$ & $\cdots$ & $\ldots$ & $\ldots$ & $\ldots$ & $\ldots$ & $\ldots$ & $\ldots$ & $16.2^{-3}$ \\
\hline Ethiopia & $3.9^{+1}$ & $5.5^{-2}$ & $11.3^{+1}$ & $23.3^{-2}$ & $\ldots$ & $\ldots$ & $\ldots$ & $\ldots$ & 11.5 & $20.1^{-2}$ \\
\hline Gabon & $3.1^{* *}$ & $\cdots$ & $\ldots$ & $\ldots$ & $\ldots$ & $\cdots$ & $\ldots$ & $\ldots$ & $\cdots$ & $\ldots$ \\
\hline Gambia & 3.0 & $\cdots$ & 14.2 & $\ldots$ & $\ldots$ & $\ldots$ & $\ldots$ & $\ldots$ & $\ldots$ & $\ldots$ \\
\hline Ghana & $4.1^{* *}$ & $\cdots$ & $\ldots$ & $\cdots$ & $\ldots$ & $\cdots$ & $\cdots$ & $\ldots$ & $\cdots$ & $\cdots$ \\
\hline Guinea & 2.4 & $2.4^{-1}$ & 14.7 & $19.2^{-1}$ & $\ldots$ & $\ldots$ & $\ldots$ & $\ldots$ & 34.4 & $\ldots$ \\
\hline Guinea-Bissau & 5.2 & $\cdots$ & 11.9 & $\ldots$ & $\ldots$ & $\cdots$ & $\ldots$ & $\ldots$ & $\ldots$ & $\cdots$ \\
\hline Kenya & 5.3 & $6.7^{+1}$ & $25.8^{+1}$ & $17.2^{+1}$ & $68.3^{+1}$ & $54.7^{-3}$ & $17.6^{+1}$ & $22.8^{-3}$ & 10.0 & $15.7^{-3}$ \\
\hline Lesotho & 14.1 & $12.4^{-1}$ & 25.5 & $23.7^{-1}$ & 42.8 & $35.7^{-1}$ & 24.4 & $20.8^{-1}$ & 26.8 & $36.8^{-1}$ \\
\hline Liberia & $\ldots$ & $2.8^{-1}$ & $\ldots$ & $12.1^{-1}$ & $\ldots$ & $\ldots$ & $\ldots$ & $\ldots$ & $\ldots$ & $\ldots$ \\
\hline Madagascar & 2.8 & 3.0 & 15.7 & $13.4^{-1}$ & $\ldots$ & 47.2 & $\ldots$ & 20.1 & $\ldots$ & 17.7 \\
\hline Malawi & 5.0 & $\cdots$ & 14.0 & $\ldots$ & 60.8 & $\cdots$ & 10.3 & $\ldots$ & 19.0 & $\cdots$ \\
\hline Mali & $3.0^{* *}$ & 4.4 & $11.4^{* *}$ & 22.3 & 48.9 & 39.9 & 33.7 & 40.7 & 16.3 & 18.7 \\
\hline Mauritius & 3.9 & 3.2 & 17.7 & 11.4 & 31.9 & $27.9^{-3}$ & 36.7 & $42.6^{-3}$ & 13.2 & $11.3^{-3}$ \\
\hline Mozambique & 3.7 & $5.0^{-3}$ & 15.8 & $21.0^{-3}$ & $\ldots$ & $56.2^{-3}$ & $\ldots$ & $28.5^{-3}$ & 19.1 & $14.3^{-3}$ \\
\hline Namibia & 8.1 & $6.4^{-1}$ & 22.3 & $22.4^{-1}$ & 59.4 & $\cdots$ & 27.7 & $\cdots$ & 11.0 & $\cdots$ \\
\hline Niger & 3.2 & 4.5 & 18.7 & 19.3 & 56.0 & 61.1 & 26.6 & 22.0 & 14.8 & 11.8 \\
\hline Nigeria & $\cdots$ & $\cdots$ & $\cdots$ & $\ldots$ & $\ldots$ & $\ldots$ & $\ldots$ & $\ldots$ & $\cdots$ & $\ldots$ \\
\hline Rwanda & 4.3 & $4.9^{+1}$ & 21.9 & $20.4^{-1}$ & 47.7 & $45.3^{-2}$ & 18.5 & $19.8^{-2}$ & 33.8 & $26.9^{-2}$ \\
\hline Sao Tome and Principe & $\ldots$ & $\cdots$ & $\cdots$ & $\ldots$ & $\ldots$ & $\cdots$ & $\ldots$ & $\ldots$ & $\cdots$ & $\cdots$ \\
\hline Senegal & $3.1^{* *}$ & 5.8 & $\cdots$ & $19.0^{* *},-1$ & $\ldots$ & 45.5 & $\cdots$ & 27.4 & $\cdots$ & 26.9 \\
\hline Seychelles & 5.3 & $5.0^{-3}$ & $\cdots$ & $12.6^{-3}$ & $\cdots$ & $\cdots$ & $\cdots$ & $\cdots$ & $\cdots$ & $20.3^{-3}$ \\
\hline Sierra Leone & $4.9^{* *},+1$ & 4.3 & $\cdots$ & 18.1 & $\cdots$ & 49.9 & $\cdots$ & 32.6 & $\cdots$ & 17.5 \\
\hline Somalia & $\cdots$ & $\cdots$ & $\cdots$ & $\cdots$ & $\cdots$ & $\cdots$ & $\cdots$ & $\ldots$ & $\cdots$ & $\cdots$ \\
\hline South Africa & 6.0 & 5.4 & 22.2 & 16.9 & 45.2 & 40.5 & 33.7 & 31.4 & 15.5 & 13.0 \\
\hline Swaziland & 5.1 & $7.8^{-1}$ & $\cdots$ & $21.6^{-1}$ & 33.2 & $35.0^{-1}$ & 26.9 & $30.2^{-1}$ & 32.1 & $22.7^{-1}$ \\
\hline Togo & 4.2 & 4.6 & 26.2 & 17.6 & 36.8 & 50.8 & 33.6 & 35.0 & 22.2 & 14.2 \\
\hline Uganda & $2.5^{* *},+1$ & 3.2 & $\cdots$ & 15.0 & $\cdots$ & 58.3 & $\cdots$ & 23.8 & $\cdots$ & 11.7 \\
\hline United Republic of Tanzania & $2.2^{* *}$ & $6.8^{-1}$ & $\cdots$ & $27.5^{-1}$ & $\cdots$ & $\cdots$ & $\cdots$ & $\cdots$ & $\cdots$ & $\cdots$ \\
\hline Zambia & 1.9 & $1.3^{-1}$ & 6.9 & $\cdots$ & $\ldots$ & $\ldots$ & $\ldots$ & $\ldots$ & $\ldots$ & $\ldots$ \\
\hline Zimbabwe & $4.6^{* *},+1$ & $\ldots$ & $\ldots$ & $\ldots$ & $\ldots$ & $\ldots$ & $\ldots$ & $\ldots$ & $\ldots$ & $\cdots$ \\
\hline
\end{tabular}


DISTRIBUTION OF TOTAL PUBLIC EXPENDITURE ON EDUCATION (\%)

\begin{tabular}{|c|c|c|c|c|c|c|c|c|c|c|}
\hline \multicolumn{2}{|c|}{$\begin{array}{l}\text { Pre-primary } \\
\text { (ISCED 0) }\end{array}$} & \multicolumn{2}{|c|}{$\begin{array}{l}\text { Primary } \\
\text { (ISCED 1) }\end{array}$} & \multicolumn{2}{|c|}{$\begin{array}{l}\text { Secondary } \\
\text { (ISCED 2-3) }\end{array}$} & \multicolumn{2}{|c|}{$\begin{array}{c}\text { Post-secondary } \\
\text { non-tertiary (ISCED 4) }\end{array}$} & \multicolumn{2}{|c|}{$\begin{array}{l}\text { Tertiary } \\
\text { (ISCED 5-6) }\end{array}$} & \multirow[t]{2}{*}{ COUNTRY } \\
\hline 1999 & 2009 & 1999 & 2009 & 1999 & 2009 & 1999 & 2009 & 1999 & 2009 & \\
\hline$\ldots$ & $13.5^{-3}$ & $\ldots$ & $31.4^{-3}$ & $\cdots$ & $42.4^{-3}$ & $\ldots$ & $\cdots$ & $\cdots$ & $8.7^{-3}$ & Angola \\
\hline $1.2^{* *},+1$ & $1.7^{-2}$ & $51.4^{* *},+1$ & $57.2^{-2}$ & $25.7^{* *},+1$ & $19.4^{-2}$ & $\ldots$ & $0.4^{-2}$ & $21.8^{+1}$ & $20.2^{-2}$ & Benin \\
\hline$\ldots$ & $\ldots$ & $\ldots$ & 17.8 & $\ldots$ & 32.7 & $\ldots$ & 4.7 & $\ldots$ & 41.5 & Botswana \\
\hline$\ldots$ & $0.6^{-2}$ & $\ldots$ & $67.0^{-2}$ & $\ldots$ & $15.7^{-2}$ & $\ldots$ & $1.3^{-2}$ & $\ldots$ & $15.2^{-2}$ & Burkina Faso \\
\hline 0.2 & 0.0 & 37.5 & 53.3 & 38.0 & 24.9 & $\ldots$ & $\ldots$ & 24.3 & 18.3 & Burundi \\
\hline$\cdots$ & 3.3 & $\cdots$ & 34.2 & $\cdots$ & 53.9 & $\cdots$ & $\cdots$ & $\cdots$ & 8.6 & Cameroon \\
\hline$\cdots$ & $0.3^{-1}$ & $\cdots$ & 39.4 & $\cdots$ & 42.0 & $\cdots$ & 1.5 & $\cdots$ & 16.6 & Cape Verde \\
\hline$\cdots$ & $1.7^{-2}$ & $\cdots$ & $48.0^{-2}$ & $\ldots$ & $29.1^{-2}$ & $\cdots$ & $\cdots$ & $\cdots$ & $17.5^{-1}$ & Central African Republic \\
\hline$\cdots$ & 0.0 & $\cdots$ & 59.2 & $\cdots$ & 28.3 & $\cdots$ & $\cdots$ & $\cdots$ & 12.4 & Chad \\
\hline$\cdots$ & $\cdots$ & $\cdots$ & $61.7^{-1}$ & $\ldots$ & $23.7^{-1}$ & $\ldots$ & - & $\cdots$ & $14.6^{-1}$ & Comoros \\
\hline$\cdots$ & $\cdots$ & $\cdots$ & $\ldots$ & $\ldots$ & $\cdots$ & $\ldots$ & $\cdots$ & $\cdots$ & $\ldots$ & Congo \\
\hline - & $\ldots$ & $41.7^{* *}$ & $\ldots$ & $37.3^{* *}$ & $\ldots$ & $\ldots$ & $7.2^{-2}$ & $20.8^{* *}$ & $21.0^{-2}$ & Côte d'Ivoire \\
\hline$\ldots$ & $\ldots$ & $\cdots$ & $\ldots$ & $\ldots$ & $\ldots$ & $\ldots$ & $\ldots$ & $\ldots$ & $\ldots$ & Democratic Republic of the Congo \\
\hline $7.6^{* *},+2$ & $\cdots$ & $26.8^{* *},+2$ & $\ldots$ & $18.1^{* *},+2$ & $\cdots$ & $\cdots$ & $\cdots$ & $34.9^{+2}$ & $\cdots$ & Equatorial Guinea \\
\hline$\cdots$ & $\cdots$ & $\cdots$ & $\ldots$ & $\ldots$ & $\cdots$ & $5.7^{* \star},+2$ & $3.7^{-3}$ & $14.0^{* *},+2$ & $19.4^{-3}$ & Eritrea \\
\hline$\cdots$ & $\cdots$ & $\cdots$ & $\cdots$ & $\cdots$ & $\cdots$ & $\cdots$ & $6.5^{-2}$ & $\cdots$ & $39.0^{-2}$ & Ethiopia \\
\hline$\cdots$ & $\cdots$ & $\cdots$ & $\cdots$ & $\cdots$ & $\cdots$ & $\cdots$ & $\cdots$ & $\cdots$ & $\ldots$ & Gabon \\
\hline$\cdots$ & $\cdots$ & $\cdots$ & $\ldots$ & $\ldots$ & $\cdots$ & $\ldots$ & $\cdots$ & $\cdots$ & $\ldots$ & Gambia \\
\hline$\cdots$ & $\ldots$ & $\cdots$ & $\ldots$ & $\ldots$ & $\cdots$ & $\cdots$ & $\cdots$ & $\cdots$ & $\ldots$ & Ghana \\
\hline$\cdots$ & $\cdots$ & $\cdots$ & $40.8^{-1}$ & $\ldots$ & $14.0^{-1}$ & $\ldots$ & $3.9^{-1}$ & $\cdots$ & $34.4^{-1}$ & Guinea \\
\hline$\cdots$ & $\cdots$ & $\cdots$ & $\ldots$ & $\cdots$ & $\ldots$ & $\ldots$ & $\ldots$ & $\cdots$ & $\ldots$ & Guinea-Bissau \\
\hline $0.6^{* *},+1$ & $0.1^{-3}$ & $68.1^{* *},+1$ & $54.1^{-3}$ & $17.4^{* *},+1$ & $21.7^{-3}$ & $2.3^{* *}+1$ & $3.7^{-3}$ & $11.7^{* *},+1$ & $15.4^{-3}$ & Kenya \\
\hline$\ldots$ & $0.1^{-1}$ & 49.6 & $36.0^{-1}$ & 21.6 & $20.5^{-1}$ & 6.9 & $5.0^{-1}$ & 21.9 & $36.4^{-1}$ & Lesotho \\
\hline$\cdots$ & $\cdots$ & $\cdots$ & $\ldots$ & $\ldots$ & $\cdots$ & $\ldots$ & $\ldots$ & $\cdots$ & $\ldots$ & Liberia \\
\hline$\cdots$ & 0.3 & $\cdots$ & 52.3 & $\ldots$ & 18.2 & $\ldots$ & 2.4 & $\cdots$ & 15.4 & Madagascar \\
\hline$\ldots$ & $\ldots$ & 65.3 & $\ldots$ & 10.1 & $\ldots$ & 1.5 & $\ldots$ & 15.0 & $\ldots$ & Malawi \\
\hline $1.0^{* *}$ & 0.9 & $44.7^{* *}$ & 44.0 & $39.7^{* *}$ & 39.2 & $\ldots$ & $\cdots$ & $14.6^{* *}$ & 15.8 & Mali \\
\hline $1.4^{+2}$ & 1.5 & $33.2^{+2}$ & 26.9 & $40.7^{+2}$ & 48.8 & $0.5^{+2}$ & 4.4 & $12.7^{+2}$ & 11.0 & Mauritius \\
\hline$\ldots$ & $\ldots$ & $\cdots$ & $57.7^{-3}$ & $\ldots$ & $29.3^{-3}$ & $\ldots$ & $\ldots$ & 22.4 & $12.1^{-3}$ & Mozambique \\
\hline$\cdots$ & $0.4^{-1}$ & 58.5 & $47.6^{-1}$ & 27.3 & $18.7^{-1}$ & 2.2 & $2.7^{-1}$ & 12.0 & $9.9^{-1}$ & Namibia \\
\hline$\ldots$ & 3.3 & $49.2^{\star *},+2$ & 63.4 & $24.5^{* *},+2$ & 20.9 & $\ldots$ & 2.5 & $16.2^{* *},+2$ & 9.9 & Niger \\
\hline$\cdots$ & $\cdots$ & $\cdots$ & $\ldots$ & $\ldots$ & $\cdots$ & $\ldots$ & $\cdots$ & $\ldots$ & $\ldots$ & Nigeria \\
\hline $0.5^{* *},+1$ & $0.2^{+1}$ & $48.2^{\star \star},+1$ & $38.5^{+1}$ & $16.7^{* *},+1$ & $29.1^{+1}$ & $\ldots$ & $1.2^{+1}$ & $34.7^{* *},+1$ & $25.5^{+1}$ & Rwanda \\
\hline$\cdots$ & $\cdots$ & $\cdots$ & $\ldots$ & $\ldots$ & $\ldots$ & $\ldots$ & $\cdots$ & $\cdots$ & $\ldots$ & Sao Tome and Principe \\
\hline$\cdots$ & 0.4 & $48.1^{* *}$ & 47.3 & $\cdots$ & 27.5 & $\cdots$ & $\cdots$ & $\cdots$ & 24.7 & Senegal \\
\hline$\cdots$ & $4.1^{-3}$ & $\ldots$ & $\ldots$ & $\ldots$ & $\ldots$ & $\cdots$ & $14.3^{-3}$ & $\ldots$ & $17.9^{-3}$ & Seychelles \\
\hline$\cdots$ & $\cdots$ & $\cdots$ & 53.0 & $\cdots$ & 25.6 & $\cdots$ & $3.9^{* *},-1$ & $\cdots$ & 21.4 & Sierra Leone \\
\hline$\cdots$ & $\cdots$ & $\cdots$ & $\cdots$ & $\cdots$ & $\cdots$ & $\cdots$ & $\cdots$ & $\cdots$ & $\ldots$ & Somalia \\
\hline$\cdots$ & 0.9 & 45.0 & 41.1 & 33.7 & 30.9 & $\ldots$ & 2.4 & 15.2 & 12.5 & South Africa \\
\hline$\cdots$ & - & 33.2 & $33.6^{-1}$ & 26.9 & $33.5^{-1}$ & $\ldots$ & $2.3^{-1}$ & 32.1 & $21.6^{-1}$ & Swaziland \\
\hline$\cdots$ & $\cdots$ & 37.9 & 50.2 & 33.0 & 35.4 & $\cdots$ & $\cdots$ & 22.0 & 14.4 & Togo \\
\hline$\cdots$ & $\cdots$ & $\cdots$ & 57.7 & $\cdots$ & 24.2 & $\cdots$ & 4.2 & $\cdots$ & 11.3 & Uganda \\
\hline$\cdots$ & $\cdots$ & $\cdots$ & $67.6^{-1}$ & $\ldots$ & $9.3^{-1}$ & $\cdots$ & $1.8^{-1}$ & $\ldots$ & $21.4^{-1}$ & United Republic of Tanzania \\
\hline$\cdots$ & $\cdots$ & $54.8^{+1}$ & $\ldots$ & $25.8^{+1}$ & $\cdots$ & $\cdots$ & $\cdots$ & $19.4^{+1}$ & $\ldots$ & Zambia \\
\hline $0.0^{* *},+1$ & $\cdots$ & $54.9^{* \star},+1$ & $\cdots$ & $28.6^{* *},+1$ & $\cdots$ & $\cdots$ & $\cdots$ & $16.6^{* *},+1$ & $\cdots$ & Zimbabwe \\
\hline
\end{tabular}


Table A6. PUBLIC EXPENDITURE ON EDUCATION PER STUDENT ${ }^{\mathrm{C}}$ | 1999 AND 2009

\begin{tabular}{|c|c|c|c|c|c|c|c|c|}
\hline \multirow{4}{*}{ COUNTRY } & \multicolumn{8}{|c|}{ TOTAL PUBLIC EXPENDITURE ON EDUCATION PER STUDENT } \\
\hline & \multicolumn{8}{|c|}{ as a $\%$ of GDP per capita } \\
\hline & \multicolumn{2}{|c|}{ Pre-primary (ISCED 0) } & \multicolumn{2}{|c|}{ Primary (ISCED 1) } & \multicolumn{2}{|c|}{ Secondary (ISCED 2-3) } & \multicolumn{2}{|c|}{ Tertiary (ISCED 5-6) } \\
\hline & 1999 & 2009 & 1999 & 2009 & 1999 & 2009 & 1999 & 2009 \\
\hline Angola & $\ldots$ & $\ldots$ & $\ldots$ & $4.2^{* * *},-3$ & $\ldots$ & $41.9^{* *},-3$ & $\ldots$ & $80.8^{-3}$ \\
\hline Benin & $9.3^{* *},+1$ & $14.8^{-3}$ & $12.1^{* *},+1$ & $12.1^{-3}$ & $24.6^{* *},+1$ & $\ldots$ & $212.7^{+1}$ & $149.8^{-3}$ \\
\hline Botswana & $\ldots$ & $\ldots$ & $\cdots$ & $12.5^{-2}$ & $\ldots$ & $37.0^{-2}$ & $\ldots$ & $\ldots$ \\
\hline Burkina Faso & $\ldots$ & $10.4^{-2}$ & $\ldots$ & $29.0^{-2}$ & $\ldots$ & $30.2^{-2}$ & $\ldots$ & $307.1^{-2}$ \\
\hline Burundi & 10.2 & 0.3 & 14.7 & 21.1 & $\ldots$ & 59.4 & $1,051.5$ & 520.4 \\
\hline Cameroon & $\ldots$ & 8.3 & $\ldots$ & 7.4 & $\ldots$ & 30.7 & $\ldots$ & 35.8 \\
\hline Cape Verde & $\ldots$ & $0.4^{-1}$ & $\ldots$ & 13.2 & $\ldots$ & 17.0 & $\ldots$ & 48.4 \\
\hline Central African Republic & $\ldots$ & $7.7^{-2}$ & $\ldots$ & $5.4^{-2}$ & $\ldots$ & $17.3^{-1}$ & $\ldots$ & $103.2^{-1}$ \\
\hline Chad & $\ldots$ & 2.4 & $\ldots$ & 12.7 & $\ldots$ & 24.1 & $\ldots$ & 217.8 \\
\hline Comoros & $\ldots$ & $\ldots$ & $\ldots$ & $27.2^{-1}$ & $\ldots$ & $\ldots$ & $\ldots$ & $\ldots$ \\
\hline Congo & $\cdots$ & $\cdots$ & $\ldots$ & $\cdots$ & $\cdots$ & $\cdots$ & $\cdots$ & $\cdots$ \\
\hline Côte d'Ivoire & $0.2^{* *}$ & $\cdots$ & $14.8^{* *}$ & $\ldots$ & $42.8^{*}$ & $\ldots$ & $146.3^{*}$ & $119.1^{-2}$ \\
\hline Democratic Republic of the Congo & $\ldots$ & $\ldots$ & $\ldots$ & $\ldots$ & $\ldots$ & $\ldots$ & $\ldots$ & $\ldots$ \\
\hline Equatorial Guinea & $1.2^{\star \star},+2$ & $\cdots$ & $1.1^{\mu *++2}$ & $\ldots$ & 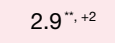 & $\ldots$ & $\ldots$ & $\ldots$ \\
\hline Eritrea & $\cdots$ & $\cdots$ & $\ldots$ & $\cdots$ & $\cdots$ & $\cdots$ & $429.6^{*,+2}$ & $\cdots$ \\
\hline Ethiopia & $\ldots$ & $\ldots$ & $\ldots$ & $\ldots$ & $\ldots$ & $\ldots$ & $\ldots$ & $642.9^{-2}$ \\
\hline Gabon & $\ldots$ & $\cdots$ & $\cdots$ & $\cdots$ & $\cdots$ & $\cdots$ & $\cdots$ & $\cdots$ \\
\hline Gambia & $\cdots$ & $\cdots$ & $\cdots$ & $\cdots$ & $\cdots$ & $\cdots$ & $\cdots$ & $\cdots$ \\
\hline Ghana & $\cdots$ & $0.8^{-3}$ & $\cdots$ & $17.9^{-3}$ & $\cdots$ & $28.3^{-3}$ & $\cdots$ & $\cdots$ \\
\hline Guinea & $\cdots$ & $\ldots$ & $\ldots$ & $7.1^{-1}$ & $\cdots$ & $6.3^{-1}$ & $\ldots$ & $102.3^{-1}$ \\
\hline Guinea-Bissau & $\cdots$ & $\cdots$ & $\cdots$ & $\cdots$ & $\cdots$ & $\cdots$ & $\cdots$ & $\ldots$ \\
\hline Kenya & $0.3^{\star \star *}$ & $0.1^{-3}$ & $21.5^{\mu *},+1$ & $22.4^{-3}$ & $14.5^{\cdots++1}$ & $21.2^{-3}$ & $209.0^{+1}$ & $\ldots$ \\
\hline Lesotho & $\ldots$ & $\ldots$ & 34.9 & $26.0^{-3}$ & 75.3 & $52.2^{-3}$ & $1,387.2$ & $1,190.9^{-3}$ \\
\hline Liberia & $\ldots$ & $\ldots$ & $\ldots$ & $\ldots$ & $\cdots$ & $\ldots$ & $\ldots$ & $\ldots$ \\
\hline Madagascar & $\ldots$ & 0.8 & $\ldots$ & 7.1 & $\cdots$ & $10.5^{*}$ & $\ldots$ & 132.4 \\
\hline Malawi & $\ldots$ & $\ldots$ & 14.0 & $\ldots$ & 10.0 & $\ldots$ & $2,613.3$ & $\ldots$ \\
\hline Mali & $13.8^{\star *}$ & 8.6 & $14.3^{*}$ & 13.0 & $56.1^{*}$ & 32.6 & $241.3^{*}$ & 117.7 \\
\hline Mauritius & $1.4^{+2}$ & 1.7 & $9.3^{+2}$ & 9.3 & $14.2^{+2}$ & $15.1^{*}$ & $25.4^{* *++2}$ & $16.7^{\prime \prime,-1}$ \\
\hline Mozambique & $\ldots$ & $\ldots$ & $\ldots$ & $14.8^{-3}$ & $\ldots$ & $85.2^{-3}$ & $1,412.2$ & $\ldots$ \\
\hline Namibia & $\ldots$ & $2.0^{-3}$ & 21.6 & $15.6^{-1}$ & 33.3 & $15.3^{-1}$ & $113.1^{*,+2}$ & $67.3^{-1}$ \\
\hline Niger & $\ldots$ & 47.6 & $24.5^{\mu \prime},+2$ & 28.3 & $74.0 ",+2$ & 56.6 & $\ldots$ & 429.3 \\
\hline Nigeria & $\ldots$ & $\ldots$ & $\ldots$ & $\ldots$ & $\ldots$ & $\ldots$ & $\ldots$ & $\ldots$ \\
\hline Rwanda & $9.3^{* *},+1$ & $\cdots$ & $11.0^{\circ,+1}$ & $8.2^{-1}$ & $41.9^{\prime \prime,+1}$ & $34.3^{-1}$ & $971.1^{*,+1}$ & $222.8^{-1}$ \\
\hline Sao Tome and Principe & $\cdots$ & $\cdots$ & $\ldots$ & $\ldots$ & $\cdots$ & $\cdots$ & $\cdots$ & $\cdots$ \\
\hline Senegal & $\cdots$ & 2.3 & $14.1^{*}$ & 20.9 & $\cdots$ & $25.7^{*},-1$ & $\ldots$ & 191.5 \\
\hline Seychelles & $\cdots$ & $\cdots$ & $\cdots$ & $\cdots$ & $\cdots$ & $\cdots$ & $\cdots$ & $\cdots$ \\
\hline Sierra Leone & $\ldots$ & $\ldots$ & $\ldots$ & $7.1^{* \prime,-2}$ & $\ldots$ & $18.0^{* \cdots,-2}$ & $\ldots$ & $\ldots$ \\
\hline Somalia & $\ldots$ & $\ldots$ & $\ldots$ & $\ldots$ & $\ldots$ & $\ldots$ & $\ldots$ & $\ldots$ \\
\hline South Africa & 0.1 & $2.8^{-2}$ & 14.3 & $14.3^{-2}$ & 20.1 & $17.4^{*,-2}$ & $\cdots$ & $\cdots$ \\
\hline Swaziland & $\cdots$ & $\cdots$ & 8.3 & $15.8^{-3}$ & 23.4 & $37.9^{-3}$ & 351.5 & $347.5^{-3}$ \\
\hline Togo & $\cdots$ & $\cdots$ & 8.5 & 13.0 & 30.3 & $19.1^{-2}$ & $\cdots$ & $155.2^{-2}$ \\
\hline Uganda & $\ldots$ & $\cdots$ & $\ldots$ & 7.0 & $\cdots$ & $19.0^{*}$ & $\ldots$ & $\ldots$ \\
\hline United Republic of Tanzania & $\ldots$ & $\cdots$ & $\cdots$ & $22.1^{-1}$ & $\cdots$ & $\cdots$ & $\cdots$ & $\ldots$ \\
\hline Zambia & $\ldots$ & $\ldots$ & $7.2^{+1}$ & $\ldots$ & $19.4^{+1}$ & $\ldots$ & $164.6 ",+1$ & $\ldots$ \\
\hline Zimbabwe & $\ldots$ & $\ldots$ & $12.7^{+1}$ & $\ldots$ & $19.3^{\prime \prime+1}$ & $\ldots$ & $193.0^{* *+1}$ & $\ldots$ \\
\hline
\end{tabular}

${ }^{\mathrm{c}}$ Expenditure on education (total or current) per student is calculated by dividing total or current expenditure on education by total enrolment (public and private) for each education level. 
TOTAL PUBLIC EXPENDITURE ON EDUCATION PER STUDENT

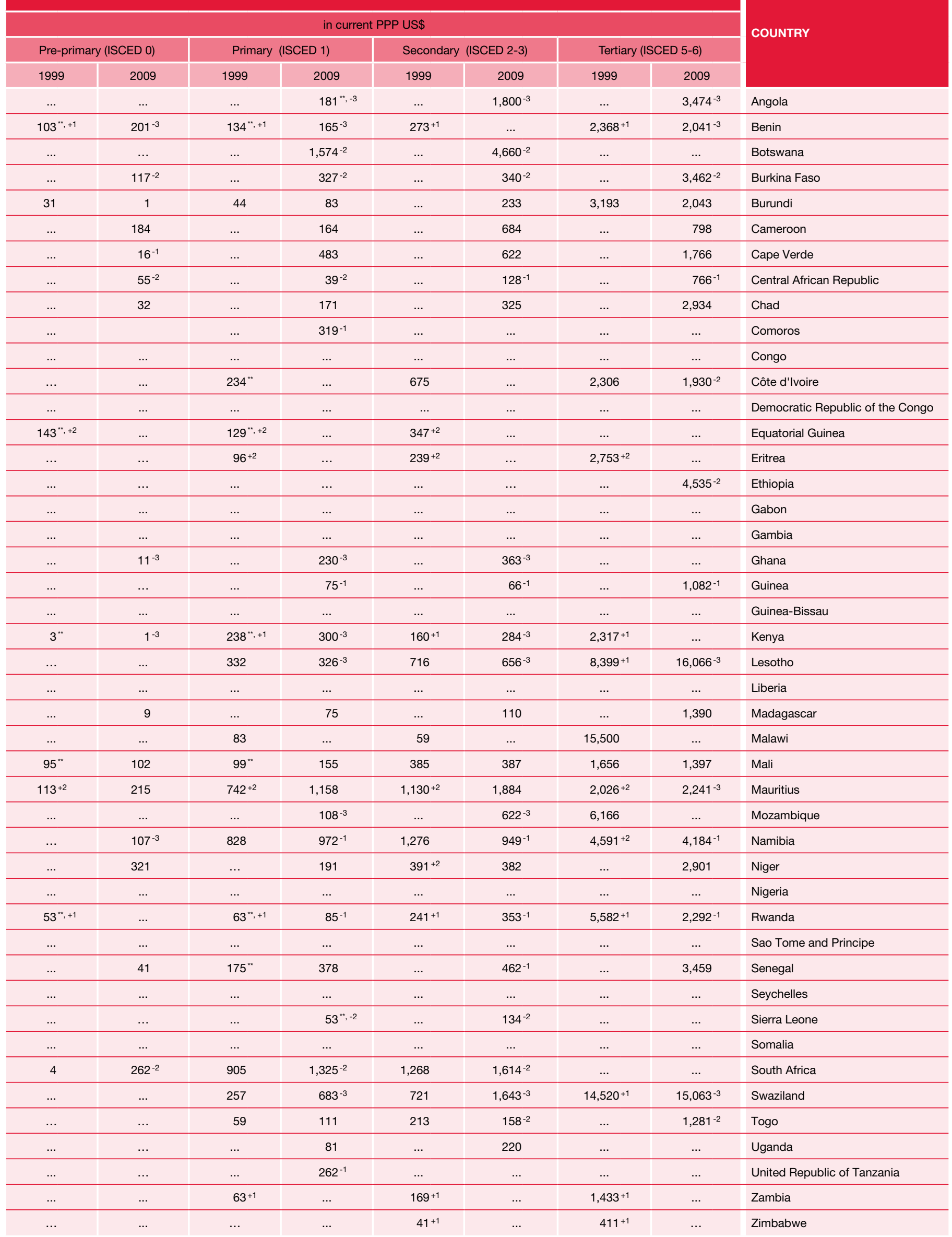




\section{Table A6. PUBLIC EXPENDITURE ON EDUCATION PER STUDENT ${ }^{\mathrm{C}}$ | 1999 AND 2009}

\begin{tabular}{|c|c|c|c|c|c|c|c|c|}
\hline \multirow{3}{*}{ COUNTRY } & \multicolumn{8}{|c|}{ CURRENT EXPENDITURE ON EDUCATION PER STUDENT (IN CURRENT PPP\$) } \\
\hline & \multicolumn{2}{|c|}{ Pre-primary (ISCED 0) } & \multicolumn{2}{|c|}{ Primary (ISCED 1) } & \multicolumn{2}{|c|}{ Secondary (ISCED 2-3) } & \multicolumn{2}{|c|}{ Tertiary (ISCED 5-6) } \\
\hline & 1999 & 2009 & 1999 & 2009 & 1999 & 2009 & 1999 & 2009 \\
\hline Angola & $\ldots$ & $\ldots$ & $\ldots$ & $120^{* *},-3$ & $\ldots$ & $1,364^{* *},-3$ & $\ldots$ & $2,470^{-3}$ \\
\hline Benin & $96^{* *+},+1$ & $201^{-3}$ & $116^{* *}+1$ & $153^{-3}$ & $244^{* *},+1$ & $\ldots$ & $1,817^{+1}$ & $1,676^{-3}$ \\
\hline Botswana & $\ldots$ & $\ldots$ & $\ldots$ & $822^{-2}$ & $\ldots$ & $3,888^{-2}$ & $\ldots$ & $28,017^{* *},-2$ \\
\hline Burkina Faso & $\cdots$ & $32^{* *},-3$ & $\cdots$ & $315^{-3}$ & $\ldots$ & $253^{-3}$ & $\ldots$ & $2,401^{-3}$ \\
\hline Burundi & 31 & 1 & 43 & 68 & $\ldots$ & 201 & 3,003 & 1,908 \\
\hline Cameroon & $\ldots$ & 184 & $\ldots$ & 117 & $\ldots$ & 608 & $\ldots$ & 559 \\
\hline Cape Verde & $\ldots$ & $16^{-1}$ & $\ldots$ & 479 & $\ldots$ & 528 & $\ldots$ & 1,564 \\
\hline Central African Republic & $\ldots$ & $55^{-2}$ & $\ldots$ & $39^{-2}$ & $\ldots$ & $123^{-1}$ & $\cdots$ & $743^{-1}$ \\
\hline Chad & $\ldots$ & 32 & 53 & 108 & 268 & 204 & $3,138^{+1}$ & 2,497 \\
\hline Comoros & $\ldots$ & $\cdots$ & $\cdots$ & $132^{-1}$ & $\cdots$ & $\cdots$ & $\cdots$ & $\cdots$ \\
\hline Congo & $\ldots$ & $\cdots$ & $\ldots$ & $\cdots$ & $\ldots$ & $\ldots$ & $\cdots$ & $\cdots$ \\
\hline Côte d'Ivoire & $11^{* *}$ & $\cdots$ & $217^{* *}$ & $\cdots$ & $588^{* *}$ & $\ldots$ & $1,984^{* *}$ & $1,820^{-2}$ \\
\hline Democratic Republic of the Congo & $\ldots$ & $\cdots$ & $\cdots$ & $\cdots$ & $\ldots$ & $\ldots$ & $\cdots$ & $\cdots$ \\
\hline Equatorial Guinea & $\cdots$ & $\cdots$ & $\cdots$ & $\cdots$ & $\cdots$ & $\cdots$ & $\cdots$ & $\cdots$ \\
\hline Eritrea & $\ldots$ & $\ldots$ & $\ldots$ & $\ldots$ & $\ldots$ & $\ldots$ & $\ldots$ & $\ldots$ \\
\hline Ethiopia & $\ldots$ & $\ldots$ & $\ldots$ & $\ldots$ & $\ldots$ & $\ldots$ & $\ldots$ & $\ldots$ \\
\hline Gabon & $\cdots$ & $\cdots$ & $\cdots$ & $\cdots$ & $\cdots$ & $\cdots$ & $\cdots$ & $\cdots$ \\
\hline Gambia & $\ldots$ & $\ldots$ & $\ldots$ & $\ldots$ & $\ldots$ & $\ldots$ & $\ldots$ & $\ldots$ \\
\hline Ghana & $\ldots$ & $\ldots$ & $\ldots$ & $\ldots$ & $\ldots$ & $\ldots$ & $\ldots$ & $\ldots$ \\
\hline Guinea & $\cdots$ & $\cdots$ & $\cdots$ & $75^{-1}$ & $\cdots$ & $66^{-1}$ & $\ldots$ & $\ldots$ \\
\hline Guinea-Bissau & $\cdots$ & $\ldots$ & $\ldots$ & $\ldots$ & $\ldots$ & $\cdots$ & $\cdots$ & $\cdots$ \\
\hline Kenya & $\ldots$ & $1^{-3}$ & $233^{* *},+1$ & $285^{-3}$ & $158^{* *},+1$ & $281^{-3}$ & $2,286^{+1}$ & $\ldots$ \\
\hline Lesotho & $\ldots$ & $5^{-3}$ & 209 & $317^{-1}$ & 612 & $620^{-3}$ & $8,094^{+1}$ & $15,579^{-3}$ \\
\hline Liberia & $\ldots$ & $\ldots$ & $\ldots$ & $\cdots$ & $\cdots$ & $\ldots$ & $\cdots$ & $\cdots$ \\
\hline Madagascar & $\ldots$ & 7 & $\cdots$ & 55 & $\cdots$ & $100^{* *}$ & $\cdots$ & 1,311 \\
\hline Malawi & $\cdots$ & $\cdots$ & 61 & $\cdots$ & 48 & $\cdots$ & 15,500 & $\cdots$ \\
\hline Mali & $95^{* *}$ & 65 & $97^{* *}$ & 106 & $293^{* *}$ & 303 & $1,652^{* *}$ & 1,245 \\
\hline Mauritius & 106 & $150^{-3}$ & 700 & $971^{-3}$ & 1,031 & $1,367^{\star \star *},-3$ & $\ldots$ & $2,146^{* *},-3$ \\
\hline Mozambique & $\cdots$ & $\cdots$ & $\cdots$ & $77^{-3}$ & $\cdots$ & $444^{-3}$ & 2,777 & $\cdots$ \\
\hline Namibia & $\ldots$ & $\ldots$ & 784 & $958^{-1}$ & 1,281 & $920^{-1}$ & $\cdots$ & $\cdots$ \\
\hline Niger & $\cdots$ & 185 & 152 & 144 & 366 & 315 & $\ldots$ & 2,702 \\
\hline Nigeria & $\cdots$ & $\cdots$ & $\cdots$ & $\cdots$ & $\cdots$ & $\cdots$ & $\cdots$ & $\cdots$ \\
\hline Rwanda & $\cdots$ & $\cdots$ & 52 & $83^{-2}$ & 245 & $294^{-2}$ & $4,403^{+1}$ & $2,292^{-1}$ \\
\hline Sao Tome and Principe & $\cdots$ & $\cdots$ & $\cdots$ & $\cdots$ & $\ldots$ & $\ldots$ & $\cdots$ & $\cdots$ \\
\hline Senegal & $\ldots$ & 23 & $\ldots$ & 332 & $\ldots$ & $\ldots$ & $\cdots$ & 3,438 \\
\hline Seychelles & $\ldots$ & $\ldots$ & $\ldots$ & $\ldots$ & $\ldots$ & $\ldots$ & $\cdots$ & $\cdots$ \\
\hline Sierra Leone & $\ldots$ & $\ldots$ & $\ldots$ & $51^{* *},-2$ & $\ldots$ & $134^{* *},-2$ & $\cdots$ & $\ldots$ \\
\hline Somalia & $\ldots$ & $\ldots$ & $\ldots$ & $\ldots$ & $\ldots$ & $\cdots$ & $\cdots$ & $\cdots$ \\
\hline South Africa & 4 & $314^{-1}$ & 885 & $1,306^{-1}$ & 1,245 & $1,545^{\star *},-1$ & $\cdots$ & $\cdots$ \\
\hline Swaziland & $\ldots$ & $\ldots$ & 258 & $603^{-1}$ & 729 & $1,459^{-1}$ & $14,092^{+1}$ & $\ldots$ \\
\hline Togo & $\ldots$ & $\ldots$ & 56 & 109 & 209 & $151^{-2}$ & $\ldots$ & $1,203^{-2}$ \\
\hline Uganda & $\ldots$ & $\ldots$ & $\ldots$ & 78 & $\ldots$ & 221 & $\cdots$ & 1,151 \\
\hline United Republic of Tanzania & $\cdots$ & $\cdots$ & $\cdots$ & $\cdots$ & $\cdots$ & $\cdots$ & $\cdots$ & $\cdots$ \\
\hline Zambia & $\cdots$ & $\cdots$ & $\cdots$ & $\cdots$ & $\cdots$ & $\cdots$ & $\cdots$ & $\cdots$ \\
\hline Zimbabwe & $\ldots$ & $\ldots$ & $30^{+2}$ & $\cdots$ & & $\ldots$ & $\cdots$ & $\ldots$ \\
\hline
\end{tabular}

${ }^{c}$ Expenditure on education (total or current) per student is calculated by dividing total or current expenditure on education by total enrolment (public and private) for each education level. 
RATIO OF PUBLIC CURRENT EXPENDITURE ON EDUCATION PER STUDENT

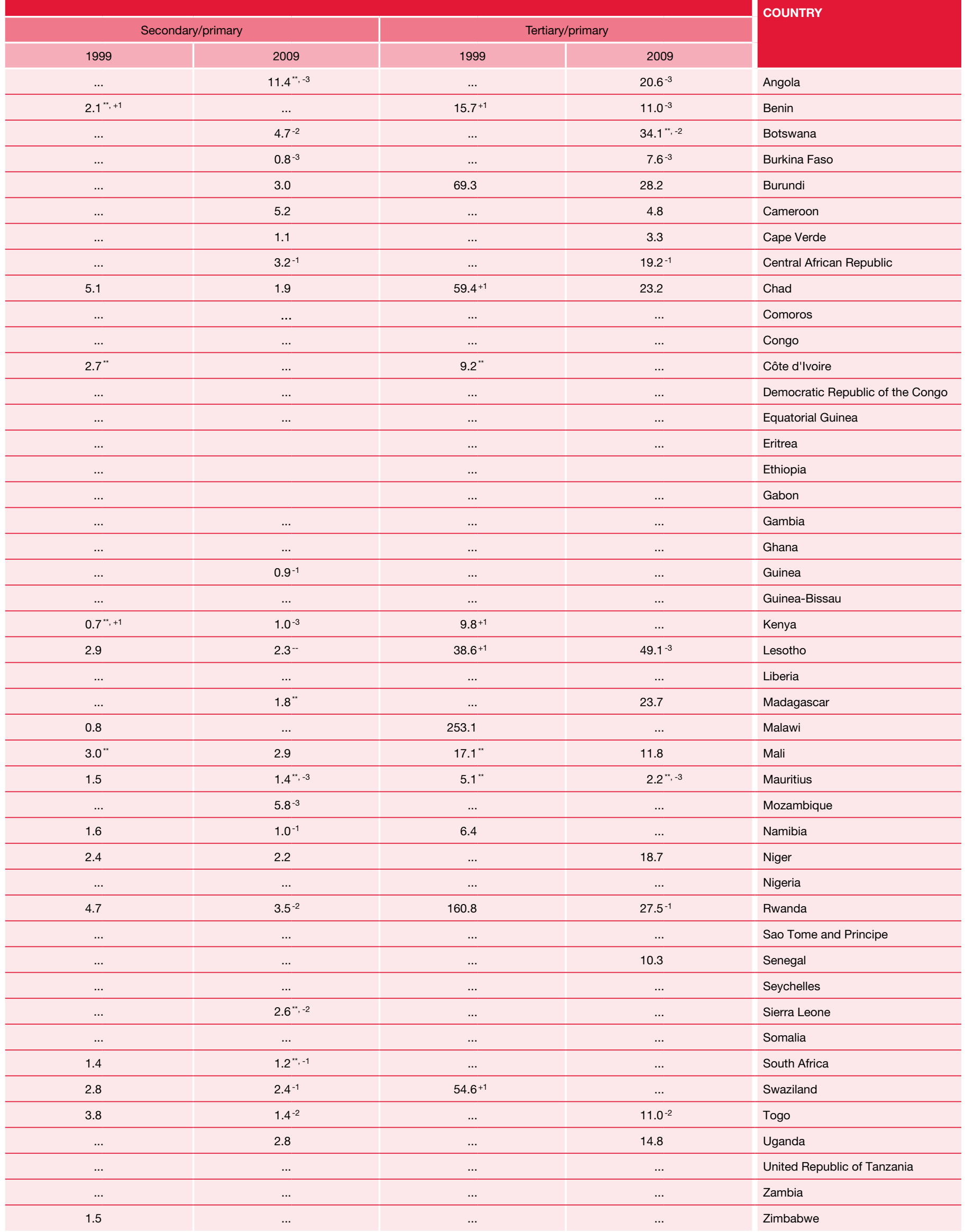


Table A7. EDUCATION EXPENDITURE BY NATURE OF SPENDING | 2009

\begin{tabular}{|c|c|c|c|c|}
\hline \multirow{3}{*}{ COUNTRY } & \multicolumn{4}{|c|}{$\begin{array}{l}\text { AS A \% OF TOTAL EDUCATIONAL } \\
\text { EXPENDITURE IN PUBLIC INSTITUTIONS }\end{array}$} \\
\hline & \multicolumn{2}{|c|}{$\begin{array}{l}\text { Primary } \\
\text { (ISCED 1) }\end{array}$} & \multicolumn{2}{|c|}{$\begin{array}{l}\text { Secondary } \\
\text { (ISCED 2-3) }\end{array}$} \\
\hline & Current & Capital & Current & Capital \\
\hline Angola & $66.2^{-3}$ & $33.8^{-3}$ & $75.8^{-3}$ & $24.2^{-3}$ \\
\hline Benin & $93.9^{-2}$ & $6.1^{-2}$ & $96.1^{-2}$ & $3.9^{-2}$ \\
\hline Botswana & 100.0 & - & 86.5 & 13.5 \\
\hline Burkina Faso & $\ldots$ & $\ldots$ & $66.3^{-2}$ & $33.7^{-2}$ \\
\hline Burundi & 83.1 & 16.9 & 88.3 & 11.7 \\
\hline Cameroon & 68.5 & $\ldots$ & 87.3 & 12.7 \\
\hline Cape Verde & 99.3 & 0.7 & 87.0 & 13.0 \\
\hline Central African Republic & $\ldots$ & $\ldots$ & $95.5^{-2}$ & $4.5^{-2}$ \\
\hline Chad & 60.6 & 39.4 & 60.2 & 39.8 \\
\hline Comoros & $\ldots$ & $\cdots$ & $\cdots$ & $\cdots$ \\
\hline Congo & $\ldots$ & $\ldots$ & $\ldots$ & $\cdots$ \\
\hline Côte d'Ivoire & $\ldots$ & $\cdots$ & $\ldots$ & $\ldots$ \\
\hline Democratic Republic of the Congo & $\ldots$ & $\cdots$ & $\cdots$ & $\cdots$ \\
\hline Equatorial Guinea & $\ldots$ & $\ldots$ & $\ldots$ & $\ldots$ \\
\hline Eritrea & $\ldots$ & $\ldots$ & $52.6^{-3}$ & $47.4^{-3}$ \\
\hline Ethiopia & $\ldots$ & $\cdots$ & $\cdots$ & $\cdots$ \\
\hline Gabon & $\ldots$ & $\ldots$ & $\ldots$ & $\ldots$ \\
\hline Gambia & $\ldots$ & $\ldots$ & $\ldots$ & $\ldots$ \\
\hline Ghana & $\ldots$ & $\ldots$ & $\ldots$ & $\cdots$ \\
\hline Guinea & $\ldots$ & $\ldots$ & $89.9^{-1}$ & $10.1^{-1}$ \\
\hline Guinea-Bissau & $\ldots$ & $\ldots$ & $\ldots$ & $\ldots$ \\
\hline Kenya & $\ldots$ & $\ldots$ & $\ldots$ & $\ldots$ \\
\hline Lesotho & $\ldots$ & $\ldots$ & $\ldots$ & $\cdots$ \\
\hline Liberia & $\ldots$ & $\ldots$ & $\ldots$ & $\ldots$ \\
\hline Madagascar & $87.9^{-1}$ & $12.1^{-1}$ & $94.9^{-1}$ & $5.1^{-1}$ \\
\hline Malawi & $\ldots$ & $\ldots$ & $\ldots$ & $\ldots$ \\
\hline Mali & 71.3 & 28.7 & 79.7 & 20.3 \\
\hline Mauritius & $\ldots$ & $\ldots$ & 100.0 & $\mathrm{n}$ \\
\hline Mozambique & $71.4^{-3}$ & $28.6^{-3}$ & $71.4^{-3}$ & $28.6^{-3}$ \\
\hline Namibia & $99.0^{* *},-1$ & $1.0^{* *,},-1$ & $93.6^{* *,-1}$ & $6.4^{* *},-1$ \\
\hline Niger & 77.9 & 22.1 & 76.8 & 23.2 \\
\hline Nigeria & $\ldots$ & $\ldots$ & $\ldots$ & $\ldots$ \\
\hline Rwanda & $84.5^{-1}$ & $15.5^{-1}$ & $83.1^{-1}$ & $16.9^{-1}$ \\
\hline Sao Tome and Principe & $\ldots$ & $\cdots$ & $\cdots$ & $\cdots$ \\
\hline Senegal & $\ldots$ & $\ldots$ & $\ldots$ & $\ldots$ \\
\hline Seychelles & $87.2^{-3}$ & $12.8^{-3}$ & $87.9^{-3}$ & $12.1^{-3}$ \\
\hline Sierra Leone & $\ldots$ & $\cdots$ & $\cdots$ & $\cdots$ \\
\hline Somalia & $\cdots$ & $\cdots$ & $\ldots$ & $\cdots$ \\
\hline South Africa & 94.7 & 5.3 & 97.6 & 2.4 \\
\hline Swaziland & $\ldots$ & $\ldots$ & $\ldots$ & $\ldots$ \\
\hline Togo & 98.7 & 1.3 & 96.6 & 3.4 \\
\hline Uganda & 92.5 & 7.5 & 89.9 & 10.1 \\
\hline United Republic of Tanzania & $\cdots$ & $\cdots$ & $\cdots$ & $\cdots$ \\
\hline Zambia & $\ldots$ & $\ldots$ & $\ldots$ & $\cdots$ \\
\hline Zimbabwe & $\ldots$ & $\ldots$ & $\ldots$ & $\ldots$ \\
\hline
\end{tabular}


SALARIES AS A \% OF CURRENT PUBLIC

EXPENDITURE ON EDUCATION IN PUBLIC INSTITUTIONS

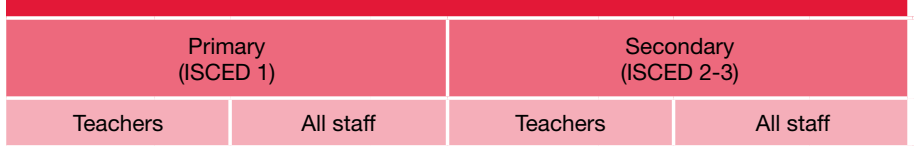

...

73.0

$90.0^{-3}$

\begin{tabular}{l}
7.6 \\
\hline
\end{tabular}

$79.2^{-2} \quad 91.8^{-2}$

$83.4 \quad 83.8$

82.5
90.7

$87.6 \quad 90.6$

$71.6^{-2} \quad 96.7^{-2}$

$76.2 \quad 85.2$

$85.9^{-1}$

$89.7^{-1}$

...

$\ldots$

(.
EXPENDITURE ON LEARNING MATERIALS AS

A \% OF TOTAL CURRENT EXPENDITURE

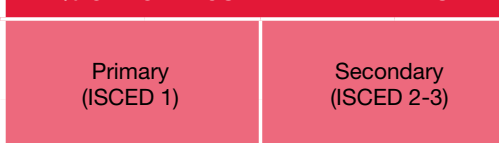

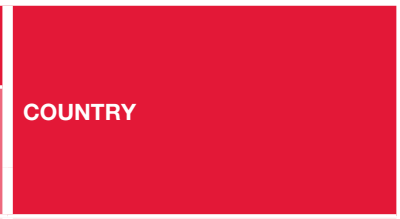

Angola

Benin

Botswana

Burkina Faso

Burund

Cameroon

Cape Verde

Central African Republic

Chad

Comoros

Congo

Côte d'Ivoire

Democratic Republic of the Congo

Equatorial Guinea

Eritrea

Ethiopia

Gabon

Gambia

Ghana

Guinea

Guinea-Bissau

Kenya

Lesotho

Liberia

Madagascar

Malawi

Mali

Mauritius

Mozambique

Namibia

Niger

Nigeria

Rwanda

Sao Tome and Principe

Senegal

Seychelles

Sierra Leone

Somalia

South Africa

Swaziland

Togo

Uganda

United Republic of Tanzania

Zambia

Zimbabw 
Table A8. OFFICIAL DEVELOPMENT ASSISTANCE (ODA) | 2008

\begin{tabular}{|c|c|c|c|c|c|c|}
\hline \multirow[t]{2}{*}{ COUNTRY } & \multirow{2}{*}{$\begin{array}{l}\text { TOTAL ODA } \\
\text { DISBURSEMENT } \\
\text { (CURRENT US\$ } \\
\text { IN MILLIONS) }\end{array}$} & \multirow{2}{*}{$\begin{array}{l}\text { ODA FOR EDUCATION } \\
\text { (CURRENT US\$ } \\
\text { IN MILLIONS) }\end{array}$} & \multirow[t]{2}{*}{$\begin{array}{c}\text { ODA FOR } \\
\text { EDUCATION AS A } \\
\% \text { OF TOTAL ODA }\end{array}$} & \multirow{2}{*}{$\begin{array}{l}\text { RATIO OF ODA } \\
\text { FOR EDUCATION } \\
\text { TO TOTAL PUBLIC } \\
\text { EXPENDITURE } \\
\text { ON EDUCATION }\end{array}$} & \multicolumn{2}{|c|}{$\begin{array}{l}\text { ODA FOR EDUCATION } \\
\text { PER POPULATION } \\
\text { AGED 5-24 }\end{array}$} \\
\hline & & & & & (US\$) & (PPP\$) \\
\hline Angola & 384.1 & 36.3 & 9.4 & $\ldots$ & 4 & 5 \\
\hline Benin & 599.0 & 60.7 & 10.1 & $29.7^{-1}$ & 15 & 29 \\
\hline Botswana & 744.5 & 17.0 & 2.3 & $2.3^{-1}$ & 20 & 39 \\
\hline Burkina Faso & 960.7 & 113.9 & 11.9 & $33.9^{-1}$ & 16 & 35 \\
\hline Burundi & 521.5 & 29.7 & 5.7 & 35.5 & 8 & 20 \\
\hline Cameroon & $1,114.0$ & 111.9 & 10.0 & 16.4 & 13 & 23 \\
\hline Cape Verde & 226.5 & 34.6 & 15.3 & 35.0 & 145 & 167 \\
\hline Central African Republic & 254.8 & 6.1 & 2.4 & 23.9 & 3 & 5 \\
\hline Chad & 495.5 & 17.1 & 3.5 & $\cdots$ & 3 & 6 \\
\hline Comoros & 40.1 & 14.7 & 36.6 & 36.3 & 51 & 72 \\
\hline Congo & 506.8 & 26.2 & 5.2 & $\cdots$ & 16 & 21 \\
\hline Côte d'Ivoire & 802.5 & 34.6 & 4.3 & 3.2 & 4 & 5 \\
\hline Democratic Republic of the Congo & $1,802.8$ & 85.7 & 4.8 & $\ldots$ & 3 & 5 \\
\hline Equatorial Guinea & 35.2 & 3.9 & 11.0 & $\ldots$ & 13 & 34 \\
\hline Eritrea & 136.8 & 15.5 & 11.3 & $34.8^{-2}$ & 7 & 13 \\
\hline Ethiopia & $3,208.3$ & 233.6 & 7.3 & $41.8^{-1}$ & 6 & 16 \\
\hline Gabon & 91.0 & 25.5 & 28.0 & $\cdots$ & 39 & 57 \\
\hline Gambia & 294.7 & 11.1 & 3.8 & $\cdots$ & 15 & 41 \\
\hline Ghana & $1,280.0$ & 80.1 & 6.3 & $\cdots$ & 8 & 16 \\
\hline Guinea & 429.3 & 44.8 & 10.4 & 48.6 & 10 & 27 \\
\hline Guinea-Bissau & 141.7 & 12.9 & 9.1 & $\ldots$ & 18 & 34 \\
\hline Kenya & $1,527.9$ & 110.6 & 7.2 & $4.3^{-2}$ & 6 & 12 \\
\hline Lesotho & 152.3 & 15.2 & 10.0 & 8.6 & 15 & 30 \\
\hline Liberia & $1,212.7$ & 16.8 & 1.4 & 71.8 & 10 & 17 \\
\hline Madagascar & 786.8 & 80.2 & 10.2 & 29.3 & 9 & 19 \\
\hline Malawi & 815.4 & 57.3 & 7.0 & $\ldots$ & 8 & 22 \\
\hline Mali & 921.0 & 170.0 & 18.5 & 51.0 & 28 & 47 \\
\hline Mauritius & 162.0 & 14.4 & 8.9 & 5.3 & 35 & 60 \\
\hline Mozambique & $1,938.4$ & 178.1 & 9.2 & $\ldots$ & 17 & 33 \\
\hline Namibia & 208.1 & 19.1 & 9.2 & 4.0 & 20 & 30 \\
\hline Niger & 580.8 & 51.2 & 8.8 & 25.9 & 7 & 14 \\
\hline Nigeria & $1,444.6$ & 102.2 & 7.1 & $\ldots$ & 1 & 2 \\
\hline Rwanda & 877.7 & 91.1 & 10.4 & 50.2 & 19 & 44 \\
\hline Sao Tome and Principe & 64.2 & 7.5 & 11.7 & $\cdots$ & 98 & 159 \\
\hline Senegal & $1,055.4$ & 156.9 & 14.9 & 23.2 & 27 & 44 \\
\hline Seychelles & $\cdots$ & 0.8 & $\cdots$ & $0.9^{-2}$ & 27 & 54 \\
\hline Sierra Leone & 355.1 & 23.6 & 6.6 & $\cdots$ & 9 & 21 \\
\hline Somalia & 741.4 & 18.6 & 2.5 & $\cdots$ & 5 & $\ldots$ \\
\hline South Africa & $1,133.4$ & 81.5 & 7.2 & 0.7 & 4 & 7 \\
\hline Swaziland & 56.7 & 3.5 & 6.2 & 1.8 & 6 & 12 \\
\hline Togo & 410.8 & 18.4 & 4.5 & 23.1 & 6 & 11 \\
\hline Uganda & $1,659.3$ & 125.3 & 7.6 & 27.0 & 8 & 20 \\
\hline United Republic of Tanzania & $2,314.7$ & 110.0 & 4.8 & 9.2 & 6 & 14 \\
\hline Zambia & $1,096.4$ & 100.9 & 9.2 & 51.2 & 17 & 19 \\
\hline Zimbabwe & 605.2 & 6.6 & 1.1 & $\ldots$ & 1 & $\ldots$ \\
\hline
\end{tabular}

Sources: OECD's Development Assistance Committee (DAC) database and World Bank for PPP\$. 


\section{Financing Education in Sub-Saharan Africa: Meeting the Challenges of Expansion, Equity and Quality}

In the current economic climate, how can African governments provide every child with a decent education? This report provides the statistical evidence to evaluate the policy trade-offs in responding to the rising demand for primary and secondary education in sub-Saharan Africa.

The report presents the most comprehensive and timely data available on the financing of education in 45 sub-Saharan African countries. In addition, historical data enable the authors to track trends since the World Education Forum in 2000 and examine the financial impact of the steadfast commitment of many African governments to provide universal primary education. Over the past ten years, real expenditure on education has risen by $6 \%$ annually across the region. It is often assumed that the resources were used to widen enrolment. Yet, recent data show that many countries also made significant investments to improve their educational services.

The report also introduces new indicators on critical issues, such as the qualifications and salaries of teachers, the running costs of schools, and the provision of textbooks. The authors examine financing trends in private education, as well as official development assistance, which accounts for more than $50 \%$ of public education budgets in some countries. In short, this report provides the facts - not assumptions - to analyse policy options and optimise the use of limited financial resources.
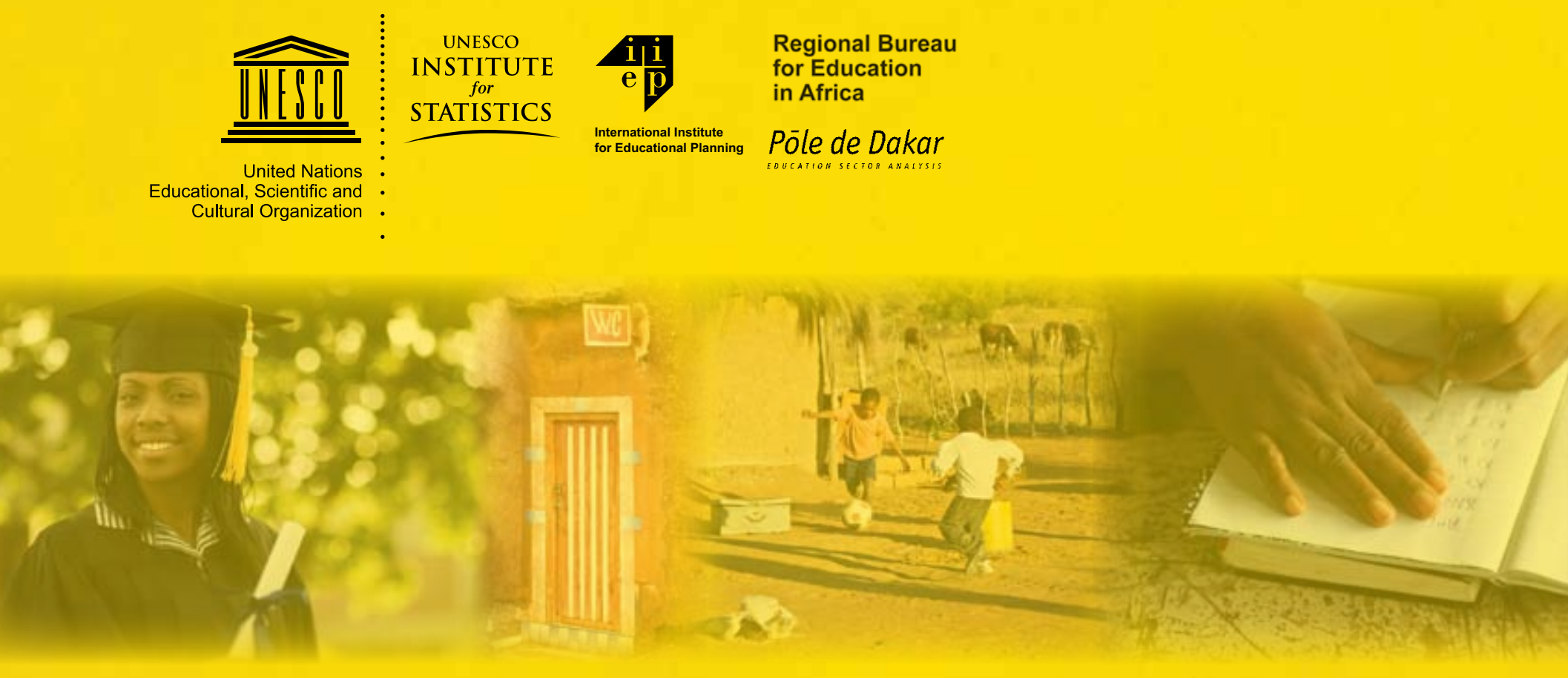

www.uis.unesco.org

For information: publications@uis.unesco.org

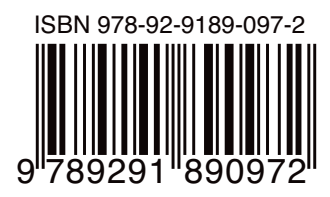

